\title{
AS MIIASES NA REGIÃO NEOTROPICAL (IDENTIFICAÇÃO, BIOLOGIA, BIBLIOGRAFIA)
}

\author{
JOSE HENRIQUE GUIMARAKES 1 \\ NELSON PAPAVERO 1 \\ ANGELO PIRES DO PRADO ${ }^{2}$
}

\section{ABSTRACT}

Data are given on the identification, biology, ecology, hosts, geographical distribution, control, and other aspects of the myiasis-producing flies in the Neotropical Region.

The bibliography contains almost 2400 references, mainly related to Cochliomyia (ca. 1170 references), Cuterebridae (with the exception of Dermatobia hominis) (over 390 references), and to Dermatobia hominis (over 520 references). For Cuterebridae and Cochliomyia the bibliography covers the Americas; for all other groups it is restricted to the Neotropics.

\section{CONTEÜDO}

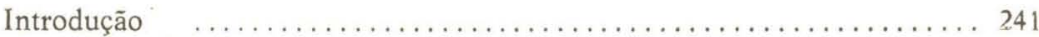

1. Generalidades sobre miíases ..................... 241

2. Chave para a identificação de dípteros causadores de miíases e pseudomiíases na região neotropical $\ldots \ldots \ldots \ldots \ldots \ldots \ldots \ldots \ldots . \ldots \ldots 44$

2.1. Adultos ................................... 244

2.2. Larvas ................................ 244

3. Pseudomiíases ................................. 249

3.1. Família Psychodidae ........................... 249

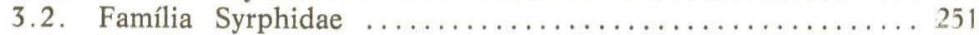

3.3. Família Tephritidae ......................... 252

3.4. Família Calliphoridae ....................... 252

4. Miíases causadas por parasitas facultativos .............. 253

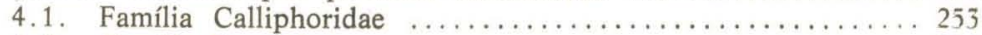

4.2. Família Fanniidae ........................... 258

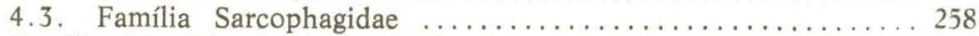

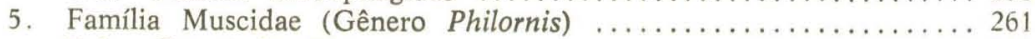

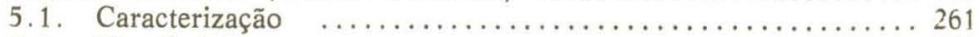

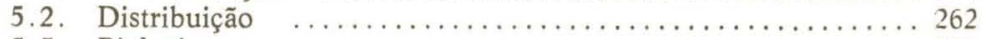

5.3. Biologia .............................. 262

6. Família Calliphoridae (Gênero Cochliomyia) .............. 270

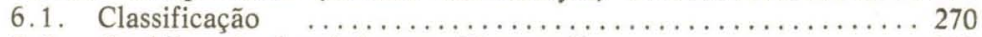

6.2. Cochliomyia hominivorax (Coquerel) ............. 270

6.2.1. Biologia ........................ 273

6.2.2. Patogênese, profilaxia e tratamento ........... 280

6.2.3. Controle .......................... 281

6.3. Cochliomyia macellaria (Fabricius) ................ 283

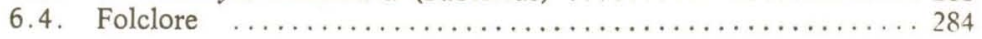

1. Museu de Zoologia, Universidade de São Paulo, Pesquisadores do Conselho Nacional de Desenvolvimento Científico e Tecnológico (CNPq).

2. Departamento de Parasitologia, Instituto de Ciências Blológicas, Universidade Estaduai do Campinas. 
7. Família Gasterophilidae .......................... 335

7.1. Classificação ............................. 335

7.2. Biologia comparativa das três espécies ............ 336

7.3. Ocorrência e distribuição na América do Sul . . . . . . . . 338

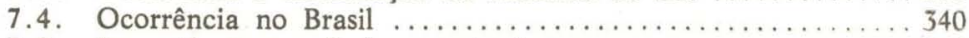

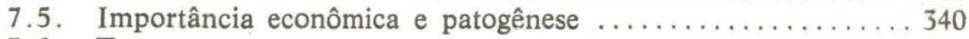

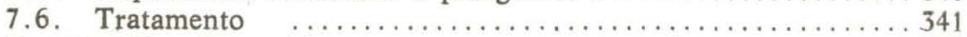

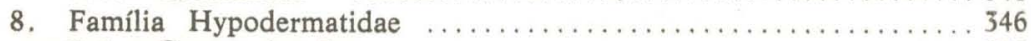

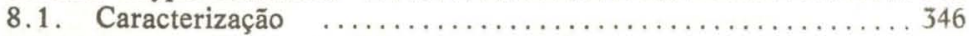

8.2. Ocorrência na América neotropical ................ 348

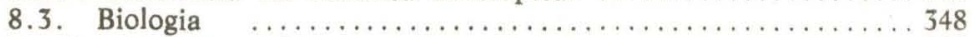

9. Família Oestridae (Oestrus ovis Linnaeus) .................. 349

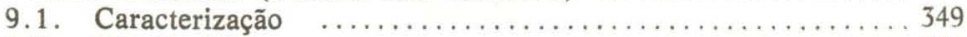

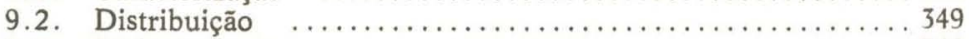

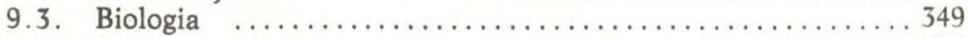

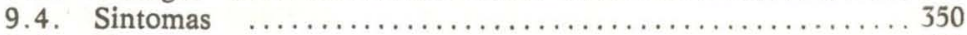

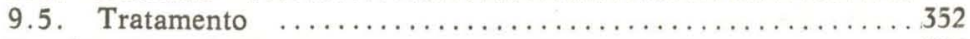

10. Família Cuterebridae (exceto Dermatobia hominis) ......... 354

10.1. Biologia ................................. 354

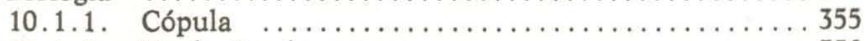

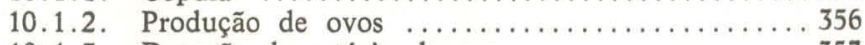

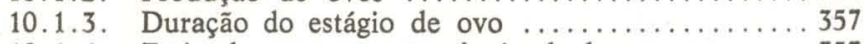

10.1.4. Estímulos para a emergência da larva ......... 357

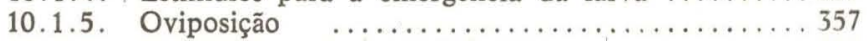

10.1.6. Longevidade da larva infestante ........... 358

10.1.7. A penetração da larva infestante .......... 358

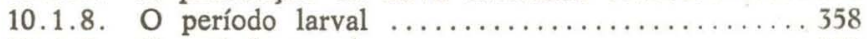

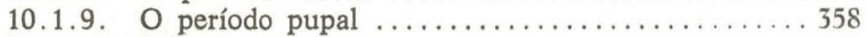

10.2. Especificidade do hospedeiro .................. 358

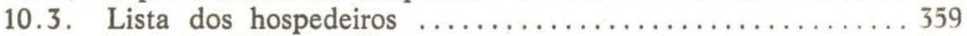

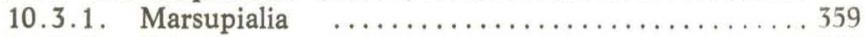

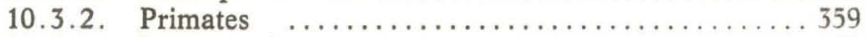

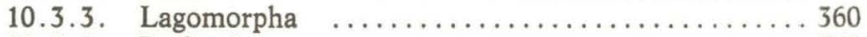

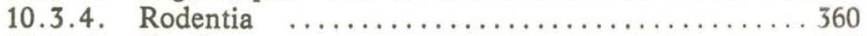

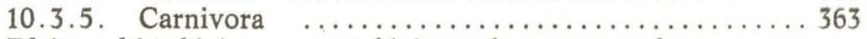

10.4. Efeitos histológicos e patológicos decorrentes da presença

da larva no hospedeiro ........................ 363

10.5. Efeito dos Cuterebridae sobre a população do hospedeiro 364

10.6. Míases no homem e animais domésticos ............. 364

11. Família Cuterebridae (Dermatobia hominis) .................. 379

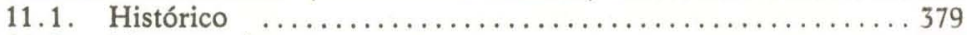

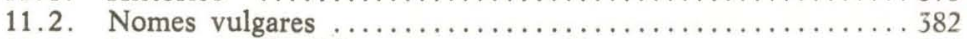

11.3. Insetos confundidos com Dermatobia .............. 383

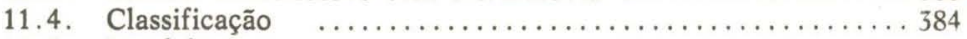

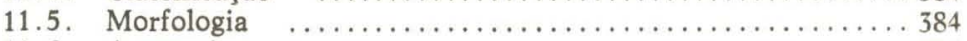

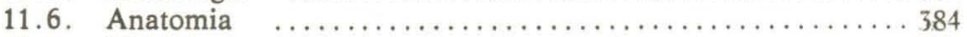

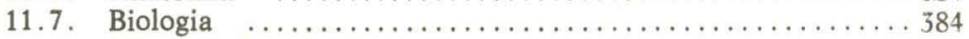

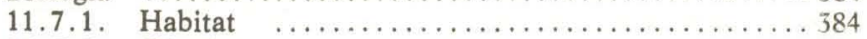

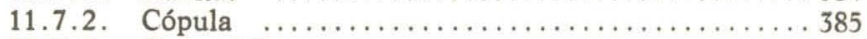

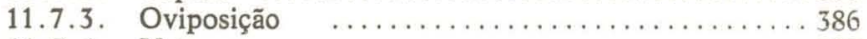

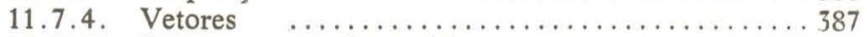

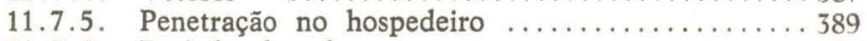

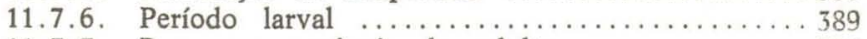

11.7.7. Pupa e emergência do adulto ............. 392

11.8. Patogênese e importância econômica .............. 392

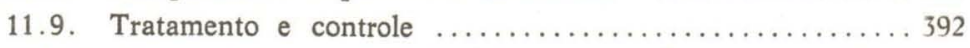

APENDICE: Os pupários de Calliphoridae encontrados em um Mega-

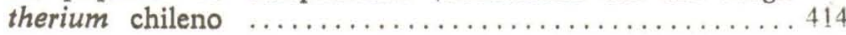




\section{INTRODUÇĀO}

Vem crescendo, em toda a América, o interesse pelo estudo dos dípteros causadores de míases, tanto por parte da Zoologia aplicada, quanto por parte da Zoologia básica, surgindo um grande número de trabalhos sobre a biologia, fisiologia, genética e controle desses insetos.

Tal progresso animou-nos a preparar esta bibliografia, para servir de base ao desenvolvimento desses vários estudos.

Inclui esta obra quase 2400 referências, principalmente relacionadas ao gênero Cochliomyia (cerca de 1170 referências), aos Cuterebridae (exceto Dermatobia hominis) (mais de 390 referências) e ao gênero Dermatobia (acima de 520 referências). A bibliografia sobre Cuterebridae e Cochliomyia abrange todas as Américas; para os outros grupos de causadores de miíases restringimo-nos à Região Neotropical.

Não pretendemos seja esta bibliografia completa, apesar de havermos incluído todas as referências encontradas (com exceção de uma certa quantidade de tratados gerais de Parasitologia).

Para a confecção desta obra contamos com o inestimável apoio e a generosidade do Prof. Dr. E. P. Catts (Department of Entomology, Washington State University, Pullman), que muito gentilmente cedeu sua bibliografia sobre Cuterebridae.

Ao Prof. Dr. Raúl Cortés P., da Universidad de Chile (Santiago) e Universidad del Norte (Arica), somos extremamente gratos pela cortesia em enviar fotos e dados sobre os pupários de Calliphoridae encontrados no $\mathrm{Me}$ gatherium de Tarapacá.

Nossos agradecimentos vão igualmente para a Dra. Cleide Costa (Museu de Zoologia da Universidade de São Paulo), pelo auxílio com as fotografias, e a Juventina dos Santos e Nelson Fernandes Gomes, pelos desenhos.

\section{GENERALIDADES SOBRE MIIASES}

Os ataques de larvas de dípteros ao homem e aos animais despertaram a atenção de vários cronistas e missionários na América Latina, desde os albores da colonização.

Já no século XVI encontramos várias referências à presença de larvas no corpo do homem ou dos animais.

Frei Bernardino de Sahagún, que viveu na Nova Espanha (México), de 1529 a 1590, em sua "Historia General de las cosas de Nueva España", onde compilou o conhecimento de história natural dos Astecas, dizia da existência de "gusanos que se crían en los brazos o miembros de los conejos y ratones"; esses vermes podiam ser vistos "metidos dentro de la carne y miran hacia fuera". Estas larvas, certamente de Cuterebra, eram chamadas nacaocuilin (de nácatl $=$ carne e ocuilin $=$ verme) (Vogelsang \& Martín del Campo, 1947: 50). Neste trecho, talvez a primeira referência a um cuterebrídeo, Frei Bernardino descreve magistralmente a abertura da chaga onde habita a larva, e seus espiráculos posteriores "que miran hacia fuera".

Pedro de Osma de Xara y Zejo, em carta de 26 de dezembro de 1568, endereçada ao médico sevilhano Nicolás Monardes, menciona a presença de larvas de dípteros encontradas em feridas ("llagas"), sem dúvida alguma referindo-se a Cochliomyia (Monardes, 1580; Lamas, 1981).

Gabriel Soares de Souza, descrevendo a Bahia em 1587, foi um dos primeiros a citar as bicheiras por Cochliomyia e seu tratamento: "E notório a todos, como é matarem com o seu sumo (extrato de fumo ou petume) os vermes que se criam em feridas e chagas de gente descuidada: com a qual curam também as chagas e feridas das vacas e das éguas sem outra cousa, e com o sumo desta erva lhe encouram" (Souza, 1938).

Simón (1626), Cobo (1653), La Condamine (1745), Arture (1753), Juzarte (1769-70), Gilij (1780-1789), entre inúmeros outros, tratam dos ataques por Dermatobia hominis. 
Grainger (1764) fala longamente das bicheiras causadas por Cochliomyia, na Jamaica.

A espécie hominivorax, hoje em Cochliomyia, só é descrita por Coquerel em 1858.

Caso após caso de bicheiras acumulam-se na literatura científica e dos viajantes, em todas as partes do mundo.

Em 1840, em seu trabalho de síntese, "On insects and their larvae occasionally found in the human body", o reverendo Hope cunhou o termo "myiasis" (de myia = mosca).

Desde então vem este termo sendo usado nas mais variadas acepções, existindo, entretanto, uma tendência para restringi-lo à síndrome geral caracterizada pelo ataque de larvas de dípteros a vertebrados vivos. Zumpt (1965: xi) forneceu a seguinte definição:

"Miíase é a infestação de vertebrados vivos por larvas de dípteros que, pelo menos durante certo período, se alimentam dos tecidos vivos ou mortos do hospedeiro, de suas substâncias corporais líquidas, ou do alimento por ele ingerido."

A importância dessa definição, segundo o autor, é de que as larvas completem pelo menos por um certo período o seu desenvolvimento normal dentro ou sobre o corpo do vertebrado.

Tais larvas podem ser separadas em dois grupos biologicamente distintos: os parasitos obrigatórios e os parasitos facultativos.

São parasitos obrigatórios os que têm larvas que normalmente se desenvolvem dentro ou sobre o corpo de vertebrados vivos. Este grupo inclui as larvas que (i) vivem nas cavidades nasofaríngeas e outros sistemas internos de certos mamíferos herbívoros (Fam. Oestridae); (ii) as que vivem nos tecidos dérmicos e subdérmicos de certos mamíferos (Fams. Hypodermatidae, Cuterebridae e o gênero Cochliomyia dentre os Calliphoridae); (iii) as que vivem nos tecidos cutâneos e subcutâneos de certas aves (gênero Philornis, Fam. Muscidae); e (iv) as que vivem no trato digestivo de cavalos e outros mamíferos (Fam. Gasterophilidae).

Os parasitos facultativos são os de larvas que se desenvolvem normalmente em substâncias orgânicas em decomposição; estas larvas, de vida livre, apenas ocasionalmente podem se desenvolver sobre tecidos necrosados de animais vivos, atuando como parasitas durante um certo período e podendo até ali completar seu desenvolvimento. Neste grupo enquadram-se várias espécies das famílias Fanniidae, Calliphoridae e Sarcophagidae.

Há ainda larvas de dípteros que são deglutidas com água ou alimento e que passam pelo trato digestivo do mamífero passivamente, vivas ou mortas, e que não podem portanto ser consideradas causadoras de miíases, por não terem um modo de vida parasitário por um certo período. Sua presença no tubo digestivo pode causar reações patológicas mais ou menos graves, e são estes casos rotulados de pseudomiíases.

São poucos, até o presente, os tratados dedicados às miíases, publicados na América Latina. Os trabalhos pioneiros neste campo foram escritos por Lesbini et al. (1878), na Argentina, e P. S. de Magalhães (1892) e Bleyer (1901, 1905), no Brasil. Destacaram-se pela quantidade de casos e informações recolhidas Mazza (1939) e Wolffenbuittel (1953). Fora estes, existem as resenhas generalizadoras dos principais tratados e manuais de parasitologia, como os de Pinto (1930, 1938), Del Ponte (1958), Pessôa \& Martins (1977) e Freitas et al. (1978).

O leitor interessado neste assunto não deve deixar de consultar sempre os trabalhos clássicos de James (1948) e Zumpt (1965).

\section{REFERENCIAS}

Arture, (-), 1753. Observations sur l'espèce de ver nommée Macaque. Mém. Acad. r. Sci. Paris 1752: 72-73.

Bleyer, J., 1905. Contribuição para o estudo de molestias tropicaes e subtropicaes. Tratado de myiasis. Ensaio de um estudo clinico sobre o papel 
das moscas na pathologia humana (2." ed.), 90 pp. Annibal Rocha \& Co., Corytiba. (1." ed., 1901).

Cobo, B., 1653. Historia del Nuevo Mundo (Editado em 1890 por M. Jimenez de la Espada; vol. 1 (1890): viii + 538 pp.; 2 (1891): 467 pp.; 3 (1892): 350 pp.; 4 (1895): 247 pp.). Imp. de E. Rasa, Sevilla.

Coquerel, C., 1858. Note sur des larves appartenant à une espèce nouvelle de diptère (Lucilia hominivorax) développées dans les sinus frontaux de l'homme à Cayenne. Annls Soc. ent. Fr. (3) 6: 171-176, pl. 2 (i.e., 4), n. ${ }^{\circ}$ II.

Del Ponte, E., 1958. Manual de entomología médica y veterinaria argentinas, 349 pp., 221 figs. Ediciones Librería del Colegio, Buenos Aires.

Freitas, M. G., H. M. A. Costa, \& P. Iide, 1978. Entomologia e acarologia médica e veterinária [sic], 253 pp., 147 figs. Belo Horizonte.

Gilij, P. S., 1780-1784. Saggio di storia americana, o sia storia naturale, civile e sacra de' regni e delle provincie spagnuole di Terra-Ferma, nell'America meridionale, 4 tomos. Luigi Perego erede Salvioni, Roma.

Grainger, J., 1764. An essay on the more common West Indian diseases and the remedies which that country itself produces, to which are added some hints on the management of negros, vi + pp. 8-75. London.

Hope, F. W., 1840. On insects and their larvae occasionally found in the human body. Trans, ent. Soc. Lond. 2: 256-271, pl. 22, figs. 1-5.

James, M. T., (1948). The flies that cause myiasis in man. U. S. Dep. Agric., misc. Publs 631: 1-75, 98 figs., 1947.

Juzarte, T. J., 1769-1770. Diario da navegação do rio Tieté, etc. (Editado por A. de E. Taunay, 1922. Revta Mus. paulista 1 (2): 31-118).

La Condamine, C. M. de, 1745. Rélation abrégée d'un voyage fait dans l'intérieur de l'Amérique méridionale, depuis de la côte de la Mer du Sud, jusqu'aux côtes du Brésil \& de la Guyane, en descendant la rivière des Amazones. Veuve Pissot, Paris.

Lamas, G., 1981. Introducción a la historia de la entomología en el Peru. I. Inicios y periodo exploratorio pré-darwiniano. Revta peru. Ent. 23(1) (1980): 17-25.

Lesbini, C., G. H. Weyenbergh \& P. A. Conil, 1878. Etudes sur la myiasis. Actas Acad. nac. Cienc. Córdoba 3(2): 39-98, pl. 8.

Linnaeus Jr., C., 1781. [Mittheilungen über Oestrus hominis]. Pallas' Neue nordische Beyträge Phys., Geogr. Erd. u. Völk. 1: 157-158.

Magalhães, P. S. de, 1892. Subsidio ao estudo das myases, 82 pp. Typographia do Brasil, Rio de Janeiro.

Mazza, S., ed., 1939. Investigaciones sobre dipteros argentinos. I. Myiasis. Publnes Misión Estud. Patol. reg. argent., Jujuy 41.

Monardes, N., 1580. Primera y segunda y tercera partes de la Historia Medicinal. De las cosas que se traen de nuestras Indias Occidentales, que sirven en medicina, (14) $+163 \mathrm{pp}$. F. Díaz, Sevilla.

Pessôa, S. B. \& A. V. Martins, 1977. Parasitologia médica (10. ${ }^{a}$ ed.), 986 pp., figs. Editora Guanabara Koogan, S. A., Rio de Janeiro.

Pinto, C., 1930. Tratado de parasitologia. Arthropodes parasitos e transmissores de doenças 2: 397-845, figs. 191-356, pls. 8-36. Bibliotheca Scientifica Brasileira, Colecção Medico-Cirurgica n. ${ }^{\circ}$ 177A. Typ. Pimenta de Mello \& Cia., Rio de Janeiro.

Pinto, C., 1938. Zoo-parasitos de interesse medico e veterinario, 376 pp., 106 pls., 162 figs., 1 mapa. Typ. Pimenta de Mello \& Cia., Rio de Janeiro.

Simón, P., 1626. Primera parte de las noticias historiales de la conquista de Tierra Firme en las Indias Occidentales. Domingo de la Yglesia, Cuenca.

Souza, G. S. de, 1938. Tratado descritivo do Brasil em 1587, (3. ${ }^{2}$ ed.), 493 pp. Companhia Editora Nacional, São Paulo.

Vogelsang, E. G. \& R. Martín del Campo, 1947. Parasitología de los Nahoas. Revta Med. vet. Parasit. Caracas 6(1-4): 47-52, 2 figs.

Wolffenbuettel, E., 1953. As várias formas de miíases no homem. Sua profilaxia e seus diferentes tratamentos (comprovados e a serem experi- 
mentados). Partes I-VII. Revta bras. Med. 10(2): 135-139; (3): 213-218;

(4): 286-289; (5): 365-370; (6): 447-449; (7): 518-521; (8): 594-598.

Zumpt, F., 1965. Myiasis in man and animals in the Old World. xy + 267 pp., ilus. London.

2. CHAVE PARA A IDENTIFICAÇÃO DE DÍPTEROS CAUSADORES DE MIIASES E PSEUDOMIIASES NA REGIÃO NEOTROPICAL

\subsection{Adultos}

1. Antenas compostas de 6 ou mais segmentos livremente articulados; em alguns machos densamente plumosas. Palpos maxilares longos, consistindo de 4-6 segmentos. Espécies pequenas, densamente pilosas, semelhantes a pequenas mariposas; asas larvas, ovaladas e pontudas no ápice (Fig. 3) ................... PSYCHODIDAE

Antenas com 3 segmentos; terceiro segmento apresentando uma arista (Fig. 1); palpo unissegmentado. Espécies de tamanho médio a

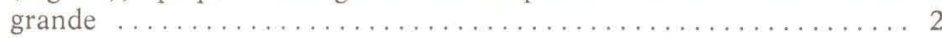

2. Veia espúria presente, entre $R^{4+5}$ e $M$, atravessando a transversal $r-m$ (Fig. 6); célula anal longa, freqüentemente alcançando a margem da asa; sutura frontal ausente ................. SYRPHIDAE Veia espúria ausente; célula anal curta ou ausente; sutura frontal

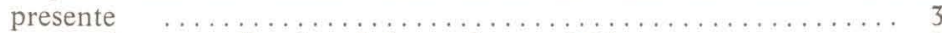

3. Abertura oral e aparelho bucal bem desenvolvidos ............ 7 Abertura oral e aparelho bucal muito pequenos ou vestigiais ....... 4

4. Arista nua; aparelho bucal vestigial. Espécies de tamanho médio .... 5 Arista pectinada a plumosa (exceto em Rogenhofera [vide Cap. 10]); aparelho bucal pequeno, aparentemente funcional. Espécies robustas.

5. Célula apical muito estreitada ou fechada no ápice Célula apical alargada no ápice (Figs. 4-5) ..... GASTEROPHILIDAE

6. Célula apical fechada e peciolada (Fig. 7) .... OESTRIDAE (Oestrus ovis) Célula apical aberta (Fig. 8) ..... HYPODERMATIDAE (Hypoderma)

7. Hipopleura (Fig. 2, hip) sem cerdas ................... 8 Hipopleura com cerdas ......................... 9

8. Segunda veia anal $\left(A_{2}\right)$ curvada ao redor do ápice da veia $A_{1}$ (Fig. 9). Espécies pequenas, excepcionalmente com mais de $7 \mathrm{~mm} \ldots \ldots \ldots$. FANNIIDAE Segunda veia anal alongada e não curvada como acima. Espécies de

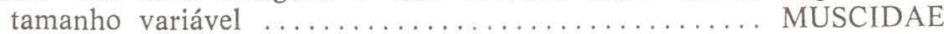

9. Notopleura (Fig. 2, not) com duas cerdas. Corpo geralmente metálico $\ldots \ldots \ldots \ldots \ldots \ldots \ldots \ldots \ldots \ldots \ldots \ldots \ldots \ldots \ldots \ldots \ldots \ldots$ CALLIPHORIDAE Notopleura com 3 a 4 cerdas. Corpo de colorido não metálico

SARCOPHAGIDAE

\subsection{Larvas}

1. Larva com cápsula cefálica bem definida e esclerosada. Corpo cilíndrico; espiráculo situado num segmento tubular esclerosado na extremidade posterior do corpo (Fig. 10)

.................. PSYCHODIDAE (Psychoda e gêns. afins)

Larva sem cápsula cefálica definida .................... 2

2. Corpo achatado, com longos processos dorsais e laterais em forma de espinhos, em cada segmento; espiráculos posteriores situados em pequenas elevações; larvas causadoras de miíases intestinais (FANNIIDAE: gên. Fannia) ...................... 3

Corpo cilíndrico, com espinhos curtos, não apresentando processos laterais ou dorsais 

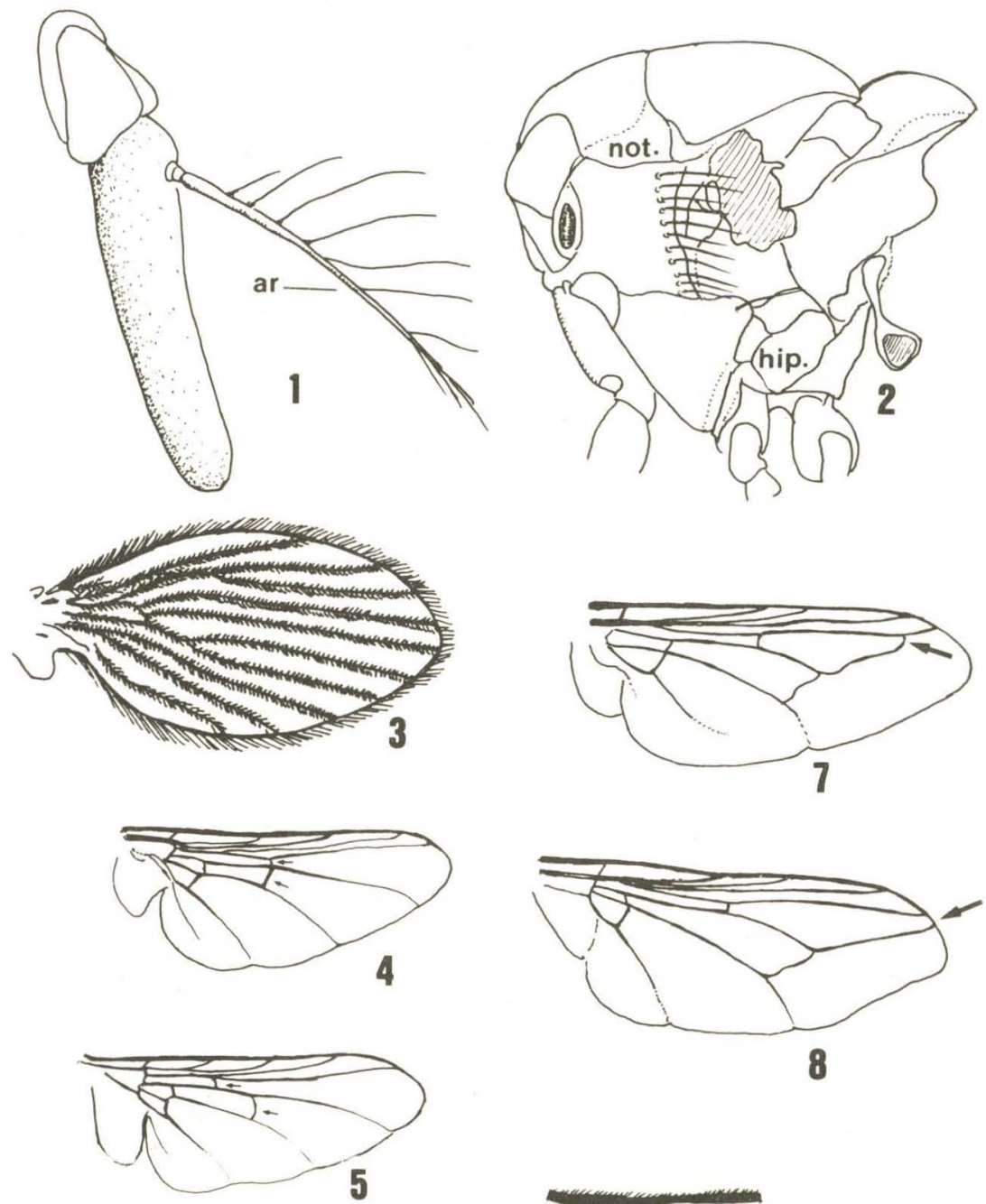

8
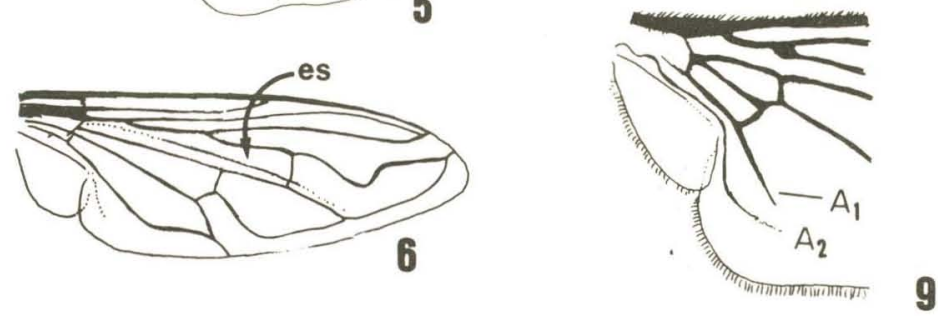

Fig. 1: Antena de Dermatobia hominis (Linnaeus Jr.); ar - arista. Fig. 2: Tórax de muscóideo, lateral; hip - hipopleura; not - notopleura. Figs. 3-9: Asas; 3, Psychoda; 4, Gasterophilus nasalis (Linnaeus); 5, G. haemorrhoidalis (Linnaeus); 6, Syrphidae; 7, Oestrus ovis Linnaeus; 8, Hypoderma; 9, Fannia. 

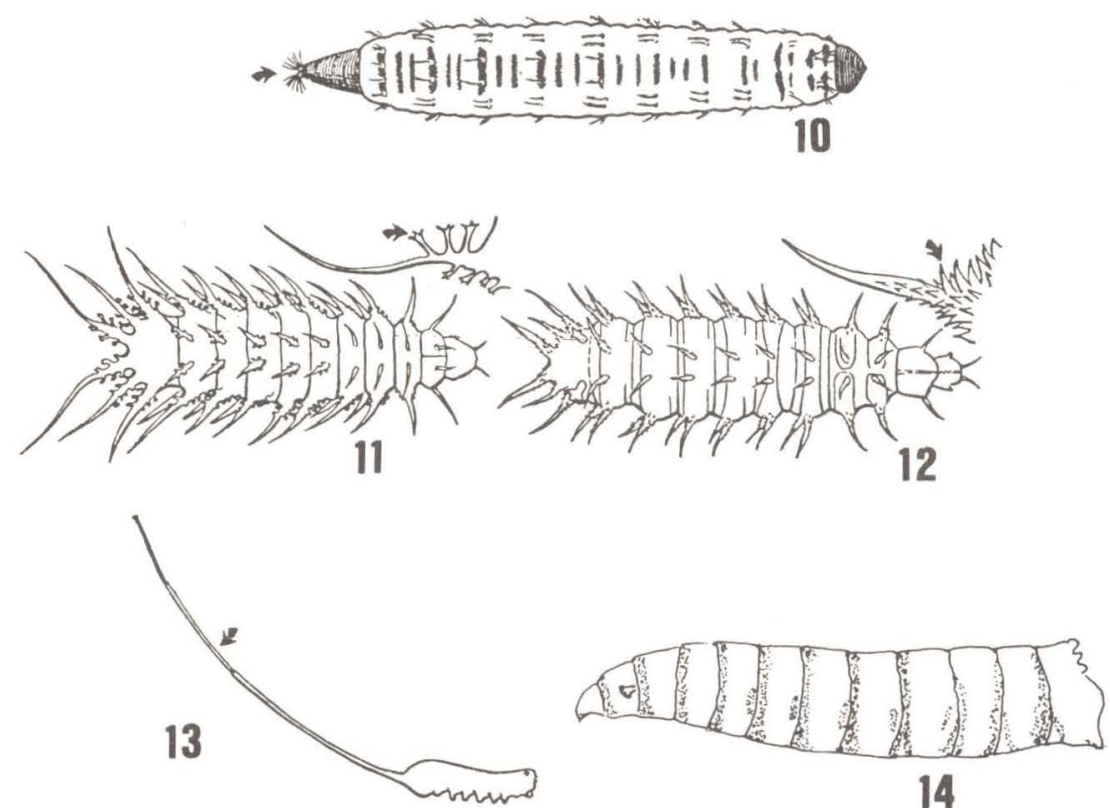

14
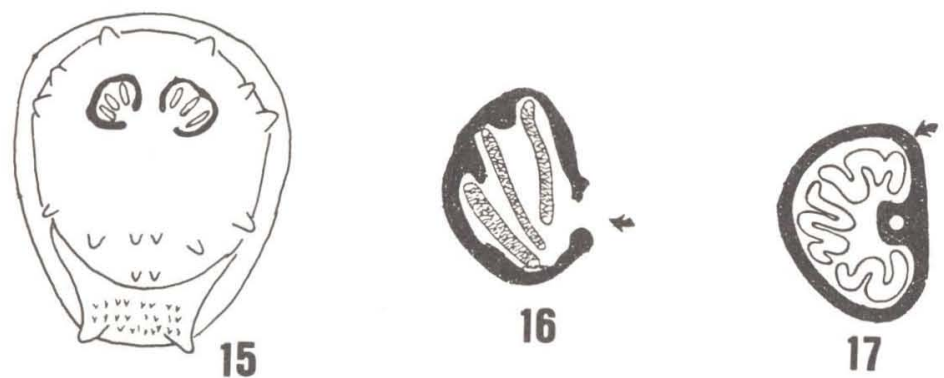

Figs. 10-17; Larvas; 10, Psychoda; 11, Fannia scalaris (Fabricius); 12, F. canicularis (Linnaeus); 13, Eristalis tenax (Linnaeus); 14, Calliphoridae; 15, Idem, extremidade caudal, mostrando tubérculos: 16, Sarcophagidae, espiráculo posterior, mostrando peritrema incompleto; 17 , Muscidae, idem, mostrando peritrema completo.

3. Processos ramificados ou plumosos (Fig. 11) ......... Fannia scalaris Processos sem ramos, espinhosos (Fig. 12) ......... Fannia canicularis

4. Extremidade posterior do corpo terminada numa cauda alongada; larvas

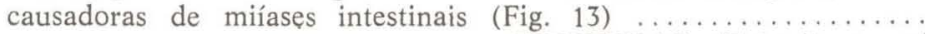
$\ldots \ldots \ldots \ldots \ldots \ldots \ldots \ldots$ SYRPHIDAE (Eristalis tenax) Corpo nunca terminando em processo em forma de cauda alongada ... 5 

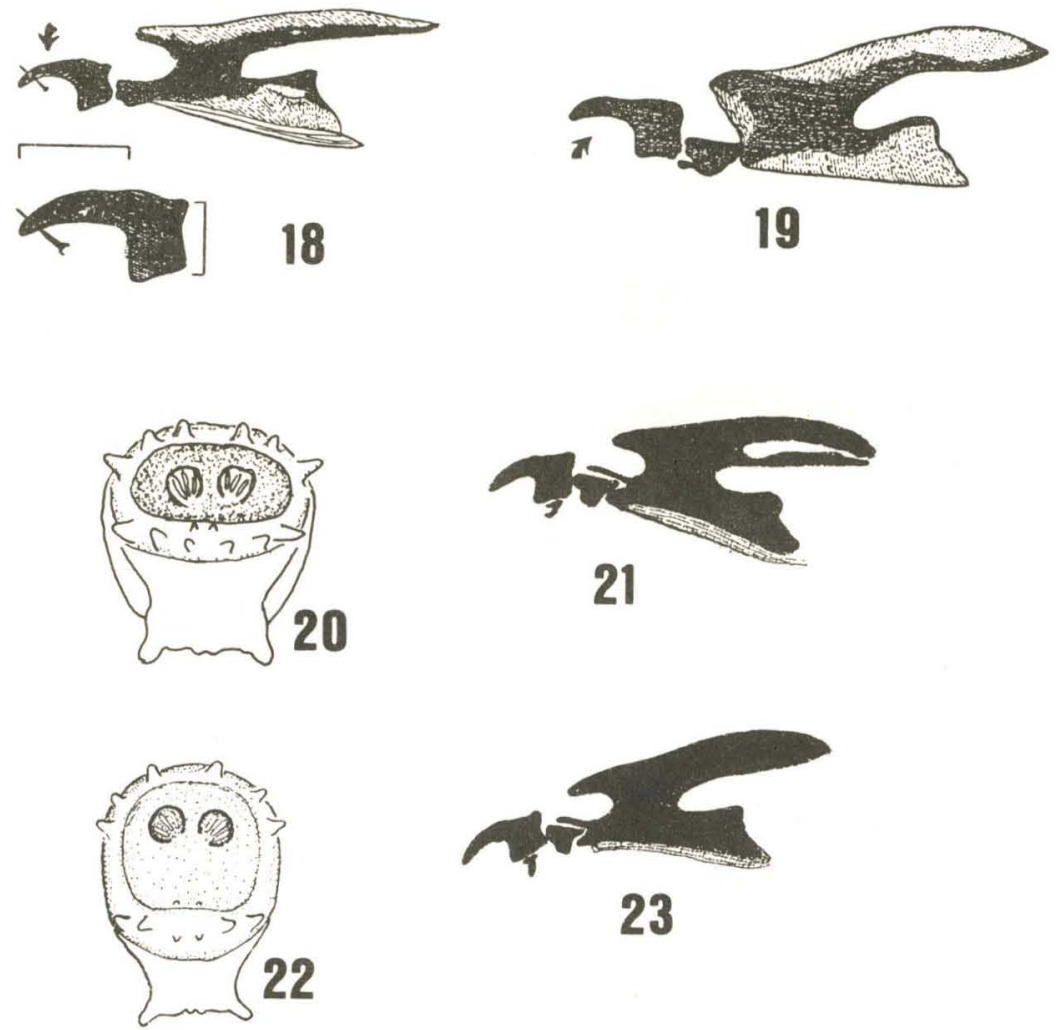

23
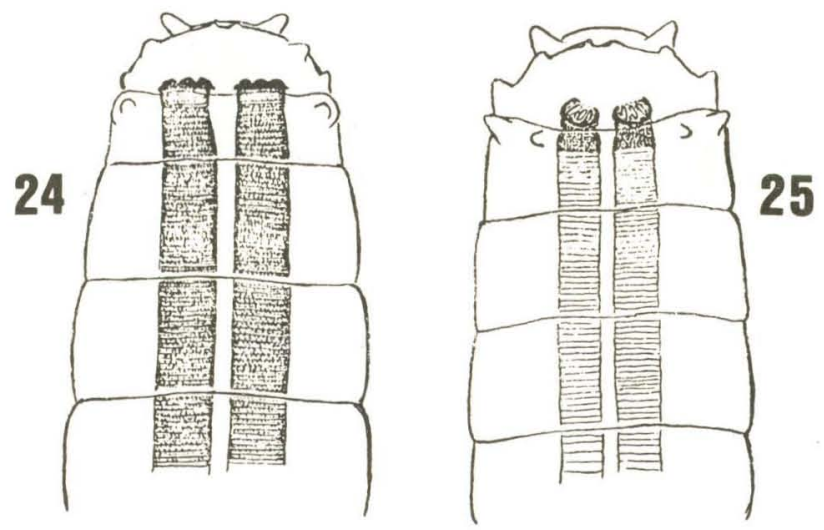

Figs. 18-25: Larvas; 18, Calliphora, ganchos bucais, mostrando esclerito oral acessório; 19, Phaenicia; 20, Sarcophagidae, extremidade caudal; 21, Idem, ganchos bucais; 22, Cochliomyia, extremidade caudal; 23, Idem, ganchos bucais; 24 , Cochliomyia hominivorax, troncos traqueais; $25, C$. macellaria, idem. 

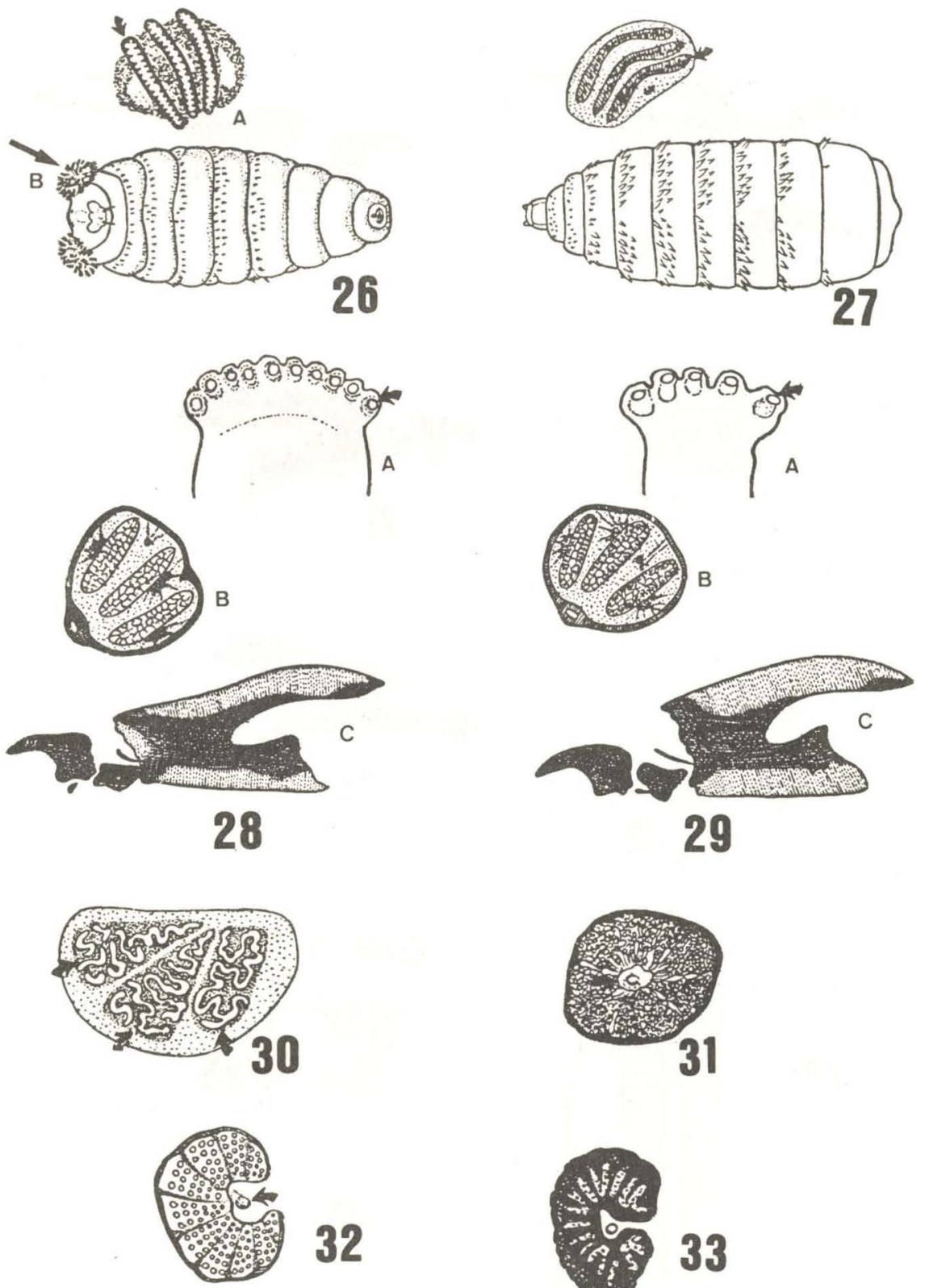

31

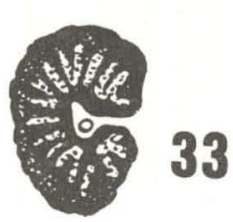

Figs. 26-33: Larvas; 26A, Dermatobia hominis (Linnaeus Jr.), abertura estigmática do espiráculo posterior; 26B, Idem, espiráculo anterior proeminente; 27, Gasterophilus, larva e abertura estigmática do espiráculo posterior; 28, Phaenicia sericata (Meigen) - A, espiráculo anterior; $\mathrm{B}$, espiráculo posterior; C, ganchos bucais; 29, Phaenicia cuprina (Wiedemann) - A-C: idem. Figs. 30-33: Espiráculo posterior - 30, Metacuterebra; 31, Oestrus ovis Linnaeus; 32, Hypoderma lineatum (De Geer); 33, H. bovis (Linnaeus). 
5. Larvas pequenas, cilíndricas, afiladas posteriormente. Área espiracular circundada por 10 ou mais tubérculos pequenos (Fig. 15) .....6 6 Larvas robustas, com mais de $15 \mathrm{~mm}$ de comprimento, cobertas de fortes espinhos. Área espiracular lisa, sem tubérculos distintos ..... 11

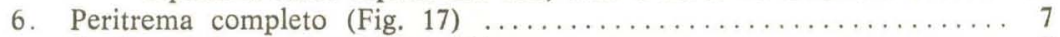

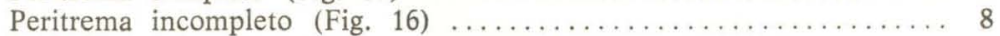

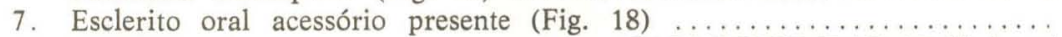
Esclerito oral acessório ausente (Fig. 19)

CALLIPHORIDAE (Phaenicia) 10

8. Espiráculos situados numa cavidade profunda, em vista posterior; asa dorsal do esclerito faringeano com uma incisão longitudinal (Figs.

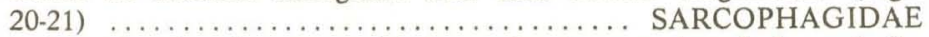

Espiráculos não situados em cavidade profunda; asa dorsal do esclerito faringeano sem incisões (Figs. 22-23) .............. 9

9. Tronco traqueal pigmentado (Fig. 24); larvas causadoras de miíases cutâneas primárias .... CALLIPHORIDAE (Cochliomyia hominivorax)

Tronco traqueal não pigmentado (Fig. 25); causadoras de miíases secundárias ............ CALLIPHORIDAE (Cochliomyia macellaria)

10. Pelo menos um dos espiráculos protorácicos com 8 ou mais aberturas; peritrema e ganchos bucais como na Fig. $28 \ldots \ldots \ldots \ldots \ldots \ldots$. ..................... CALLIPHORIDAE (Phaenicia sericata)

Pelo menos um dos espiráculos protorácicos com 6 ou menos aberturas; peritrema e ganchos bucais como na Fig. 29

. PALLIPHORIDAE (Phaenicia cuprina)

11. Aberturas estigmáticas lineares (Figs, 26-27, 30) . . . . . . . . 12

Aberturas estigmáticas porosas, não lineares (Figs. 31-33) . . . . . 14

12. Aberturas estigmáticas retas, fracamente curvadas (Figs. 26-27) . . ... 13

Aberturas estigmáticas fortemente sinuosas (larvas parasitas de roedores e lagomorfos, principalmente) (Fig. 30)

$\ldots \ldots \ldots \ldots \ldots \ldots \ldots \ldots \ldots \ldots$ CUTEREBRIDAE (Metacuterebra)

Abertura estigmática reta; espiráculo anterior proeminente (miíases dérmicas em vertebrados) (Fig. 26)

CUTEREBRIDAE (Dermatobia hominis)

Abertura estigmática curvada; espiráculo anterior ausente (Fig. 27) (miíases gástricas em equinos) .... GASTEROPHILIDAE (Gasterophilus)

14. Botão localizado no centro (Fig. 31); larvas causadoras de miíases nasais em ovinos e caprinos ........... OESTRIDAE (Oestrus ovis)

Botão não localizado no centro ..................... 15

15. Abertura ao redor do botão estreita (Fig. 33); larvas causadoras de míase dérmica em bovinos .... HYPODERMATIDAE (Hypoderma bovis)

Abertura ao redor do botão larga (Fig. 32); miíases dérmicas em bovinos HYPODERMATIDAE (Hypoderma lineatum)

\section{PSEUDOMIIASES}

Pseudomilase é a presença, com manifestações patológicas ou não, de larvas de dípteros acidentalmente ingeridas com comida ou bebida, no tubo digestivo do homem. Estas larvas se alimentam na natureza de substâncias orgânicas em decomposição, sendo sempre de vida livre. $\mathrm{Na}$ região neotropical registraram-se apenas uns poucos casos de pseudomíases, causadas por larvas de Psychodidae, Syrphidae, Tephritidae e Calliphoridae.

\subsection{Família Psychodidae}

Os Psychodidae são pequenos dípteros, raramente excedendo $4 \mathrm{~mm}$ de comprimento, de asas largas, pontudas no ápice e revestidas de pelos e escamas, assemelhando-se a mariposinhas. As larvas são saprobiontes de hábitos aquáticos ou semiaquáticos, diferenciando-se dos outros nematóceros por apresentar 


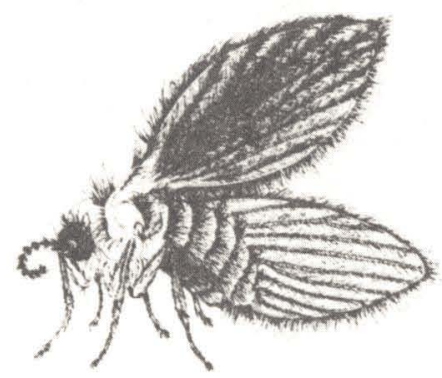

a
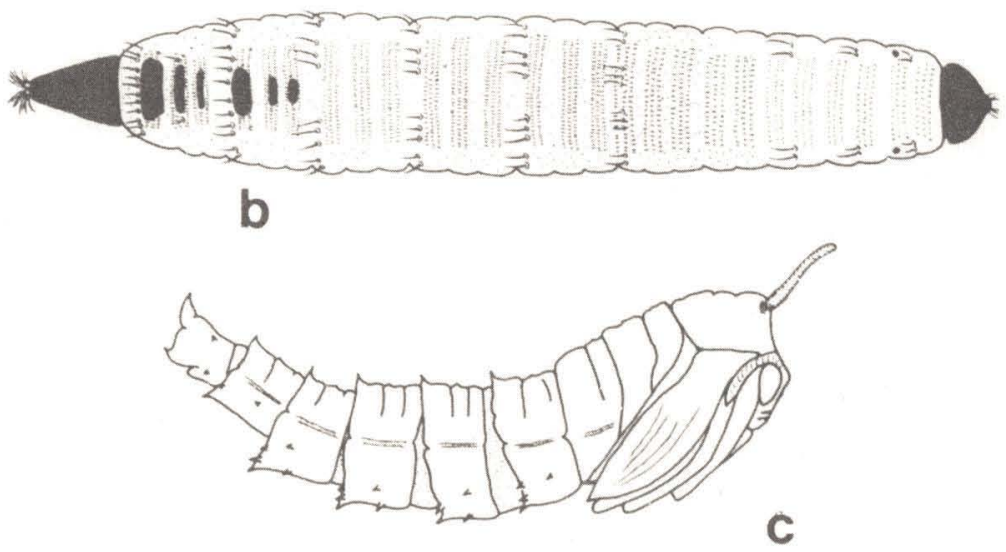

34

Fig. 34: Psychoda sp. - a, adulto; b, larva; c, pupa (apud Quate, 1960, Guide to the insects of Connecticut 6(7)).

o corpo cilíndrico, um tanto achatado dorsoventralmente, com os anéis do corpo subdivididos secundariamente, havendo para cada segmento torácico e para o primeiro segmento abdominal dois anéis e, para os segmentos abdo. minais 2-7 três anéis; alguns destes anéis apresentam dorsalmente bandas transversais esclerosadas (placas tergais) (Fig. 34). A respiração larval é feita por um par de espiráculos torácicos e um tubo respiratório no último segmento.

$\mathrm{Na}$ região neotropical ocorrem três espécies de Psychoda e uma de Telmatoscopus que têm importância em relação ao ambiente humano.

Tais espécies criam-se com freqüência nos filtros das estações de água e esgotos (moscas dos filtros) e podem ocorrer com grande densidade nos encanamentos e ralos das residências, chegando a causar desconforto aos habitantes. Algumas espécies de Psychoda foram incriminadas como responsáveis 


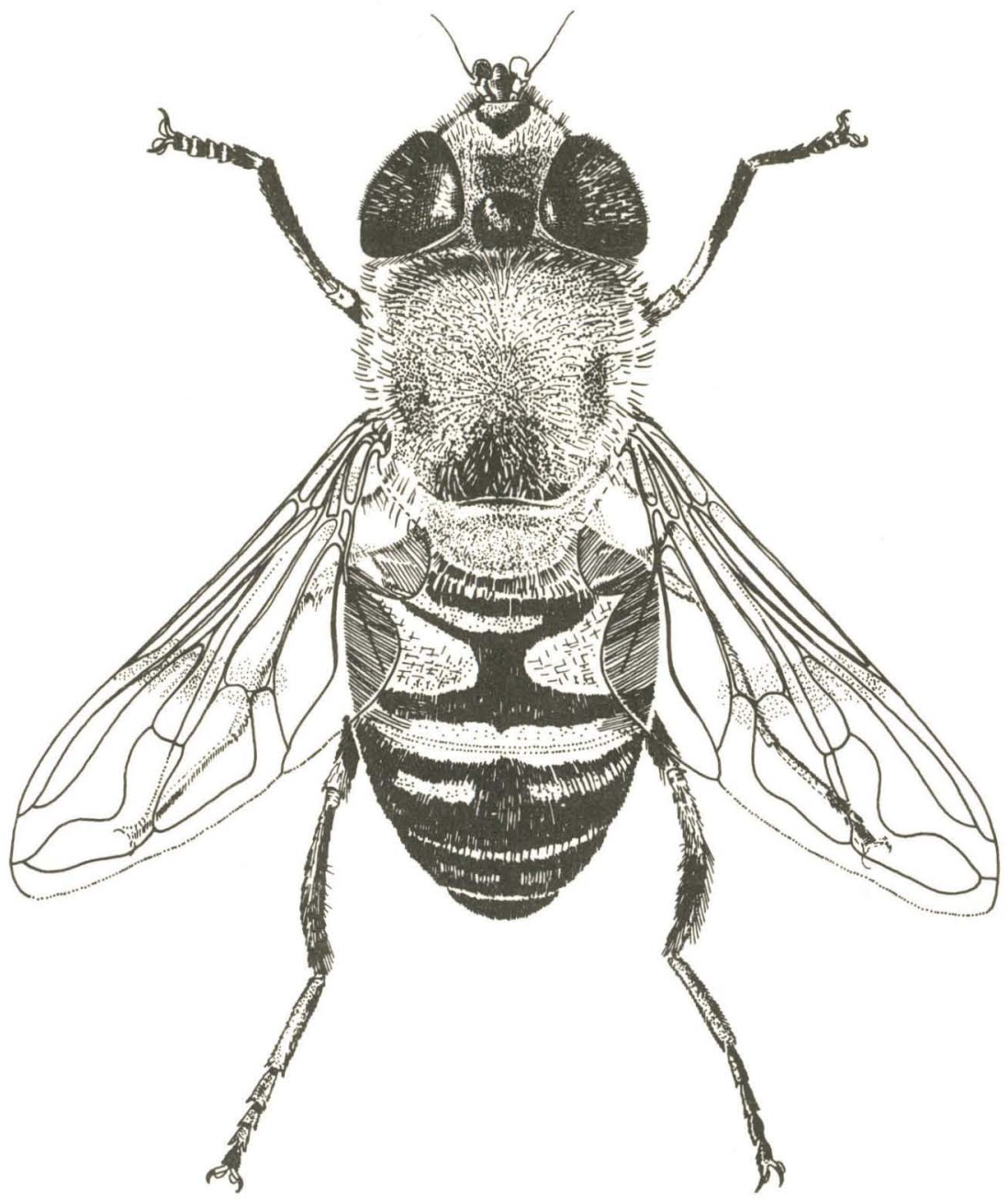

35

Fig. 35: Eristalis tenax (Linnaeus).

por pseudomiíases (James, 1948); para nossa região há apenas um único caso publicado (Donoso Barros \& Cambiazo Ch., 1950).

Forattini (1973) resumiu os vários processos usados para reduzir a densidade populacional de adultos e larvas.

\subsection{Família Syrphidae}

A espécie mais comumente encontrada causando pseudomiíases é Eristalis tenax (Linnaeus). $\mathrm{O}$ adulto tem a aparência geral de uma abelha: mede 
cerca de $15 \mathrm{~mm}$ de comprimento, a antena é castanho-escura, a arista com pubescência curta na parte basal, os olhos pilosos; tórax castanho-escuro, revestido de pelos amarelos; abdome negro-brilhante, com áreas transversais amarelas lateralmente (Fig. 35).

A larva desta espécie, caracterizada por seu longo e fino apêndice caudal, vive em esgotos, excrementos líquidos, carcaças em decomposição, etc. A sua presença em água estagnada é indicadora de alto grau de poluição; apesar disto, alguns casos de pseudomíases causados por E. tenax foram registrados na região neotropical (Faggioli, 1927, 1928; Rivarola, 1944; Silva-Campos, 1955; Vogelsang, 1926).

Há também um caso de pseudomiíase atribuído a Ornidia obesa (Fabricius) (Machado, 1937).

\subsection{Família Tephritidae}

As larvas de Tephritidae são encontradas em frutos maduros; são os vulgarmente chamados "bicho-de-frutas", "bicho-de-goiaba", ou "goró". Acidentalmente podem ser deglutidos, causando pseudomiíases. Apenas um trabalho incrimina-os neste sentido (Jirón \& Zeledón, 1979).

\subsection{Família Calliphoridae}

Esta família inclui geralmente larvas de vida livre que se alimentam de substâncias orgânicas em decomposição. As espécies causadoras de miíases propriamente ditas serão vistas mais adiante. Os casos de pseudomiíases intestinais registrados estão listados na bibliografia abaixo.

\section{BIBLIOGRAFIA}

Amorim, J., 1909. Miíase intestinal. Impr. méd., S Paulo 17(16): 241-247.

Barralt, R., 1929. A propósito de una observación de miasis intestinal. Semana méd., B Aires 36(49): 1679.

Bonilla-Naar, A., 1953. Un caso de miasis intestinal. Medna Cirug. Bogotá 17(9): 319-323, ilus.

Carini, A. \& E. Mastrangioli, 1908. Dous casos de myiase intestinal observados em São Paulo. Revta méd. S Paulo 11(24): 502. (Também em Zentbl. Bakt. ParasitKde 45(6): 183).

Castro, O. de, 1924. Myase intestinal. Folha méd. 5(9): 107.

Donoso Barros, R., 1949. Un caso de myiasis digestiva en Chile. Consideraciones sobre una nueva etiología. Lucilia coesar (Linnaeus), 1759 [sic] (nov. sp. in fauna chilensis). Revta méd. Chile 77(3): 209-211.

Donoso Barros, R. \& C. Cambiazo Ch., 1950. Un caso de myasis digestiva por larvas de Psychoda sp. Ibid. 78(7): 471.

Faggioli, R., 1927. Eristalis tenax, parásito accidental del cuerpo humano. Semana méd., B. Aires 34(14): 887.

Faggioli, R., 1928. Presentación de una larva de Syrphidae parásita del hombre. Revta Soc. ent. argent. 2(6): 67.

Forattini, O. P., 1973. Entomologia médica. 4 (Psychodidae, Phlebotominae, Leishmanioses, Bartonelose), 658 pp. Editora Edgar Blücher Ltda. e Editora da Universidade de São Paulo.

James, M. T, (1948). The flies that cause myiasis in man. U. S. Dep. Agric. misc. Publs 631: 1-175, 98 figs., 1947.

Jirón, L. F. \& R. Zeledón, 1979. The genus Anastrepha (Diptera: Tephritidae) in the most popular fruits of Costa Rica and its implication in human pseudomyiasis. Revta Biol. trop. 27(1): 155-160.

Lopes, H. de S., 1938. Sur une fausse myiase des poules produite par la larve de la Lucilia eximia Wied. (Dipt. Calliphoridae). C. R. hebdom. Acad. Sci. Paris 129(27): 426.

Machado, O., 1937. Parasitismo accidental pela larva de Volucella obesa. Revta flum. Med. 2(7): 239-242, fig. 
Maia, D. de P., 1913. Casos de myases intestinaes. Revta méd. S Paulo 16(12): 223-226. (Resumo em Trop. Dis. Bull. 3(5): 273-274).

Pazos, J. H., 1902. Larvas de moscas vomitadas. Revta Med. trop. (?) 3(12): 200-202.

Poblete, L., 1958. Miasis intestinal. Revta chil. Pediat. 29(2-3): 68-70.

Rivarola, J. B., 1944. Miasis intestinal humana por larva de Eristalis sp. Revta bras. Biol. 4(2): 239-241, figs.

Rivas Plata, N., 1951. Miasis intestinal. 1. Aspectos clínicos. Norte méd. 2(7): 255-257.

Silva, F. I. da, 1907. Contribuição ao estudo da myiase gastrointestinal. Brasil-méd. 21(18): 171-173.

Silva, F. I. da, 1909a. Uncinariose e myiase intestinal. Ibid. 23(24): 243-244.

Silva, F. I. da, 1909b. Contribuição ao estudo da myiase gastrointestinal. Gazeta clín. S Paulo 5(7): 61-62.

Silva Campos, R., 1955. Hallazgo de larvas de Tubifera tenax (Eristalis tenax). Boln chil. Parasit. 10(4): 75-77, 1 fig.

Silveira, J. X. da, 1906. Um caso de miíase intestinal. Gazeta clín. S Paulo 4(11): 330-331.

Splendore, A., 1907. Contribuição para o estudo das myiasis. Nota sobre uma nova espécie anthropophaga e sobre um caso de myase intestinal observados em S. Paulo (Brasil). Revta méd. S Paulo 10(19): 398-406, ilus.

Splendore, A., 1908a. Contribuzione allo studio delle miasi. Nuova specie di mosca antropofaga e caso di miasi intestinale verificati in Sao Paulo (Brasile). Archs Parasit. 12(2): 287-299, 2 figs.

Splendore, A., 1908b. Contribuição para o estudo das myiasis. Nota sobre uma nova espécie anthropophaga e sobre um caso de myase intestinal observado em São Paulo. Brasil-méd. 22(5): 49.

Travella, (-) \& R. Barralt, 1929. A propósito de un caso de miasis intestinal. Semana méd., B. Aires 36(24): 1569-1570.

Vergara Almendez, R., 1951. Miasis intestinal. II. Aspectos de laboratório. Norte méd. 2(7): 258-262, ilus. (vide Rivas Plata, 1951).

Vogelsang W., E. G., 1926. Caso de parasitismo humano por larvas de Syrphidae. Revta Med. vet. Montev. 2(28): 435-436, 1 fig.

\section{MIIAASES CAUSADAS POR PARASITAS FACULTATIVOS}

Registraram-se na região neotropical alguns casos de miíases causadas por representantes das famílias Calliphoridae, Fanniidae e Sarcophagidae, que podem ser classificados como facultativos. As larvas ocasionam miíases urinárias, otomiíases, miíases ulcerosas e miíases oculares.

\subsection{Família Calliphoridae}

Corpo de tamanho médio a grande, comumente de coloração metálica-azul, violeta, verde ou cuprina; arista plumosa, os pelos geralmente longos, até o ápice; não existe pós-escutelo ou é pouco desenvolvido; cerdas hipopleurais e pteropleurais presentes, bem desenvolvidas; 3 cerdas esternopleurais, 2 notopleurais e raramente uma acessória; a cerda pós-umeral mais posterior situa-se geralmente de modo mais lateral que a pré-sutural; mesonoto com (geralmente 3) ou sem faixas pretas longitudinais; nervura $\mathrm{M}_{1}+_{2}$ fortemente curvada para cima distalmente, estreitando desse modo a célula apical $\left(\mathrm{R}_{5}\right)$; esquamas torácicas bem desenvolvidas; $2 .^{\circ}$ esternito abdominal cobrindo as margens laterais do tergito correspondente; segmentos abdominais sem cerdas discais, ou estas pouco desenvolvidas; cerdas marginais de desenvolvimento variável.

Os Calliphoridae que ocorrem na região neotropical são agrupados em 4 subfamílias: Mesembrinellinae, Chrysomyinae, Calliphorinae e Toxotarsinae, com cerca de 27 gêneros e 125 espécies (James, 1970). As espécies assinaladas como causadoras de miíases encontram-se nos gêneros: Cochliomyia Townsend, 
Paralucilia Brauer \& Bergenstamm, Lucilia Robineau-Desvoidy, Phaenicia Robineau-Desvoidy e Calliphora Robineau-Desvoidy. Deve-se ressaltar que apenas Cochliomyia hominivorax (Coquerel) causa miíases primárias; todas as outras espécies dos gêneros acima são invasoras secundárias de ferimentos, causando mí́ases facultativas de tipo variado.

\section{Chave para identificação dos gêneros de Calliphoridae (adultos)}

1. Base do Rádio (antes da nervura transversal umeral) com uma fileira de pelos ou cílios na superfície superior, posteriormente (CHRYSO-

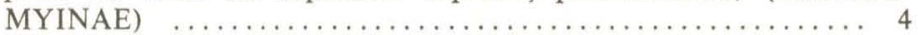

Base do Rádio sem pelos ou cílios (CALLIPHORINAE) ......... 2

2. Esquama ou calíptero inferior sem pelos superiormente ......... 3

Esquama inferior pilosa superiormente .............. Calliphora

3. Eșclerito subcostal só com pubescência delicada, não intercalada com pelos negros rígidos ..................... Phaenicia

Esclerito subcostal com pelos negros erectos em adição à pilosidade deli-

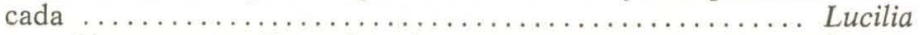

4. Coxa posterior com uma fileira de pelos posteriormente; espécies violeta-esverdeadas, com 3 faixas negras longitudinais no mesonoto .... 5

Coxa posterior sem pelos posteriormente; espécies verdes a negro-azuladas, mesonoto às vezes com faixas transversais ou 2 faixas longitudinais estreitadas, ou ambas as alternativas, porém nunca tão conspícuas como acima .............................. 6

5. Palpos curtos e filiformes, nunca atingindo a margem do epístoma ....... Cochliomyia Palpos alongados e clavados; quase sempre atingindo a margem do epís-

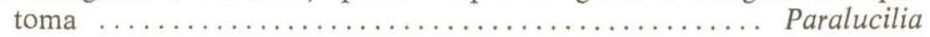

6. Esquama inferior pilosa superiormente $\ldots \ldots \ldots \ldots \ldots$ Chrysomya

Esquama inferior sem pelos superiormente .............. Phormia*

O gênero assinalado com asterico (*) ainda não foi encontrado causando qualquer tipo de miíase no homem ou animais domésticos na região neotropical.

Chave para identificação de larvas de 3 . $^{\circ}$ estágio de Calliphoridae

As larvas de espécies de Calliphoridae que podem causar míases não têm sido estudadas detalhadamente em todos os seus estágios; em virtude disto, em casos de míase é necessário e desejável que se tente o desenvolvimento completo das formas imaturas, obtendo-se então alguns adultos que possibilitem a identificação correta da espécie envolvida.

1. A superfície ventral e as laterais dos segmentos sem qualquer projeção

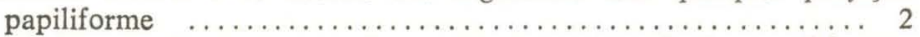

A superfície ventral e as laterais dos segmentos com projeções papiliformes conspícuas e compridas, terminando por um tufo de pelos ou

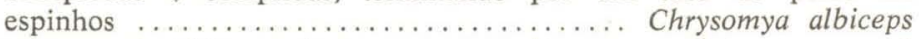

2. Espiráculos respiratórios posteriores com peritrema completo ...... 3 Espiráculos respiratórios posteriores com peritrema incompleto (Chrysomya

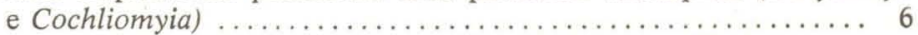

3. Esclerito acessório oral presente entre os escleritos mandibulares ...... Calliphora vicina

Esclerito acessório oral ausente (Lucilia, Phaenicia) ............ 4

4. Margem posterior dorsal do segmento 11 sem fileiras de espinhos .....

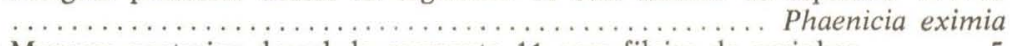
Margem posterior dorsal do segmento 11 com fileira de espinhos ..... 5

5. Tubérculos internos da margem superior da cavidade posterior separados por uma distância aproximadamente igual à distância dos tubérculos internos aos médios de cada lado ........... Phaenicia sericata 
Tubérculos internos da margem superior da cavidade posterior separados por uma distância aproximadamente igual à distância dos tubérculos internos aos exteriores de cada lado ......... Phaenicia cuprina

6. Troncos traqueais principais que partem dos espiráculos respiratórios anteriores com pigmentação castanho-escura ou negra ............ $\ldots \ldots \ldots \ldots \ldots \ldots \ldots \ldots \ldots \ldots \ldots \ldots \ldots \ldots \ldots \ldots$ Cochliomyia hominivorax

Troncos tranqueais principais não pigmentados $\ldots \ldots \ldots \ldots \ldots \ldots 7$

7. Margem posterior do segmento 11 sem espinhos dorsais

Cochliomyia macellaria

Margem posterior do segmento 11 com espinhos dorsais (Chrysomya) .. 8

8. Peritremas dos espiráculus posteriores separados um do outro por uma distância aproximadamente de $1 / 3$ a $1 / 2$ do diâmetro de um

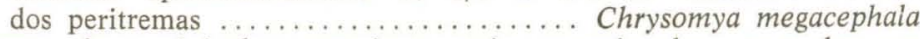

Peritremas dos espiráculos posteriores muito aproximados, separados um do outro por uma distância de aproximadamente $1 / 5$ do diâmetro de um dos peritremas

Chrysomya chloropyga

\section{Gênero Phaenicia Robineau-Desvoidy}

Phaenicia Robineau-Desvoidy, 1863: 750. Espécie-tipo, concinna Robineau-Desvoidy (Townsend, 1916: 8) = sericata (Meigen). Ref. - Mello, 1961.

Olhos sem pilosidade; triângulo ocelar atingindo cerca de $1 / 3$ da distância que vai do vértice à lúnula; arista com plumosidade longa: carena facial ausente ou aparecendo só na altura do $1 .^{\circ}$ segmento antenal; palpos clavados; tórax: com 3 cerdas dorsocentrais pós-suturais e 2 a 3 acrosticais pós-suturais; propleura e prosterno pilosos; declividade pós-alar com raros pelos; fossa timpânica com pelos fortes e numerosos; esclerito subcostal sem pelos; espinho da costal pouco diferenciado; segmentos abdominais sem cerdas discais; $4 .^{\circ}$ e $5 .^{\circ}$ segmentos com cerdas marginais compridas.

Cerca de 11 espécies listadas para a região neotropical (James, 1970), das quais apenas $P$. sericata (Meigen) foi comprovadamente observada como causadora de miíase tegumentar e genital no homem. Douglas et al. (1977) relatam um caso de otomíase em Cuba, por Phaenicia $s p$.

Chave para a determinação das espécies do gênero Phaenicia

1. Com 2 cerdas acrosticais pós-suturais $\ldots \ldots \ldots \ldots \ldots \ldots \ldots$ eximia*

Com 3 cerdas acrosticais pós-suturais ................... 2

2. Área occipital central ("cerebrale") com uma única seta de cada lado, logo atrás da cerda vertical interna; abdome geralmente de coloração fortemente cuprina: macho usualmente com 2 pares de cerdas ocelares; a fronte medindo 0,18 da largura da cabeça ao nível do estreitamento máximo; parte posterior do calo umeral com 2-4 sétulas; braços do $5 .^{\circ}$ esternito tão compridos quanto $\circ 4 .^{\circ}$ tergito; fêmea: buca menor que $1 / 3$ da altura do olho ...... P. cuprina*

Área occipital central geralmente com um grupo de 5 setas (algumas vezes reduzidas a 2 ou mesmo 1) de cada lado, logo atrás da cerda vertical interna; abdome de coloração variando de verde-brilhante ao cobre; macho comumente com 1 par de cerdas ocelares; a fronte medindo 0,11 da largura da cabeça em seu nível de máximo estreitamento; parte posterior do calo umeral com 6-8 sétulas; braços do $5 .^{\circ}$ esternito muito mais curtos que o $4 .^{\circ}$ tergito; fêmea: buca com quase $2 / 5$ da altura do olho ................ sericata

* As espécies eximia e cuprina são muito comuns na região neotropical, embora nunca tenham sido incriminadas como causadoras de miliases de qualquer tipo nessa região. 


\section{Phaenicia sericata (Meigen)}

Musca sericata Meigen, 1826: 53. Localidade-tipo: "Haiti".

Espécie de tamanho médio $(6-9 \mathrm{~mm})$, de coloração geral desde o verdeamarelo até o azul ou verde-cuprino, com reflexos metálicos, a cabeça escurecida e os palpos amarelos, ligeiramente avermelhados; 3 cerdas acrosticais pós-suturais e 1 par de cerdas ocelares.

A larva madura chega a atingir cerca de $14 \mathrm{~mm}$ de comprimento; coloração creme a rósea: os segmentos $2-8$ com fileiras completas de espinhos; o $9 .^{\circ}$ e $10 .^{\circ}$ segmentos dorsalmente lisos e o $11 .^{\circ}$ com fileiras completas de espinhos; espiráculos respiratórios anteriores com 7-8 processos digitiformes; placas espiraculares posteriores quase circulares; o peritrema de parede estreitada, amarelado e nunca preto ou castanho-escurecido.

Espécie de distribuição quase cosmopolita, ocorrendo no Novo Mundo desdẹ o sudoeste do Canadá até a Argentina (James, 1970); muito comum nas regiões temperadas do Hemisfério Norte.

À temperatura de $27^{\circ} \mathrm{C}$ o ciclo completo de $P$. sericata, da oviposição até a emergência dos adultos, requer cerca de 12 dias (eclosão do ovo: cerca de 8 horas; desenvolvimento larval: aproximadamente 120 horas; pupariação: 6 dias em média). A primeira oviposição ocorre entre os 3 e 8 dias após a emergência dos adultos e as fêmeas estão aptas a produzir entre 2000 a 3000 ovos, distribuídos por 9-10 posturas. As larvas vivem em substrato constituído por carcassas de vertebrados, fezes e outros produtos de origem animal em decomposição. A longevidade dos adultos, em laboratório, varia de 41 dias para os machos e 55 dias para as fêmeas; sua capacidade de dispersão é de cerca de 3,5 milhas para cada 48 horas.

No Brasil, Ferreira (1978) encontrou o índice de +79.0 em Curitiba, Paraná, onde esta espécie ocorre predominantemente na zona urbana $(85,7 \%$ do total dos espécimes capturados). Em Campinas, São Paulo, Linhares (1979) só encontrou 4 exemplares, durante um ano de coletas, o que fala em favor de sua extinção na região, provavelmente em virtude da acirrada competição com outras espécies de califorídeos. Em Goiânia, Goiás, Ferreira (1980) também encontrou poucos espécimes (69 espécimes) desta espécie, a maioria (41) capturados na zona urbana. Neste caso o indice sinantrópico foi de $+27,5$.

Segundo James (1948) P. sericata, como produtora de miíases em seres humanos, é usualmente de caráter benigno, isto é, as larvas alimentam-se de tecidos necrosados. Culturas de larvas, bacteriologicamente esterilizadas (axênicas) foram utilizadas há alguns anos atrás no tratamento da osteomielite, onde elas removiam os tecidos necróticos e, através dos produtos da excreção (alantoína), promoviam a cicatrização dos tecidos doentes da ferida. Entretanto, os tecidos sadios também podem ser invadidos, o que aumenta sua importância como produtora de miíases no homem e animais domésticos.

$\mathrm{Na}$ região neotropical só são conhecidos os casos apresentados por Reyes et al. (1967) e Székely et al. (1975), ambos no Chile, como miíases secundárias a úlceras tróficas das extremidades inferiores e como miíase genital em crianças lactentes.

\section{Gênero Calliphora Robineau-Desvoidy}

Calliphora Robineau-Desvoidy, 1830: 433. Espécie-tipo, Musca vomitoria Linnaeus (des. orig.). Ref. - Mello, 1962.

Olhos sem pilosidade; cerdas frontorbitais presentes; arista longa e densamente plumosa; carena facial vestigial ou ausente; mesonoto não achatado logo após a sutura transversal; esquama inferior pilosa na superfície dorsal; asas hialinas sem enfuscamento definido.

Este gênero, de distribuição predominantemente paleártica, ocorre na região neotropical com 5 espécies; a única incriminada como causadora de miíase tegumentar ou cutânea é $C$. vicina Robineau-Desvoidy, de origem holártica, que se distribui também pelo México, Uruguai, Argentina, Chile e Terra do Fogo (James, 1970). 


\section{Calliphora vicina Robineau-Desvoidy}

Calliphora vicina Robineau-Desvoidy, 1830: 435. Localidade-tipo, Estados Unidos, Pennsylvania, Philadelphia. Distr. - Holártica, do Alasca ao México; Uruguai, Argentina e Chile até a Terra do Fogo.

Espécie robusta (9 a $11 \mathrm{~mm})$; cabeça negra superiormente, sendo a metade anterior ou a maior parte da buca e a parte inferior da faciália amarelo-avermelhadas; tórax negro, o mesonoto com densa polinosidade acinzentada; abdome azul com enxadrezamento prateado.

A larva madura é de coloração esbranquiçada ou amarelada, medindo cerca de $17 \mathrm{~mm}$ de comprimento; os segmentos 2-9 com fileiras completas de espinhos; espiráculos respiratórios anteriores com 7-9 processos digitiformes; as placas espiraculares posteriores são circulares e estão separadas uma da outra por uma distância igual ao diâmetro de uma das placas: o peritrema é largo e completamente esclerosado (James, 1948).

Os adultos são encontrados na zona urbana repousando sobre folhagens; as fêmeas são comumente observadas sobre cadáveres e outros tipos de material em decomposição. As larvas desenvolvem-se em qualquer tipo de material em decomposição (fezes, carcassas, lixo, frutos apodrecidos, etc.). $\mathrm{O}$ período de pré-oviposição é de $4-15$ dias (a mais ou menos $24^{\circ} \mathrm{C}$ ); a cópula ocorre geralmente entre 5 a 9 dias após a emergência dos adultos; cada fêmea produz de 540 a 720 ovos durante sua vida, ovipondo massas de mais ou menos 180 ovos de cada vez. A eclosão do ovo se dá após 3-8 horas a $24^{\circ} \mathrm{C}$ e $65 \%$ de umidade relativa; o desenvolvimento larval leva em média 220 horas e o pupal entre 7 a 9 dias. A longevidade dos adultos, em laboratório, alcança cerca de 25 dias.

É uma espécie eusinantrópica e comunicativa; os adultos são freqüentemente encontrados ao redor de mercados, feiras-livres, matadouros e abatedouros de pequenos animais, sendo desta forma potenciais veiculadores de patógenos.

Segundo Zumpt (1965) esta espécie pode produzir miíases tegumentárias traumáticas no homem e animais domésticos; a única notícia de $C$. vicina como agente produtor de miíase na região neotropical é a de Jörg (1939) na Argentina, que relata a presença desta espécie em casos de miíase cutânea (o autor identificou-a como $C$. vomitoria).

\section{Gênero Paralucilia Brauer \& Bergenstamm}

Paralucilia Brauer \& Bergenstamm, 1891: 391. Espécie-tipo, Calliphora fulvipes Macquart (mon.) = fulvicrura (Robineau-Desvoidy). Ref. - Mello, 1968.

Olhos sem pilosidade; cerdas frontorbitais ausentes; arista longa, plumosa; palpos clavados, compridos; tórax: mesonoto com 4 faixas longitudinais de polinosidade prateada; 2 a 3 cerdas acrosticais pós-suturais; esquamas brancas, amarelas ou castanhas com pelos escuros só na depressão da superfície superior da esquama inferior; segmentos abdominais sem cerdas discais; cerdas marginais dos tergitos 3 a 5 fracamente desenvolvidas.

Este gênero é predominantemente neotropical, com 7 espécies (James, 1970).

\section{Paralucilia fulvicrura (Robineau-Desvoidy)}

Chrysomya fulvicrura Robineau-Desvoidy, 1830: 446. Localidade-t.po: Uruguai. Montevideo. Distr. - Do México ao Chile e Argentira (Kıo Negru), além das ilhas de Juan Fernandez e Páscoa (James. 19:0).

Espécie de tamanho médio $(7.9 \mathrm{~mm})$, com a cabeca unareiu-alarajjada inferiormente e escurecida superiormente; o corpo ć escurccido, son refiexus metálicos azulados ou prateados e com 4 faixas longitı:dindis de pulinusidade prateada no mesonoto; as esquamas são brancas con peios castanhus ra 'fice superior. 
Del Ponte (1958) refere o achado de um caso de miliase em carneiro (Ovis aries L. na cidade de Rocha, Província de Buenos Aires, Argentina; sua extensão e importância para a criação de ovinos, entretanto, não foram investigadas.

\subsection{Família Fanniidae}

Esta família, próxima a Muscidae, compreende dípteros de tamanho médio a pequeno, olhos grandes, genas estreitas e probóscida curta; a veia $\mathrm{A}_{2}$ (sétima veia longitudinal) é curvada ao redor do ápice da veia $\mathrm{A}_{1}+\mathrm{Cu} \mathrm{A}_{2}$ (sexta veia longitudinal).

$\mathrm{Na}$ literatura existem numerosos casos de miíases facultativas no trato digestivo e vias urinárias do homem por várias espécies de Fannia.

A larva de Fannia se desenvolve em quase todos os tipos de matéria orgânica em decomposição; algumas espécies foram encontradas em ninhos de pássaros e de insetos sociais. A larva deste grupo é muito característica, por apresentar o corpo deprimido, afilado em ambas extremidades e apresentando em cada segmento (além do primeiro) apêndices laterais. Tais apêndices são proeminentes e se apresentam simples ou pectinados.

James (1948) registrou vários casos de parasitismo do tubo digestivo do homem por Fannia. Quando presentes no estômago, as larvas podem causar vertigens, náusea e dores violentas, podendo ser expelidas pelo vômito. No intestino podem produzir dores abdominais, diarréias e algumas vezes hemorragias, resultantes de lesões da membrana da mucosa intestinal. O paciente apresenta o estômago aumentado de volume, perda de apetite e enfraquecimento geral. As miíases intestinais podem ser diagnosticadas pelo encontro de larvas expulsas nas fezes.

Vários casos de míases urogenitais foram também registrados. Os sintomas usuais nestes casos consistem em dores e dificuldade para urinar, resultante, da passagem da larva pela bexiga e uretra.

A infestação pode se dar pela ingestão de alimentos crus ou os ovos podem ser depositados sobre ou próximos ao ânus. Neste último caso, as larvas, logo após a emergência, podem penetrar no meato urinário ou intestino.

Tais infestações são freqüentemente resultantes do uso de instalações sanitárias sem higiene, ou em crianças que dormem nuas em lugares sujos, onde as moscas são abundantes.

Fannia canicularis (Linnaeus), espécie cosmopolita, é responsável por $75 \%$ dos casos de miíases intestinais e muitos casos de míases urogenitais e nasofaringeanas, registrados na literatura.

Fannia scalaris (Fabricius), também cosmopolita, comumente referida na literatura estrangeira como "latrine fly" tem sido implicada em vários casos de miíases intestinais, nasofaringeanas e urogenitais (James, 1948).

$\mathrm{Na}$ América do Sul, Mazza \& Reyes Oribe (1934) descreveram um caso de miíase urinária, supostamente causado por Fannia fusconotata Rondani, em Formosa, Argentina. Pelas fotos apresentadas pelos autores, acreditamos que tal espécie foi identificada erroneamente e que se trata simplesmente de Fannia scalaris (Fabricius).

\subsection{Família Sarcophagidae}

Esta família compreende moscas de tamanho médio, geralmente de cor cinza, arista nua ou pilosa apenas na base, mesonoto com três faixas negras longitudinais, abdome geralmente ornamentado de manchas com reflexos cinzentos ou negros em xadrez. Os Sarcophagidae separam-se dos Muscidae por apresentar cerdas hipopleurais e dos Tachinidae por não apresentar o pós-escutelo desenvolvido.

A larva cria-se em carcaças, excrementos ou matéria orgânica em decomposição. Algumas espécies são parasitas de Orthoptera, Lepidoptera, moluscos, anelídeos e outros invertebrados. Acidentalmente podem produzir miíases em homens e animais. 
Tabela 4.1

Casos de miíases produzidas por Sarcophagidae registrados na Neotrópica

\begin{tabular}{|c|c|c|c|}
\hline Espécie & Localização & Referência & Pais \\
\hline Bercaea haemorrhoidalis (Fall.) & Auricular & Cerruti, 1913 & Argentina \\
\hline Paraphryssopoda chrysostoma (Wiedemann) & Cutânea & Calero, 1948 & Panamá \\
\hline Parasarcophaga (Thomsonea) argyrostoma (Robineau-Desvoidy) & Cutânea & Mazza \& Basso, 1939 & Argentina \\
\hline Sarcodexia sternodontes Townsend & $\begin{array}{l}\text { Cutânea } \\
\text { Auricular (bezerro) }\end{array}$ & $\begin{array}{l}\text { Neiva \& Faria, } 1913 \\
\text { Almeida, } 1933\end{array}$ & $\begin{array}{l}\text { Brasil } \\
\text { Brasil }\end{array}$ \\
\hline Sarcophaga $s p$. & $\begin{array}{l}\text { Ocular } \\
\text { Labial } \\
\text { Em Coendu }\end{array}$ & $\begin{array}{l}\text { Mazza, Parodi \& Smith, } 1930 \\
\text { Sawaya \& Pinto, in Pinto, } 1930 \\
\text { Lacey \& George, } 1981\end{array}$ & $\begin{array}{l}\text { Argentina } \\
\text { Brasil } \\
\text { Brasil }\end{array}$ \\
\hline $\begin{array}{l}\text { Sarcophagidae não identificados } \\
\text { ou identificados erroneamente }\end{array}$ & Cutânea & $\begin{array}{l}\text { Blanco Ledesma, } 1917 \\
\text { Torres, 1915, 1916, } 1924 \\
\text { Splendore, 1907, 1908a-b }\end{array}$ & $\begin{array}{l}\text { Venezuela } \\
\text { Brasil } \\
\text { Brasil }\end{array}$ \\
\hline
\end{tabular}


Os casos de miíases encontrados na literatura da América Neotropical estão registrados na tabela 4.1. Algumas das identificações originais são extremamente duvidosas. As citações dos nomes das espécies foram modernizadas pelo catálogo neotropical de Sarcophagidae de Lopes (1969).

\section{REFERENCIAS}

Almeida, J. L. de, 1933. "Otomyase" em bezerro por Sarcophaga sternodontes (Towsend [sic], 1892). Archos Esc. sup. Agric. Med. vet. Rio de J. 10(2): 171-172.

Blanco Ledesma, D. A., 1917. Dos nuevos casos de miasis. Miasis ulcerosa (Sarcophaga carnaria). Miasis nasal. Lucilia hominívorax [sic] o Chrysomyia macellaria. Gac. méd. Caracas 24(9): 79-80. (Resumo em Rev. appl. Ent. (B) 6(3): 51-52,1918).

Bowe Douglas, L. et al., 1977. Miiasis otica en un recien nacido, causada por larvas de Calliphoridae del genero Phaenicia. Revta cub. Med. trop. 29(2): 75-79, fig.

Brauer, F. \& J. E. von Bergenstamm, 1891. Die Zweiflügler des kaiserlichen Museums zu Wien. V. Vorarbeiten zu einer Monographie der Muscaria Schizometopa (exclusive Anthomyidae). Pars II. Denkschr. k. Akad. Wiss. Wien, math.-naturw. Cl. 58: 305-446.

Calero M., C., 1948. Cutaneous myiasis due to Chrysostomia bergi (Blanchard). First report from the Isthmus of Panama. J. Parasit. 35 (5): 545.

Cerruti, T., 1913. Miasis del oído. La Sarcophaga nurus nueva productora de miasis. An. Soc. argent. Oto-rino-laringol. 2(1-2): 64-68, ilus.

Del Ponte, E., 1958. Manual de entomología médica y veterinaria argentinas, 349 pp., 221 figs. Ediciones Librería del Colegio, Buenos Aires.

Douglas, L. B., E. A. Trapaga, F. S. Guerra \& P. A. Bermudez, 1977. Otic myiasis due to Calliphoridae larvae of the genus Phaenicia. Revta cub. Med. trop. 29(2): 75-80.

Ferreira, M. J. de M., 1978. Sinantropia de dípteros muscóideos de Curitiba, Paraná. I. Calliphoridae. Revta bras. Biol. 38: 445-454.

Ferfeira, M. J. de M., 1980. Sinantropia de Calliphoridae (Diptera) em Goiânia, Goiás, 119 pp. Tese, Escola Superior de Agricultura Luiz de Queiroz, Piracicaba.

James, M. T., (1948). The flies that cause myiasis in man. U. S. Dep. Agric. misc. Publs 631: 1-175, 98 figs., 1947.

James, M. T., 1970. Family Calliphoridae, in Museu de Zoologia, Universidade de São Paulo, A Catalogue of the Diptera of the Americas south of the United States 102: 1-28. São Paulo.

Jörg, M. E., 1939. Miasis de ulcera por Calliphora vomitoria (Investigaciones sobre dipteros argentinos. I. Miasis). Publnes Misión Estud. Patol. region. argent., Jujuy 41: 76-77, ilus.

Lacey, L. A. \& T. K. George, 1981. Myiasis in an Amazonian porcupine. Ent. News 92(2): 79-80.

Linhares, A. X., 1979. Sinantropia de dipteros muscóideos de Campinas, 129 pp. Tese, Instituto de Biologia, Universidade Estadual de Campinas.

Lopes, H. S., 1969. Family Sarcophagidae, in Departamento de Zoologia, Secretaria da Agricultura, A Catalogue of the Diptera of the Americas south of the United States 103: 1-88. São Paulo.

Mattos, W. R. B., 1921. Myasis produzida por larvas de Sarcophaga. Folha méd. 2(5): 33.

Mazza, S. \& R. Basso, 1939. Miasis de úlcera crónica de pierna por Sarcophaga barbata y Cochliomyia hominivorax (Investigaciones sobre dipteros argentinos. I. Miasis). Publnes Misión Estud. Patol. region. argent., Jujuy 41: 47-54, ilus.

Mazza, S., S. Parodi \& C. M. Smith, 1930. Miasis ocular por larva de Sarcophaga sp. 5. Reun. Soc. argent. Patol, region. Norte 2: 1157-1159, 3 figs. 
Mazza, S. \& H. Reyes Oribe, 1939. Miasis urinaria por Fannia fusconotata (Rondani) en Formosa (Investigaciones sobre dipteros argentinos. I. Miasis). Publnes Mision Estud. Patol. region. argent., Jujuy 41: 66-69, 2 figs.

Meigen, J. W., 1826. Systematische Beschreibung der bekannten europäischen zweiflügelige Insekten 5: xii $+512 \mathrm{pp}$.

Mello, R. P. de, 1961. Contribuição ao estudo do gênero Phaenicia (R. D., 1863) (Diptera, Calliphoridae). Mems Inst. Oswaldo Cruz 59: 259-278.

Mello, R. P. de, 1962. Contribuição ao estudo do gênero Calliphora R. D., 1830 (Diptera, Calliphoridae). Ibid. 60: 263-274.

Mello, R. P. de, 1968. Contribuição ao estudo do gênero Paralucilia Brauer \& Bergenstamm, 1891 (Diptera, Calliphoridae). Revta bras. Biol. 28: 177-192.

Neiva, A. \& J. G, de Faria, 1913. Notas sobre um caso de miiase humana ocasionada por larvas de Sarcophaga pyophila, n. sp. Mems Inst. Oswaldo Cruz 5(1): 16-23.

Pinto, C., 1930. Tratado de Parasitologia. Arthropodes parasitos e transmissores de doenças 2: 397-845, figs. 191-356, pls. 8-36. Bibliotheca Scientifica Brasileira, Collecção Medico-cirurgica n. ${ }^{\circ}$ 177A. Typ. Pimenta de Mello \& Cia., Rio de Janeiro.

Reyes, H., H. Hevia, H. Schenone \& J. Sapunar, 1967. Myiasis humana por Phaenicia sericata (Meigen, 1826) en Chile (Diptera, Calliphoridae). Boln chil. Parasit. 22: 168-171.

Splendore, A., 1907. Contribuição para o estudo das myiasis. Nota sobre uma nova espécie anthropophaga e sobre um caso de myase intestinal observados em S. Paulo (Brasil). Revta méd. S Paulo 10(19): 398-406. (Também em Archs Parasit. 12(2): 287-299, 1908; e Brasil-méd. 22(5): 49, 1908).

Székely, R., C. Herreros \& M. Rojo, 1975. Myiasis humana umbilical por Phaenicia sericata en un recién nacido. Boln chil. Parasit. 30: 25-26.

Torres, O., 1915. Sobre algumas observações de myiases. Brasil-méd. 29(32): 252-253.

Torres, O., 1916. Considerações sobre as myiasis. Gazeta méd. Bahia 1916: 289-298.

Torres, O., 1924. Considerações sobre as myiasis. Revta Med. vet. Montev. 2(24): 279.

Townsend, C. H. T., 1916. Description of muscoid genotypes, with new genera and species. Ins. Insc. menstr. 4: 4-12.

Valério, A., 1938. (?). J. Syph. Urol., Rio de J. 9(10): 142-144.

Zumpt, F., 1965. Myiasis in man and animals in the Old World, xv + 267 pp., ilus. London.

\section{FAMILIA MUSCIDAE (GENERO Philornis)}

\subsection{Caracterização}

\section{Philornis Meinert}

Philornis Meinert, 1890: 315. Espécie-tipo, molesta Meinert (mon.).

Neomusca Malloch, 1921: 41. Espécie-tipo, Mydaea obscura Wulp (des. orig.). Mesembrinellopsis Townsend, 1927: 208, 328. Espécie-tipo, mima Townsend (des, orig.).

Philornis pode ser geralmente distinguido de outras espécies de Muscidae pela seguinte combinação de caracteres do adulto.

Dípteros de coloração castanha-clara até quase pretos. Abdome raramente azul-metálico, freqüentemente amarelado na base e ventralmente. Asa com a veia anal longa, porém não alcançando a margem da asa; $4 .^{2}$ veia longitudinal reta ou com uma ligeira curvatura subapical. Declive pós-alar e pteropleura 
pilosos. Calípteros largos, fortemente aderidos ao tórax, atingindo até a base do escutelo. Prosterno, propleura e margem posterior da coxa posterior nus. Arista plumosa. Palpos amarelos, um tanto achatados. Haustelo mais curto que o paipo.

Pupário - $\mathrm{Na}$ maioria das espécies os espiráculos posteriores estão situados numa concavidade, o peritrema com as margens fortemente espessadas e rugosas. As coberturas estigmáticas variam na forma desde um " $C$ " até fortemente sinuosas. Nas espécies de vida livre os espiráculos posteriores não estão situados em concavidades.

\subsection{Distribuição}

As espécies deste gênero, num número total de 33, segundo o catálogo de Pont (1972; como Neomusca), têm ampla distribuição na região neotropical; não ocorrem no Chile.

\subsection{Biologia}

Os ovos são provavelmente depositados diretamente no ninho ou sobre os filhotes das aves. A fase de ovo é muito rápida.

As larvas, na maioria dos casos, são parasitas subcutâneas dos filhotes das aves, formando intumescimentos debaixo da pele da cabeça, asas, costas e uropígio (Fig. 36). Nos pássaros infestados pode-se encontrar larvas de todas as idades. As larvas maduras, próximas da época de emergência, conservam sempre os estigmas ao nível do orifício cutâneo, circunstância que as torna muito aparentes, ao passo que as larvas mais jovens são encontradas sob a pele, distante do orifício (Lutz \& Neiva, 1912). O desenvolvimento larvário é muito rápido. O estágio pupal leva de 11 a 13 dias e os adultos emergem geralmente antes que os filhotes estejam completamente emplumados e prontos para abandonar o ninho. Pode ocorrer diapausa no período pupal, coincidindo com o período do ano em que a ave hospedeira não está nidificando. O pupário adere, nor meio de uma substância espumosa, a pequenos grãos de areia ou partículas outras no ninho (palha, etc.), formando assim um verdadeiro casulo (Fig. 37). O mesmo ocorre com vários outros Muscidae (Ferrar, 1980). Entretanto, as espécies $P$. torquans e $P$. aitkeni não foram registradas formando casulos.

Segundo Dodge \& Aitken (1968), as larvas de P. falsifica e P. downsi se alimentam externamente nos filhotes como ectoparasitas. Philornis aitkeni é, por outro lado, uma espécie ainda coprófaga, de vida livra - foi criada em grandes números de ninhos de Galbula ruficauda. Segundo Dodge (1963), Aitken, em Trinidad, recolheu mais de 300 larvas desta espécie em um único ninho e criou as larvas em laboratório, usando como substrato excrementos de galinha e de aves silvestres.

A lista de hospedeiros é dada a seguir. Não se conhecem casos de parasitismo em aves marinhas ou de rapina.

Existem dois casos na literatura, de Philornis atacando aves adultas, ambos em pica-paus; em cada caso apenas uma larva foi encontrada; e, estranhamente, não há nem um registro em filhotes de pica-paus. Tais registros são os de Macquart (1854), de Philornis pici sobre Picus striatus (atualmente Melanerpes striatus), na República Dominicana ("Saint Domingue"); o outro é o de Aitken, que encontrou Philornis angustifrons em um adulto de Piculus rubiginosus, em Trinidad (Dodge \& Aitken, 1968). 1952).

Existe ainda um registro de parasitismo em frango doméstico (Garcia,

Infestações severas devem ter um efeito debilitante; entretanto, uma vez que as aves jovens estão sendo intensamente alimentadas por seus pais, elas se recuperam rapidamente do ataque desses parasitas. Lutz \& Neiva (1912) registraram a observação de Ladislao Neto, de uma coleta de 154 larvas de Philornis em um filhote de guaxo (Cacicus haemorrhous) já crescido, o que constitui um caso extraordinário. 


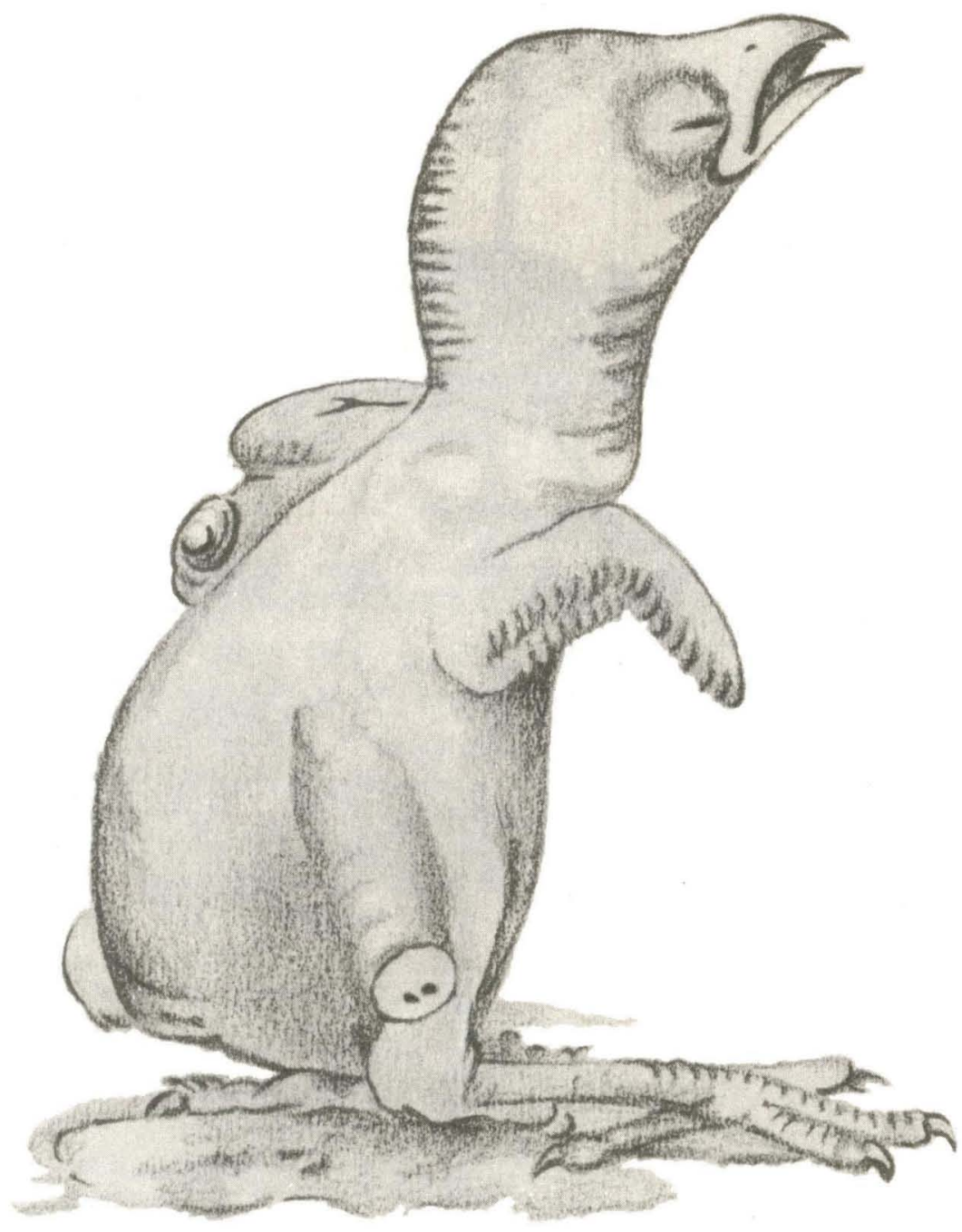

36

'Fig. 36: Filhote de ave com larvas de Philornis (adaptado de Meinert, 1890). 


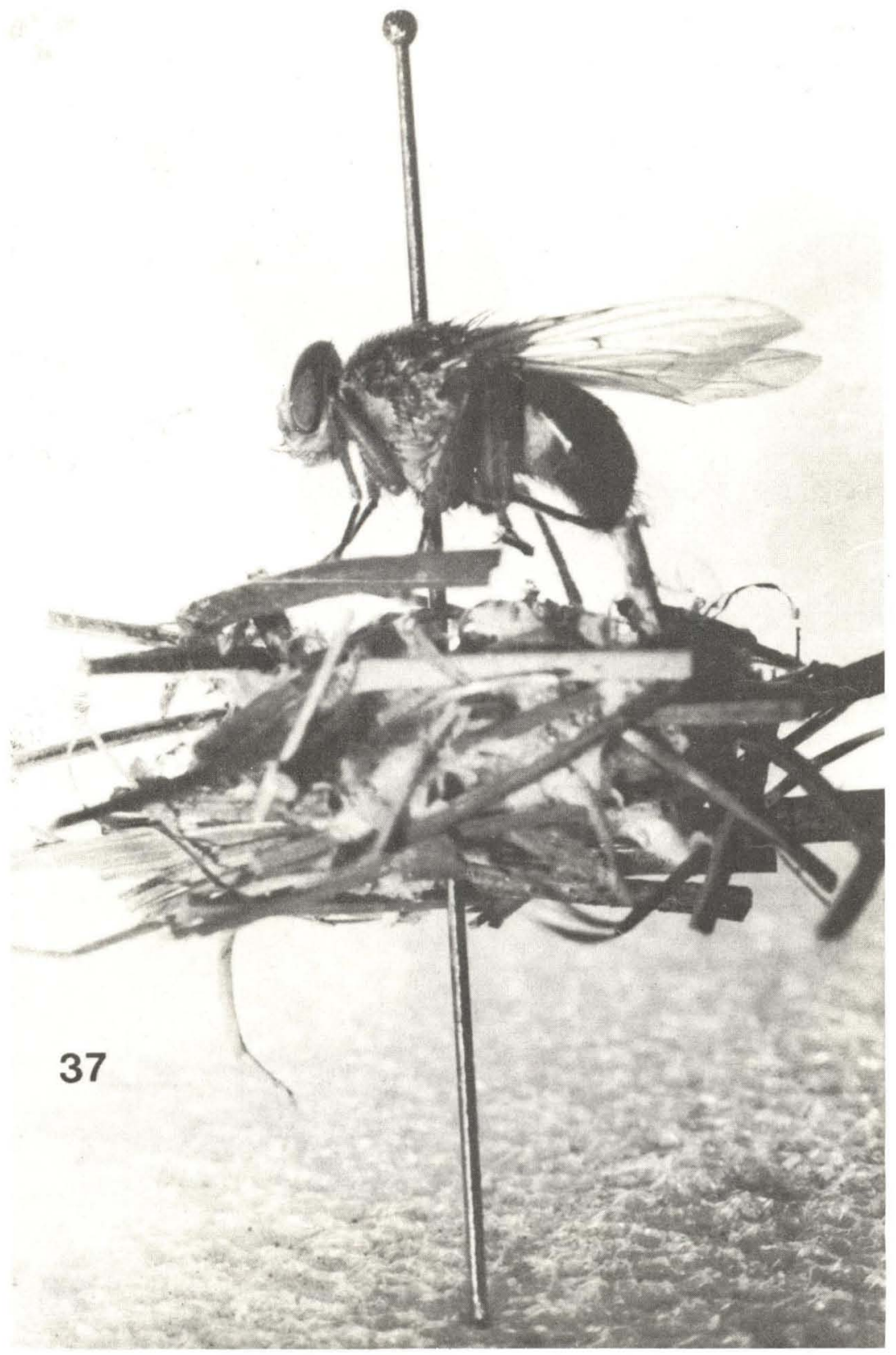

Fig. 37: Exemplar de Philornis (Brazil, Pará, Santarém, Faz. Taperinha) junto com seu casulo feito de fragmentos de palha de ninho de guaxo (japiim). 
Ainda resta muito a ser descoberto e estudado neste gênero. Exceto por alguns trabalhos mais antigos, e o de Dodge \& Aitken (1968) e Dodge (1963, 1968) para as espécies de Trinidad, sabe-se pouco ou nada sobre as espécies neotropicais. Os dados antigos, quase todos se referindo a "Philornis pici", erroneamente, não podem ser utilizados, por falta de identificação correta da espécie do parasito.

\section{LISTA DAS AVES HOSPEDEIRAS ARRANJADAS SOB AS ESPÉCIES, DE Philornis QUE AS PARASITAM}

\section{Philornis angustifrons (Loew)}

Icterus dominicensis (Linnaeus) (Icteridae) - Loew, 1861 (Cuba).

Cacicus cela (Linnaeus), Icterus icterus (Linnaeus), Molothrus bonariensis (Gmelin), Quiscalus lugubris Swainson, Psarocolius decumanus (Pallas) (Icteridae); Mimus gilvus Vieillot (Mimidae); Thraupis episcopus (Linnaeus) (como virens) (Thraupidae); Sporophila intermedia Cabanis, Sycalis flaveola (Linnaeus) (Fringillidae); Pitangus sulfuratus (Linnaeus) (Tyrannidae) - Vogelsang \& Fernández Yépez, 1952 (Venezuela); Schäfer, 1957 (Venezuela).

Columbigallina talpacoti (Temminck), Leptotila rufaxila (Richard \& Bernard), Leptotila verreauxi (Bonaparte) (Columbidae); Crotophaga ani Linnaeus (Cuculidae); Piculus rubiginosus (Swainson) (Picidae); Manacus manacus (Linnaeus) (Pipridae); Pitangus sulfuratus (Linnaeus) (Tyrannidae); Psomocolax oryzivorus (Gmelin) (Icteridae); Thraupis episcopus (Linnaeus) (Thraupidae) Dodge \& Aitken, 1968 (Trinidad).

2. Philornis deceptiva Dodge \& Aitken

Pitangus sulfuratus (Linnaeus) (Tyrannidae); Mimus gilvus Vieillot (Mimidae); Cacicus cela (Linnaeus), Icterus nigrogularis (Hahn), Psomocolax oryzivorus (Gmelin) (Icteridae) - Dodge \& Aitken, 1968 (Trinidad).

\section{Philornis downsi Dodge \& Aitken}

Crotophaga ani Linnaeus (Cuculidae); Galbula ruficauda Cuvier (Galbulidae); Legatus leucophaius (Vieillot), Tyrannus melancholicus Vieillot (Tyrannidae); Progne chalybea (Gmelin) (Hirundinidae); Troglodytes musculus Neumann (Troglodytidae); Mimus gilvus Vieillot (Mimidae); Turdus fumigatus Lichtenstein, Turdus nudigenis Lafresnaye (Turdidae); Coereba flaveola Linnaeus (Coerebidae); Cacicus cela (Linnaeus), Molothrus bonariensis (Gmelin) (Icteridae); Rhamphocelus carbo (Pallas), Tachyphonus rufus (Boddaert), Thraupis palmarum (Wied) (Thraupidae) - Dodge \& Aitken, 1968 (Trinidad).

4. Philornis falsifica Dodge \& Aitken

Amazona amazonica (Linnaeus) (Psittacidae); Crotophaga ani Linnaeus (Cuculidae); Otus choliba (Vieillot) (Strigidae) - Dodge \& Aitken, 1968 (Trinidad).

5. Philornis glaucinis Dodge \& Aitken

Glaucis hirsuta (Gmelin) (Trochilidae) - Dodge \& Aitken, 1968 (Trinidad).

6. Philornis mimicola Dodge

"Mockingbird" - Dodge, 1968 (Estados Unidos: Texas).

7. Philornis molesta Meinert

"Oscine bird" - Meinert, 1890 (Brasil). 
8. Philornis nielseni Dodge

Xiphocolaptes albicollis (Vieillot) (Dendrocolaptidae) - Nielsen, 1913 (Argentina).

9. Philornis nigra Dodge \& Aitken

Glaucis hirsuta (Gmelin) (Trochilidae) — Dodge \& Aitken, 1968 (Trinidad).

10. Philornis pici (Macquart)

Melanerpes striatus (P. L. S. Müller) (Picidae) - Macquart, 1854 (República Dominicana).

11. Philornis querula Dodge \& Aitken

Mimus gilvus Vieillot (Mimidae) - Dodge \& Aitken, 1968 (Trinidad).

12. Philornis sanguinis Dodge \& Aitken

Leptotila sp., Leptotila verreauxi (Bonaparte) (Columbidae); Pitangus sulfuratus (Linnaeus) (Tyrannidae); Sporophila lineola (Linnaeus) (Fringillidae) Dodge \& Aitken, 1968 (Trinidad).

13. Philornis spermophila (Townsend)

Sporophila sp. (como Spermophila) - Townsend, 1895 (Jamaica).

14. Philornis torquans (Nielsen)

Pseudoseisura lophotes (Reichenbach) (Furnariidae); Pitangus sulfuratus bolivianus (Lafresnaye) (Tyrannidae): Agelaius thilius Molina (Icteridae); Sporophila nigricollis (Vieillot) (Fringillidae) - Nielsen, 1912 (Argentina). 1950.

Pseidoseisura sp., Pitangus sp., Mimus sp., Sporophila sp. - Séguy, 1946,

\section{Philornis trinitensis Dodge \& Aitken}

Pitangus sulfuratus (Linnaeus), Tyrannus melancholicus Vieillot (Tyrannidae); Troglodytes musculus Naumann (Troglodytidae); Turdus fumigatus Lichtenstein (Turdidae); Molothrus bonariensis (Gmelin) (Icteridae); Thraupis episcopus (Linnaeus) (Thraupidae); Oryzoborus angolensis (Linnaeus), Sporophila lineola (Linnaeus) (Fringillidae) - Dodge \& Aitken, 1968 (Trinidad).

16. Philornis spp. (às vezes erradamente identificadas como pici)

Spilogaster anomalus, Oriolus cajanensis, O. mexicanus - Blanchard, 1895 (Guiana Francesa).

Peristera rufaxila - Ribeiro, 1901 (Brasil).

Furnarius rufus, Molothrus bonariensis, Paroaria dominicana, Amazona sp., Pionus sp. - Neiva \& Penna, 1908 (Brasil).

Cacicus haemorrhous - Lutz \& Neiva, 1912 (Brasil).

Sporophila sp. - Garcia, 1952 (Argentina).

Zenaidura macroura - Glasgow \& Hanson, 1957 (USA: Louisiana). 


\section{LISTA DAS AVES HOSPEDEIRAS DE Philornis, ARRANJADAS SISTEMATICAMENTE}

ORDEM

COLUMBIFORMES Columbidae

PSITTACIFORMES

CUCULIFORMES

STRIGIFORMES

APODIFORMES

PICIFORMES

PASSERIFORMES

Psittacidae

Cuculidae

Strigidae

Trochilidae

Galbulidae

Picidae
Dendrocolaptidae

Furnariidae

Pipridae

Tyrannidae

Hirundinidae

Troglodytidae

Mimidae

Turdidae

Coerebidae

Icteridae

Thraupidae
Columbigallina talpacoti

(Temminck)

Leptotila rufaxila

(Richard \& Bernard)

Leptotila verreauxi (Bonaparte)

Zenaidura macroura (Linnaeus)

Amazona amazonica (Linnaeus)

Crotophaga ani Linnaeus

Otus choliba (Vieillot)

Glaucis hirsuta (Gmelin)

Galbula ruficauda Cuvier

Melanerpes striatus

(P. L. S. Müller)

Piculus rubiginosus (Swainson)

Xiphocolaptes albicollis (Vieillot)

Furnarius rufus (Gmelin)

Pseudoseisura lophotes

(Reichenbach)

Manacus manacus (Linnaeus)

Legatus leucophaius (Vieillot)

Pitangus sulfuratus (Linnaeus)

Pitangus sulfuratus bolivianus

(Lafresnaye)

Tyrannus melancholicus

Vieillot

Progne chalybea (Gmelin)

Troglodytes musculus Naumann

Mimus gilvus Vieillot

Mimus modulator Sharpe

Turdus fumigatus Lichtenstein

Turdus nudigenis Lafresnaye

Coereba flaveola Linnaeus

Agelaius thilius Molina

Cacicus cela (Linnaeus)

Cacicus haemorrhous (Linnaeus)

Icterus dominicensis (Linnaeus)

Icterus icterus (Linnaeus)

Icterus nigrogularis (Hahn)

Molothrus bonariensis (Gmelin)

Quiscalus lugubris Swainson

Psarocolius decumanus (Pallas)

Psomocolax oryzivorus (Gmelin)

Ramphocelus carbo (Pallas)

Tachyphonus rufus (Boddaert)

Thraupis episcopus (Linnaeus)

Thraupis palmarum (Wied)

Oryzoborus angolensis 


\author{
Paroaria dominicana (Linnaeus) \\ Sporophila intermedia Cabanis \\ Sporophila lineola (Linnaeus) \\ Sporophila nigricollis (Vieillot) \\ Sycalis flaveola (Linnaeus)
}

\title{
BIBLIOGRAFIA
}

Aitken, J., 1913. A subcutaneous larva of Mydaea. Brit. Guiana med. Annual 1913: $1-4,3$ pls.

Aitken, T. H. G., W. G. Downs \& C. R. Anderson, 1958. Parasitic Philornis flies as possible source of arbovirus infections (Diptera, Anthomyidae). Proc. Soc. expl Biol. Med. 55(3): 635-637.

Albuquerque, D. de O., 1953. Fauna do Distrito Federal. IV. Nova espécie baseada em "Philornis pici" (Blanchard, 1896) nec Macquart (Diptera, Muscidae). Revta bras. Biol. 13: 141-144, 8 figs.

Albuquerque, D. de O., 1957. Fauna do Distrito Federal. XLI. Notas sobre alguns muscideos, com descrição de dois alótipos (Diptera, Muscidae). Bolm Mus. nac., Rio de J. (Zool.) 164: 1-13, 17 figs.

Aldrich, J. M., 1905. A catalogue of North American Diptera. Smithson. misc. Collns 46(2 [= publ. 1444]): 1-680.

Aldrich, J. M., 1923. The genus Philornis - a bird infesting group of Anthomyiidae. Ann. ent. Soc. Am. 16(4): 304-309.

Bezzi, M., 1922. On the dipterous genera Passeromyia and Ornithomusca, with notes and bibliography on the non-pupiparous Myiodaria parasitic on birds. Parasitology 14(1): 29-46.

Bezzi, M., 1926. Le "stupide mosche". Natura, Riv. Sci. nat. 17: 1-19.

Blanchard, R., 1895. [Séance du 14 mai]. Bull. Soc. zool. Fr. 20: 115-118.

Blanchard, R., 1896. Contribution à l'étude des diptères parasites. (Troisième série). XI. Sur l'Aricia pici Macquart. Ann. Soc. ent. Fr. 65: 652-654, pl. 17, figs. 5-9.

Brauer, F. \& J. E. von Bergenstamm, 1893. Die Zweiflügler des kaiserlichen Museums zu Wien. VI. Vorarbeiten zu einer Monographie der Muscaria Schizometopa (exclusive Anthomyidae). Pars III. Denkschr. $k$. Akad. Wiss. Wien, math.-nat. Cl. 60: 89-240.

Busck, A., 1906. [Mydaea pici Macquart]. Proc. ent. Soc. Wash. 8: 2-3.

Cassamagnaghi, A., 1946. Miasis primitiva, a forma cutaneoforunculosa en las aves del Uruguay (Comunicación previa). Boln inf. Minist. Ganad. Agric., Montevideo 29(2): 517-530, ilus., pls.

Dodge, H. R., 1963. A new Philornis with coprophagous larva, and some related species (Diptera: Muscidae). J. Kans. ent. Soc. 36: 239-247, 11 figs.

Dodge, H. R., 1968. Some new and little-known species of Philornis (Diptera: Muscidae). Ibid. 41: 155-164, 1 fig.

Dodge, H. R. \& T. H. G. Aitken, 1968. Philornis flies from Trinidad (Diptera: Muscidae). Ibid. 41: 134-154, 22 figs.

Engel, E. O., 1920. Dipteren, die nicht Pupiparen sind, als Vogelparasiten. Z. wiss. InsektBiol. 15: 249-258, 9 figs.

Ferrar, P., 1980. Cocoon formation by Muscidae (Diptera). J. Aust. ent. Soc. 19: $171-174$.

Garcia, P. C., 1952. Las especies argentinas del genero Philornis Mein., con descripción de especies nuevas (Dipt. Anthom.). Revta Soc. ent. argent. 15: $277-293,6$ figs.

Glasgow, L. L. \& R. Henson, 1957. Mourning dove nestlings infested with larvae of Philornis. Wilson Bull. 69(2): 183-184.

Guimarães, J. H., 1971. Nota sobre a fêmea de Neomusca sabroskyi (Diptera, Muscidae). Papéis avulsos Zool., S Paulo 25(11): 95-97, 1 fig.

Jaennicke, F., 1867. Neue exotische Dipteren. Abh. Senckenb. naturf. Ges. 6: 311-408, pls. $43-44$. 
Keilin, D., 1917. Recherches sur les anthomyides à larves carnivores. Parasitology 9: 325-450, pls. 5-15.

Loew, H., 1861. Diptera aliquot in insula Cuba collecta. Wien. ent. Monatschr. 5: 33-43.

Lutz, A. \& A. Neiva, 1912. Notas dipterolojicas. A proposito de Mydaea pici Macquart. Mems Inst. Oswaldo Cruz 4: 130-135.

Macquart, J., 1854. Notice sur une nouvelle espèce d'Ariciẹ, diptère de la tribu des Anthomyzides. Ann. Soc. ent. Fr. (3) 1(1853): 657-660, pl. 20, II, figs. 1-4.

Malloch, J. R., 1921. Notes on some of van der Wulp's species of North American Anthomyiidae (Diptera). Ent. News 32: 40-45.

Meinert, F., 1890. Philornis molesta, en paa Fugle snyltende Tachinarie. Vidensk. Meddr dansk naturh. Foren. (V) 1 (1889): 304-317, pl. 6.

Neiva, A. \& B. Penna, 1916. Viajem scientifica pelo norte da Bahia, sudoeste de Pernambuco, sul do Piauhi e de norte a sul de Goiaz. Mems Inst. Oswaldo Cruz 8: 74-224, 28 pls.

Nielsen, J. C., 1911. Mydaea anomala Jaenn., a parasite of South-American birds. Vidensk. Meddr dansk naturh. Foren. 63: 195-208, 14 figs.

Nielsen, J. C., 1913. On some South-American species of the genus Mydaea, parasitic on birds. Ibid. 65: 251-256, 4 figs.

Osten Sacken, C. R., 1878. Catalogue of the described Diptera of North America. [Ed. 2]. Smithson. misc. Collns 16 (2 [= publ. 270]): 1-276.

Pont, A. C., 1972. Family Muscidae, in Museu de Zoologia, Universidade de São Paulo, A Catalogue of the Diptera of the Americas south of the United States 97: 1-111. São Paulo.

Ribeiro, A. de M., 1901. Sobre a Mydaea pici Macq. Archos Mus. nac., Rio de J. 11: 153-156, pl. 1.

Rodhain, J. \& J. Bequaert, 1916. Histoire de Passeromyia heterochaeta Villen. et de Stasisia (Cordylobia) Rodhaini Ged. Bull. scient. Fr. Belg. (7) 49: 236-289, 1 pl., 14 figs.

Schäfer, E., 1957. Les conotos. Etude comparative de Psarocolius angustifrons et Psarocolius decumanus. Bonn. zool. Beitr. 8: 1-147, ilus.

Séguy, E., 1946. Notes biologiques et taxonomiques sur les diptères. Enc. ent. (B) 10: 105-150.

Séguy, E., 1950. La biologie des diptères. Ibid. (A) 26: 1-609.

Stein, P., 1904. Die amerikanischen Anthomyiden des königlichen Museums für Naturkunde zu Berlin und des Ungarischen National-Museums zu Budapest. Ann. Mus. natn Hung. 2: 414-495.

Stein, P., 1918. Zur weitern Kentniss aussereuropäischen Anthomyiden. Ibid. 16: $147-244$.

Townsend, C. H. T., 1893. A bot-like anthomyid, parasite of a bird. J. Inst. Jamaica 1: 381-382.

Townsend, C. H. T., 1894. The grass-quit bot, an anthomyid parasite of nestling birds. Ibid. 2(2): 173-174.

Townsend, C. H. T., 1895. Contributions to the dipterology of North America. II. - Tabanidae, Conopidae, Tachinidae, etc. Trans. Am. ent. Soc. 22: 55-80.

Townsend, C. H. T., 1927. Synopse dos generos muscoideos da região humida tropical da America, com generos e especies novas. Revta Mus. paulista 15: 203-385, 7 figs.

Vogelsang, E. \& A. Fernández Yépez, 1952. Philornis angustifrons (Loew), parasitos en aves de Venezuela. Revta Medna vet. Parasit. Caracas 11(3-4): 329-333.

Wulp, F. M. van der, 1896. Fam. Muscidae, pp. 273-280, 281-288, 289-304, 305-312, 313-320, 321-344, pls. 7-8, in F. D. Godman \& O. Salvin, eds., Biologia Centrali-Americana. Zoologia-Insecta-Diptera 2: 489 pp., 11 pls., 13 figs. London. 


\section{FAMILIA CALLIPHORIDAE (GENERO Cochliomyia)}

\subsection{Classificação}

\section{Gênero Cochliomyia Townsend}

Callitroga Brauer, 1883: 47, 74. Espécie-tipo, Musca macellaria Fabricius (Hall, 1948: 120). Baseado em um nome citado originalmente em sinonímia e portanto inválido.

Cochliomyia Townsend, 1915: 646. Espécie-tipo, Musca macellaria Fabricius (des. orig.).

Este gênero inclui a "mosca da bicheira", "vareja" ou "varejeira".

Moscas de tamanho médio, colorido verde-metálico ou azul-esverdeado Cabeça, incluindo palpos e antenas, de colorido amarelo a alaranjado. Palpos curtos, filiformes (caráter que diferencia este dos demais gêneros de Chrysomyinae neotropicais). Epístoma distintamente mais estreitado do que o clípeo. Asas hialinas. Mesonoto com três faixas longitudinais bem conspícuas.

Segundo James (1970), na região neotropical ocorrem 5 espécies, duas das quais - macellaria e hominivorax - são conhecidas como causadoras de miíases no homem e animais.

Estas duas espécies são identificadas da seguinte maneira:

1. Esclerito basicostal preto em ambos os sexos. Parte inferior da parafrontália com pelos pretos em ambos os sexos. Abdome com o $4 .^{\circ} \mathrm{seg}$ mento visível, sem áreas laterodorsais de polinosidade cinza-prateada; genitália do macho como nas Figs. 57 e 61-62. Comprimento $8-10 \mathrm{~mm}$............... Cochliomyia hominivorax (Coquerel)

Esclerito basicostal esbranquiçado, amarelo ou amarelo-alaranjado nas fêmeas. Parte inferior da parafrontália com pelos amarelo-claro. Abdome com o $4 .^{\circ}$ segmento visível, apresentando em ambos os sexos uma área bem definida de polinosidade cinza-prateada na área laterodorsal; genitália do macho como nas Figs. 58-60. Comprimento $6-9 \mathrm{~mm}$............ Cochliomyia macellaria (Fabricius)

As larvas de terceiro estágio podem ser identificadas pelas seguintes combinações de caracteres (Laake, Cushing \& Parish, 1936):

\section{C. macellaria}

Troncos traqueais principais não pigmentados de negro

Margem posterior do segmento 11 só com espinhos ventralmente

Espiráculos posteriores pequenos

Espiráculos anteriores geralmente com 9-11 dígitos

Parede ventral da faringe com estrias longitudinais

\section{C. hominivorax}

Troncos traqueais principais pigmentados, atingindo a distância de 3-4 segmentos

Margem posterior do segmento 11 com anel completo de espinhos Espiráculos posteriores maiores

Espiráculos anteriores geralmente com 7-9 dígitos

Parede ventral da faringe lisa

A maior parte destas diferenças são aplicáveis igualmente ao segundo estágio.

As diferenças entre os ganchos bucais das larvas de segundo e terceiro estágio, assim como suas diferenças de espiráculo e troncos traqueais, estão esquematizadas nas Figs. 42-56.

\subsection{Cochliomyia hominivorax (Coquerel)}

Lucilia hominivorax Coquerel, 1858: 173. Localidade-tipo: Guina Francesa. Cochliomyia americana Cushing \& Patton, 1933: 539. Localidade-tipo: U.S.A., Texas. Refs. - Laake, Cushing \& Parish, 1936; Cushing \& Hall, 1937. 


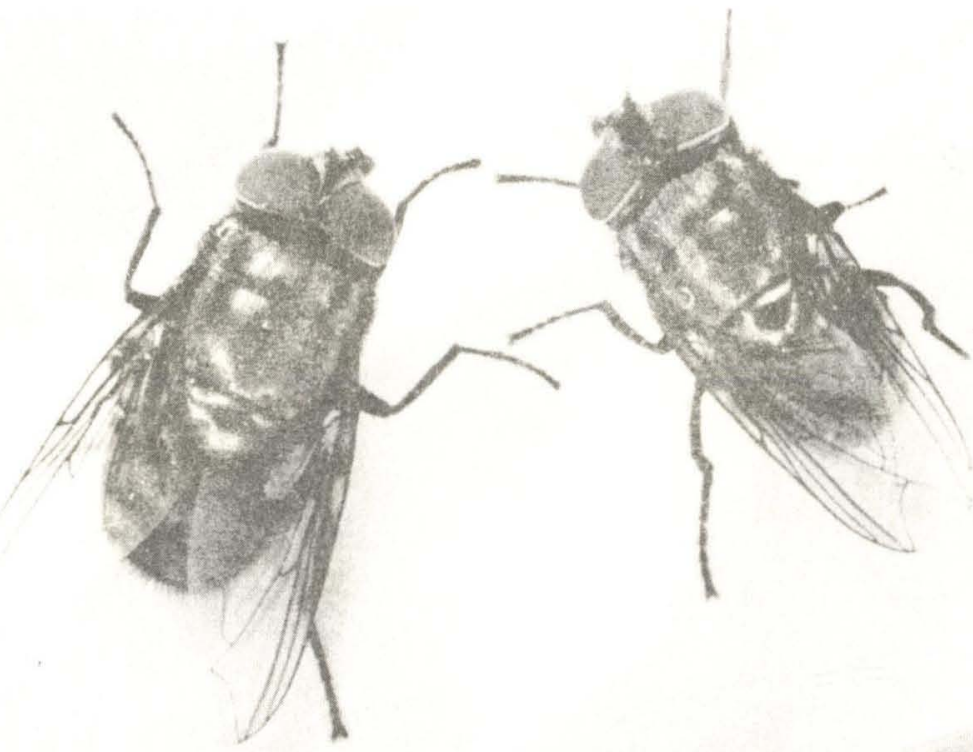

38

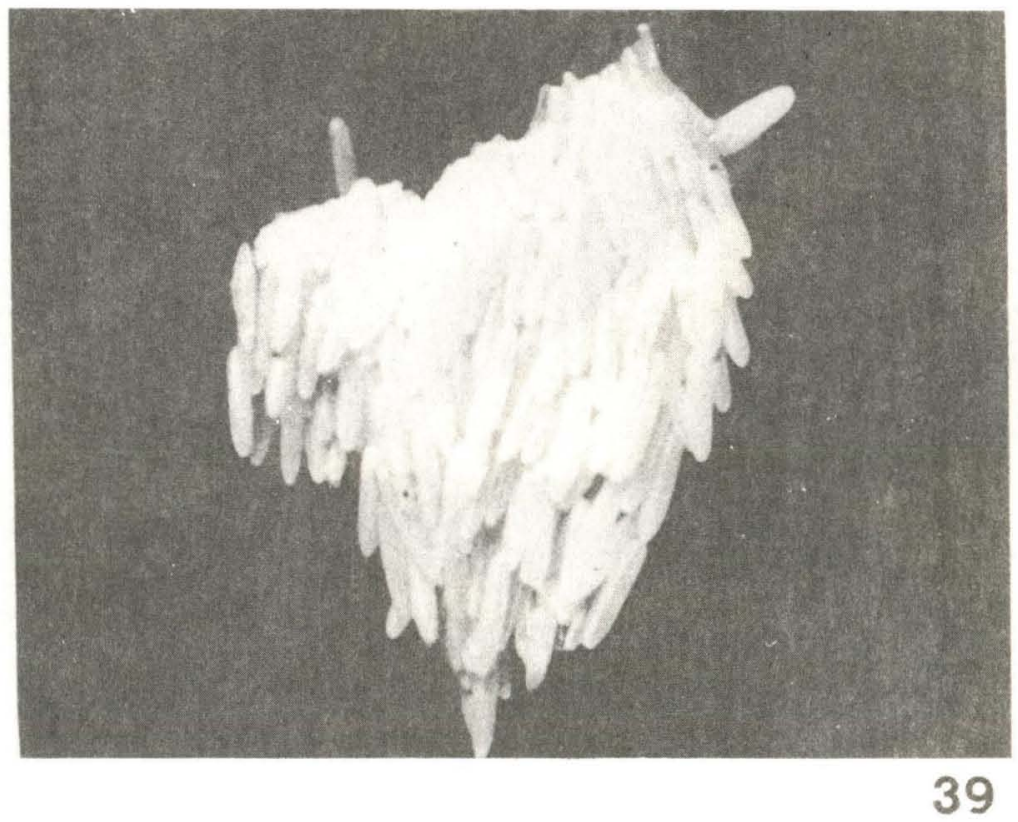

Figs. 38-39: Cochliomyia hominivorax; 38, adultos (macho à esquerda, fêmea à direita); 39, ovos (apud Knipling, 1959b). 


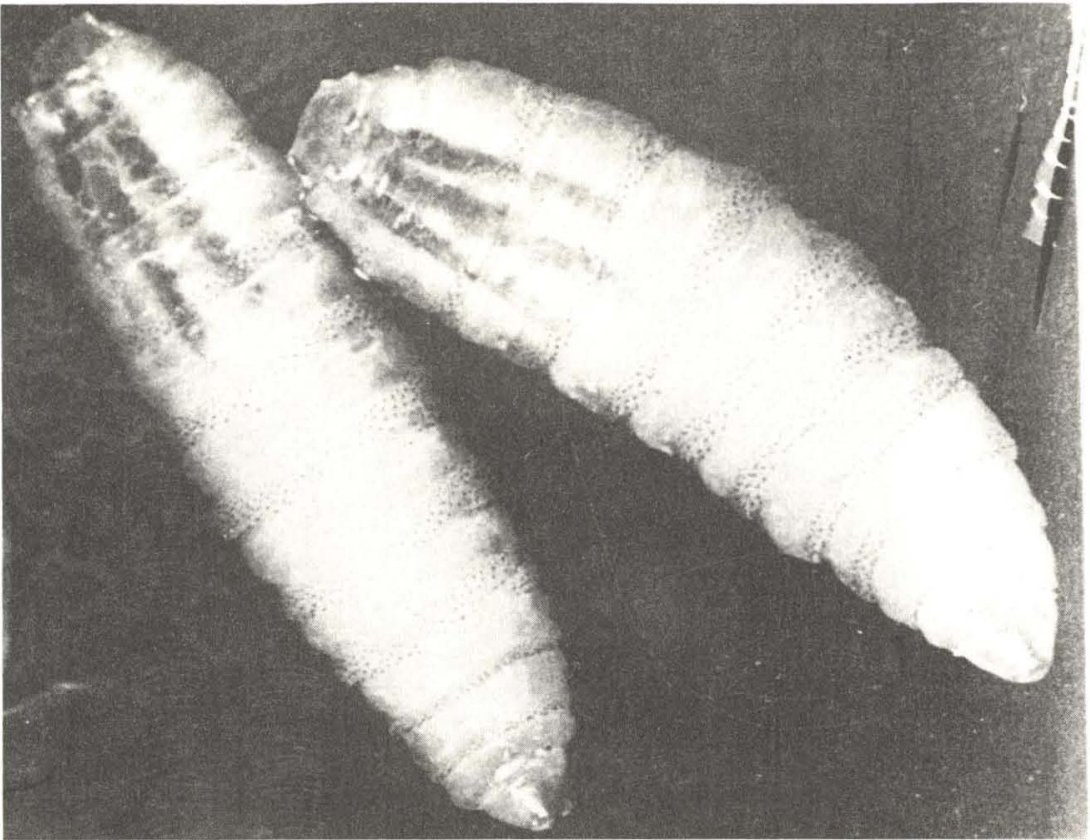

40

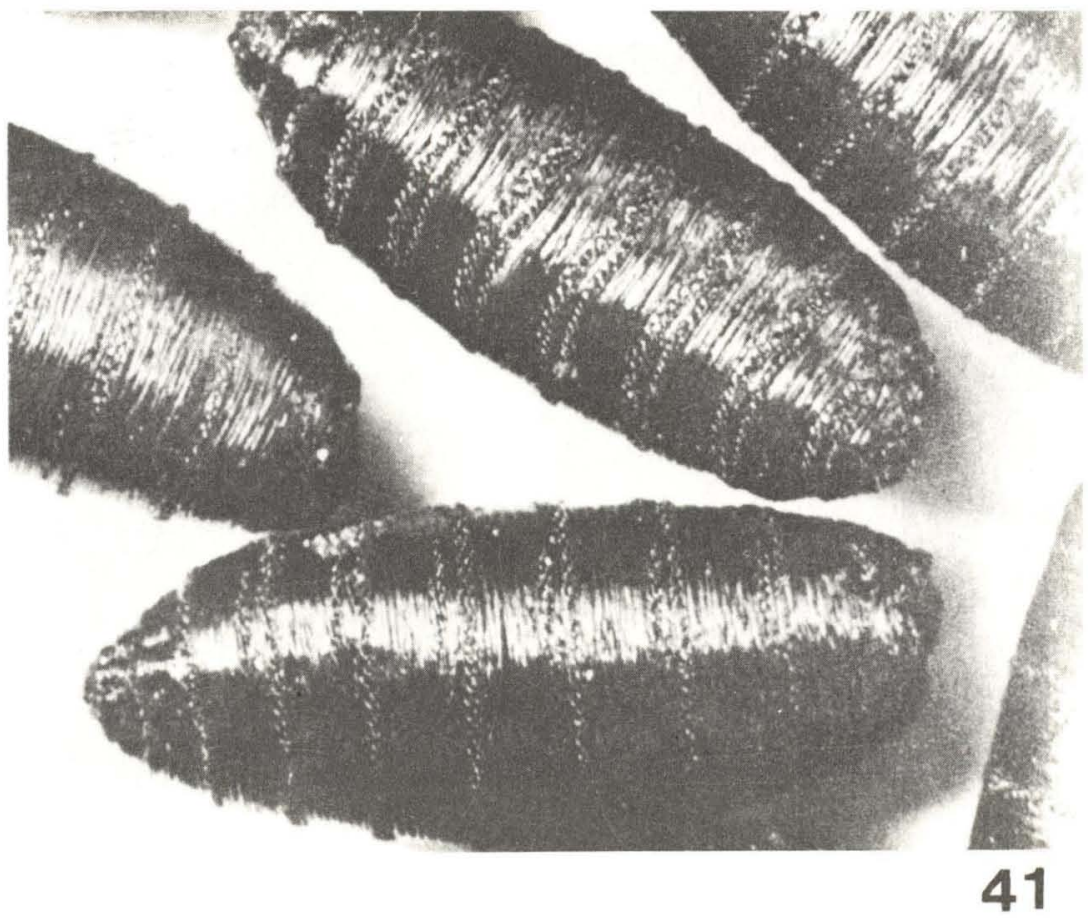

Figs. 40-41: Cochliomyia hominivorax; 40, larvas; 41, pupas (apud Knipling, 1959b). 
Para a sinonímia mais completa reportar-se a Hall (1948) e James (1970).

Características: $\mathrm{O}$ adulto é de coloração azul ou azul-esverdeada, distinguindo-se das demais espécies do gênero pela presença de pelos pretos na extremidade inferior da parafrontália. O esclerito subcostal é preto. O occipício das fêmeas geralmente vermelho, alaranjado a castanho. Cerdas proclinadas frontorbitais raramente presentes. As principais diferenças são encontradas na genitália do macho (Figs. 57, 61-62).

Informações adicionais sobre morfologia e taxonomia podem ser encontradas nos seguintes trabalhos: Cushing \& Hall, 1937; Cushing \& Patton, 1933; Del Ponte, 1938: Dixon, 1962; Gaminara, 1930; Garcia (M.), 1952; Hall, 1948; James, 1970; Knipling, 1939; Lahille, 1915; Lynch Arribálzaga, 1879, 1880a, 1880b; Mazza \& Jörg, 1939; Patton, 1934; Rocha, 1956; Sabrosky, 1962; Shannon \& Del Ponte, 1926; Tao, 1927; Vaz (Z.), 1935a.

\subsubsection{Biologia}

As informações referentes a esta espécie na literatura são difíceis de serem separadas de $C$. macellaria. A situação das duas espécies só foi esclarecida por Cushing \& Patton (1933) que mostraram haver duas espécies envolvidas na confusão - uma, claramente saprófaga (macellaria) e outra, de aparência externa muito semelhante, porém responsável pelas miíases primárias no homem e nos animais, por eles descrita como Callitroga americana, e atualmente conhecida como Cochliomyia hominivorax.

Esta segunda espécie é a mais importante mosca produtora de miíases na América tropical, acorrendo desde o sul dos Estados Unidos até o norte do Chile. As larvas de hominivorax parasitam obrigatoriamente tecidos vivos do homem e outros mamíferos (biontófagas). Somente atacam feridas recentes e são uma séria praga de animais domésticos, especialmente ovinos, caprinos, e bovinos, ocasionando graves prejuízos econômicos.

A biologia desta espécie, assim como alguns dados sobre sua etologia, foram estudados por: Baumhover, 1965; Bishopp, 1918b, 1921b; Brody, 1939; Brody \& Knipling, 1943; Brody \& Rogers, 1945; Chamberlain \& Hopkins, 1978; Crystal, 1976c, 1967d, 1970d, 1971d, 1977, 1978b; Crystal \& Guillot, 1978; Crystal \& Meyners, 1965; Deonier, 1945; DeVaney \& Garcia, 1975; Dunn, 1918, 1919; Guillot, Brown \& Broce, 1978; Guillot, Coppedge, Goodenough, Adams \& Ahrens, 1977a-b; Hightower, 1963; Hightower, O’Grady \& Garcia, 1972; Hightower, Spates \& Garcia, 1972a-b; Krafsur, 1978; Laake, Cushing \& Parish, 1936; La Paz, 1973; Lindquist, 1938; 1942a-b; Melvin \& Bushland, 1938; Norris, 1965; Oliveira (C. M. B.), 1979; Snow, Rauliston \& Guillot, 1976; Spates \& Hightower, 1967; Travis, Knipling \& Brody, 1940; Verhuell, 1850.

Vôo: Observações de campo, feitas com indivíduos marcados, liberados e recapturados, indicam que voos individuais tendem a ser curtos (Parish, 1937), porém podem cumulativamente propiciar deslocamentos por longas distâncias (Hightower et al., 1965). Crystal (1977) encontrou que moscas jovens criadas em laboratório têm pouca capacidade de vôo, mas sua eficiência aumenta durante a primeira semana após a emergência. Crystal \& Guillot (1978), trabalhando com moscas criadas em laboratório, corielacionaram a capacidade de vôo com o desenvolvimento ovariano, verificando que nos estágios de pré-vitelogênese e início de vitelogênese esta capacidade é menor; estes autores constataram ainda que moscas silvestres têm duração, distância e rapidez de vôo muito maiores do que moscas criadas em laboratório.

Comportamento do macho sexualmente ativo: Guillot et al. (1978) observaram machos sexualmente ativos em "sítios de espera" (waiting stations) dos quais disparavam em direção a qualquer inseto que voejasse por perto; freqüentemente retornavam a seus sítios originais, ou a poucos centímetros destes, sem entrar em contacto com os intrusos. Quando faziam contacto, porém, os encontros eram determinados por uma vigorosa luta, com o resultado de que o par de insetos caía ao chão e se separava. Ocasionalmente, se o encontro era com a fêmea da espécie, o par voava com o macho segurando o dorso da fêmea e ia pousar num ramo, onde copulava. Estes autores 

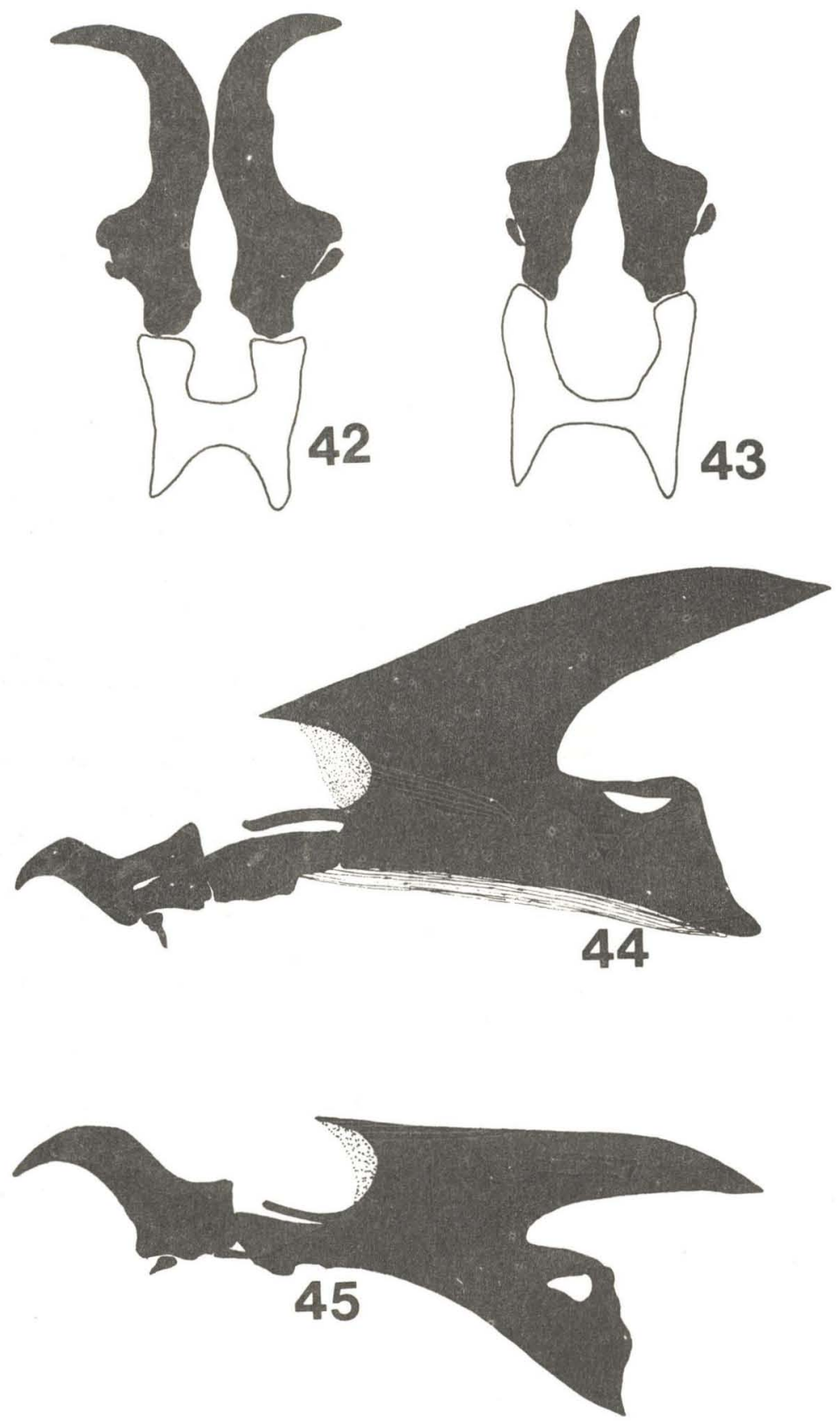

Ganchos bucais da larva II de Cochliomyia; 42, 45, C. hominivorax (Coquerel); 43-44, C. macellaria (Fabricius). 

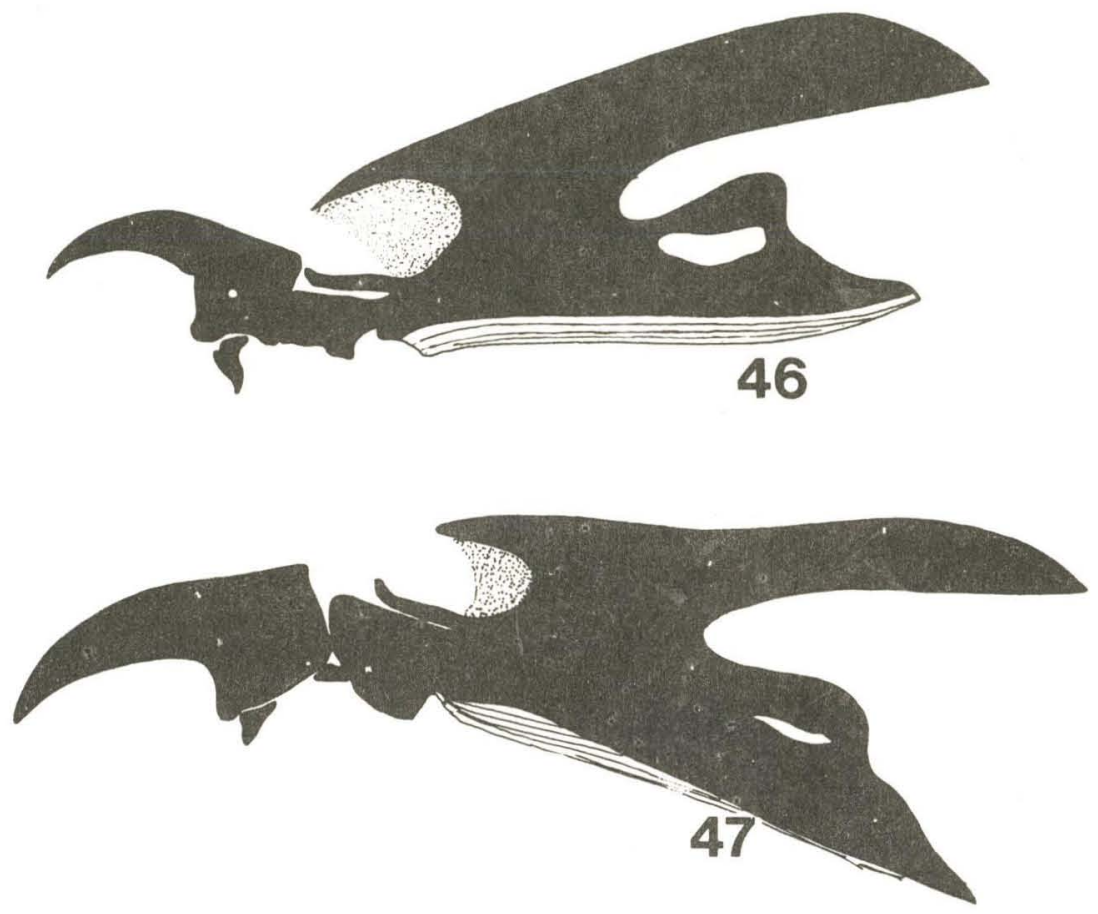

Ganchos bucais da larva III de Cochliomyia; 46, C. macellaria (Fabricius); 47, C. hominivorax (Coquerel). 

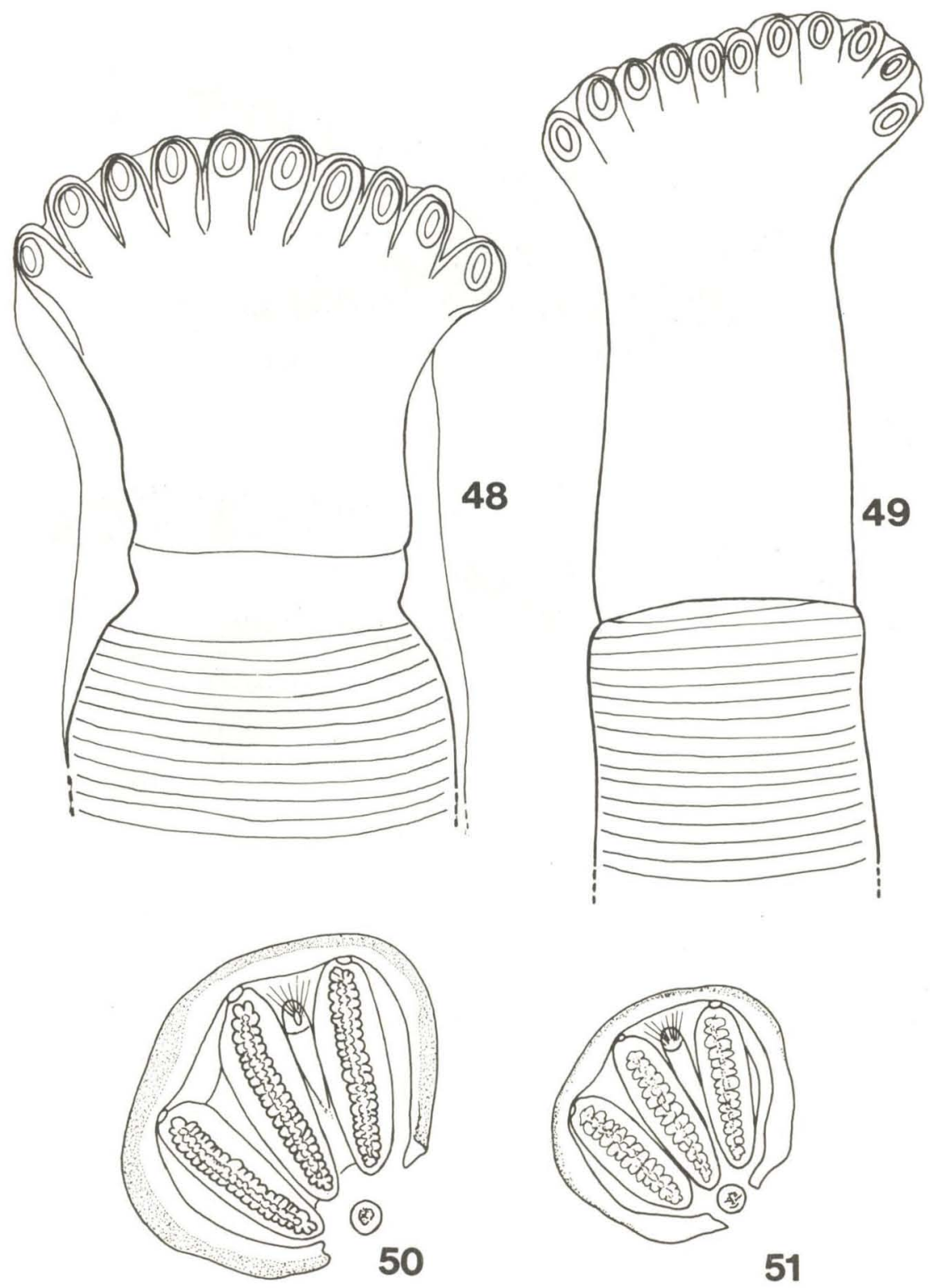

Larva III de Cochliomyia; 48-49: Espiráculo anterior - 48, C. hominivorax (Coquerel); 49, C. macellaria (Fabricius). 50-51: Espiráculo posterior - 50, C. hominivorax; 51, C. macellaria. 


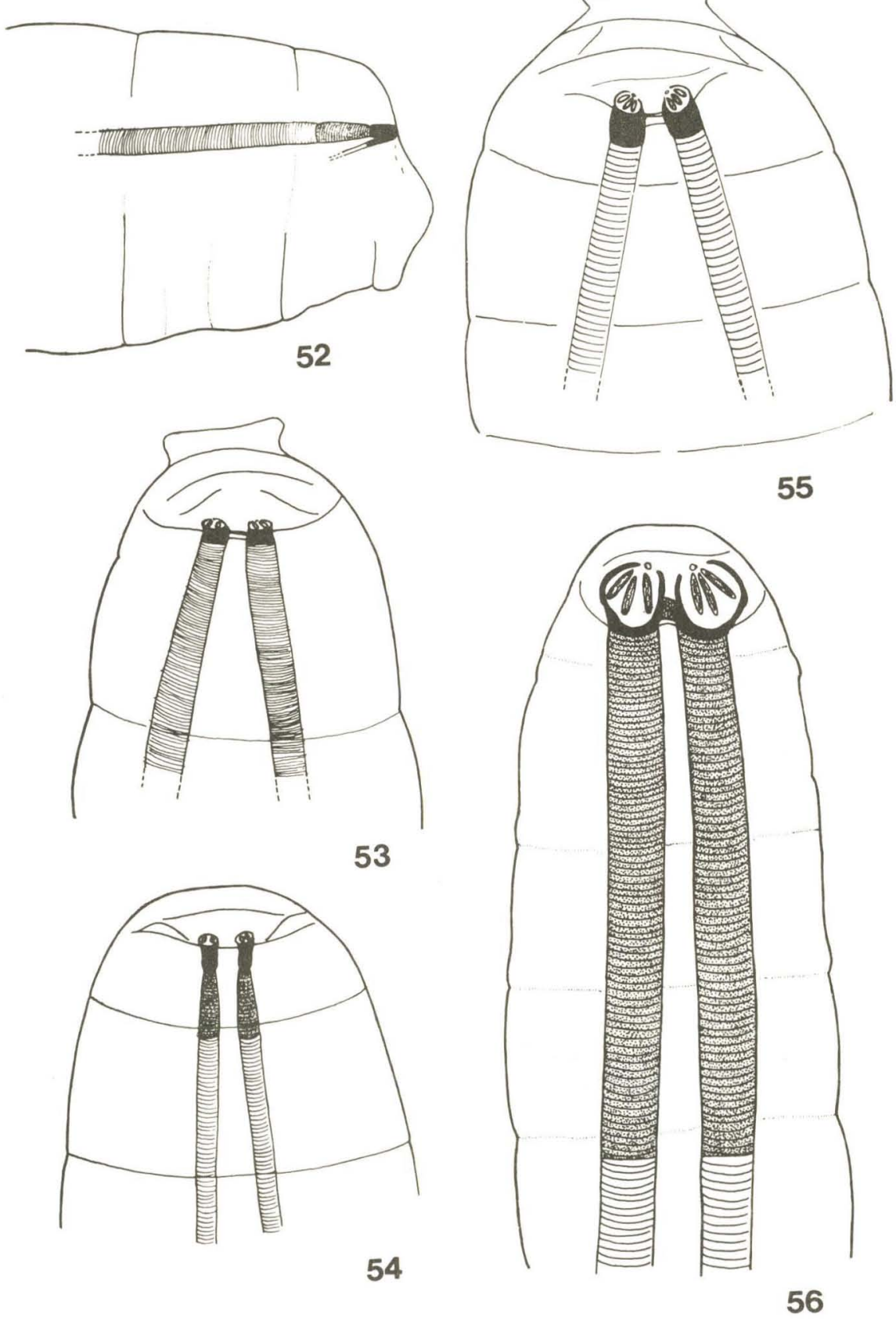

Troncos traqueais da larva II (Figs. 52-54) e larva III (Figs. 55-56) de Cochliomyia; 52-53, 55: C. macellaria (Fabricius); 54, 56: C. hominivorax (Coquerel). 

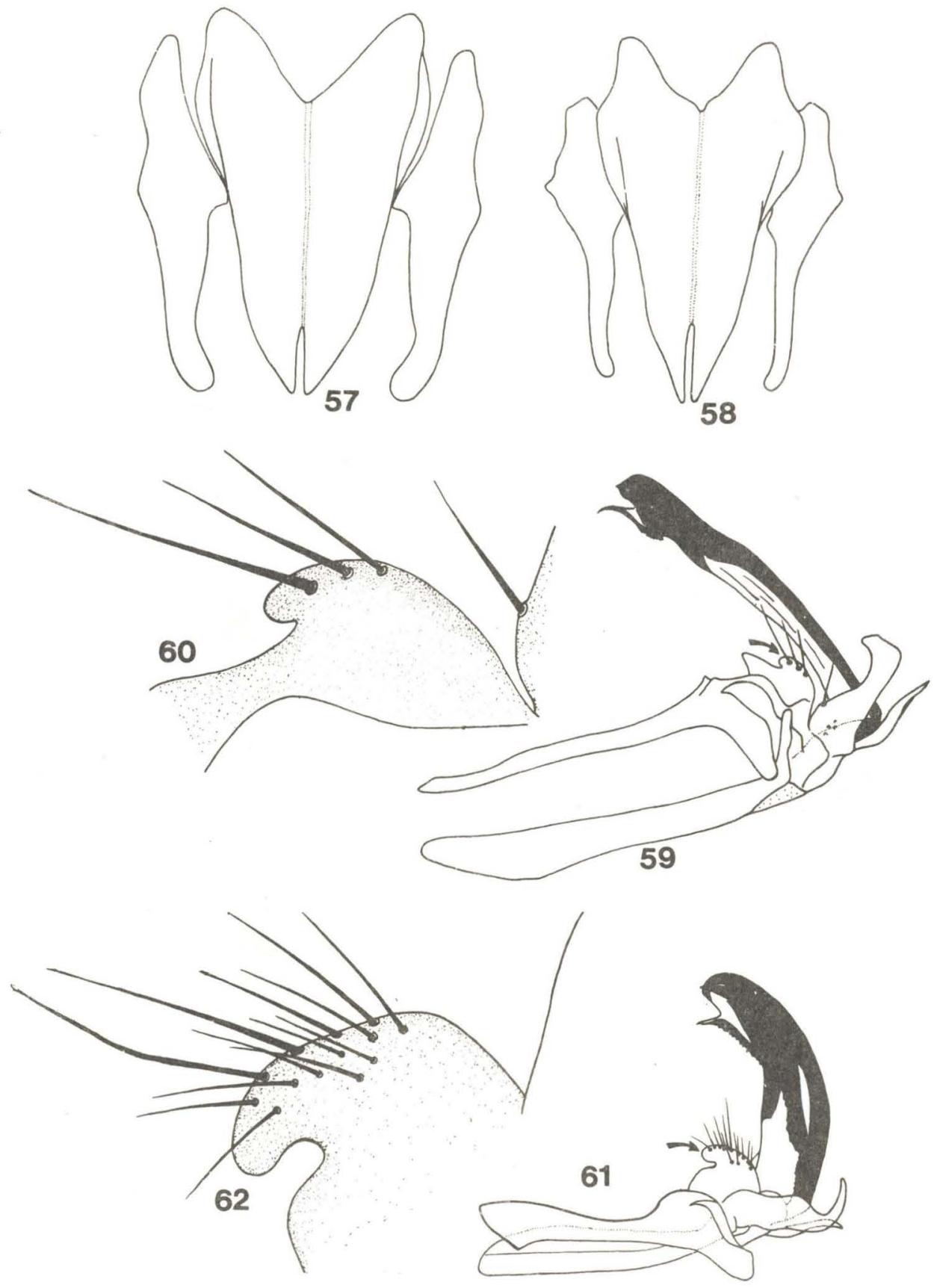

Fig. 57: Cercos e surstilos de C. hominivorax (Coquerel); 58, idem, C. macellaria (Fabricius). Figs. 59-60: Aedeagus e pinças fálicas de C. macellaria, com detalhe da gonapófise posterior (60); 61-62: idem, $C$. hominivorax. 
sugeriram que a oportunidade de os machos encontrarem fêmeas receptivas deveria ser maior nas proximidades dos animais hospedeiros; porém Parish (1937) achou que os machos nunca formavam agregações na proximidade dos hospedeiros.

Oogênese. Como nos outros dípteros, o ovário de $C$. hominivorax contém ovaríolos politróficos meroísticos; o folículo ovariano contém 15 trofócitos e 1 oócito cercados por células foliculares (LaChance \& Bruns, 1963). Cada ovário tem cerca de 100 ovaríolos e a oogênese é um evento sincronizado. A oogênese foi dividida em um contínuo de 10 estágios, baseados nas mudanças do oócito, trofócitos e células foliculares. A oogênese e o efeito da temperatura sobre este fenômeno foram estudados por Adams (1979), Adams \& Reinecke (1979), e LaChance \& Bruns (1963).

Cópula: As moscas copulam na idade de 2 ou 3 dias. Um intervalo entre 15.6 e $43.3^{\circ} \mathrm{C}$ não produziu qualquer efeito na porcentagem de fêmeas inseminadas (Adams, 1979). As fêmeas morrem antes de copular à temperatura de $10^{\circ} \mathrm{C}$, mas a $12.8^{\circ} \mathrm{C}$ observou-se cópula (moscas com 480 hs de idade) e a $43^{\circ} \mathrm{C}$ houve cópula de moscas com apenas 96 hs de idade (op. cit.). O máximo poder de cópula entre machos foi observado entre o $4 .^{\circ}$ e o $16 .^{\circ}$ dias pós-emergência; as fêmeas, porém, tinham baixa capacidade para a cópula até 5 dias pós-emergência (op. cit.). Crystal (1967) observou capacidade máxima de cópula em machos com 3-4 dias pós-emergência e Bushland \& Hopkins (1951) observaram cópula em machos com 2 a 3 dias de idade. Alley \& Hightower (1966) observaram 2.6 cópulas por macho em linhagens do México e da Flórida em 1 hora (3 machos versus 30 fêmeas); Crystal (1967) 4.8 cópulas por macho em 1 hora ( 1 macho versus 15 fêmeas) e 6.4 cópulas por macho em 2 horas. As fêmeas copulam apenas uma vez (Crystal, 1967).

Oviposição: As fêmeas depositam seus ovos em massas compactas de 200 a 300 ovos. Estes são colocados nas bordas de ferimentos recentes na pele dos animais e eclodem em menos de 24 horas.

Desenvolvimento das larvas: A infestação experimental de cobaias mostrou um determinado curso na evolução das larvas. Segundo Esslinger (1958: 202), dentro de uma hora depois de colocados na ferida, os ovos dão origem às larvas, que começam a se agregar ao redor dos bordos da ferida; durante o primeiro dia aparece pequena quantidade de exsudato seroso claro. No $2 .^{\circ}$ dia de infestação, as larvas, então já no $2 .^{\circ}$ estágio, iniciam a formação de uma bolsa sob os bordos da ferida e a quantidade de exsudato aumenta; nesta fase ocorre um pequeno aumento no tamanho das larvas, que alcançam o peso de $4,9 \mathrm{mg}$. No 3 . $^{\circ}$ dia quase todas as larvas já estão no $3 .^{\circ}$ estágio a atingem cerca de $16 \mathrm{mg}$ de peso; o volume do exsudato aumenta consideravelmente e o bolsão no tecido está mais profundo. Do $3 .^{\circ}$ ao $6 .^{\circ}$ dias as larvas de $3 .^{\circ}$ estágio crescem rapidamente, a destruição de tecidos atinge o clímax e o exsudato torna-se escurecido e transborda da lesão. Pelo 6. dia todas as larvas já atingiram o peso máximo (120 mg em média). No $7^{\circ}$ dia, quando a maior parte das larvas já abandona a lesão, a purulência ocorre em algumas feridas. No final do $8 .^{\circ}$ dia todas as larvas já saíram da ferida e um exsudato purulento espesso substitui o exsudato fluido da lesão. Finalmente, pelo $12 .^{\circ}$ dia (4 a 5 dias após a saída das larvas) uma crosta já se formou sobre a ferida. A ocorrência de sintomas está correlacionada com o curso do desenvolvimento larval e podem estes ser melhor observados entre os $3 .^{\circ}, 4 .^{\circ}$ e $5 .^{\circ}$ dias, pois coincidem com o periodo em que as larvas de $3 .^{\circ}$ estágio atingem sua maior taxa dẹ desenvolvimento. Cobaias com infestações subletais manifestam marcante perda de peso, aumento de temperatura (hipertermia), leucopenia e anemia. Também em cobaias, Borgstron (1938) encontrou fraqueza, emaciação e perda de apetite. Em casos de nasomiíase humana, Micks \& Callum (1953) descreveram um acentuado aumento de glóbulos brancos e febre $\left(103-150^{\circ} \mathrm{F}=39,5-41^{\circ} \mathrm{C}\right)$.

Pupa e adulto: As larvas maduras caem ao solo, transformando-se em pupas. O período pupal leva cerca de 7 dias, nas épocas quentes do ano. Os adultos podem atingir até 65 dias em cativeiro. As moscas adultas encontram-se alimentando-se de excrementos, exsudatos de ferimentos, carnes, lixo urbano, etc. 


\subsubsection{Patogênese, profilaxia e tratamento}

Pessoas com boa saúde física dificilmente serão atacadas por bicheiras. Indivíduos permanentemente alcoolizados, sujos, que dormem ao ar livre, ou pessoas com ozena ou ulcerações varicosas oferecem grande atração para a C. hominivorax. As larvas podem atacar a pele íntegra, segundo experimentos de laboratório com cobaias e coelhos.

São bastante numerosos os trabalhos que registram casos de miíases humanas por C. hominivorax: Adams, 1904; Aguilar, 1941, 1945; Aguilar et al., 1960; Aguirre, 1885; Albernaz, 1933a-b; Alegría, 1945; Aleixo, 1919; Almeida (T.), 1919; Almeida (W.), 1916, 1917, 1918; Altamirano, 1907; Amaral, 1940; Amorim, 1909; André, 1925; Anduze, 1945; Arenas \& Perez, 1936; Angumosa, 1875a-b; Arias, 188; Arias Schreiber \& Escudero Franco, 1928; Assis, 1938; Aubertin \& Buxton, 1934; Audouit, 1864; Ayut \& Lopes, 1957; Azevedo, 1970; Balea, 1952; Barilatti, 1918; Barlaro, 1919; Barroso, 1922; Bassewitz, 1904; Basso, 1939; Beretevide et al., 1949; Blain, 1909a-b; Blanco Ledesma, 1916, 1917a-b; Bleyer, 1905; Boero \& Morini, 1961; Bogliano, 1906; Brandão \& Menezes, 1875; Brandau, 1930; Brea \& Canale, 1947; Briceño Iragorry, 1933; Brown, 1943; Bustos, 1930; Calero, 1947, 1948; Caréaga, 1886; Casco Muñoz, 1944; Castro, 1924; Cavassa, 1920, 1925; Cerna, 1893; Chiodi, 1905; Codazzi Aguirre, 1932; Collum, 1934; Conde Flores, 1903a-b; Conde Jahn, 1934; Conil, 1879; Coquerel, 1858a-b, 1859a-b; Cornejo \& Mazza, 1939; Corrêa, 1928, 1929; Cortelezzi, 1919; Costa (J. D. M. H.), 1957; Costa (s.), 1881; Courtis, 1927; Cricco, 1921; Donoso Barros, 1947; Dove, 1937a; Emiliani \& Farjat, 1937; Emmel, 1937; d'Empaire, 1910; Ernst, 1880; Faria, 1945; Fernandez \& Marciano, 1944; Fernandez Soto, 1916; Ferrari, 1903, 1939; Floch \& Abonnenc, 1942; Foster, 1897, 1900; Frantzius, 1868; Furman, 1953; Gajardo Tobar \& Honorato, 1947; Galvão, 1900; Fraiha et al., 1978, 1979; Gaminara, 1928a-b; Gaminara \& Talice, 1928; Garay Figuerosa, 1936; Garcia (H.), 1888; Garcia Alvarez, 1927, 1928; Garcia Rijo, 1908; Garzón Maceda, 1915, 1923, 1925; Gastelumendi et al., 1957; Gayle, 1933; Gilbert, 1908; Gobbi \& Itano, 1971; Gomes, 1940; Gore, 1940; Gori, 1955; Gourrier, 1879; Grayson, 1891; Greene, 1956; Greenway, 1929; Greenway et al., 1926; Griffith, 1940; Haddad, 1946; Hansen \& Mazza, 1918; Harly, 1943; Harris, 1929; Harrison, 1885; Hart, 1912; Heely, 1885; Hevia et al., 1961; Hubert \& Flack, 1914; Humbert, 1883a-c, 1884; Iriarte, 1928; Jacob (s/d); James, 1948; Jauregui \& Barabino, 1914; Jelski, 1872; Jiménez, 1867, 1869; Jorge, 1878; Jourdran, 1895; Jones, 1941; Judd, 1876; King, 1914, 1915; Knowles, 1925; Laboulbène, 1868, 1870; Lauzurica, 1909; Lawton et al., 1957; Leclerc, 1964; Leclercq, 1948; Lemos, 1877; Leonissa, 1906; Lesbini, Weyenbergh \& Conil, 1878; Lima Filho, 1945; Lindsay, 1902; Lins e Silva, 1938; López Rondon, 1936; Lucas, 1868; Lumbreras Cruz \& Polack, 1955; Lutz, 1899; Luz, 1888; McCulloch, 1914; Mac Donald, 1924; Macias et al., 1973; Madera \& Morales, 1937; Magalhães, 1892, 1895; 1897; Maia, 1913; Maillard, 1870, 1872; Mandarino \& Paula, 1958; Marciano \& Greenkay, 1926; Matta, 1911, 1921a-b; Mazza, 1918; Mazza \& Basso, 1939; Mazza \& Cornejo, 1939; Mazza \& Jörg, 1939; Mazza \& Reyes Oribe, 1939; Melton, 1943; Micks \& Calma, 1952; Miranda, 1971; Monteiro, 1938; Moreira, 1933, 1939; Moura, 1899, 1913; Mutfeldt, 1891; Nason \& Hoxie, 1908; Nelson, 1893; Neveu-Lemaire, 1921; Niño, 1941a-b, 1950; Niño \& Defazio, 1945; Niño \& Fernandez, 1944; Niño \& Triaca, 1934; Nores, 1897; Núñez Andrade, 1960a-b; Odriozola, 1858; Ollet, 1869; Ortega Reyes, 1887; Parodi \& Saccone, 1916; Pastorino, 1930; Pereira (H.), 1928; Pereira (H.), 1928; Pereira (J. M. S.), 1947; Pereira (M. V.), 1876; Perez \& Arenas, 1936; Pescetto et al., 1962; Philippi, 1861; Pierre, 1888; Pieter, 1912; Pietri Andrez, 1919; Pogorelsky, 1927; Porto, 1929; Posada Arango, 1883; Posada Berrio, 1910; Powell, 1888; Prima, 1882; Puga Borne, 1895; Pujadas y Ortiz, 1923; Pupo, 1928; Queiroz, 1935; Radice \& Kaplan, 1950; Ramon, 1926; Reed, 1932; Rezende (C.), 1939; Rhodes, 1930; Ribeyro, 1915; Richardson, 1935; Rincón Araujo, 1957; Rivas, 1914; Rivas Plata, 1951; Rosa, 1950; Roura, 1883; Scott, 1964; Silva \& Santos, 1965; Silva (P.), 1912; Smith (H. H.), 1892; Snow, 1883; Stabile, 1942; Straud, 1927; Talice \& Ilaria, 1934; Taylor, 
1950; Tennant, 1906; Torres, 1915, 1916, 1924; Turnley, 1954; Umaña, 1914; Urgell, 1924; Valdecasas, 1947; Varalla, 1905; Vargas (J. H.), 1928; Vargas (L.), 1951; Vaz (Z.), 1938; Villiers (J. M.), 1941; Villiers (R.), 1945; Wallace, 1936; Weber, 1867; Wolffenbüttel, 1953; Xavier, 1944; Young, 1902; e Zucoloto \& Rossi, 1971.

O tratamento das miíases humanas fazia-se por meio de injeções endovenosas ou intramusculares de oxicianeto de mercúrio, aplicações de clorofórmio, eletricidade, etc., ou por técnicas cirúrgicas: Amaral, 1910; Caldas, 1936; Campello, 1934; Campos, 1934; Diaz, 1875; Faria, 1937; Ferrari, 1948; Gualberto \& Magalhães, 1934; Gurgel, 1903; Kimball, 1893; Lagos, 1937; Magalhães \& Magalhães, 1934; Moreira, 1933, 1939; Peckolt, 1933; Pedro, 1923; Porto, 1934; Primio, 1934; Rezende (E.), 1934; Smith (J. A. P.), 1905; Stewart \& Boyd, 1934; Vaz (H.), 1904; e Wolffenbüttel, 1935, 1953.

Para os animais domésticos a $C$. hominivorax representa uma séria praga. Qualquer tipo de ferimento, desde um simples arranhão, pode ser infestado por larvas desta espécie. A tosquia, castração, marcação ou descorna são práticas que predispõem ao ataque de bicheiras. Em tais casos os animais devem ser examinados com freqüência e suas feridas, cortes e bicheiras, o mais prontamente tratados. Os animais jovens são os mais seriamente prejudicados.

Rocha \& Vaz (1950) relataram no Brasil casos de miíases no rumen de bezerros causados pelo ataque de larvas desta espécie, responsáveis por $8-15 \%$ das mortes num total de 300 animais necropsiados. Vaz \& Carvalho (1938) registraram em São Paulo casos de miíase gengivo-alveolar em bezerros, durante o período de formação dos dentes. A miíase umbilical em bezerros é muito freqüente, especialmente em animais nascidos no campo sem assistência.

O tratamento é feito pela limpeza das feridas pela aplicação de inseticidas ou produtos repelentes no ferimento. Existem várias formulações comerciais de inseticidas clorados e fosforados, contendo cresóis, alcatrão, etc., ou com efeito repelente para a mosca.

Modernamente, os inseticidas fosforados e os carbamatos são os mais indicados para o controle das bicheiras. Uma lista de tais inseticidas foi apresentada por Beesley (1973), especialmente daqueles empregados no controle das miíases de ovinos.

A literatura sobre os casos de miíase em animais domésticos, incluindo galinhas, métodos e técnicas de tratamento, etc., é bastante vasta: Abdallah et al., 1970; Arravel, 1915; Babcock, 1932; Babcock et al., 1933, 1934; Bassford, 1950; Beckmann, 1941; Bentley, 1936; Bernard, 1924; Bishopp, 1915, 1918, 1921, 1927, 1930, 1934a, 1934c, 1935, 1936; Bishopp et al., 1926, 1917, 1922, 1923, 1936, 1938; Bissell, 1935; Bergstrom, 1938; Brennan, 1937a b, 1938; Bruce, 1944, 1945, 1952; Bruce et al., 1936, 1944, 1947; Carlyle, 1899; Cary, 1934; Chaddock, 1940; Cobb, 1941; Cook, 1940; Cordeiro, 1958; Corrêa, 1950; Damonte, 1945; Davis, Pratt, Lopes \& Turner, 1967; Demichelis, 1949; Diaz, (A. R.), 1946; Dixon, 1958; Drake \& Andre, 1936; Eddy \& Bushland, 1957; Emmel, 1945a-b; Esslinger, 1955, 1958; Fidler, 1943; Finch, 1941; Firor, 1935; Flanery, 1942; Gomez, 1944; Greene, 1956; Griffiths \& Cook, 1962; Haseman, 1943; Hecht, 1944; Holzman, 1949a-b; Howell, 1935; Knipling \& Tate, 1935; Laake, 1936, 1939a; Laake, Hixson \& Severin, 1950; Laake, Parman, Bishopp \& Roark, 1926; Lahille, 1915; Libermann, 1935; Lord, 1954; Martin, 1958; Maxwell-Lefroy, 1902; Meaden, 1895; Melvin, Parish, Knipling \& Bushland, 1939a-b; Melvin, Smith, Parish \& Barrett, 1941a-d; México (Secretaria de Agricultura), 1927; Naylor, 1943; Parish, 1942, 1943; Parish \& Knipling, 1942; Parish \& Laake, 1935; Parman, 1925, 1940; Parman \& Barrett, 1941; Peraza, 1930; Reedy, 1954; Richardson et al., 1978; Rocha, 1953; Rocha \& Vaz, 1950; Rosa \& Niec, 1959, 1961; Severin, 1954; Sheely, 1942; Siddal, 1941a-g, 1942; Souto, 1943; Stephan, 1935; Stewart, 1941; Stilman, 1976; Vaz (Z.), 1935a-b; e Vaz \& Carvalho, 1938.

\subsubsection{Controle}

O controle da Cochliomyia hominivorax sofreu grande evolução neste século. As primeiras tentativas foram feitas através de diferentes métodos e 
diferentes inseticidas. Escreveram sobre este assunto: Ahrens, Gladney, McWhorter \& Deer, 1977; Anon., 1932; Ball, 1960, 1962; Barnes, 1942; Baumhover, 1958, 1966; Beesley, 1973; Bishopp, 1934b: Bishopp \& Dove, 1937; Bishopp, Roark, Parman \& Laake, 1925a-b; Broce, Goodenogh \& Coppedge, 1977; Broce \& Ideker, 1978; Brundrett, 1957; Brundrett \& Gordon, 1958; Bush, 1978; Bush, Neck \& Kitto, 1976; Bushland, 1952; Calman, 1973; Campbell. 1960; Clark, 1955; Costello \& Talor, 1975; Corrêa, 1954, 1956a-c; Crystal \& Ramirez, 1975a; Crystal \& Whitten, 1976; Cushing, 1939, 1941a-c; Cushing \& Barrett, 1943; Dameron \& Babcock, 1937; Davis (J. J) 1942; Davis (R. E.), 1940; Deterling, 1962a-b, 1963a-b, 1964a-e; Diamant, 1963; Dixon, 1958; Dove, 1935a-b, 1936a-c, 1937b-e, 1938, 1943a-b, 1944, 1948; Drake \& Decker, 1943; Drummond, Ernst, Barrett \& Graham, 1966; Drummond, Ernst, Trevino \& Graham, 1967; Eddy \& DeVaney, 1970; Finch, 1940; Francis, 1889; Fuller, 1962; Gladney, 1976; Guthrie, 1941; Graham, Moore, Wrich, King, Warren \& Drummond, 1959; Henlerson, 1938a-b, 1940; Johnston, 1942; Knipling, 1951; McAdory, 1945; McCapes, 1940; McCrohan, 1934; McElroy, 1947; McLean, 1941a-b; Meadows, 1960; Moya Borja, 1979; Nettles \& Sparks, 1957; Newton \& Ferguson, 1974; Nory, 1978; Oglesby, 1935; Parish, 1937; Richardson, 1978; Roberts, 1936; Schurr, 1978; Scruggs, 1962, 1978; Sharman, 1959, 1960; Sharman \& Campbell, 1960; Smith (R. H.), 1973; Snow \& Whitten, 1979; Spink, 1960; Strong, 1936a-b, 1937; U. S. Department of Agriculture (vários trabalhos); Vaughn, 1941; Williams, 1977; Wilson, 1960, 1963; Wrich \& Bushland, 1960; Wrich, Chamberlain \& Smith, 1961; e Wright et al., 1974.

Utilizaram-se também armadilhas especiais para a captura de adultos: Parish \& Cushing, 1938; Goodenough \& Snow, 1977.

Outro método empregado para o controle das moscas foram diversas substâncias atraentes: Brandstein, Baumhover \& New, 1956; Coppedge, Ahrens, Goodenough \& Snow, 1977; Coppedge, Broce, Tannahil, Goodenough, Snow \& Crystal, 1978; Coppedge, Goodenough, Broce, Tannahill, Snow, Crystal \& Petersen, 1978; Coppedge \& Snow, 1977; Crystal, 1964a; Eddy, DeVaney, Handke \& Lopez, 1975; Grabe \& Grabe, 1973; e Jones, Oehler, Snow \& Grable, 1976.

Finalmente, desenvolveram-se várias técnicas para a cultura em massa de moscas, para possibilitar sua disseminação após esterilização. Estas técnicas de criação foram desenvolvidas por: Brown \& Snow, 1978a, 1979; Gibson, 1963; Gingrich, 1964; Gingrich, Graham \& Hightower, 1971; Graham \& Dudley, 1957, 1958, 1959; Melvin, 1937; Melvin \& Bushland, 1936; Smith (C. L.), 1960.

O princípio em que se baseia essa tentativa é o seguinte: ficou demonstrado que o macho desta espécie podia ser esterilizado por substâncias químicas, raios-X ou raios gama, e que tais moscas copulavam normalmente com fêmeas férteis. O resultado era que as moscas esterilizadas, liberadas dentro de uma população de moscas nativas, produziam um número relativamente grande de acasalamentos estéreis (Knipling, 1960). Os machos, criados em massa em grandes laboratórios, verdadeiras "fábricas" de moscas, eram depois disseminados em locais escolhidos (Curaçao foi a primeira tentativa) por meio de aviões (Husman \& Baumhover, 1957, 1958).

Trabalharam com quimioesterilização: Ascher, 1964; Borkovec, 1962; Chamberlain, 1962; Chamberlain \& Barrett, 1964; Crystal, 1963, 1964b-e, 1965a-b, 1966a-b, 1967a-b, 1968a-d, 1969a-c, 1970a-f, 1971a-c, 1972, 1973a-e, 1978a; Crystal \& LaChance, 1963; Crystal \& Ramirez, 1975b; DeMilo \& Crystal, 1972; Gouck, Crystal, Borkovec \& Meifert, 1963; Knipling, 1962; LaChance \& Crystal, 1963; Lindquist, 1961; Oliver \& Crystal, 1972; Smith, LaBrecque \& Borkovec, 1964; Terranova \& Crystal, 1970; e Terry \& Crystal, 1972.

Os sucessos e insucessos da esterilização por radiação, suas técnicas, etc., foram tratados por: Ahrens, Hoffman, Goodenough \& Peterson, 1976; Baumhover, 1963a; Baumhover, Graham, Bitter, Hopkins, New, Dudley \& Bushland, 1955; Baumhover, Husman \& Graham, 1966; Baumhover, Husman, Skipper \& New, 1957; Bushland, 1955, 1960a-c, 1974, 1975; Bushland \& Hopkins, 1951, 1953; Bushland, Knipling \& Lindquist, 1956; Crystal, 1979; Cueler \& 
Brinklow, 1973; Dunbar, 1957; Hightower, 1969; Hightower \& Graham, 1968; Jefferson, 1960; Kaufman \& Wasserman, 1957; Knipling, 1953, 1955, 1959a-b, 1960a-c, 1965; LaChance, 1973; LaChance \& Bruns, 1963; LaChance \& Leverich, 1962; La Paz, 1973; Lindquist (A. W.), 1955a-b, 1959; Lindquist (d:a:), 1973; Mitchell, 1955; Moya Borja, 1973; Moya Borja, Katiyar \& Ferrer, 1966; Riemann, 1967; Umbager \& Malanify, 1972; e U. S. Department of Agriculture, 1955a-c, 1958, 1959c.

Como resultado destas tentativas modernas de controle, publicaram-se vários trabalhos relativos à ecologia, fisiologia e genética de $C$. hominivorax, numa tentativa de se obter melhores dados sobre o entendimento de sua biologia: Adams (T. S.), 1979; Adams \& Reinęcke, 1979; Ahrens, Coppedge, Guillot \& Goodenough, 1977; Alley \& Hightower, 1966; Barrett, 1937; Baum. hover, 1963b; Baumhover \& Spates, 1965; Brown \& Snow, 1978b; Bush, 1975; Bush \& Neck, 1976; Cushing \& Parish, 1938; Davis (R. B.), 1967; Davis, Hightower, Alley, Turner \& Lopez, 1968; Deonier, 1939, 1946; DeVaney, Eddy, Lopez \& Handke, 1971; Eddy, DeVaney \& Handke, 1975; Esslinger \& Chandler, 1960; Fletcher, 1966; Fletcher, Claborn, Turner \& Lopez, 1968; Fletcher, O'Gradey, Claborn \& Graham; Fletcher \& Turner, 1973; Fletcher, Turner \& Husman, 1973; Flitters \& Benschotter, 1968; Goodenough, Wilson \& Agee, 1977; Goodenough, Wilson \& Whitten, 1978; Guimarães, Prado \& Buralli, 1979; Hightower, 1969; Hightower \& Adams, 1969; Hightower, Adams \& Alley, 1965; Hightower \& Alley, 1963; Hightower \& Chavarria Ch., 1964a-b: Hightower, Davis, Baumhover \& Graham, 1966; Jones, Snow \& Villasenor, 1976; Kitto, Neck \& Bush, 1976; Krueger, 1930; Laake, 1938, 1939b; LaChance \& Crystal, 1965; LaChance, Dankins \& Hopkins, 1966; LaChance \& Hopkins, 1962; LaChance \& Leverich, 1968; LaChance \& Riemann, 1964; LaChance \& Ruud, 1977; Lindquist, 1938; Lindquist \& Barrett, 1945; Lyddiat \& Boulter, 1977; Melvin \& Bushland, 1940; Melvin, Bushland \& Smith, 1943; Meyer; 1977; Nellis, 1977; Nelson, Adams \& Pomonis, 1969; Parish, 1945; Parman, 1945; Ricks, 1941; Snow, Coppedge, Baumhover \& Gorsira, 1978; e Whitten, 1974 .

\subsection{Cochliomyia macellaria (Fabricius)}

Musca macellaria Fabricius, 1775: 776. Localidade-tipo: Indias ocidentais. Cochliomyia macellaria; Townsend, 1915: 645; Shannon \& Del Ponte, 1926: 566; Townsend, 1931: 70; Cushing \& Patton, 1933: 539; Aubertin \& Buxton, 1934: 245; Del Ponte, 1938: 475; Hall, 1948: 138.

Como foi anteriormente mencionado, esta espécie carece de importância como produtora de miíases, pois suas larvas são invasoras secundárias de ferimentos (necrobiontófagas), podendo contudo ser de importância na infestação de carcassas em açougues e abatedouros. Após a introdução de várias espécies exóticas de Chrysomya no Brasil, esta espécie, antes muito comum, está se tornando rara nas áreas urbanas (Guimarães, Prado \& Buralli, 1978).

Os ovos são depositados em massas, em número que varia de 40 a 250 ovos (Hall, 1947), no lixo, tecidos necrosados de ferimentos de animais, carcassas em putrefação, etc. Várias fêmeas se reunem para postura, formando massas de milhares de ovos. O período de pré-oviposição é de 3 a 18 dias (Bishopp, 1917). Os ovos eclodem dentro de 4 horas em condições favoráveis. A larva atinge a maturidade dentro de 6 a 20 dias. Após completar seu desenvolvimento, as larvas abandonam o substrato para se enterrar no solo, onde se transformam em pupas. $O$ período pupal leva 3 dias ou mais. $O$ período total de desenvolvimento vai de 9 a 39 dias, dependendo da temperatura e umidade (Bishopp, 1915). O adulto vive de 2 a 6 semanas, alimentando-se de uma variedade de substâncias, incluindo néctar de flores, lixo urbano, frutos caídos e peixes expostos nas feiras livres.

Os registros desta espécie como causadora de miíases na América tropical devem ser atribuídos à $C$. hominivorax, pois macellaria é estrita saprófaga e se cria em abundância em carcassas. Casos de macellaria em miíases são devidos a invasões secundárias. 


\subsection{Folclore}

As feridas ou chagas causadas na pele dos animais domésticos, principalmente no gado bovino (após a castração, no umbigo de bezerros recém-nascidos, ou nas feridas decorrentes de picadas de morcegos), causadas por Cochliomyia hominivorax, chamam-se bicheiras.

As moscas que produzem as bicheiras são conhecidas como varejas ou varejeiras; em outras regiões do país chama-nas ainda beronha, beruanha, bironha, meruanha, merianha, murianha, murinhanha e muruanha; as larvas causadoras das bicheiras são conhecidas por bichos, vermes, morotó, tapuru ou varejas.

As moscas de varejeira são freqüentemente confundidas pelo povo com as inofensivas Ornidia obesa, da família Syrphidae, a quem são aplicados tam. bém os mesmos nomes populares.

Como foi visto no primeiro capítulo, são muito antigos os relatos de casos de bicheiras na América tropical. Desde o século XVI foram registrados casos e tratamentos. Curam-se as bicheiras, entre o povo, pelo uso de substâncias vegetais, práticas mágicas, rezas e benzeduras, etc.

O viajante G. Gardner anotou, no século passado: "Uma espécie de Aspidospermum, árvore que cresce em grupos e a que os habitantes dão o nome pereira: tem a casca grossa, que é usada [no Ceará] em infusão para destruir piolhos e bichos que atacam o gado."

Roquette-Pinto (1950: 302) também registrou: “Os tropeiros matam as bicheiras lavando-as com infuso de tabaco e untando-as com a bosta dos próprios animais. As fezes do gado levam para as lesões novos germes infecciosos e a doença raras vezes sara com esse processo de cura."

Em Barueri, estado de São Paulo, socam-se bem folhas de pêssego; o caldo verde resultante despeja-se na bicheira; a boca da ferida é tampada com as folhas amassadas (Lenko \& Papavero, 1979: 416).

Frei Valete (s. d., p. 88) diz ainda que "Os vaqueiros servem-se da raiz fresca do mercúrio do campo [Gên. Clodonia, Fam. Malpighiaceae] para matar as bicheiras que acometem o gado vacum, cavalar e muar."

Marconi (1976: 33) registrou de um caboclo: "Quano o animal tá com bichera é bão di pô pó de café na firida."

Mas, pelo resultado "milagroso" que operam, preferem-se no Brasil os "curadores" ou "rezadores" de bicheiras, que, com cerimônias e rezas variadas, fazem com os "bichos" ou "vermes" abandonem as chagas causadas no gado. Naturalmente, tais curadores são grandemente ajudados pela natureza, pois, depois de um certo tempo, os próprios "bichos" se encarregam de abandonar a ferida, caindo ao solo para empupar, com ou sem rezas...

O poeta baiano João Gualberto Ferreira Santos Reis, nascido em 1787 em Santo Amaro, Bahia, publicou em 1817 um livrinho sobre a criação de bois no Brasil, em versos, com textos em latim e português, face a face De Cura Boum in Brasilia - Da Creação dos Bois no Brasil - onde menciona o curador de bicheiras e as rezas e onde sugere um remédio para evitar o mal (Magalhães, 1902). Damos aqui um trecho, em latim e em português:

"Nom minus in teneros vaccarum saevit alumnos

Muscarum fatale genus; nam molle vitelli

Abdomen fodicat medium teterrima pestis,

Progenienque malum vermes ibi linguit edaces,

Ulcere, qui penetrant vel viscera ab usque profundo,

Exitiumque ferunt misero, nisi forte ministri

Accurant, promptoque aegrum medicamine curent.

$\mathrm{Ne}$ patere, ut quisquam (namque id solemne bubulcis)

Carmina nescio quae mussans, digitisque figuram

Ter crocis effigens super ulceris ore, caducus

Devoveat vermes: sit praesentissima quamvis

Haec medicina malo; pestemque eliminet omnem,

Secretis, ne fide dolis, nam forsitan illis

Sub verbis tegi antiquus sua toxica, serpens" 
"Abjectis igitur, quae religione vetantur, Auxiliis, sincera gregi medicamina prome. Fac servi religent aegros ad linea saepta, Executiantque manu vermes, herbaque salubri

Turpe fricant ulcus; tum pinguem expaugere cornu Infundant, ricini sudat, quam bacca, liquorem. Inspiciant quoque num linguae summoque palato Haecreseat pestis, nam pestes buculus illuc Invahit adlambens, quae prurit vermibus, alvum."

"Classe maligna de nojentas Moscas

Não menos damno causa aos Bezerrinhos; Já no meio do abdomen os penetra A lethal peste, já progenie immensa Alli derrama de famintos Vermes; Que na chaga estendendo-se ao interno O interno irão roendo ao miserável Até murchar-lhe a vida, se propicios, Cuidadosos Serventes não lhe acodem. Com subito remédio o mal vedando.

Mas não consistas, que Impustor infame, Não sei que vozes fatuos murmurando, (Superstição solemne entre os Vaqueiros) $E$ vezes três de cruz fingindo a forma Co'a mentirosa mão sobre a ferida, Os caducos conjure immundos Vermes;

Surta embora tal cura optimo effeito; Embora desarreigue, extinta a peste; No recondito embuste não confies:

Talvez desfarce nelle o seu veneno

O Tartáreo Dragão, de enganos fertil.

Detestados assim os criminosos

Remédios, que repugna a Fé mais pura, Os licitos somente ao Gado exhibe.

Faze que os Servos nos cercados atem

Os Bezerros molestos; e extrahindo

Os impios vermes, com salubres hervas

Proveitosa fricção à chaga appliquem:

Depois lhe infundam a substancia oleosa,

Que usa a baga verter da Mamoneira.

Indaguem outrossim, se os Bezerrinhos Afferrada na lingoa ou entre as rugas

Têm do sumo palato a indigna peste;

Que eles mesmos alli nescios conduzem, Indo a chaga lamber, que os Vermes comem."

Outras práticas são apresentadas a seguir:

1. Rosário de garras - Espécie de amuleto destinado à cura de animais bichados, por "simpatia". "Compunha-se de garras enfiadas, isto é, de pedaços de arreios velhos e imprestáveis ou pontas de couro. O curandeiro ou qualquer peão de confiança lançava o estranho colar ao pescoço do animal atacado de bicheira, feridas cheias de vermes, e aguardava a cura sem recorrer aos produtos geralmente usados na benzedura: passes mágicos, orações, fórmulas sacramentais da taumaturgia indigena" (Meyer, 1951: 156-157).

2. “Apanham-se três folhas de uma árvore qualquer e abre-se-lhes um furo no meio: depois toma-se uma e, visando-se a bicheira pelo orifício, pronun- 
ciam-se estas palavras: 'Bicheira amaldiçoada, os bichos que te comam e que caiam, com os poderes de Deus e da Virgem Maria. Assim como esta folha é verde e seca, bem assim secará esta malvada bicheira, com os poderes de Deus e da Virgem Maria, Amém'. O rezador, à medida que vai rezando, joga as folhas para trás, por cima do ombro" (Iglésias, 1951: 553-554).

3. "Quando um animal tiver bicheiras, deve-se fazer determinado número de nós num fio de capim, atirá-lo para trás passando sobre os ombros, e os bichos cairão" (Santa Catarina)

4. "Se algum cavalo ficar com bicheira, o melhor meio (e talvez único na ingênua crendice rural) de curá-lo é virar o casco do animal. Para isso o nosso campônio usa o seguinte expediente: quando o cavalo passa por alguma estrada ou lugar em que possa deixar a impressão do casco, ele, com auxílio de faca na generalidade, destaca do chão o rasto, com o máximo cuidado para que se não desfaça, e o vira ao invés, isto é: a impressão para baixo, escondendo-a. Outro processo é o das benzeduras, bastante conhecidas, feitas com raminhos de arruda, mangericão, ou alecrim do campo e outras plantas de 'poder divino"' (Rio Grande do Sul; Spalding, 1955: 86).

5. Tomam-se três folhas verdes, procura-se o rastro do animal que está doente com bicheira, cruzam-se as folhas por cima do rastro, cobre-se com uma pedra, e diz-se:

\author{
"Bicho-figueira \\ Foge desia bicheira \\ Com os podere: das três pessoas \\ Da Santíssima Trindade. \\ De um a um, de dois a dois, \\ De três a três" (Barueri, SP; Lenko \& Papavero, 1979: 419)
}

6. "Toma-se um raminho em forma de cruz e benze-se, colocando depois sobre o rastro da rês doente. Assim que o ramo seque... os bichos sairão. Deve-se observar que a rês benzida não pode ser tratada por outro processo e nem sequer olhada, depois da benzedura, pois isso tiraria todo o efeito da simpatia. Outra maneira de curar a bicheira por simpatia é a seguinte: toma-se uma palha de milho e faz-se uma laçada do mesmo tamanho da ferida atacada; cerra-se o laço e joga-se para trás dizendo: 'Serviço em domingo não vai pra frente... e esta bichêra também não vai!' e assim cairão os bichos dentro de três dias." (Teixeira, 1949: 20).

\title{
7. Fausto Teixeira (1954) oferece vários métodos:
}

(i) "No rastro de um pé de uma rês coloca-se uma folha em posição horizontal; no rastro de uma das mãos outra folha em posição contrária; uma pedra sobre cada folha. Quando as folhas estiverem secas... os bichos caem" (Jacutinga, MG);

(ii) "Benzer, 3 vezes, com um raminho de alecrim (Baccharis sylvestris L. ?), dizendo: Assim como serviço de domingo, de dia santo, num leva ninguém adiante, as línguas má e desacriditadêra fala do que vê e do que num vê, assim os bichos dessa bichêra há de caí tudo, ou vivo ou morto, de $1 \mathrm{em} \mathrm{1,} \mathrm{de} 2$ em 2, de 3 em 3, de 4 em 4, de 5 em 5, de 6 em 6, de 7 em 7, de 8 em 8, de 9 em 9. Jogar o raminho de alecrim no fogo." (Betim, MG).

(iii) "Tomam-se três cipós de $20 \mathrm{~cm}$ de comprimento cada um, fazem-se três laçadas com eles, colocando uma por vez diante do olho direito, quando se mira o animal atacado de bicheira, enquanto se vai cerrando a laçada. Terminada a operação, jogam-se os três cipós para trás, sem olhar onde caíram" (Sete Lagoas, MG).

(iv) "Colocam-se no rastro do animal doente, e do lado atacado pela bicheira, duas folhas cruzadas, tendo por cima delas uma pedra; à medida que as folhas se vão secando... os bichos vão caindo" (Sete Lagoas, MG). 
(v) "Corta-se com uma faca o rastro do animal doente; tira-se a placa de terra com vegetação e vira-se com as raízes para cima; quando estas se secarem... os bichos caem" (Jacutinga, MG).

8. Com um espinho "pinica-se" a pegada do animal, do mesmo lado do corpo em que a bicheira está localizada, acompanhando-se a operação com três "Ave-Marias" (Serra do Navio, AP).

9. Rodrigues de Carvalho, citado por J. A. Teixeira (1954) registrou que o vaqueiro, de longe, sem ver a rês atacada de bicheira, concentra-se e benze-se, lançando este ensalmo: "Mão que comeis, a Deus não louvais, e nesta bicheira não comereis mais. Há de cair caminho de 10 em 10, de 9 em 9 , etc., até de 1 em 1, e nesta bicheira não ficará nenhuma." Reza 3 Padre-Nossos, e 3 Ave-Marias. O ensalmo é oferecido às Cinco Chagas de N. S. Jesus Cristo. Nestor Diógenes (1924), em Pernambuco, e Sebastião Almeida Oliveira (1940), em São Paulo, registraram práticas semelhantes.

10. Faz-se "com uma palha de milho uma laçada do tamanho da ferida. E, apertando-lhe o nó, dizem: 'Como não vai adiante serviço de domingo, não irá adiante esta bicheira!' E jogam para trás das costas a laçada. Dizem que a cura é certa".

11" "A bicheira evita-se e cura-se pondo no pescoço uma bolsa contendo azougue" (Peixoto, 1944: 30).

12. "Contra bichêra, além de medicamentos (cramelanos - calomelanos criolin - creolina) é eficaz a reza contra a bicheira, no rastro do animal ou na presença de um lenço ou de um objeto do dono. Os bichos caem e a ferida limpa-se, à medida que a reza opera o benefício. Um rezador é precioso, porque nem toda a gente, recitando fórmulas, é capaz de curar bicheiras" (Peixoto, 1944: 47).

13. "Cura rápida e certa era também a das bicheiras: com uma folha tenra de capim fazia um laço frouxo, olhava demoradamente com o olho esquerdo o pequeno círculo e murmurava em voz baixa, de corpo vergado para diante: 'Esses bichos hão de aumentar como o serviço de domingo e dia santo'. Fechava o laço sem mais olhar e o atirava para trás de costas. $O$ animal não caminhava mais que cinquenta metros com as larvas na ferida. Estas caíam, rapidamente, como sob a ação de cáústico poderoso" (Sul de Minas Gerais; R. Prata, 1953: 114).

14. "As miíases são tratadas também racionalmente, pois empregam os calo. melanos e a creolina. O emprego desta, porém, à medida que as fazendas vão se afastando das povoações, diminui pelo alto preço que atinge, mas desde que o animal foge usam-se então das rezas; segue-se o rastro da rês atacada e logo que é encontrada forma-se, com duas folhas verdes, introduzidas uma na outra, uma cruz, a qual é colocada sobre a pegada do animal e coberta com terra apanhada no mesmo rastro, e reza-se em seguida: também empregam a 'golda' (infusão) das cascas das juremas (Mimosae) com o fim de debelar as bicheiras" (Brasil Central; Neiva \& Penna, 1916: 163).

15. "Tratam os vaqueiros as bicheiras das reses que lhes são confiadas, cortando-lhes cabelos da cauda, esfregando com eles, energicamente, a parte doente, prendendo-os depois bem lambusados no sangue da ferida num pauzinho dẹ marmeleiro lascado em cruz, o qual é enfiado no mourão do curral. À proporção que os cabelos vão secando, o mal vai cedendo, dizem. É o que eles chamam 'cura de cabelo'. Usam, ainda, azeite de piqui misturado com picumã para que a varejeira não ponha na ferida. Enxuta esta, aplicam picumã com nata de leite" (Pinheiro, s. d., p. 140).

16. 'Para estourar bicheira - suco de 'aninga-pára', tabaco de mólho (rolo) com azeite de andiroba e bagana de tabaco" (Vigia, PA). 
17. G. Cesar (1941: 65-66) apresenta este interessante trecho: "Uns, para curar um animal que tenha maus [bicheiras], basta somente (?) e nisto confiam com sinceridade,

Passar um ramo verde sobre o rastro do animal.

Outros são mais complicados no curativo.

Cobrem o rastro com uma pedra, mas de maneira que a face que se achava para cima fique agora voltada para baixo.

Alguns outros revestem a crendice de mais um apêndice: batem três vezes, com uma pedra, em três rastros do animal doente.

Outros ainda: Tomam de uma embira, formam com a mesma um laço, de longe, diante de uma vista põem o laço e o tornam do tamanho da ferida. Isto feito vão apertando o laço até fechá fora, pelas costas, e o animal está curado.

Muitos vaqueiros recorrem, sem réplica, e com uma confiança que admira, às rezas curadoiras, rezando eles próprios, quando são senhores do assunto. Fazendo cruzes com a mão sobre o rastro do animal doente, rezam:

Maus que come não se logra, quem come e não reza não se salva. Oficial de justiça não se salva. Delegado não se salva. Promotor não se salva. Juiz de Direito não se salva e muitos padres colados não se salva, e assim caia de um em um, de dois em dois, de três em três, de... treze em treze, caia de um em um, não fique nem um. Amém!

Quando, porém o vaqueiro não sabe a oração curadora, e o dia não seja uma segunda-feira, porque, sendo dia das almas é perigoso de campear rês com ferimento que contenha larvas de moscas, tange 0 animal para a fazenda, onde procura o remédio desejado com algum vaqueiro velho sabedor de tudo que diz respeito ao gado, ou alguma velha acostada à casa grande, para rezar a rês. Se, porém, a alimária doente é arisca e suspicaz, ele deixa-a em liberdade, porque os rezadores querem somente saber o lado em que ela ficou. Sabendo e, com as mãos descarnadas, desenham cruzes em profusão pra banda da rês, enquanto rezam num murmúrio precípite:

Maus que comês que a Deus não louvas-se, permita a meu Senhor Jesus que esses maus caíssem; é de sete em sete, de seis em seis, de cinco em cinco, de quatro em quatro, de três em três, de dois em dois, permite meu Jesus Cristo que um a nenhum. Amém!

Depois persignam-se e terminam com um Padre-Nosso, uma Ave-Maria e um Glória-Padre, oferecidos às cinco chagas de Nosso Sr. Jesus Cristo.

$\mathrm{O}$ animal assim curado é entregue à sua sorte. A natureza completa a cura, depois que as larvas, completando o seu ciclo evolutivo, caem para se enterrar a fim de que se opere a metamorfose."

18. O mesmo autor (o. c., p. 66, nota) diz ainda: "No Piauí, os vaqueiros curam os animais encurralados por um processo crendo-mecânico: Tomam eles de um galho de malva, fazem em uma das extremidades duas rachaduras em cruz e nelas introduzem uns fios de cabelos retirados da cauda do animal doente. Esse pincel, ou hissope, uma vez ultimado, é introduzido na bicheira para friccioná-la lentamente, umas três vezes; ęm seguida o hissope é colocado verticalmente sobre o moirão da porteira do curral. Esse modo de proceder será bastante para o animal ficar curado, afirmam eles, se não levássemos em linha de conta o ciclo de vida larvário."

19. Campos (1936: 117) registrou a seguinte oração contra bicheiras, no sul de Goiás: "São Jacó teve 12 filhos, de 12 ficaram 11, de 11 ficaram 10, etc.; de 1 ficou nenhum; assim, também caiam os bichos de 1 a 1 , de 2 a 2 , etc., de 12 a 12, e as feridas logo sequem. Deus Padre, Deus Filho, Espírito Santo!"

20. A. Queiroz (1945: 56) assinalou: “... eu não deixo de não acreditar na força do imã de certas pessoas..." e, mais adiante: “...benzimento não hai quem não acredite. Todo o mundo acha que é infalível. Pra bicheira do gado, pra peste 'cadeira', e pra bicho de nariz de gente, não tem outro! - Benzimento, hoje em dia, qualquer um aplica! 
- Qualquer um, não senhor! Carece conhecer a fala apropriada e arranjar o nome de uma pessoa bem ruim, que seja aprovado pra derrubar bicheira.

- Disso nunca vi falar!

- Antão ocê não sabe o que é benzimento. Quando o benzedor opera faz uma oração própria, vai andando pra trás, rasgando uma palha, jogando os fiapos por cima dos ombros e vai falando sem parar o nome de uma gente ruim, velhaca, de maus costumes. Feito isso, e se o nome da pessoa tem força, bicho não fica um... Diz-se que na Vila hai gente graúda que tem nome que é porrete pra qualquer uma bicheira!"

21. A. Claudio (1923: 78) contou que "Na cura das feridas (bicheiras) dos quadrúpedes, o rezador toma uma palhinha flexível e enlaça as duas extremidades de modo a formar um círculo de diâmetro mais ou menos igual ao da ferida, círculo que é posto em face da parte ofendida do animal, e diz:

\author{
Foge doença \\ De bicho mau \\ Da santa presença \\ De São Nicolau. \\ Verme da terra - \\ Na terra dura \\ São Nicolau \\ Fez tua sipurtura."
}

22. Vidal (1950) contou que, no litoral do Nordeste, "Assim é que a rês doente, primeiramente fica identificada, na sua ausência, examinando-se as coincidências do casco com ạ depressões, constatadas na areia. Então o vaqueiro que entende do riscado analisa o terreno pisado, verifica o fato, e traçando uma cruz, com acentuado e pachorrento cuidado, retira a terra de 4 pontas correspondentes às 4 pernas da cruz. Coloca a terra colhida numa xícara com água - joga a mistura pelas costas -

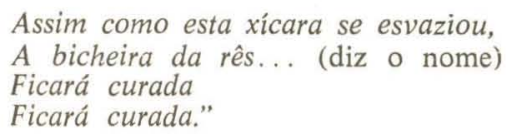

23. Deda (1967: 89-90) registrou: "Para curar bicheiras dos animais há uma ręza 'milagrosa'. E não há necessidade da presença do animal doente! Basta seu rastro, diante do qual se ajoelha o curandeiro, coloca sobre o mesmo alguns garranchos, em forma de cruz, e benzendo-os com um ramo verde, recita, fervoroso, esta curiosa reza -

\title{
Em nome do Padre Eterno
}

Eu te mando pros inferno...

Prá casa do juiz,

$\mathrm{Ou}$ de muié meretriz...

Pra casa de advogado,

Ou de home amancebado...

Pra casa do escrivão,

E faça dele seu pão...

Caia tudo de sete em sete,

$\mathrm{Na}$ ponta do canivete...

Caia tudo de três em três,

E se acabe de uma vez...

Com o poder de São Brás,

Caiam todos para trás..." 
24. O. Cabral publicou em 1958 um excelente trabalho sobre fórmulas de benzeduras de bicheiras, que aqui transcrevemos:

(i) Assim como a mulher do padre

Não assiste à missa inteira,

Assim cairão todos os bichos

Desta bicheira.

(ii) "Pela manhã, em jejum, sem lavar a boca, dirige-se para perto do animal e sem tocá-lo, diz as seguintes palavras 'Bom dia, bicho berne, bicho da imundície, o que estás fazendo no corpo deste animal? Deus permita que aumentes tanto como a mesa em que se come e não se reza. Em nome de Deus e da Virgem Maria, Amém'. Dizê-la três vezes consecutivas, em três dias seguidos. Logo na primeira benzedura, isto é, no dia seguinte a ela, os bichos começam a 'debulhar' e por fim acabam secando."

(iii) "O benzedor deve estar munido com um 'brevinho' denominado 'patuazinho das imundícies' (convém notar que poucos são os mortais que têm a honra de conhecer este segredo, suas características e fases) e com a frente voltada para a bicheira empunha o mencionado brevinho, levanta-o à altura da testa, descreve no ar três cruzes invertidas, ou de cabeça para baixo (segundo a expressão usual), dizendo: 'Do Fiio - do Padre - do Santo - do Espírito. - Amém.' Com o mesmo brevinho descreve-se um círculo ao redor da bicheira e prossegue: 'Pelo sangue do bom Abel, pela torre de Babel. E pelo trabalho dos dias santificados e dos domingos, que Deus amaldiçoou, - eu também te maldigo, bicharedo, judiação...' O benzedor dá três passos à retaguarda e exclama de cada vez: 'Daqui só para trás - daqui só para trás - daqui só para trás'. Se a 'criação doente' estiver presente, está realizada a cerimônia; e se a mesma estiver ausente, depois de estar a par da direção do animal, e de seu respectivo pelo, a cerimônia é repetida três vezes.

O brevinho é confeccionado da seguinte maneira: - em uma sexta-feira, toma-se um pedaço de algodão (fazenda) que ainda não foi lavado, costura-se à mão, com linha branca, na forma de um saquitel; depois coloca-se nele uma antiga moeda de prata, três cruzes de capim e três bichos da bicheira, atados pelo meio, por um fio de linha branca. En seguida é costurada a boca do saquitel e o mesmo é enterrado com seu conteúdo em terras de mata virgem e desenterrado no domingo de Páscoa, às 10 horas da manhã, pronto para entrar em ação. O gesto de descrever um círculo ao redor da bicheira é para limitar-lhe o raio de ação."

(iv) "O benzedor procura o rastro do animal que traz a bicheira e recorta-o na terra com uma faca de ponta e inverte o molde assim recortado. Primeiro o rastro da mão de montar, depois do pé do lado de laçar, e depois da mão do lado de laçar, e por último, do pé do lado de montar. E, cada vez que inverte o molde, pronuncia o seguinte: 'Se és da Serra, vá pra terra! Se és do ar, vá pro mar!' Toma três fios de linha branca e, de costas para o local da operação, dá três passos à frente e a cada um joga um pedaço de fio, no qual deu um nó cego, para trás, pensando firmemente na destruição da bicheira. Não deve olhar pra trás nem mandar ver o animal durante três dias."

(v) "O benzedor deve fazer cruzes com um ramo de arruda molhada em água corrente. Durante a benzedura, vai jogando a água para trás das suas costas, e reza - 'Esta imundície que aí criou, foi mal que aconteceu. Uma varejeira em ti pousou e aí depositou a bicheira nesse pobre animal. E assim como ela entrou, assim deve sair, para desaparecer para sempre. Amém."

(vi) "O benzedor deve indagar previamente a cor do pelo do animal, mandando virar as suas pegadas no terreno antes de recitar a oração: 'Este animal de .... (tal pelo), que tem bicho em... (tal lugar), Deus permita que de nove em nove, de oito em oito, de sete em sete, etc., todos os bichos caiam, não ficando nenhum."

(vii) "Assim como as Três Pessoas da Santíssima Trindade são certas e verdadeiras, saiam os bichos desta bicheira. Caiam de 7 em 7 , etc.”. A primeira vez, reza 5 vezes a oração acima; a segunda, 3 vezes; e a terceira 1 vez. 
Se a benzedura é feita à distância, vira-se o benzedor para o lado em que presumivelmente se encontra o animal atacado.

(viii) "Em nome do Padre, do Filho e do Espírito Santo. Amém. Faraó tinha 19 filhos; morreu um, ficaram 18; morreu mais um, ficaram 17; etc.: morreu mais um e ficou só um; de um morreu um e ficou nenhum. Assim os bichos desta bicheira hão de morrer de um em um, até que não fiquem mais nenhum. Amém. A benzedura é realizada fazendo o benzedor o sinal da cruz e persignando-se ao final."

(ix) "Adão tinha 10 filhos; de 10, parou-se em 9; de 9 parou-se em 8; etc.: de 2 parou-se em 1; permita Jesus que estes bichos caia tudo de $1 \mathrm{em} \mathrm{1;}$ que ela seja tão atrasada como serviço de domingo."

(x) Ainda para as mí́ases de animais, recolhidas foram em Santa Catarina mais as seguintes: 'Isidora era mulher; bichos agudos, que leve o diabo tudo' (3 vezes); 'A bicheira deste animal há de aumentar tanto, como a pessoa que trabalha em domingo ou dia santo."

(xi) Tais rezas e simpatias são tão eficazes, que até os colonos alemães as utilizam, como a seguinte fórmula recolhida pelo Prof. Egon Schaden (in Cabral, 1958: 163) mostra:

"O benzedor prepara três hastes de capim com as quais faz um laço. Segura-o diante dos olhos e olha através do mesmo a ferida em que estão os bichos, e recita:

- So wahr wie an Sonn - und Feiertag nicht man knechtliche Arbeit mit Nutzen verricht, keil Gott uns jene zu Alten gebot, so war solles auch bei den Tiere sein, dass die Bichos fortab nicht weiter gedeihn, und über sie kommt der rasche Tod. In Namen der Hohen Dreifaltigkeit sei os von seinem Uebel befreit. (Tão certo como não se tira proveito de trabalhos servis em domingos e dias santos, tão certo não hão de prosperar doravante os bichos neste animal e serão colhidos pela morte rápida. Em nome da Santa Trindade, fique liberto de seu mal)".

As mesmas interessantes práticas existem em muitas outras localidades da América Latina. Na Argentina, por exemplo, diz Coluccio (1950: 179), em seu célebre "Diccionario folklórico argentino":

"Gusanos - D. Granada narra algunas de [las maneras de curar los gusanos]. Una de la más interesantes es la que dice 'que el paisano sigue al animal agusanado (vacuno o caballo). Observa pónde asienta la pezuña o el casco. Apéase sin quitar la vista de la gusanera; se pone en cuclillas, saca el largo y puntiagudo cuchillo; corta, soslayándolo, el espacio de terreno en que está impresa la pisada, lo voltea; hace una cruz con la punta del cuchillo y se va, sin mirar más la gusanera. También hacen lo mismo con los espacios hollados por una mano y la pata del lado opuesto. Cuando el pasto de la tierra desprendida del suelo se seca, 'caen (dicen) los gusanos'. También se hacen 'caer' los gusanos colgando del pescuezo del animal agusanado, un cráneo de perro, un sapo vivo o una pata de oveja."

Além de Granada (1947), trataram deste assunto os seguintes autores: Saubidet (1943), Granada (1890), Ambrosetti (1917), Terrera (1947), Coluccio (1948) e Acuña (L. A.) (1949).

\section{BIBLIOGRAFIA}

Abdallah, E. I., U. F. Rocha, O. P. Serra, S. P. Oba \& R. G. Serra, 1970. Miíase primária em búfalos - Bubalus bubalis L.., 1758 - do estado de São Paulo, Brasil, por Cochliomyia hominivorax (Coquerel, 1858), Diptera, Calliphoridae. Revta Farm. Bioquim. Univ. S Paulo 8(1): 135-138, 1 fig.

Acuña, L. A., 1949. Folklore del Departamento de Santander. Revta Folkl. Bogotá 5: 97-143.

Adams, J. L., 1904. Tropical cutaneous myiasis in man. J. Am. med. Ass. 42(15): 947-949, 3 figs. (Também publ. sep., 7 pp., 3 figs., Chicago, 1904).

Adams, T. S., 1979a. The reproductive physiology of the screwworm, Cochliomyia hominivorax (Diptera: Calliphoridae). II. Effect of constant temperatures on oogenesis. J. med. Ent. 15(5-6): 484-487. 
Adams, T. S., 1979b. Idem. III. Mating. Ibid. 15(5-6): 488-493.

Adams, T. S., C. G. Holt \& W. D. Sundet, 1970. Physical and physiological effects on the response of female screwworms, Cochliomyia hominivorax (Diptera: Calliphoridae), to carrion odors in an olfactometer. Ibid. 15 (5-6): 124-131.

Adams, T. S. \& J. P. Reinecke, 1979. The reproductive physiology of the screwworm, Cochliomyia hominivorax (Diptera: Calliphoridae). Oogenesis. Ibid. 15 (5-6): 472-483.

Aguilar, A., 1941. Sobre un caso de miasis forunculosa localizada en órganos genitales, por larvas de Cochlioma [sic] macellaria. Semana méd., B Aires 48(14): 800-802.

Aguilar, A., 1945. Miasis forunculosa localizada en el cuello producida por larvas de Cochliomyia macellaria. Ibid. 52(3): 144-145.

Aguilar, F. J., F. Labbe C. \& R. Robles, 1960. Consideraciones sobre la miasis nasal en Guatemala. Revta Col. méd. Guatem. 11(2): 75-79, fig.

Aguirre, F., 1885. Larvas de la Calliphora limensis en fosas nasales, 18 pp. Santiago de Chile.

Ahrens, E. H., J. R. Coppedge, F. S. Guillot \& J. L. Goodenough, 1977. Comparison of the distribution and daily activity periods of released and native screwworm flies. Envir. Ent. 6(1): 138-142, mapa.

Ahrens, E. H., J. A. Deer \& G. M. McWhorter, 1978. Field evaluation of insecticide impregnated ear tags and bands for the control of the Gulf Coast tick. Folia ent. mex. 39-40: 197.

Ahrens, E. H., W. J. Gladney, G. M. McWhorter \& J. A. Deer, 1977. Prevention of screwworm infestation in cattle by controlling Gulf Coast ticks with slow release insecticide devices. J. econ. Ent. 70(5): 581-585.

Ahrens, E. H., H. C. Hoffmann, J. L. Goodenough \& H. D. Peterson, 1976. A field comparison of two strains of sterilized screwworm flies. J. med. Eni. 12(6): 631-634.

Albernaz, P. M., 1933a. De algumas localizações raras das miiases. Revta oto-lar. $S$ Paulo 1(3): 226-227.

Albernaz, P. M., 1933b. Locali־ações raras das myases. Brasil-méd. 47(19): 345.

Aldrich, J. M., 1925. New Diptera or two-winged flies in the United States National Museum. Proc. U. S. natl Mus. 66(18) (= n. ${ }^{\circ}$ 2555): 1-36, figs. (P. 16: Key to genera of world Chrysomyini).

Alegría, C., 1945. Miasis. Consideración sobre dos casos. Revta Soc. méd.-quir. Zulia 19(4): 142.

Aleixo, A., 1919. Myiasis do grande labio esquerdo. Archos mineir. Dermat. Syph. 1919: 44.

Alley, D. A. \& B. H. Hightower, 1966. Mating behavior of the screwworm fly as affected by differences in strain and size. J. econ. Ent. 59(6): $1499-1502$.

Almeida, T. de, Jr., 1919. Myiasis cavitaria e seu tratamento. Archos bras. Med. 9: 496-503, 1 fig.

Almeida, W. de, 1916. Disturbios mentaes no decurso da nasomyiasis. Rio de Janeiro.

Almeida, W. de, 1917. Disturbios mentaes no decurso da myiasis nasal. Archos bras. Med. 7(4): 229-242, figs. 1-2.

Almeida, W. de, 1918. Disturbios mentaes no decurso da nasomyiasis (Res. de 1916). Brasil-méd. 32(6): 47.

Altamirano, F., 1907. Myiasis nasal. Gac. méd. Méx. (3) 2(7): 221-225, 1 fig.

Alves Netto, F., 1950. Combate às moscas das bicheiras. Bahia rural 18(11): 29-30.

Alves Netto, F., 1951. Combate às moscas das bicheiras. Controle das moscas. Ibid. 19(4): 24-25.

Amaral, A. A. de, 1910. Tratamento da miiase. Impr. méd., S Paulo 18(21): 332-333.

Amaral, A. D. F., 1940. Observações em torno de dois casos de miíases humanas pela "Cochliomyia hominivorax" (Coq. 1858). Acta méd., Rio de I. 5(3): 134.

Ambrosetti, J. B., 1917. Supersticiones y leyendas: Región misionera, valles 
calchaquies, las pampas. Con una introducción de Salvador Debenedetti, 239 pp. La Cultura Argentina, Buenos Aires.

André, E. H., 1925. Sur un cas de myiase cutanée chez l'homme. Parasitology 17(2): 173-175, 3 figs.

Anduze, P. J., 1945. Breve nota sobre miasis humana en Venezuela. Boln Ent. Venez. 4(1): 37-40.

Anon., 1918. Notícias úteis sobre as "bicheiras do gado". Cha. Quint. 18(2): 115,2 figs.

Anon., 1932. A derris e a raiz de cube no combate às moscas varejeiras. Bolm Agric., S Paulo 1932: 669-671.

Anon., 1957. Combate às môscas das bicheiras. Sítios Faz., S Paulo 23(8): 19.

Arenas, N. \& M. L. Perez, 1936. Miasis de la vulva. 5 Reun. Soc. Patol. reg. Norte: 919-923.

Argumosa, J. R. de, 1875a. Algunos dípteros en la clínica. Crón. méd-quir. Habana 1: 213-219.

Argumosa, J. R. de, 1875b. Larvas de la mosca de Cayena en las fosas nasales. Ibid. 1: 213-219.

Arias, J., 1888. Estudo de las miasis de las fosas nasales. Tesis, Facultad de Medicina de Buenos Aires.

Arias Schreiber, L. \& F. Escudero Franco, 1928. Un caso de miasis cutánea. Crón. méd., Lima 45: 58-61, 1 fig.

Arravel, R. A., 1915. La mosca agusanadora (Calliphora oceaniciae, Desv.). Revta Fac. rur. Urug. 44(6): 340-344.

Ascher, K. R. S., 1964. A review of chemosterilants and oviposition-inhibitors in insects. Med. Rev. Pest Control 3: 7-27.

Assis, J. E. de P., 1938. Localização raríssima de miíase. Revta oto-lar. S Paulo 6(1): $79-80$.

Aubertin, D. \& P. A. Buxton, 1934. Cochliomyia and myiasis in tropical America. Ann. trop. Med. Parasit. 28(3): 244-254, pl. 4, figs. A-D.

Audouit, V., 1864. Des désordres produits chez l'homme par les larves de la Lucilia hominivorax, $43 \mathrm{pp}$. Thèse, Paris.

Ayut, J. \& M. Lopes, 1957. Sobre um caso de fístulas anais complicadas com úlcera miásica. Revta paul. Med. 51(6): 396-399.

Azara, F. de, 1809. Voyage dans l'Amérique méridionale, depuis 1781 jusq'en 1801, contenant la description géographique, politique et civile du $\mathrm{Pa}$ raguay et de la rivière de la Plata, etc. 1: 1x + 389 pp.; 2: 562 pp.; 3: 479 pp.; 4: 380 pp. Pls. e mapas em vol. sep., Paris.

Azevedo, D. J., 1970. Miiase ocular. Folha méd. 61(1): 17-20.

Babcock, O. G., 1932. Insects affecting animals and man. 44. a. Rep. Tex. agric. Exp. Stn 1931: 162-163.

Babcock, O. G. \& D. H. Bennett, 1921. The screwworm and the wool maggot. Circ. Tex. agric. Exp. Stn 27: 1-15, 7 figs.

Babcock, O. G. \& I. B. Boughton, 1933a. Blow flies. 45. a. Rep. Tex. agric. Exp. Stn 1932: 200.

Babcock, O. G. \& I. B. Boughton, 1933b. Insects affecting animals. Ibid. 1933: 199-200.

Babcock, O. G., I. B. Boughton \& W. T. Hardy, 1934. Insects affecting animals. 46. a. Rep. Tex. agric. Exp. Stn 1933: 214-217.

Balea, O., 1952. Sobre un caso de "miasis nasal". Revta Col. méd. Cienfuegos 3(3): 86-87.

Ball, C. E., 1960. Coming screwworm eradication in the Southwest. Fm J. 84(9): 38.

Ball, C. E., 1961. Atomic war on insects. Saturday Evening Post 234(36): 36-37, 51-52.

Ball, C. E., 1962. Stockmen put big money into screwworm battle. Fm J. $86(2): 52$.

Ballenger, W. L., 1914a. Foreign bodies in the ear. Ceruminous plugs in the meatus, in Diseases of the nose, throat, and ear, pp. 635-636. Lea \& Fabiger, Philadelphia.

Ballenger, W. L., 1914b. Screw-worms in the nose, in Ibid., pp. 289-290.

Barilatti, J., 1918. A propósito de una rara localización de miasis. Revta 
Sanidad milit. argent. 17(3): 265-268.

Barlaro, P. M., 1919. Sobre un caso de miasis, muerto por hemorragia. Prensa méd. argent. 6(5): 54.

Barnes, G. W., 1942. Trappings show screw worm decline. Coastal Cattleman $8(10): 37$.

Barnes, C. W. \& W. G. Cibula, 1979. Some implications of remote sensing technology in insect control programs including mosquitoes. Mosquito News 39(2): 271-282.

Barrett, W. L., Jr., 1937. Natural dispersion of Cochliomyia americana. J. econ. Ent. 30: 873-876.

Barroso, G., 1921. Ao som da viola (Folk-lore), 733 pp. Livraria Editora Leite Ribeiro, Rio de Janeiro.

Barroso, S. M., 1922. O que todos devemos saber sobre os parasitas vegetaes $e$ animaes que se implantam no nosso corpo e os males que nos causam. Meios de os evitar (sic), 230 pp., 131 figs. Bahia.

Barry, W. B., 1943. Nasal myiasis. Ann. Otol-rhinol-laryngol. 52: 486-495.

Bassewitz, E. von, 1904. Os muscideos perante a pathologia humanu. Monographia das myiasis. Revta méd. S Paulo 7(7): 146-152; (8): 166-171.

Bassford, F., 1950. Screw worm attacks appear imminent. West. Livestock J. 28(46): 9 .

Basso, R., 1939. Frecuencia y naturaleza de las miasis en Mendoza. (Investigaciones sobre dípteros argentinos. I. Miasis). Publnes Misión Estud. Patol. reg. argent. Jujuy 41: 55-65, 5 figs.

Baumhover, A. H., 1958. Florida screwworm control program. Vet. Med. 53(4): 216-219, ilus.

Baumhover, A. H., 1963a. Influence of aeration during gamma irradiation of screwworm pupae. J. econ. Ent. 56: 628-631.

Baumhover, A. H., 1963b. Susceptibility of screwworm larvae and prepupae to dessication. Ibid. 56: 645-649.

Baumhover, A. H., 1965. Sexual agressiveness of male screwworm flies measured by effects on female mortality. Ibid. 58(3): 544-548.

Baumhover, A. H., 1966. Eradication of the screw-worm fly. J. Am. med. Ass. 196: $240-248$.

Baumhover, A. H., A. J. Graham, B. A. Bitter, D. E. Hopkins, W. D. New, F. H.Dedley \& R. C. Bushland, 1955. Screwworm control through release of sterilized flies. J. econ. Ent. 48(4): 462-466, mapa.

Baumhover, A. H., C. N. Husman \& A. J. Graham, 1966. Chapter 37. Screwworm, pp. 533-554, in C. N. Smith, ed., Insect colonization and mass production, xxi $+618 \mathrm{pp}$. Academic Press, New York.

Baumhover, A. H., C. N. Husman, C. C. Skipper \& W. D. New, 1959. Field observation on the effects of releasing sterile screwworms in Florida. J. econ. Ent. 52(6): 1202-1206.

Baumhover, A. H. \& W. D. New, 1956. New colonization of a Florida strain of the screw-worm fly. Bull. ent. Soc. Am. 2(3): 23.

Baumhover, A. H., C. C. Skipper \& W. D. New, 1957. Field observation on the effects of releasing sterile screw-worm in a 2,000 square mile area in Florida. Proc. 15. a. Conv. Ass. s. agric. Wkrs (Little Rock): 114.

Baumhover, A. H. \& G. E. Spates, Jr., 1964. Selection for extended survival of adult screw-worms under starvation. Folia ent. mex. 7-8: 68.

Baumhover, A. H. \& G. E. Spates, Jr., 1965. Artificial selection of adult screw-worms for extended survival without food and water. J. econ. Ent. 58: 645-649.

Baurac, J. C., 1889. Note sur un cas de Lucilia hominivorax observé à Tay-Ninh (Cochinchine). Archs Méd. navale 52: 391-410. (Também publ. sep., 10 pp., Saigon, 1890). (Identificação errônea do Calliphoridae envolvido).

Beck, A. A. H., H. J. H. de Melo, I. Bianchin \& M. R. J. Soares, eds., 1979. Anais do $1 .^{\circ}$ Seminário Nacional sobre parasitoses dos bovinos, 386 pp. Campo Grande.

Beckman, H. J., 1941. Screw worms bad in San Bernardino Co. Calif. Wool Grow. 17(16): 50. 
Beesley, W. N., 1973. Control of arthropods of medical and veterinary importance, pp. 115-192, in B. Dowes, ed., Advances in Parasitology 11: $\mathrm{xx}+777$ pp., ilus., mapas. Academic Press, London \& New York.

Beneden, P. J. van, 1883. Parasites free during their whole life, in Animal parasites and messmates, pp. 119-120. D. Appleton \& Co., New York.

Bentley, G. M., 1936. The screw worm fly. Bien. Rep. Dep. Agric. Tenn. (1935-36): 47-48.

Beretervide, E. A., D. Aguilar Giraldes \& J. R. Calcerami, 1949. Sobre un caso de miasis en un niño con displasia ectodérmica. Archos Pediat. Urug. 20(1): 40-41.

Bernard, L. M. J., 1924. La médecine vétérinaire à la Guadeloupe. Recl Méd. vét. Ec. Alfort 100(23): 729-740.

Beroza, M. \& G. T. Bottger, 1954. The insecticidal value of Tripterygium wilfordii. J. econ. Ent. 47(1): 188-189.

Bertarelli, E., 1934. A therapeutica com larvas de mosca. Folia clin. biol. 6(6): 55-58.

Beyer, G. E., 1925. The bacteriology of market flies of New Orleans. Louis. St. Bd Hlth quart. Bull. 16: 110-116.

Bigot, J. M. F., 1877. Diptères nouveaux ou peus connus. 7e. Partie. IX: Genre Somomyia (Rondani). Lucilia (Rob. Desv.). Calliphora, Phormia, Chrysomyia (id.); 8e. Partie, X: Genre Somomya (Rondani). Calliphora, Melinda, Mufetia, Lucilia, Chrysomya (alias Microchrysa Rond.) Robineau-Desvoidy. Annls Soc. ent. Fr. (5) 7: 35-48, 243-259.

Bigot, J. M. F., 1883. [Notas sobre Compsomyia (Lucilia) macellaria Fabr.]. Ibid. (6) 3(Bull.): cix-cx.

Bigot, J. M. F., 1888. (Diagnoses abrégées de quelques diptères nouveaux, provenant de l'Amérique du Nord). Ibid. (6) 7(Bull.): clxxx-clxxxii (1887).

Bishopp, F. C., 1915. Flies which cause myiasis in man and animals. Some aspects of the problem. J. econ. Ent. 8(3): 317-329.

Bishopp, F. C., 1916. Flytraps and their operation. US Dep. Agric Fmrs' Bull. 734: 1-14.

Bishopp, F. C., 1918a. Myiasis; its prevention and treatment. Proc. Class Sutdy Ent. Dis. US Bur. Ent., mimeo pp. 335-341.

Bishopp, F. C., 1918b. Myiasis; types of injury and life history and habits of species concerned. Ibid., pp. 317-334.

Bishopp, F. C., 1921a. Myiasis - its prevention and treatment, in W. D. Pierce, Sanitary entomology, pp. 200-208, fig. 40, pl. 14. Boston.

Bishopp, F. C., 1921b. Myiasis - types of injury and life history, and habits of species concerned. Id., Ibid., pp. 175-199, figs. 37-39, pls. 9-13.

Bishopp, F. C., 1921c. Flytraps and their operation. US Dep. Agric. Fmrs' Bull. 734: 1-16.

Bishopp, F. C., 1927. The screw worm problem. J. Parasit. 14(2): 132.

Bishopp, F. C., 1930. Screw-worm losses to livestock industry can be reduced. Yb. US Dep. Agric.: 469-472, figs. 163-165.

Bishopp, F. C., 1934a. A destructive outbreak of the screw worm fly, Cochliomyia ssp. (sic) in the southeast. J. Parasit 20(6): 337.

Bishopp, F. C., 1934b. Screw-worm control in the southeastern states, 4 pp. mimeo. Bur. Ent., US Dep. Agric., Washington, D. C.

Bishopp, F. C., 1934c. Screw worms sweeping southeast calls for concerted action, 3 pp. mimeo. Press. Serv., Off. Inform., US Dep. Agric.

Bishopp, F. C., 1935. Screw worms (Cochliomyia spp.). Insect Pest Surv. Bull. 15(5): 268-269.

Bishopp, F. C., 1936. Screw-worm. Ibid. 15(10): 361-462, 1935.

Bishopp, F. C., 1937. Flytraps and their operation. US Dep. Agric. Fmrs' Bull. 734: 1-14.

Bishopp, F. C. et al., 1938. Screwworm, Cochlimyia americana C. \& P. South Carolina, Georgia, Florida, Alabama, Oklahoma, Texas. Insect Pest Surv. Bull. 18(7): 508.

Bishopp, F. C., F. C. Cook, D. C. Parman \& E. W. Laake, 1923. Progress report of investigations relating to repellents, attractants and larvicides 
for the screw-worm and other flies. J. econ. Ent. 16(2): 222-224.

Bishopp, F. C. \& W. E. Dove, 1937. Screw-worm control, in B. Schwartz et al., Report of committee on parasitic diseases. J. Am. med. Ass. 43(3): 348-350.

Bishopp, F. C. \& H. Hixson, 1936. Biology and economic importance of the Gulf Coast tick. J. econ. Ent. 29(6): 1068-1076.

Bishopp, F. C. \& E. W. Laake, 1921. Dispersion of flies by flight. J. agric. Res. 21(10): 729-766.

Bishopp, F. C., E. W. Laake \& D. C. Parman, 1926. Screw worms and other maggots affecting animals. Fmrs' Bull. U. S. Dep. Agric. 857: 1-10.

Bishopp, F. C., J. D. Mitchell \& D. C. Parman, 1917. Screwworms and other maggots affecting animals. Ibid. 857: 1-18, 8 figs.

Bishopp, F. C., J. D. Mitchell \& D. C. Parman, 1922. Idem. Ibid. 857: $1-19,8$ figs.

Bishopp, F. C., J. D. Mitchell \& D. C. Parman, 1923. Idem. Ibid. 857:1-15, 9 figs.

Bishopp, F. C. \& H. E. Parish, 1936. Screw-worm (Cochliomyia americana C. and P.). Insect Pest Surv. Bull. 16(4): 145.

Bishopp, F. C., R. C. Roark, D. C. Parman \& E. W. Laake, 1925a. Repellents and larvicides for the screw worm and other flies. J. econ. Ent. 18(2): 336-337.

Bishopp, F. C., R. C. Roark, D. C. Parman \& E. W. Laake, 1925b. Idem. Ibid. 18(6): 776-778.

Bissell, T. L., 1935. The screw worm. Bull. Ga. agric. Exp. Stn 189: 1-11, 5 figs.

Blain, A. W., 1909a. The screw-worm fly, with the report of a case of myiasis narium. Detroit med. J. 9(7): 253-254, 3 figs.

Blain, A. W., 1909b. Idem. 11. Rep. Mich. Acad. Sci.: 114-115, 3 figs.

Blanchard, R., 1896. Contribution à l'étude des diptères parasites. XII. Sur la Compsomyia macellaria (Fabricius, 1794) Rondani, 1875. Annls Soc. ent. Fr. 65: 654-668, pl. 17, figs. 1-4, pl. 18, figs. 1-6.

Blanco Ledesma, D.A., 1916. Un caso de miasis nasal. Gac. méd. Caracas 23 (24): 188-189. (Também em Gac. méd. Ciudad Bolivar 3: 27, 58, 1916).

Blanco Ledesma, D. A., 1917a. Dos nuevos casos de miasis. Miasis ulcerosa (Sarcophaga carnaria). Miasis nasal (Lucilia hominivorax o Chrysomyia macellaria). Ibid. 24 (9): 79-80. (Res. em Rev. appl. Ent. (B) $6(3): 51-52,1918)$.

Blanco Ledesma, D. A., 1971b. Miasis nasal. Presentación de larvas muscides productoras. Ibid. 24(9): 79-80.

Bleyer, I., 1905. Contribuição para o estudo de molestias tropicaes e subtropicaes. Tratado de myiasis. Ensaio de um estudo clinico sobre o papel das moscas na pathologia humana (2a. ed.), 90 pp. Annibal Rocha \& C., Corytiba (1a. ed., 1901).

Boero, J. J. \& E. G. Morini, 1961. Miiasis. Revta Fac. Cienc. vet. La Plata (3) 3(7): 73-83, il.

Bogliano, E., 1906. Algunas consideraciones sobre miasis nasal y un tratamiento nuevo. Tesis, Fac. Med. Buenos Aires.

Boller, E., 1972. Behavioral aspects of mass-rearing of insects. Entomophaga 17(1): 9-25.

Borgstrom, F. A., 1938. Studies on experimental Cochliomyia americana infestation with special reference to the bacterial flora and the development of immunity. Am. J. trop. Med. 18(4): 395-411.

Borkovec, A. B., 1962. Sexual sterilization of insects by chemicals. Science, N. Y. 137: 1034-1037.

Borstel, R. C. von, 1960. Population control by release of irradiated males. Ibid. 131: 878, 880-882.

Boyes, J. W., 1961. Somatic chromosomes of higher Diptera. V. Interspecific and intraspecific variation in the Calliphoridae. Can. J. Zool. 39: 549-570.

Boyes, J. W., 1967. The cytology of muscoid flies, pp. 371-384, in J. W. Wright \& R. Pal, eds., Genetics of insect vectors of áisease. Elsevier 
Publ. Co., New York.

Boyes, J. W. \& G. E. Shewell, 1975. Cytotaxonomy of Calliphoridae (Diptera). Genetica 45: 435-488.

Brandão, M. de S. \& L. de Meneses, 1875. Contribuições para a história da myiasis ou bicheiro das fossas nasaes. Rio de Janeiro.

Brandau, G. M., 1930. Rhinal myiasis. Am. J. med. Sci. 179(5): 643-653.

Brandstein, M., A. H. Baumhover \& W. D. New, 1956. Development of attractants for the screwworm fly. Bull. ent. Soc. Arn. 2(3): 23.

Brauer, F., 1889. Beiträge zur Kenntniss der Muscaria Schizometopa. Sitz. K. Akad. Wien, Math.-nat. Cl., Abt. 1, 108: 495-529.

Brea, C. A. \& E. C. Canale, 1947. Miasis vulvar. Revta Asoc. méd. argent. 61: 734-735, il.

Brennan, J. M., 1937a. The incidence of screwworm in wounds for 1936. Fla Cattleman 15 Jan 1937: 12, 16, 21.

Brennan, J. W., 1937b. Primary screw worm fly. SWest Sheep Goat Rais. 7(11): 12-13, 36, il.

Brennan, J. W., 1938. The incidence and importance of Cochliomyia americana and other wound-infesting species, J., econ. Ent. 31(6): 646-649.

Briceño Iragorry, L., 1933. Comentarios sobre dos casos de miasis. Revta Policlín. Caracas 2(9): 586.

Broce, A. B., 1980. Sexual behavior of screwworm fly (Cochliomyia hominivorax) stimulated by swormlure-2. Ann. ent. Soc. Am. 73(4): 386-389,

Broce, A. B., R. B. Davey \& J. W. Snow, 1979. Plastic wicks as dispensers of the screwworm attractant, swormulure-2. J. econ. Ent. 72(11): $115-118$.

Broce, A. B., J. L. Goodenough \& J. R. Coppedge, 1977. A wind oriented trap for screwworm flies. Ibid. 70(4): 413-416, fig.

Broce, A. B., J. L. Goodenough \& J. R. Coppedge, 1978. The development of a new trap for screwworms. Folia ent. mex. 39-40: 195.

Broce, A. B., J. L. Goodenough \& J. W. Snow, 1979. Recovery of screwworm flies released at various distances and directions of the attractant swormlure-2. Envir. Ent. 8(5): 824-828.

Broce, A. B. \& J. Ideker. 1978. Oleander flowers as insect traps. Ann. ent. Soc. Am. 71(4): 628-629, 1 fig.

Brody, A. L., 1939. Natural foods of Cochliomyia americana, the true screwworm. J. econ. Ent. 32: 346-347.

Brody, A. L. \& E. F. Knipling, 1940. Methods of destroying blowfly larvae and pupae in carcasses and in soil. Ibid. 33(4): 662-665.

Brody, A. L. \& E. F. Knipling, 1943. Can larvae of Cochliomyia americana C. and P. mature in cascasses? J. Parasit. 29(1): 59-60.

Brody, A. L. \& E. E. Rogers, 1945. Winter activity of Cochliomyia americana in the southeastern states. J. econ. Ent. 38(1): 85-89.

Brown, E. H., 1945. Screwworm infestation in the nasal passages and paranasal sinuses. Laryngoscope, St. Louis 55(7): 371-374.

Brown, H. E. \& J. W. Snow, 1978a. Protein utilization by screwworm larvae (Diptera: Calliphoridae) reared on liquid medium. J. med. Ent. 14(5): 531-533.

Brown, H. E. \& J. W. Snow, 1978b. Activity of $\alpha$-glycerophosphate dehy. drogenase in screwworm flies as related to age, sex, and irradiation. SWest. Ent. 3(1): 30-33.

Brown, H. E. \& J. W. Snow, 1979. Ssrewworms (Diptera, Calliphoridae): A new liquid medium for rearing screwworm larvae. I. med. Ent. 16(1): 29-32.

Bruce, W. G., 1939. Some observations on insect edaphology. J. Kans. ent. Soc. 12(3): 91-93.

Bruce, W. G., 1944. Screwworm survey of the southeastern states in 1943. J. econ. Ent. 37(5): 687-689.

Bruce, W. G., 1945. Screwworm survey of the southeastern states in 1944. Ibid. 38(3): 327-329, mapa.

Bruce, W. G., 1952. Screwworms. Yb. Agric. US Dep. Agric.: 666-672.

Bruce, W. G. \& W. J. Sheely, 1936. Screwworms in Florida. Bull. Fla agric. 
Exp. Stn 86: 1-27, il., pls.

Bruce, W. G. \& W. J. Sheely, 1944, Screwworms in Florida. Bull. Fla agric. Ext. Serv. 123: 1-28, il., pls.

Bruce, W. G., A. L. Smith \& C. C. Skipper, 1947. Screwworm survey of the southeastern states in 1945. Fla Entom. 29: 1-4.

Brumpt, E., 1922. Cochliomyia macellaria, in Précis de parasitologie 1: 874-894. Masson, Paris.

Brundrett, H. M., 1957. Bayer $21 / 199$ as a deterrent to screwworm attack in sheep. Bull. ent. Soc. Am. 3(3): 33.

Brundrett, H. M., 1953. A homemade fly trap. US Bur. Ent. Plant Quarant. ET-312: 1-4.

Brundrett, H. M. \& O. H. Graham, 1958. Bayer $21 / 199$ as a deterrent to screw-worm attack in sheep. J. econ. Ent. 51(3): 407-408.

Burgos, C., 1899. A propósito de um caso de bicheira da garganta. Revta méd. S Paulo 2(11): ?

Burlage, G., 1968. FAA/USDA airdrops say... “don't bug me!”. FAA Horizons $15 \mathrm{Apr}$ 1968: 1-2.

Bush, G. L., 1975. Genetic changes occurring in flight muscles enzymes of the screwworm fly during mass rearing. $J l N$. Y. ent Soc. 83(4): 275-276.

Bush, G. L., 1978. Planning a rational quality control program for the screwworm fly, pp. 37-47, in R. H. Richardson, ed., q. v.

Bush, G. L. \& R. W. Neck, 1976. Ecological genetics of the screwworm fly, Cochliomyia hominivorax (Diptera: Calliphoridae) and its bearing on the quality of mass-reared insects. Envir. Ent. 5(5): 821-826.

Bush, G. L., R. W. Neck \& G. B. Kitto, 1976. Screwworm eradication: Inadvertent selection for noncompetitive ecotypes during mass rearing. Science, N. Y. 193(4552): 491-493.

Bushland, R. C., 1939. Volatile oils as ovicides for the screwworm, Cochliomyia americana C. \& P. J. econ. Ent. 32(3): 430-431.

Bushland, R. C., 1940a. The toxicity of fenothiazine and certain related compounds to young screwworms. Ibid. 33(4): 666-669.

Bushland, R. C., 1940b. The toxicity of some organic compounds to young screwworms. Ibid. 33(4): 669-676.

Bushland, R. C., 1952. Screw-worm control. Cattleman 38(12): 34-36, 38, il.

Bushland, R. C., 1955. Screw-worm eradication through release of sterilized flies. Symp. Appl. Radiact. Food \& Food process. Ind., Boston: C3.

Bushland, R. C., 1956. Use of radiation in insect control. Proc. 10th int. Congr. Ent. 3: 711-715.

Bushland, R. C., 1959. New research results with systemic insecticides. 62nd a. Proc. US Lustck Ass.: 192-197.

Bushland, R. C., 1960a. Insect eradication by release of sterilized males, pp. 276-290, in Int. Atom. Energy Agency, Large radiation sources in industry, vol. 2. Vienna.

Bushland, R. C., 1960b. Screw-worm research and eradication, in C. A. Brandly \& E. L. Jungherr, eds., Advances in veterinary science 6: 1-18. Academic Press, New York \& London.

Bushland, R. C., 1960c. Male sterilization for the control of insects, in R. L. Metcalf, ed., Advances in pest control research 3: 1-25. Interscience Publishers, Inc., New York \& London.

Bushland, R. C., 1960d. Need more detailed studies of screwworm ecology in Mexico. Cattleman 46(11): 23.

Bushland, R. C., 1971. Sterility principle for insect control, historical development and recent innovations, pp. 3-14. Int. Atomic Energy Agency, Vienna.

Bushland, R. C., 1974. Screwworm eradication program. Science, N. Y. 184 (4140): 1010-1011.

Bushland, R. C., 1975. Screwworm research and eradication. Bull. ent. Soc. Am. 21(1): 23-26.

Bushland, R. C. \& D. E. Hopkins, 1951. Experiments with screwworm flies sterilized by X-rays. J. econ. Ent. 44(5): 725-731. 
Bushland, R. C. \& D. E. Hopkins, 1953. Sterilization of screwworm flies with $\mathrm{X}$-rays and gammarays. Ibid. 46(4): 648-656.

Bushland, R. C., E. F. Knipling \& A. W. Lindquist, 1956. Eradition of the screw-worm fly by releasing gamma-ray-sterilized males among the natural populations. Proc. int. Conf. peaceful Uses atom. Energy 12: 216-220, il.

Bushland, R. C., A. W. Lindquist \& E. F. Knipling, 1955. Eradication of screw-worms through release of sterilized males. Science, N. Y. 122: 287-288.

Bushland, R. C., R. D. Radeleff \& R. O. Drummond, 1963. Development of systemic insecticides for pests of animals in the United States. A. Rev. Ent. 8: 215-238.

Bustos, F., 1930. Dos casos de miasis vulvar. 5. Reun. Soc. argent. Patol. reg. Norte 2: 1149-1152, 1 fig.

Cabral, O., 1958. A medicina teológica e as benzeduras. Suas raízes na história e sua persistência no folclore. Revta Arq. munic. S Paulo 160: $1-204$.

Cairns, D. W., 1906 (?). Post-Graduate 21(10): 1004-1009, pl.

Caldas, S., 1936. Reflexões acerca do tratamento de míase nasal. Nova indicação terapêutica do método de Provetz. Anais Oto-rino-lar. 2(3): 169-175.

Calero M., C., 1947. Miasis de la piel en Panamá. Archos Hosp. S Tomás, Panamá 2(1): 11-17, il.

Calero M,, C., 1948. Cutaneous myiasis in Panama. J. Parasit. 34(4): 343-344.

Calman, J., 1973. Screwworm control. Science, N. Y. 182: 775.

Campbell, C. L., 1960. Screwworm eradication a challenge. Cattleman 46(11): 23-25.

Campello, A., 1934. Processo de Prado Moreira no tratamento das myases. Publções méd. 55: 28-29.

Campos, M. de, 1936. Interior do Brasil. Noroeste de Mato-Grosso, do Rio de Janeiro a Cuyabá, através de Goyaz, o valle do Juruena-Tapajoz. Notas medicas e ethnographicas, $210 \mathrm{pp}$. Rio de Janeiro.

Campos, P. A., 1934. A cura radical e rápida da mí́ase pelo oxicianeto de mercúrio (processo Prado Moreira). Revta oto-lar. S Paulo 2(4): 275-278.

Canavan, W. P. N., 1936. Occurrence of intestinal and nasal myiasis in Oklahoma. I. Parasit. 22: 228-229.

Caréaga, A., 1886. Nuevo caso de myiasis. Gac. méd. Méx. 21(5): 89-94.

Carlyle, W. L., 1899. Protecting cows from flies. 16. a. Rep. Wis, agric. Exp. Stn: 92-96. (Res. em 2. a. Rep. Wis. agric. Exp. Stn: 105, 1904).

Carrazoni, J. A. \& F. R. Almazán, 1973. Miasis y parición en Chaco y Formosa. Gac. vet. B Aires 25(271): 23-26.

Carriere, B., 1980. New sterile screwworm strain saves livestock. Agric. Res. 29 (5): 14 .

Cary, C. A., 1934 (?). Screw-worm flies. A. Rep. St. Vet. Ala. (1933-34): 24-28.

Casco Muñoz, E. D., 1944. Un caso de myiasis perianal por Cochliomyia macellaria. Revta Med. Cienc. afin. 6(4): 212-214, il.

Causey, O. R., 1937. Notes on forms of myiasis. J. econ. Ent., 30(1): 39-40.

Cavassa, W. E., 1920. Un caso de miasis cutánea. Crón. méd., Lima 37: 262-264.

Cavassa, W. E., 1925. Idem. Ibid. 42: 102-103.

Cerna, J., 1893. Maggots in the nose. N. Y. med. J. 57(13): 363.

César, G., 1941. Crendices do Nordeste, 207 pp. Irmãos Pongetti Editores, Rio de Janeiro.

Chaddock, T. T., 1940. What to do about screw worms and distemper. Black Fox Mag. 24(2): 13, 15.

Chamberlain, W. F., 1962. Chemical sterilization of the screwworm. J. econ. Ent. 55: 240-248.

Chamberlain, W. F. \& C. C. Barrett, 1964. A comparison of the amounts of metapa required to sterilize the screwworm fly and the stable fly. Ibid. 57(2): 267-269.

Chamberlain, W. F. \& D. E. Hopkins, 1960. Effect of colchicine on screw- 
worm. Ibid 53(6): 1133-1134.

Chamberlain, W. F. \& D. E. Hopkins, 1962. Absorption and elimination of general chemical 4072 applied dermally to cattle. Ibid. 55(1): 86-88.

Chamberlain, W. F. \& D. E. Hopkins, 1978. Copulation of the secondary screwworm fly, Cochliomyia macellaria (F.), with the screwworm fly, Cochliomyia hominivorax (Coquerel). SWest Ent. 3(1): 59-61.

Chiodi, G., 1905. Sobre alguns casos de miasis en el hombre y sus complicaciones. Argent.-médic. 3: 153, figs.

Clark, C., 1955. I fight screw flies with used cylinder oil. Natl Fur News 27 (6): $21,28$.

Cláudio, A., 1923. Trovas e cantares capichabas. S. Monteiro \& Cia. Ltda., Rio de Janeiro.

Cobb, W. T., 1941. Beware of screwworms; signs of an epidemic. Coastal Cattleman 7(5): 26.

Cockerell, T. D. A., 1894. Notes from New Mexico. Insect Life 7: 210.

Codazzi Aguirre, J. A., 1923. Notas sobre miasis por Cochliomyia macellaria en el norte santafecino. 7. Reun. Soc. Patol. reg. Norte: 801, 1 fig.

Collum, O. F., 1934. Screw worms in man. Report of a case. J. med. Ass. Ga 23(10): 402.

Coluccio, F., 1948. Folklore de las Américas, primera antología. Prólogo de Augusto Raúl Cortázar, 468 pp. Buenos Aires.

Coluccio, F., 1950. Diccionario folklórico argentino. Con voces afines, comparaciones americanas y un apéndice sobre folkloristas e instituciones folklóricas del continente (2a. ed.), 503 pp., ilus. Librería "El Ateneo" Editorial, Buenos Aires.

Comer, M. C., 1927. Report of six unusual cases. SWest Med. 11: 308-313.

Conde Flores, E., 1903a. Larvas en las fosas nasales. Boln Hosps, Caracas 2(8): 212-214.

Conde Flores, E., 1903b. Larvas en el conducto auditivo externo. Ibid. 2(11): 303-304.

Conde Jahn, F., 1934. Un caso de otomiasis. Caracas méd. 1: 131, 133, 135-137.

Conil, P. A., 1878. Vide Lesbini et al., 1878.

Conil, P. A., 1879. Nouveau cas de myiasis observés dans la province de Córdoba (R. A.) et dans la République de Venezuela. Boln Acad. nac. Cienc. Córdoba 3(4): 296-326. (Também em Annls Sci. nat., Zool. (6) 10(6): 177-259, pls. 2-5, 1880; Periodico zool. argent. 3(2-3): 146-175, 1880; res. em Archs Zool. exp. gén. 9: 276-298, 1881).

Cook, A. H., 1940. Screwworms infest beaver in Texas. J. Mammal. 21(1): 93.

Coppedge, J. R., E. Ahrens, J. L. Goodenough, F. S. Guillot \& J. W. Snow, 1977. Field comparisons of liver and a new mixture as attractants for the screwworm fly. Envir. Ent. 6(1): 66-68.

Coppedge, J. R., E. H. Ahrens \& J. W. Snow, 1978. Swormlure-2 baited traps for detection of native screwworm flies. J. econ. Ent. 71(4): 573-575.

Coppedge, J. R., A. B. Broce, J. L. Goodenough, M. M. Crystal, F. H. Tannahill \& J. W. Snow, 1978. Preliminary evaluation of baits as a means of suppressing screworm populations. Folia ent. mex. 39-40: 193.

Coppedge, J. R., A. B. Broce, F. H. Tannahill, J. L. Goodenough, J. W. Snow \& M. M. Crystal, 1978. Development of a bait system for suppression of adult screwworms. J. econ. Ent. 71(3): 483-486.

Coppedge, J. R., H. E. Brown, J. L. Goodenough, F. H. Tannahil, J. W. Snow, H. D. Petersen \& H. C. Hoffmann, 1980. Field performance of a new formulation of the screwworm adult suppression system. Ibid 73(3): $411-414$.

Coppedge, J. R., H. E. Brown, J. W. Snow \& F. H. Tannahill, 1981. Bait stations for the suppression of screwworm populations. Ibid. 74: 168-172.

Coppedge, J. R., J. L. Goodenough, A. A. Broce, S. J. Wendell \& O. H. Graham, 1979. El sistema Swass y su uso en la reducción de poblaciones del gusano barrenador del ganado, Cochliomyia hominivorax. Folia ent. mex. 42: 55.

Coppedge, J. R. \& J. W. Snow, 1977. Seasonal response of screwworm adults to two attractants in subtropical Texas. SWest. Ent. 2(2): 57-61. 
Coppedge, J. R., J. P. Spencer, H. E. Brown, C. J. Whitten, J. W. Snow \& J. W. Wright, 1979. A new dye marking technique for the screwworm. J. med. Ent. 72(1): 40-42.

Coppedge, J. R., C. J. Whitten, F. H. Tannahill, H. E. Brown, J. W. Snow \& H. C. Hofmann, 1980. Investigation of a recurring screwworm problem in the municipality of Aldama, Tamaulipas, Mexico, $7 \mathrm{pp}$. Animal \& Plant Health Inspection Service, USDA, Washington, D. C.

Coquerel, C., 1858a. Des larves de diptères développées dans les sinus frontaux et les fosses nasales de l'homme à Cayenne. Archs gén. Méd. (5) 11: 513-528.

Coquerel, C., 1858b. Note sur des larves appartenant à une espèce nouvelle de diptère, (Lucilia hominivorax) développée dans les sinus frontaux de l'homme à Cayenne. Annls Soc. ent. Fr. (3) 6: 171-176, pl. 2 (i.e., 4), n. ${ }^{\circ}$ II.

Coquerel, C., 1859a. Sur un nouveau cas de mort produit par le développement de larves de la Lucilia hominivorax dans le pharynx, description de la larve de ce diptère. Archs gén. Méd. (5) 13: 685-691.

Coquerel, C., 1859b. Nouveau cas de mort produit par la Lucilia hominivorax et description de la larve de ce diptère. Annls Soc. ent. Fr. (3) 7: 234-237, pl. 6, fig. 1.

Coquillett, D. W., 1900. Report on a collection of dipterous insects from Puerto Rico. Proc. U. S. natl Mus. 22(1198): 255.

Cordeiro, A., 1958. Considerações gerais sobre miiases. Revta milit. Remonta Vet. 18(1-4): 49-50.

Cornejo, A. \& S. Mazza, 1939. Consideraciones sobre miasis observadas en la provincia de Salta. Publnes Misión Estud. Patol. reg. argent. Jujuy 41: $78-86,12$ figs.

Corrêa, C., 1928. Myase vulvar. Brasil-méd. 42(41): 1166.

Corrêa, C., 1929. Ueber Myiasis vulvo-vaginalis. Zentbl. Gynäk. 53(21): 1325 1327, ilus.

Corrêa, O., 1950. Miiase cutânea em galinha. Revta agron., Porto Alegre 14: 136 , ilus.

Corrêa, O., 1954. Contribuição ao estudo da profilaxia das miases cutâneas pelo emprego do toxafeno, $61 \mathrm{pp}$,, ilus. Tese, Universidade do Rio Grande do Sul, Porto Alegre.

Corrêa, O., 1956a. Miiases. I-III. Granja, Porto Alegre 12(11): 63-65; (111112): 73-74; (113): 63-64.

Corrêa, O., 1956b. Contribuição ao estudo da profilaxia das miiases cutâneas pelo emprêgo do toxafeno. Bolm Dir. Prod. anim. Rio Grande Sul 13: $35-43$.

Corrêa, O., 1956c. Toxafeno contra as bicheiras (Resumo da tese apresentada à Escola de Agronomia e Veterinária da URS, para inscrição ao concurso da cadeira de Higiene Veterinária e Rural sobre a profilaxia das miíases cutâneas (bicheiras)). Mundo agríc., Porto Alegre 5(1): 21-22.

Cortelezzi, E. D., 1919. Dos casos de miasis ocasionadas por Chrysomyia macellaria. Semana méd., B. Aires 26: 334.

Costa, J. D. M. H., 1957. Sobre um caso de miíase de localização anômala. Revta méd. Sul Minas 3(1): 59-67.

Costa, L. A. C. da, 1941. Sobre três casos de míase da vulva. Anais bras. Ginec. 12(3): 200-204, ilus.

Costa, (-) S., 1881. Breves considerações sobre a myasis das fossas nazaes, seguidas de uma observação da mesma moléstia, colhida no Rio de Janeiro. União méd. 1(5): 212-224.

Costello, W. G. \& H. M. Taylor, 1975. Mathematical models of the sterile male technique of insect control, pp. 318-359, in A. Charnes \& W. Lynn, eds., Lecture notes in biomathematics. Vol. 5. Mathematical analysis of decision problems in ecology. Proceedings of the NATO Conference, Istanbul, Turkey, July 9-13, 1973, viii + 421 pp., ilus., mapa. SpringerVerlag, Berlin \& New York.

Courtis, B., 1927. Miasis del saco lagrimal. Revta Cienc. med., B. Aires 10: 89-91. (Também em Semana méd., B. Aires 34(21): 1307-1309, 2 figs.). 
Cricco, J. J., 1921. Miasis. Tesis, Facultad de Medicina de Buenos Aires.

Crystal, M. M., 1963. The induction of sexual sterility in the screwworm fly by antimetabolites and alkylating agents. J. econ. Ent. 56: 468-473.

Crystal, M. M., 1964a. Observations on the role of light, temperature, age, and sex in the response of screw-worm flies to attractants. Ibid. 57(3): 324-325.

Crystal, M. M., 1964b. Antifertility effects of anthelminthics in insects. Ibid. 57(4): 606-607.

Crystal, M. M., 1964c. Chemosterilization of screw-worm flies by tetramine and thiotepa. Folia ent. mex. 7-8: 66-67.

Crystal, M. M., 1964d. Insect fertility: Inhibition by folic acid derivatives. Science, N. Y. 144: 308-309.

Crystal, M. M., 1964e. Chemosterilant efficiency of bis (1-Azyiridinyl) Phosphinyl Carbamates in screw-worm flies. J. econ. Ent. 57(5): 726-731.

Crystal, M. M., 1965a. Sexual sterilization of insects by aerosol administration of alkylating agents. Ibid. 58(4): 678-680.

Crystal, M. M., 1965b. First efficient chemosterilant against screwworm flies (Diptera: Calliphoridae). J. med. Ent. 2(3): 317-319.

Crystal, M. M., 1966a. Some structure-activity relationships among aziridinyl antifertility agents in screw-worm flies. J. econ. Ent. 59(3): 577-580.

Crystal, M. M., 1966b. Sexual sterilization of screw-worm flies by a peroral chemosterilant: Quantitative aspects and relation to pretreatment starvation. Ibid. 59(3): 580-585.

Crystal, M. M., 1967a. Chemosterilant effect of tetramine enhanced in screwworm flies exposed to extraoptimal temperatures. Ibid. 60(3): 880-881.

Crystal, M. M., 1967b. Carbon dioxide anesthetics of untreated and chemosterilant-treated screw-worm flies, Cochliomyia hominivorax (Coquerel) (Diptera: Calliphoridae). J. med. Ent. 4(4): 415-418.

Crystal, M. M., 1967c. Reproductive behavior of laboratory-reared screw-worm flies (Diptera: Calliphoridae). Ibid. 4(4): 443-450.

Crystal, M. M., 1967d. Chemical structure and sterilizing activity of N,N'alkylene bis (I-aziridine carboxamide) in screw-worms flies. J. econ. Ent. 60(4): 1005-1007.

Crystal, M. M., 1967d. Longevity of screw-worm flies, Cochliomyia hominivorax (Coquerel) (Diptera: Calliphoridae): Effect of sex and grouping. Ibid. 4 (4): $\quad 479-482$.

Crystal, M. M., 1968a. Sexual sterilization of screw-worm flies by N, N'-tetramethylene-bis-(1-aziridinocarboxamide): Influence of route of administration. J. econ. Ent. 61(1): 134-139.

Crystal, M. M., 1968b. Sexual sterilization of screw-worm flies by orally administered 1 [bis(1-aziridinyl) phosphinyl]-3(3,4-dichlorophenyl) urea: Effects of feeding times and concentration of vehicle. Ibid. 61(1): 140-142.

Crystal, M. M., 1968c. Sulfonic acid esters as chemosterilants of screw-worm flies with particular reference to methanediol dimethanesulfonate. Ibid. 61(2): 446-449.

Crystal, M. M., 1968d. Chemosterilization of screw-worm flies, Cochliomyia hominivorax (Coquerel) (Diptera: Calliphoridae): Influence of age of treatment and mating, effects on survival, and transfer of chemosterilant by contamination. J. med. Ent. 5(4): 439-445.

Crystal, M. M., 1969a. Chemosterilant-induced increase in mating ability of male screw-worm flies (Diptera: Calliphoridae). Ibid. 6(1): 90-91.

Crystal, M. M., 1969b. Sexual sterilizations of screw-worm flies: Reliability of the chemosterilant technique. J. econ. Ent. 62(1): 136-139.

Crystal, M. M., 1969c. Changes in susceptibility of screw-worm flies to the chemosterilant N, N'-tetramethylene bis (1-aziridinecarboxamide), with time of administration. Ibid. 62(1): 275-276.

Crystal, M. M., 1970a. Effects of delayed fertilization in screw-worm flies on induction of dominant lethal mutations by $\mathrm{N}, \mathrm{N}$-tetramethylene bis (1-aziridinecarboxamide). Ann. ent. Soc. Am. 63(1): 71-74.

Crystal, M. M., 1970b. Vanadium compounds as inhibitors of reproduction 
of the screw-worm fly. J. econ. Ent. 63(1): 321-323.

Crystal, M. M., 1970c. Thiosemicarbazones, a new category of antifertility compounds for screw-worm flies. Ibid. 63(2): 491-492.

Crystal, M. M., 1970d. Size and weight of pupae and adults of laboratory-reared screw-worm flies. Ibid. 63(2): 551-554.

Crystal, M. M., 1970e. Dose-response curves for dominant lethal mutations induced in the sperm and oöcytes of screw-worm flies by N, N'-tetramethylene bis (1-aziridinecarboxamide). Ann. ent. Soc. Am. 63(5): 13691372.

Crystal, M. M., 1970f. Antifertility effects of inorganic iodine in screw-worm flies. J. econ. Ent. 63(6): 1851-1853.

Crystal, M. M., 1971a. Sexual sterilization of screw-worm flies by N, N'-tetramethylene bis (1-aziridinecarboxamide): Further studies on influence of route of administration. J. med. Ent. 8(3): 304-306.

Crystal, M. M., 1971b. Sexual sterilization of screwworm flies: Further studies of reliability of the chemosterilant technique. Ibid. 8(5): 549-551.

Crystal, M. M., 1971c. Chemosterilization of screwworm flies with negligible residues for release in nature. Ibid. 8(6): 696-699.

Crystal, M. M., 1971d. Diel periodicity of mating in laboratory adapted screwworm flies relative to photoperiod. Ibid. 8(6): 747-748.

Crystal, M. M., 1972. Chemosterilization of male screwworm flies by immersion: Changes in susceptibility with time of treatment, permanence of sterility, and effect of treatment on survival. Ibid. 9(6): 509-510.

Crystal, M. M., 1973a. Chemosterilization of male screwworm flies by immersion: Changes in susceptibility with time of treatment, permanence of sterility and effect of treatment on survival. Folia ent. mex. 25-26: 127.

Crystal, M. M., 1973b. Chemosterilization of screwworm flies: Modification of action by temperature. Envir. Ent. 2(1): 145-147.

Crystal, M. M., 1973c. Chemosterilant-induced decrease in size of testes of the adult screwworms. J. econ. Ent. 66(2): 424-426.

Crystal, M. M., 1973d. Toxicity of some herbicides to the screw-worm. Ibid. 66(2): 529.

Crystal, M. M., 1973e. Toxicity of some herbicides to the screwworm, p. 529, in S. Nilsson, ed., Bulletins from the Ecological Research Committee NFR (Statens Naturvetenskapliga Forkningsrad) n. 18. Scandinavian Aerobiology Symposium, Sweden, April 1972, 222 pp., ilus., mapa. NFR Ecological Research Committee, Stockholm.

Crystal, M. M., 1977. Tethered flight of screwworm flies, Cochliomyia hominivorax: effect of age and sex. Ann. ent. Soc. Am. 70(5): 702-706.

Crystal, M. M., 1978a. Diflubenzuron-induced decrease of egg hatch of screwworm (Diptera: Calliphoridae). J. med. Ent. 15(1): 52-56.

Crystal, M. M., 1978b. Screwworm flies (Diptera: Calliphoridae): Influence of sex ratio on primiparous fertility of caged populations. Ibid. 15(1): 85-86.

Crystal, M. M., 1979. Sterilization of screwworm flies (Diptera: Calliphoridae) with gamma rays: Restudy after two decades. Ibid. 15(2): 103-108.

Crystal, M. M. \& F. S. Guillot, 1978. Flight of tethered screwworm flies in relation to ovarian development. Ann. ent. Soc. Am. 71(2): 243-246.

Crystal, M. M. \& L. E. LaChance, 1963. The modification of reproduction in insects treated with alkylating agents. I. Inhibition of ovarian growth and egg production and hatchability. Biol. Bull. 125(2): 270-279.

Crystal, M. M. \& H. H. Meyners, 1965. Influence of mating on oviposition by screw-worm flies (Diptera: Calliphoridae). J. med. Ent. 12(3): 214-216.

Crystal, M. M. \& R. Ramirez, 1975a. Screwworm flies for sterile-male release: Laboratory tests of the quality of candidate strains. Ibid. 12(4): 418-422.

Crystal, M. M. \& R. Ramirez, 1975b. Chemosterilization of screwworms (Diptera: Calliphoridae): Influence of age at time of treatment on sterility and longevity. Ibid. 12(4): 423-425.

Crystal, M. M. \& C. J. Whiten, 1976. Screwworm flies for sterile-male releases: Laboratory observations of the quality of newer candidate strains. Ann. ent. Soc. Am. 69(4): 621-624. 
Cueller, C. B. \& D. M. Brinklow, 1973. The screwworm strikes back. Nature, Lond. 242(5399): 493-494.

Cushing, E. C., 1939. Some new developments relating to the control of screwworms. Proc. ent. Soc. Wash. 41(7): 227.

Cushing, E. C., 1941a. Catching up with the screwworm. Fm Ranch 60(2): 46.

Cushing, E. C., 1941b. Federal and state agencies cooperating in combating screwworm in Texas. Cattleman 28(6): 57-58, mapa.

Cushing, E. C., 1941c. Severe screwworm outbreak imminent. SWest. Sheep Goat Rais. 11(8): 29.

Cushing, E. C., 1969. The great insect impostor. Cattleman 56(6): 25-28, $158-160$.

Cushing, E. C. W W. L. Barrett, Jr., 1943. Stop losses by stopping screwworms. Many outbreaks can be prevented by halting shipments of infested livestock - most satisfactory remedy yet found in Smear-62 - fly migration starts May 1. Am. Hereford J. 33(10): 62-63.

Cushing, E. C. \& D. G. Hall, Jr., 1937. Some morphological differences between the screwworm fly Cochliomyia americana C. and P. and other closely allied or similar species in North America (Diptera: Calliphoridae). Proc. ent. Soc. Wash. 39(7): 195-200, pls.

Cushing, E. C. \& H. E. Parish, 1938. Seasonal variation in the abundance of Cochliomyia spp., Phormia spp. and other in Menard County, Tex. J. econ. Ent. 31(6): 764-769.

Cushing, E. C. \& D. C. Parman, 1942. The screwworm and blowfly problem. Yb. Agric. USDA 1942: 313-322, ilus. (Também em Cattleman 30(2): 19-21, 46-47, mapa, ilus., 1943).

Cushing, E. C., D. C. Parman \& W. L. Barrett, Jr., 1941. Preventing losses from screwworms in Texas. SWest. Sheep Goat Rais. 11(4): 6, ilus.

Cushing, E. C. \& W. S. Patton, 1933. Studies on the higher Diptera of medical and veterinary importance. Cochliomyia americana sp. nov., the screwworm fly of the New World. Ann. trop. Med. Parasit. 27(4): 539-551, 7 figs.

Dalrymple, W. H., 1907. The screw-worm fly. Am. vet. Rec. 30(11): 13511353.

Dameron, W. H. \& O. G. Babcock, 1937. Screwworm and fly repellent study. 49. a. Rep. Tex. agric. Exp. Stn 1936: 274.

Damonte, E. R., 1945. Miasis: Agusanamiento. Res, B. Aires 13: 17.720.

Darden, E. B., Jr., E. Maeyens \& R. C. Bushland, 1954. A gammaray source for sterilizing insects. Nucleonics 12(10): 60-62.

Davis, J. J., 1942. Screwworm is harmful to stock; five suggestions given to prevent. Indiana Fmr's Guide 98(6): 10.

Davis, L. L, 1923. Myiasis of the ear. U. S. nav. med. Bull. 19(3): 345-348.

Davis, R. B., 1967. Contour maps of infestation incidence useful in epizootology of screw-worms, Cochliomyia hominivorax (Coquerel). Ecology 48(6): 985-991, 7 figs.

Davis, R. B. \& M. Camino, 1968. Life cycle of the screw-worm reared in outdoor cages near Veracruz City, Mexico. J. econ. Ent. 61(3): 824827.

Davis, R. B., B. G. Hightower, D. A. Alley, J. E. Turner \& E. Lopez, 1968. Releases of sterile screw-worm flies in Northern Mexico, measured by recovery of sterile egg masses. Ecology 61(1): 96-101.

Davis, R. B., R. W. Pratt, E. Lopez \& J. P. Turner, 1967. Oviposition by screw-worm flies in infested Mexican burros. Ibid. 60(3): 690-691.

Davis, R. E., 1940. Controlling screw worms. Coastal Cattleman 6(5): 25.

DeBord, B. A., 1959. Rapid extermination of nasal myiasis. Laryngoscope, St Louis 69(5): 543-544. (Também em Trans. Am. Laryngol. Rhinol. Otol. Soc. : 523-525).

Deda, C., 1967. Brefaias e burundangas do folclore sergipano, 270 pp. Livraria Regina, Aracaju.

Degrugillier, M. \&. G. Grosz, 1981. Effects of female accessory gland ablation on fertility of screwworms (Cochliomyia hominivorax), stable flies (Stomoxys calcitrans) and face flies (Musca autumnalis). Ann. 
ent. Soc. Am. 74(2): 217-221.

Del Ponte, E., 1931. Nota sobre Cochliomyia macellaria (Fabr.). Actas Congr. int. Biol. Montev. 5: 1299-1301. (Supl. a Archos Soc. Biol. Miontev.).

Del Ponte, E., 1938. Las especies argentinas del género Cochliomyia T. T. (Dipt. Musc.). Revta Ent., Rio de J. 8(3-4): 273-281, 2 figs.

Demichelis, L. A., 1949. Miasis de la piel de los animales (gusaneros o bicheras). Revta mens. B. A. P. 32: 22-23.

DeMilo, A. B. \& M. M. Crystal, 1972. Chemosterilants against screwworm flies. 3. J. econ. Ent. 65(2): 594-595.

Deonier, C. C., 1939. Responses of the blowfly, Cochliomyia americana C. \& P., and Phormia regina Meigen, to stimulations of the tarsal chemoreceptors. Ann. ent. Soc. Am. 32(3): 526-532.

Deonier, C. C., 1940. Carcass temperatures and their relation to winter blowfly populations and activity in the Southwest. J. econ. Ent. 33(1): 166-170.

Deonier, C. C., 1942. Seasonal abundance and distribution of certain blowflies in southern Arizona and their economic importance. Ibid. 35(1): 65-70.

Deonier, C. C., 1945. Overwintering and dispersion of Cochliomyia americana in Arizona. J. econ. Ent. 38(1): 90-95.

Deonier, C. C., 1946. Population studies on Cochliomyia americana in Arizona. J. Kans. ent. Soc. 19(1): 26-29.

Depied, (-), 1897. La "Lucilia hominivorax" au Tonkin. Archs Méd. navale 67: 127.

Deterling, D., 1962a. October action month for screwworm program. Cattleman 49(6): 20, 22, mapa.

Deterling, D., 1962b. Screwworm eradication program enters crucial period. Ibid. 49(7): 77.

Deterling, D., 1963a. Foundation hears future plans on screwworm eradication program. Ibid. 49(8): 34.

Deterling, D., 1963b. Screwworm program observes lst anniversary. Ibid. 49(9): 26-27, mapa.

Deterling, D., 1964a. Screwworm cases up. Ibid. 51(1): 16.

Deterling, D., 1964b. Screwworm buildup causes concern, but no panic. Ibid. 51(6): 12-13, mapa.

Deterling, D., 1964c. Screwworm eradication in the southwest year of program. Ibid. 50(8): 37, 58, 60 .

Deterling, D., 1964d. Success of screwwarm progtam depends on you. Ibid. 50(12): 70, 118.

Deterling, D., 1964e. Screwworm threatens again. Ibid. 50(11): 22, 24.

Deterling, D., 1965. Screwworm eradication has changed Southwest's sheep industry. Natl Wool Grow. 55(7): 12-14, 25.

DeVaney, J. A., G. N. Eddy, E. M. Ellis \& R. Harrington Jr., 1973. Attractancy of inoculated and incubated bovine blood fractions to screwworm flies (Diptera: Calliphoridae): Role of bacteria. J. med. Ent. 10(6): 591-595.

DeVaney, J. A., G. W. Eddy, B. D. Handke \& E. Lopez, 1970. Olfactory responses of the adult screw-worm after removal of the antennae, mouthparts, tarsi, and legs. J. econ. Ent. 63(6): 1816-1819.

DeVaney, J. A., G. W. Eddy, E. Lopez \& B. D. Handke, 1971. Response of three colonies of screwworm flies to proteins and sugars in a multiple-choice olfactometer. Ibid. 64(4): 809-812.

DeVaney, J. A. \& J. J. Garcia, 1975. Longevity, oviposition, and fertility of seasonal strains of the screwworm, Cochliomyia hominivorax (Diptera: Calliphoridae). J. med. Ent. 12(5): 511-513.

Diamant, G., 1963. Screwworm eradication in southeastern United States. Am. J. publ. Hlth 53(1): 22-26.

Diaz, J. J., 1875. Curación por el cloroformo de gusanos en las fosas nasales. Revta méd.-quir., B. Aires 12(6): 88-90.

Diaz R., A. R., 1946. Sobre miasis producida por la mosca azul. Agricultor Norte 30(4): 94-96.

Diógenes, N., 1924. Brasil virgem, 218 pp. Recife. 
Dixon, E. B., 1962. Wing variations found in screwworm flies and three other Calliphoridae. Ann. ent. Soc. Am. 55: 210-212.

Dixon, J. H., 1958. Screwworms can take heavy toll when not controlled. Sheep Goat Rais. Mag. 38(11): 14-16.

Donoso Barros, R., 1945. Consideraciones epidemiologicas sobre las miasis humanas. Revta Est. méd. 2(2): 49.

Donoso Barros, R., 1947. Myiasis humana en Chile - Consideraciones clínicas y epidemiológicas. Revta chil. Hig. Med. prev. 9(1): 3-40, pls.

Dove, W. E., 1935a. Screw worm control. Circ. Bur. Ent. Plant Quar. U. S. Dep. Agric. E-356: 1-8, ilus.

Dove, W. E., $1935 \mathrm{~b}$. The screw worm fly and the Gulf Coast tick. Coastal Cattleman 1(7): 4.

Dove, W. E., 1936a. Kill Coast tick and prevent screw worms. Cattleman 23(5): $8,10$.

Dove, W. E., 1936b. Screwworm (Cochliomyia americana C. \& P.). General. Insect Pest Surv. Bull. 16(6): 307.

Dove, W. E., 1936c. Idem. United States. Ibid. 16(7): 353, 389.

Dove, W. E., 1937a. Myiasis of man. J. econ. Ent. 30(1): 29-39.

Dove, W. E., 1937b. Screwworm. Insect Pest Surv. Bull. 16(10): 532-533.

Dove, W. E., 1937c. Screwworm, Cochliomyia americana C. \& P. United States. Ibid. 17(2): 64-65.

Dove, W. E., 1937d. Screwworm, Cochliomyia americana C. and P. Ibid. 17(7): 260, 376-377.

Dove, W. E., 1937e. Idem. United States. Ibid. 18(3): 106-107.

Dove, W. E., 1938. Screwworm control. Leafl. U. S. Dep. Agric. 162: 1-6, ilus.

Dove, W. E., 1943a. Idem. Ibid. 162: 1-6, ilus.

Dove, W. E., 1943b. Stockmen are warned of screwworm infestations. Fmr's Exch. 17(31): 6.

Dove, W. E., 1944. Para evitar los gusanos en las heridas de los animales. Chacra 14: 12-13, 77, ilus.

Dove, W. E., 1948. Improved smear kills more screwworms. Progve Fmr, Miss.-Ark.-Louis. Ed. 63(11): 110, ilus.

Dove, W. E. \& F. C. Bishopp, 1936. The screwworm situation in 1935. J. econ. Ent. 29: 1076-1085, ilus.

Dove, W. E. \& D. C. Parman, 1935. Screw worms in the southeastern states. Ibid. 28(5): 765-772, figs. 111-114.

Dove, W. E., C. F. Stiles \& D. C. Parman, 1937. Screwworm (Cochliomyia americana C. \& P.). Insect Pest Surv. Bull. 17(6): 328-329.

Doyle, K., 1976. Screw-worm control in North America. Anim. Qt. 5: 8-13.

Drake, C. J. \& F. Andre, 1936. Observations on screw-worm outbreaks and myiasis in Iowa. Iowa Dep. Agric. Bull. 79: 1-8.

Drake, C. J. \& G. C. Decker, 1943. Controlling screwworms. Southern states' pest of livestock has been found this year southern Iowa. Fm Sci. Reptr 4(3): 8-9, ilus.

Drummond, R. O., 1958. Laboratory screening tests of animal systemic insecticides. J. econ. Ent. 51: 425-427.

Drummond, R. O., 1960. Preliminary evaluation of animal systemic insecticides. Ibid. 53(6): 1125-1127.

Drummond, R. O., 1961. Compounds screened as animal systemic insecticides at Kerrville, Texas, 1953-1959. USDA Res. Serv. Agric. Res. Serv. 33-64: $1-50$.

Drummond, R. O., 1970. Materials screened as animal systemic insecticides at Kerrville, Texas, 1960-1967. USDA Prod. Res. Rep. 116: 1-46.

Drummond, R. O., 1976. Materials screened as animal systemic insecticides at Kerrville, Texas, 1967-1973. USDA Res. Serv. Agric. Res. Sta.-S-101: 1-57.

Drummond, R. O., 1978. Myiasis-producing flies, in R. A. Bram, ed., Surveillance and collection of arthropods of veterinary importance, pp. 89-96. US Dep. Agric., Agric. Handb. 518.

Drummond, R. O.,S. E. Ernst, C. C. Barrett \& O. H. Graham, 1966. Sprays 
and dips of Shell compound 4072 to control Boophilus ticks and larvae of the screwworm on cattle. J. econ. Ent. 59(2): 395-400.

Drummond, R. O., S. E. Ernst, J. L. Trevino \& O. H. Graham, 1967. Control of larvae of the screwworm in cattle with insecticidal sprays. Ibid. 60(1): 199-200.

Dunbar, D. C., 1957. Control of the screw worm fly by atomic radiation. SWest. Vet. 9(2): 50-52.

Dunn, L. H., 1918. Studies on the screw worm fly, Chrysomyia macellaria Fabricius in Panama. J. Parasit. 4(3): 111-121.

Dunn, L. H., 1919. Studies on the screw-worm fly, Chrysomyia macellaria in Panama. Proc. med. Ass. Isthm. Canal Zone 19(2): 33-66.

Eaves, J. F., 1892. Lucilia macellaria, "Texas screw worm". Daniel's med. J. $7(7): 247-248$.

Eddy, G. W., 1951. Toxicity of some organic insecticides to screwworm larvae. J. econ. Ent. 44(2): 254.

Eddy, G. W. \& R. C. Bushland, 1957. Screwworms that affect livestock. Yb. Agric. US Dep. Agric. 1956: 172-175.

Eddy, G. W. \& J. A. DeVaney, 1970. A brief statistical review of the United States-Mexico screwworm eradication program. Bull. ent. Soc. Am. 16: 159-164.

Eddy, G. W., J. A. DeVaney \& B. D. Handke, 1975. Response of the adult screwworm (Diptera: Calliphoridae) to bacterial-inoculated and incubated bovine blood in olfactometer and oviposition tests. J. med. Ent. 12(3): 379-381.

Eddy, G. W., J. A. DeVaney, B. D. Handke \& E. Lopez, 1975. Attractants for the screwworm: Irradiation effects on bacteria-inoculated media. Ann. ent. Soc. Am. 68(2): 269-270.

Eddy, G. W. \& O. H. Graham, 1950. An improved laboratory method for testing materials as screwworm larvicides. J. econ. Ent. 43: 558-559.

Eddy, G. W., W. S. McGregor, D.E. Hopkins \& J. M. Dreiss, 1954. Effects on some insects of the blood and manure of cattle fed certain chlorinated hydrocarbon insecticides. J. econ. Ent. 47(1): 35-38.

Edson, L. J., 1978. Chemical communication used by insects for habitat selection and mate choice, pp. 67-82, in P. H. Richardson, q. v.

Eerde, E., 1977. Checkmate for the screwworm. Mex.-Am. Rev. 45(2): 4-9.

Emiliani, C. M. \& F. P. Farjat, 1937. Miasis de los senos craneofaciales (Presentacion de enfermo). Revta Asoc. méd. argent. 51: 320.

Emmel, M. V., 1937. Miasis de los senos craneofaciales. Ibid. 51: 320.

Emmel, M. W., 1945a. The primary screw-worm fly, Cochliomyia americana C. and P., as a vector of joint ill in calves. J. Am. vet. med. Ass. 106: 223.

Emmel, M. W., 1945b. Screwworm blamed for swollen joints in Florida calves. West. Livestk J. 23: 6.

Emmel, M. W., 1945c. "Swollen joints" in range calves. Fla Agric. Exp. Stn Bull. 407: 4-23.

Emmel, M. W., 1945d. Idem. J. Am. vet. Ass. 106(817): 225-226.

Emmel, M. W., 1950. Idem. Fla Agric. Exp. Stn Circ. S-23: 1-4.

Emmett, J. \& R. E. Siverly, 1951. Human myiasis from the screwworm fly in Arizona. Ariz. Med. 8(9): 57-60.

d'Empaire, A., 1910. Notas clínicas. Larvas en las fosas nasales. La Benef., Maracaibo 1910. ?

Ernst, A., 1880. Noticia sobre las larvas de un insecto diptero en las fosas nasales de un leproso (?).

Eppele, P. M., 1960. Screw-worm eradication program. Insect Condit. Louisiana 2(1959): 36-37.

Espinoza B., A., 1974. Métodos para colectar gusano barrenador del ganado, Cochliomyia hominivorax (Coquerel, 1858) en la costa del Pacífico de la República Mexicana. Folia ent. mex. 29: 74-75.

Espinoza B., A., 1975. Colecta del gusano barrenador del ganado, Cochliomyia hominivorax (Coquerel) en la costa del Pacífico de la República Mexicana. Ibid. 33: 65-66. 
Esslinger, J. H., 1955a. A clinical study of the effects of the American screwworm, Callitroga hominivorax (Coquerel) on Guinea pigs, $47 \mathrm{pp}$. MS Thesis, Rice Institute, Houston.

Esslinger, J. H., 1955b. Studies on the clinical effects of the screw-worm, Callitroga hominivorax (Coquerel) on Guinea pigs. J. Parasit. 41(6, Suppl.): 33.

Esslinger, J. H., 1958a. Host-parasite relations of the screwworm Callitroga hominivorax, $126 \mathrm{pp}$. $\mathrm{PhD}$ Thesis, Rice Institute, Houston.

Esslinger, J. H., 1958b. Effects of the screw-worm on Guinea pigs. J. Parasit. 44: 201-209.

Esslinger, J. H. \& A. C. Chandler, 1960. Studies on the properties of the metabolic products of the screw-worm Callitroga hominivorax (Coquerel). Expl Parasit. 8(6): 527-538, pl., ilus.

Fabricius, J. C., 1775. Systema entomologiae, sistens insectorum classes, ordines, species, adiectis synonymis, locis, descriptionibus, observationibus, 832 pp. Flensborgi et Lipsiae.

Faria, F. B. de, 1937. Do mercurio na miase. Publções méd. 29: 30-35.

Faria, J. S., 1945. Míase vulvar. Bolm Sanat. S Lucas 6(8): 126-128.

Felch, R. E., 1973. Winter weather assists screwworm program. US Environ. Data Serv., Wkly Weather Crop Bull., Jan. 15: 12.

Fenton, R. K., 1961. The screw-worm in the Bahamas. Vet. Rec. 73(4): $75-76,77$.

Fernandez, J. V. \& A. Marciano, 1944. Miasis cutánea por larva de Cochliomyia hominivorax (Coquerel), 1858. Prensa méd. argent. 31: 26532656, 8 figs.

Fernández Soto, E., 1916. Miasis nasal. Revta Med. Cirug. Habana 21(9): 185-195.

Ferrari, A., 1903. Um caso de myiasis e tinha favosa em uma creança. Brasil-méd. 17(22): 216-217.

Ferrari, A., 1939. Berne e myases. Ibid. 53(32): 793-794.

Ferrari, A., 1948. Os tratamentos clinicos das miases. Ibid. 62(49-52): 428-429.

Fidler, C. E., 1943. Early discovery of screw worm fly saves livestock. Ill. agric. Ass. Rec. 21(9): 13.

Finch, F. H., 1940. Screw worms and the new remedies in use against them. Cattleman 27(1): 37, 40, ilus.

Finch, F. H., 1941. F. H. Finch writes on screw worms in Argentina. Fla. Cattleman 5(5): 23.

Firor, J. W., 1935. The screw-worm menace. Cty Gentl. 105(2): 81.

Firor, J. W., 1936. Losses from screwworms. Ibid. 106(7): 73.

Flanery, C. C., 1942. Screw worm in livestock. Rep. Dep. Agric. Tenn. 1939-42: 140-141.

Flemings, M. B., 1959. Blowfly myiasis in man, report of two cases. US Armed Forces med. J. 10(3): 297-303.

Fletcher, L. W., 1966. Two genetic markers for larvae of the screw-worm fly. J. econ. Ent. 59(4): 877-880, 2 figs.

Fletcher, L. W., 1970. Abdominal and genitalic homologies in the screw-worm, Cochliomyia hominivorax (Diptera, Calliphoridae), established by a genetic marker. Ann. ent. Soc. Am. 63(2): 490-495.

Fletcher, L. W., H. V. Claborn, J. P. Turner \& E. Lopez, 1968. Difference in response of two strains of screw-worm flies to the male pheromone. Ibid. 61(5): 1386-1388.

Fletcher, L. W., J. J. O'Grady, H. V. Claborn \& O. H. Graham, 1966. A pheromone from male screw-worm flies. Ibid. 59: 142-143.

Fletcher, L. W. \& J. P. Turner, 1970. Selection for mating aggressiveness in female screw-worms. J. econ. Ent. 63(5): 1611-1612.

Fletcher, L. W. \& J. P. Turner, 1973. Response of female screwworm flies to a selected odor. Ann. ent. Soc. Am. 66(1): 84-85.

Fletcher, L. W., J. P. Turner \& C. N. Husman, 1973. Surface temperature as factor in selection of ovipositional sites by three strains of the screwworm. I. econ. Ent. 66: 422-423.

Flitters, N. E. \& C. A. Benschotter, 1968. Survival of screwworm pupae 
exposed of simulated winter temperatures from selected sites in Texas. Ann. ent. Soc. Am. 61(1): 65-67.

Floch, H. \& E. Abonnenc, 1942. Myiases humaines en Guyane française. Cochliomyia hominivorax et Cochliomyia macellaria. Publ. Inst. Pasteur Guyane franç. 46: 1-4.

Florida Livestock Board \& US Department of Agriculture. Screworm Eradication Program, 1958a. 2 1/2 billion sterile flies battle screwworm menace. Fla Inf. Off. illus. Bull. 1: 1-8.

Florida Livestock Board \& US Department of Agriculture. Screwworm Eradication Program, 1958b. Field reports and surveys key to final screwworm eradication. Ibid. 2: 1-6.

Foster, H., 1897. Report of a case of two hundred and seven screw-worms taken from the nose. Laryngoscope, St Louis 3(6): 341-342.

Foster, H., 1900. Removal of thirty-five screw-worms from the nose. Med. Rec., N. Y. 58(25): 975.

Fox, I. \& L. Galindo, 1962. Human cutaneous myiasis due to the primary screwworm, Callitroga hominivorax (Coquerel) in Puerto Rico. Am. J. trop. Med. Hyg. 11(1): 96-97, ilus.

Fox, I., A. Hurtado de Mendoza, A. Ortiz, R. P. Belihar \& R. I. Fox, 1965. Human hominivorax myiasis in Puerto Rico. Boln Asoc. méd. Puerto Rico 57: 409-416.

Fox, I., A. Hurtado de Mendonza, A. Ortiz, R. P. Belihar \& C. J. Lee, 1965. Myiasis in Puerto Rico. US Publ. Hlth Serv. Mortality Wkly Rep. 14(47): 402-403, 408.

Fraiha Neto, H., J. B. C. Azevedo \& J. V. C. Azevedo, 1978. Míase gengival por Cochliomyia hominivorax (Coquęrel) 1858 (Diptera, Calliphoridae). Comunicação de dois casos humanos no Estado do Pará, Brasil, p. 389, in Resumos dos Temas-livres, XIV Congr. Soc. Bras. Med. Trop. \& IH Congr. Soc. Bras. Parasit. Editora Universitária, Univer. sidade Federal da Paraíba.

Fraiha, H., J. B. C. de Azevedo \& J. V. C. de Azevedo, 1979. Miíases humanas na Amazônia - I: Miíase gengival por Cochliomyia hominivorax (Coquerel) 1858 (Diptera, Caliphoridae). Comunicação de 2 casos humanos no Estado do Pará, Brasil. Revta FSESP 24(2): 31-34, figs.

Francis, M., 1889. The "screw-worm" and methods of preventing its attacks. 1. a. Rep. Tex. agric. Exp. Stn 1888: 45-49.

Francis, M., 1890a. The screw-worm. Bull. Tex. agric. Exp. Stn 12: 21-25, 8 figs.

Francis, M., 1890b. Idem. Am. vet. Rev. 14: 534-537.

Francis, M., 1890c. Idem. Orange Judd Fmr 8(20): 309.

Francis, M., 1891a. Idem. J. comp. Med. vet. Archs 12(1): 16-20, 8 figs.

Francis, M., 1891b. The screw-worm again. Insect Life 3(9-10): 362.

Frantzius, A. von, 1868. Ueber das Vorkommen von Fliegenlarven in der Nasenhöhle von Tropenbewohnern, die an Ozaena leiden. Virchows Arch. path. Anat. Physiol. (4) 3(1): 98-107.

Freire, O. \& O. Torres, 1915. Algumas observações de myases. Brasil-med. 29(32): 254.

Fuller, G., 1962. How screwworm eradication will affect wildlife. Cattleman 48(12): $82,84$.

Furman, D. P., 1953. Nasal myiasis caused by the primary screwworm Callitroga hominivorax (Coquerel). Calif. Med. 79(3): 244.

Furtado, A. H., 1936. Myiasis vulvo-vaginal. Revta Ginecol. Obstet. 30(8): 636-639.

Gajardo-Tobar, R. \& A. Honorato, 1947. Anotaciones acercá de una epidemia de miiasis humana. Hosp. Viña del Mar 3: 5-14.

Gall, M., 1968. The insect destroyer - portrait of a scientist [E. F. Knipling]. USDA, Yb. Agric. 1968: 54-57.

Galvão, D., 1900. Mais um caso de míase ou bicheira da garganta. Revta méd. S Paulo 3(1): 2-3. 
Gaminara, A., 1928a. Miasis humana en el Uruguay. Trab. Actas Congr. nac. Med. 17: 426-433, 5 figs.

Gaminara, A., 1928b. Abcesos miasicos subcutáneos. 4. Reun. Soc. Patol. reg. Norte: 695-696.

Gaminara, A., 1930. Clasificación de algunos muscoideos uruguayos (Muscidae y Calliphoridae). An. Fac. Med. Univ. Montev. 14: 1235-1282, 19 figs.

Gaminara, A. \& R. N. Talice, 1928. Dos notas de entomologia médica. 4 Reun. Soc. Patol. reg. Norte: 653-656.

Garay Figuerosa, F., 1936. Las larvas de las moscas. Boln Curso Med. vet. práct. 1(8): 24-26.

Garcia, H. de, 1888. (?). Bolm Soc. méd., Rio de J. 1888: ?

Garcia, M., 1952. Consideraciones generales sobre el genero Cochliomyia Townsend, 1916 y descripcion de $C$. fontanai n. sp. (Diptera Calliphoridae). Publnes Inst. reg. Ent. sanit. argent. (1948-50): 68-80, 7 figs.

Garcia R., R., J. Casarrubias P. \& D. B. Woodward, 1980. Trampeo comparativo entre dos tipos de mechas cebadas con atrayente químico, utilizadas en la captura de Cochliomyia hominivorax Coquerel en Aldama, Tamaulipas. Folia ent. mex. 43: 49-50.

Garcia Alvarez, J., 1927. Un caso de miasis del conducto auditivo. Boln Hosps Caracas 17(9): 440-441.

Garcia Alvarez, J., 1928. Un caso de miasis del conducto auditivo (Extracto de un trabajo publicado en el Boletín de los Hospitales de Caracas). Semana méd., B. Aires 35: 721.

Garcia Rijo, R., 1908. Miasis (enfermedad parasitaria producida por las moscas). Crón. méd.-quir., Habana 34(17): 263-270; (18): 279-284.

Gardner, G., 1846. Travels in the interior of Brazil, principally through the northern provinces, and the gold and diamond districts, during the years 1836-1841, xvi + 562 pp., figs. Reeve Brothers, London.

Garzón Maceda, F., 1915. La parasitologia humana en la Argentina. (Antecedentes bibliográficos). Revta Univ. nac. Córdoba 2(1): 3-62.

Garzón Maceda, F., 1925. La zoo-parasitología humana en la República Argentina. Síntesis de un livro. Ibid. 12 (7-9): 98-112.

Gassner, G., 1980. Insect embryology: Low molecular weight preblastoderm proteins and cytoplasmic nucleoplasmic membrane associated receptor sites for microtubular polymerization. Europ. J. Cell Biol. 22(1): 306.

Gastelumendi V., R. \& H. Lumbreras Cruz, 1957. Sobre dos nuevos casos de myasis cutaneas producidas por larvas de la mosca Cochliomyia hominivorax (Coquerel, 1858). Revta méd. Hosp. Obrero, Lima 6(1-2): 177-183, ilus.

Gayle, S., 1933. Myiasis. Two cases report. Milit. Surg. 72(3): 225-227.

Giard, A., 1895. La Lucilia macellaria Fabr. au Chili. Actes Soc. scient. Chili 5: 51-54.

Gibbons, H. L., J. R. Dille \& R. G. Cowley, 1965. Inhalant allergy to the screwworm fly. Arch. environ. Hlth 10: 424-430.

Gibson, J., 1963. Raising the sterile flies for screwworm eradication. Am. Breed. Mag. 14(12): 10-11, ilus.

Gibson, M. S. \& D. E. Phinney, 1974. Selection parameters influencing the growth and survival of Cochliomyia hominivorax (Coauerel). NASA tech. Memo LEC 4090: 1-26.

Gilbert, N. C., 1908. Infection of man by dipterous larvae. With report of four cases. Arch. Inst. Med. Chicago 2(3): 226-240.

Gingrich, R. E., 1964. Nutritional studies on screwworm larvae with chemically defined media. Ann. ent. Soc. Am. 57: 351-360.

Gingrich, N. C., 1972. Nutritional studies: Their bearing on the development of practical oligidic diets for mass rearing larvae of the screwworm, Cochliomyia hominivorax, in Insect and mite nutrition, pp. 257-268. North-Holland, Amsterdam.

Gingrich, R. C., A. J. Graham \& B. G. Hightower, 1971. Media containing liquified nutrients for mass-rearing larvae of the screw-worm. I. econ. Ent. 64: 678-683. 
Gladney, W. J., 1976. Field trials of insecticides in controlled-release devices for control of the Gulf tick and prevention of screwworm in cattle. Ibid. 69(6): 757-760.

Gladney, W. J., M. A. Price \& O. H. Graham, 1977. Field tests of insecticides for control of the Gulf Coast tick on cattle. J. med. Ent. 13 (4-5): 579-586.

Gobbi, A. F. \& M. Itano, 1971. Miíase em otorrinolaringologia. Revta Oto-rino-lar. 37(2): 231-233.

Goldstein, M. A., 1891. On the treatment of human patients affected with screw worm. Insect Life 4(7-8): 275.

Goldstein, M. A., 1897. The Texas screw-worm and its invasion of the nasal cavities. Laryngoscope, St Louis 3(6): 335-340.

Gomes, J. P., 1940. Considerações sobre miiases oculares. Archos bras. Oftal. 3(5): 259-268, figs.

Gomez, O. J., 1944. Como tratar a los animales atacados por miasis o gusaneras. Medicamentos que deben emplearse según sea el carácter de las lesiones contaminadas. Res, B. Aires 12: 15.876.

Goodenough, J. L., 1978. Visual sensitivity of screwworm flies from the United States and Mexico as measured by the electroretinogram. Folia ent. mex. 39-40: 196.

Goodenough, J. L., 1979. Adult screwworms: Comparison of capture in wind oriented and electrocuter grid traps. J. econ. Ent. 72: 419-422.

Goodenough, J. L., J.R. Coppedge, A. B. Broce \& H. Detvar Petersen \& A. Higgins, 1979. Screwworm flies: A system for baiting and distributing Screwworm Adult Suppression System units. Trans. ASAE 22(6): 1260-1263.

Goodenough, J. L. \& J. W. Snow, 1977. Increased captures of adult screwworms and secondary screwworms in electrocuter grid traps. J. econ. Ent. 70(1): 70-71.

Goodenough, J. L. \& J. W. Snow, 1979. Capture of screwworm and secondary screwworm flies (Diptera: Calliphoridae) in a time-interval grid trap and correlation with temperature and humidity. J. med. Ent. 16(2): 95-103.

Goodenough, J. L. \& J. W. Snow, 1977. Increased captures of adult screwworms and secondary screwworms in electrocuter grid traps. I. econ. Ent. 70(1): 70-71.

Goodenough, J. L., D. D. Wilson \& H. R. Agee, 1977. Electroretinographic measurements for comparison of visual sensitivity of wild and massreared screwworm flies, Cochliomyia hominivorax (Diptera: Calliphoridae). J. med. Ent. 14(3): 309-312.

Goodenough, J. L., D. D. Wilson \& C. J. Whitten, 1978. Visual sensitivity of four strains of screwworm flies. Ann. ent. Soc. Am. 71(1): 9-12.

Gore, C. E., 1940. Vulval infection by Chrysomyia macellaria. Clin. Osteopath. 36(11): 610.

Gori, R. M., 1955. Miasis vulvar. Obstet. Ginec. lat.-am. 13(6): 228-231, ilus.

Gouck, H. K., M. M. Crystal, A. B. Borkovec \& D. W. Meifert, 1963. A comparison of techniques for screening chemosterilants of house flies and screw-worm flies. J. econ. Ent. 56(4): 506-509.

Gourrier, F. A., 1879. Un cas de mort par suite d'introduction de larves de Lucilia hominivorax dans les fosses nasales, à Cayenne. Archs Méd. navale 31: 471.

Grabbe, R. R. \& J. P. Grabbe, 1973. Screwworm attractants isolation and identification of organic compounds from bacterially inoculated and incubated blood. Folia ent. mex. 25-26: 121.

Grabbe, R. R. \& J. P. Turner, 1973. Screwworm attractants: Isolation and identification of organic compounds from bacterially inoculated and incubated blood. Folia ent. mex. 25-26: 120-121.

Graham, O. H., 1979. The chemical control of screwworms: A review. South. Ent, 4(4): 258-264.

Graham, A. J. \& F. H. Dudley, 1957. Culture methods for mass-rearing of 
screw-worm larvae. Bull. ent. Soc. Am. 3(3): 35.

Graham, A. J. \& F. H. Dudley, 1958. Culture methods for massrearing of screwworm larvae. Proc. 55. A. Conv. Ass. S. agric. Wrkrs (Little Rock): 113.

Graham, A. J. \& F. H. Dudley, 1959. Idem. J. econ. Ent. 52(5): 1006-1008.

Graham, O. H., 1964. Problems in livestock insect control of mutual interest to Mexico and the United States. Folia ent. mex. 7-8: 71.

Graham, O. H., A. H. Baumhover \& M. Chavarria, 1965. Investigaciones sobre la erradicacion de la queresa. Medna vet. Zootec. 4(1): 5-9.

Graham, O. H., E. C. Corristan \& C. M. Jones, 1974. Studies on the ecology of the screwworm in Tamaulipas in 1973. Folia ent. mex. 29: 73-74.

Graham, O. H., R. O. Drummond \& R. A. Hoffman, 1968. Possibilities of the sterile-male technique for the control of livestock insects in the United States of America, in Control of livestock insect pests by sterile-male technique, pp. 41-44. Int. Atom. Energy Agency, Vienna.

Graham, O. H. \& J. L. Hourrigan, 1977. Eradication programs for the arthropod parasites of livestock. J. med. Ent. 13(6): 643-647.

Graham, O. H., B. Moore, M. J. Wrich, S. Kung, J. W. Warren \& R. O. Drummond, 1959. A comparison of ronnel and coral sprays for screwworm control. J. econ. Ent. 52(6): 1217-1218.

Grainger, J., 1764. An essay on the more common West India diseases and the remedies which that country itself produces, to which are added some hints on the management, etc., of negros, vi + pp. 8-75. London.

Grainger, J., 1802. Idem, 2nd ed., with practical notes, and a Linnean index by William Wright, xii + vi + 106 pp., Edinburgh.

Granada, D., 1890. Vocabulario rioplatense razonado (2a. ed.), 441 pp. Montevideo.

Granada, D., 1947. Reseña histórico-descriptiva de antiguas y modernas supersticiones del Río de la Plata, 438 pp. Guillermo Kraft, Buenos Aires.

Gray, St. G., 1903. Screw-worms in St. Lucia. Brit. med. J. 1: 724-725. (Res. em Dt. med. Wschr. 29(15): 90, 1903; J. trop. Med., Lond. 6(8): 132; Philad. med. J. 11(16): 658, 1903).

Grayson, W H., 1891. A case of myiasis narium; recovery. St Louis med. surg. J. 61(2): 80-84, 2 figs. (Também publ. sep., 4 pp., 2 figs., St Louis, 1891).

Greene, C. T., 1956. Dipterous larvae parasitic on animals and man and some dipterous larvae causing myiasis in man. Trans. Am. ent. Soc. 82(1): 17-34, pls.

Greenway, D. F., 1929. Miasis humanas de localización genital en la Argentina. Libro Homen. Crugero Aráoz Alfaro, B. Aires: 266.

Greenway, D. F. \& A. Marciano, 1926. Miasis vulvar por larvas de Cochliomyia macellaria. Prensa méd. argent. 13: 393, 1 fig.

Griffith, M. F. H., 1940. A case of myiasis. Caribb. med. J. 2(3): 122-123.

Griffiths, H. J. \& E. F. Cook, 1962. Occurrence of screwworm infestation in Minnesota. J. Am. vet. med. Ass. 140(12): 1313.

Gualberto, L. \& G. de Magalhães, 1934. Injecções hidrargíricas curam mais um caso de miíase nasal. Archos Biol., S Paulo 18(181): 80.

Guillot, F. S., H. E. Brown \& A. B. Broce, 1978. Behavior of sexually active screwworm flies. Ann. ent. Soc. Am. 71(2): 199-201.

Guillot, F. S., J. R. Coppedge, J. L. Goodenough, T. S. Adams \& E. Ahrens, 1977a. Behavior and reproductive status of native female screwworms attracted to a host. Ibid. 70(4): 588-590.

Guillot, F. S., J. R. Coppedge, J. L. Goodenough, E. Ahrens \& T. S. Adams, 1977b. Reproductive status of female screwworms captured from hosts or in traps. SWest. Ent. 2(1): 49-52.

Guimarães, J. H., A. P. do Prado \& G. M. Buralli, 1979. Dispersal and distribution of three newly introduced species of Chrysomya Robineau-Desvoidy in Brazil (Diptera, Calliphoridae). Revta bras. Ent. 23(4): 245-255, ilus.

Gurgel, N., 1903. Intervenção cirúrgica e myiasis. Brasil-méd. 19: 185. 
Guthrie, T. F., 1941. Avert screw worms losses. Capper's Fmr 52(11): 34. Haddad, O., 1946. Miíase da região anal. Publções méd. 17(7): 53, 55-56. Hall, D. G., 1948. The blowflies of North America. Thomas Say Foundation, Ent. Soc. Am., Vol. 4: 477 pp., ilus.

Hall, D. G., 1965. Family Calliphoridae, in Stone, A. et al., A catalog of the Diptera of America north of Mexico. USDA Agric. Hdbk 276.

Hall, R. D., 1979. The blow flies of Missouri: An annotated checklist. (Diptera: Calliphoridae). Trans. Mo. Acad. Sci. 13: 33-36.

Hansen, J. \& S. Mazza, 1918. Sobre um caso de miasis palatina a Chrysomyia macellaria (Fabr.). Revta Sanid. milit. argent. 17(3): 260-264. (Também em Prensa méd. argent. 5(2): 23-24, 3 figs.).

Hanson, F. W., 1959. Screwworm regulations. Okla. Vet. 6(2): 19.

Harley, R. D., 1943. Ocular myiasis (ophthalmomyiasis). Report of a case. Am. J. Ophthal. (3) 26(7): 742-743.

Harris, S. T., 1929. Human myiasis, externa. U. S. Veteran's Bur. med. Bull. 5(6): $412-416$.

Harrison, C. M., 1885. Maggots in the head. Med. Rec. 28(15): 399-400.

Hart, H. B., 1912. A case of myiasis. Boston med. surg. J. 146(5): 170-171.

Haseman, L., 1943. Screwworm menace to livestock. Circ. Mo. agric. Exp. Stn 267: 1-2.

Hecht, O., 1944. Nota breve sobre casos de miasis en heridas del ganado en Venezuela. Mems Minist. Agric. Cria, Caracas 1: 311-313.

Heely, D. C., 1885. Maggots in the nose; a remarkable case. Peoria med. Mo. 5(10): 609-610.

Henderson, B. L., 1938a. Texas screw worm control. Pest eradication information. Coastal Cattleman 4(6): 19.

Henderson, B. L., 1938b. Texas screw worm fly. Fm Ranch 57(11): 9.

Henderson, B. L., 1940. Ear-tick and screw-worm control in the south. Coastal Cattleman 6(6): 17.

Hevia, H., H. Schenone F., F. Pescetto \& H. Reyes, 1961. Myiasis tegumentaria. Boln chil. Parasit. 16(4): 96-98, 5 figs.

Hightower, B. G., 1963. Nocturnal resting place of the screwworm fly. J. econ. Ent. 56(4): 498-500.

Hightower, B. G., 1969. Population dynamics of the screwworm fly, Cochliomyia hominivorax (Coquerel), with respect to control by the sterile-male technique, pp. 25-31, in Insect ecology and the sterile male technique, International Agency of Atomic Energy, Vienna.

Hightower, B. G., 1970. Status of screw-worm eradication in the Southwwest and Mexico. Proc. 2nd a. Conf. Insect Plant Dis. Weed Brush Control: 45-49.

Hightower, B. G. \& A. L. Adams, 1969. Dispersal and local distribution of laboratory-reared sterile screwworm flies released in winter. J. econ. Ent. 62(1): 259-261.

Hightower, B. G., A. L. Adams \& D. A. Alley, 1965. Dispersal of released irradiated laboratory-reared screw-worm flies. Ibid. 58(2): 373-374.

Hightower, B. G. \& D. A. Alley, 1963. Local distribution of released laboratory reared screw-worm flies in relation to water resources. Ibid. 56(6): 799-802.

Hightower, B. G., D. A. Alley \& J. C. Edde, 1968. Observation of the effects of releasing sterile screw-worm flies in northern Veracruz, Mexico. Folia ent. mex. 17: 1-16.

Hightower, B. G. \& M. Chavarria Chavarria, 1964a. A survey of screw-worm habitats in northern Mexico. Folia ent. mex. 7-8: 65.

Hightower, B. G. \& M. Chavarria, 1964b. Estudio de las regiones donde habita el gusano barrenador del ganado en el norte de México. Med. vet. $y$ zootec. 3(3): 93-96, 97-104.

Hightower, B. G., R. B. Davis, A. H. Baumhover \& O. H. Graham, 1966. Seasonal abundance of the screw-worm in northern Mexico. J. econ. Ent. 59(2): 416-420, 6 figs.

Hightower, B. G. \& C. C. Dawkins, 1969. Use of a genetically marked strain to evaluate the retention of marking dyes by released screw-worm 
flies. Ibid. 62(4): 966-967.

Hightower, B. G. \& J. J. Garcia, 1972. Longevity and sexual activity of newly eclosed irradiated screwworm flies held at immobilizing low temperatures. Ibid. 65(3): 877-878.

Hightower, B. G. \& O. H. Graham, 1968. Current status of screwworm eradication in the south-western United States of America and the supporting research programme, pp. 51-54, in Control of livestock insect pests by the sterile male technique. Int. Atomic Energy Agency, Vienna.

Hightower, B. G., J. J. O’Grady, Jr. \& J. J. Garcia, 1972. Ovipositional behavior of wild-type and laboratory-adapted strains of screwworm flies. Envir. Ent. 1: 227-229.

Hightower, B. G., G. E. Spates \& A. H. Baumhover, 1971. Emergence rhythm of adult screwworms. J. econ. Ent. 64(6): 1474-1477.

Hightower, B. G., G. E. Spates, Jr. \& J. J. Garcia, 1972a. Relationship between weight of mature larvae, size of adults, and mating capability in medium-reared male screwworms. J. econ. Ent. 65: 1527-1528.

Hightower, B. G., G. E. Spates, Jr. \& J. J. Garcia, 1972b. Growth and critical size at pupation for larvae of the screwworm developing in fresh wounds. Ibid. 65(5): 1349-1352, ilus.

Hoehne, F. C., 1937. Botânica e agricultura no Brasil no século XVI. Série "Brasiliana", vol. 71. Companhia Editora Nacional, São Paulo.

Holt, G. G., T. S. Adams \& W. D. Sundet, 1979. Attraction and ovipositional response of screwworms, Cochliomyia hominivorax (Diptera: Calliphoridae), to simulated bovine wounds. J. med. Ent. 16(3): 248-253.

Holzman, H. P., 1949a. Screwworm infestation in South Dakota. S. Dak. Stockgrower 3(7): 10-12.

Holzman, H. P., 1949b. We are no longer free from the screwworm infestations. S. Dak. Fmr 69(17): 16, 19.

Hough, G. N., 1899. Synopsis of the Calliphorinae of the United States. Zool. Bull. 11(6): 283-290.

Howell, L. L., 1935. Screw worms removed from intestine of a dog. Vet. Med. 30(4): 176.

Huber, G. V. \& F. L. Flack, 1914. An unusual case of screwworms in the nose and nasal accessory sinuses. J. Am. med. Ass. 63(26): 2288-2289. (Também em J. trop. Med. Hyg. 18(3): 33, 1915).

Humbert, F., 1883a. Catarrh of the ethmoid cells and the frontal sinus and the nasal canae; the cause; deposit of eggs of the screw maggot (larvae) and their development. J. Am. med. Ass. 1(22): 644-646.

Humbert, F., 1883b. Lucilia macellaria infesting man. Proc. U. S. natl Mus. 6(7): 102-103 (Report by C. V. Riley, pp. 104-105).

Humbert, F., 1883c. Idem [com ligeiras variações]. Ann. Mag. nat. Hist. (5) 12: $353-355$.

Humbert, F., 1884. Idem. Am. Naturalist 18(5): 540-542.

Humphrey, D., 1961. The screwworm is being whipped. Pgve Fmr 74(10): $52,57$.

Hunter, G. W., III \& C. M. Berrocal, 1957. A case of human myiasis in Texas caused by the primary screw worm, Callitroga hominivorax (Coquerel). Tex. Rep. Biol. Med. 15(3): 378-380.

Husbands, R. C., 1955. Lesser screw fly occurrence. Calif. Vector Views 2(10): 51.

Husman, C. N. \& A. N. Baumhover, 1957. Mechanical devices for dispersal of sterilized screwworm flies from aircraft. Bull. ent. Soc. Am. 3(3): 35.

Husman, C. N. \& A. H. Baumhover, 1958. Mechanical devices for dispersal of sterilized screw-worm flies from aircraft. Proc. 55. a. Conv. Ass. s. agric. Wrkrs (Little Rock): 114.

Iglésias, F. de A., 1951. Caatingas e chapadões. (Notas, impressões e reminiscências do meio norte brasileiro), 638 pp. Série "Brasiliana", vol. 271. Companhia Editora Nacional, Săo Paulo.

Iriarte, D. R., 1928. Sobre un caso de nasomiasis a Chrysomyia macellaria. Revta Med. Cirug., Caracas 11: 307-309. 
Israel, S., 1915. Texas screw-worm infection of entire nose and throat, including the accessory sinuses. Laryngoscope, St Louis 25(9): 657-660.

Jacob, (-), s.d. Affection parasitaire des fosses nasales, observée au Mexique; traitement par les injections chloroformées; guérison; expulsion ou extraction totale de 220 larves. Recl Mém. Obsns Hyg. Méd. vét. milit. (3) 17: 58-60.

Jacobsen, J. L., 1889a. Lucilia hominivorax. Revta Cienc. med., Habana 4(5): 220-221.

Jacobsen, J. L., 1889b. Larvae of flies in the nasal fossae. Brit. med. J. 2: $1238-1239$.

James, M. T., (1948). The flies that cause myiasis in man. U. S. Dep. Agric. misc. Publs (1947) 631: 175 pp., 98 figs.

James, M. T., 1970. Family Calliphoridae, in Museu de Zoologia, Universidade de São Paulo, A Catalogue of the Diptera of the Americas south of the United States 102: 28 pp. São Paulo.

Jauregui, P. J. \& S. Barabino Amadeo, 1914. Sobre un caso de miasis. Revta Circulo méd. argent. ?: 563, 1 fig.

Jefferson, M. E., 1960. Irradiated males eliminate screwworm flies. Nucleonics 18: $74-76$.

Jelski, K., 1872. Note sur la larve d'une mouche (Lucilia hominivorax?) nuisible pour les habitants du Pérou. Petites Nouvelles ent. 1: 260.

Jiménez, L. M., 1866. Larva de un género nuevo y probablemente indígena de los oestrideos. Gac. méd. Méx. 2(14): 209-212.

Jiménez, L. M., 1867. Myiasis; Lucilia hominivora (sic). Ibid. 3(10): 155-158.

Jiménez, L. M., 1869. Otro hecho de myiasis producida por la nueva especie Lucilia versicolor. Ibid. 4(2): 27-32, 1 pl.

Johnson, C. W., 1894. List of the Diptera of Jamaica with descriptions of new species. Proc. Acad. nat. Sci. Philad. 1894: 271-281.

Johnson, C. W., 1908. The screw worm (Chrysomyia macellaria). Psyche, Cambr. 15(3): 60 .

Johnson, C. W., 1919. Revised list of Diptera of Jamaica. Bull. Am. Mus. nat. Hist. 41: 439-440.

Johnston, H. G., 1942. Screwworms are sure bad! But Smear 62 and modern techniques help cowmen defeat pesky pest. Ariz. Fmr 22(10): 18.

Johow, A., 1927. Discusion de casos de miasis presentados a la Sociedad medica. Revta med. Chile 51(11): 828.

Jones, C. M., D. D. Oehler, J. W. Snow \& R. R. Grabbe, 1976. A chemical attractant for screwworm flies. J. econ. Ent. 69(3): 389-391.

Jones, C. M., J. W. Snow \& M. A. Villasenor, 1976. Screwworm flies: Seasonal occurrence in central Tamaulipas, Mexico, 1973-74. Ibid. 69(6): 761-762.

Jones, G. D., 1941. Screwworms in man in Missouri. Ibid 34(2): 320.

Jones, W., 1894. Observations on the insects of Jamaica. Annotated by $\mathrm{T}$. D. A. Cockerell. J. Inst. Jamaica 1(8): 368-372. (Também em Insect Life 7: 273, 1894).

Jorge, (-), 1878. Sobre miasis (Calliphora macellaria). An. Círc. méd. argent. ?: 2

Jourdran, (-), 1895. Un cas de Lucilia hominivorax observé à la Guyane; 315 larves extraites des fosses nasales (guérison). Archs Méd. navale 64: 383.

Judd, G. S., 1876. Occurrence of maggots in a boy. Am. Naturalist 10(6): 374-375.

Kakinohara, H., 1978. [Present status of the factory for large scale production of Cochliomyia hominivorax] (In Japanese). Shokobutsu Boeki Plant Prot. 32(9): 375-378.

Kaplanis, J. N., D. E. Hopkins \& G. H. Treiber, 1969. Dermal and oral treatments of cattle with phosphorus-32-labeled Co-Ral. Agric. Food Chem. 7(7): 483-486.

Katz, S. I. \& R. Taylor, 1971. Cutaneous myiasis. Sth med. J. 64(6): 759-760, fig.

Kaufman, G. \& M. Wasserman, 1957. Effects of irradiation on the screw. worm, Callitroga hominivorax (Coq.). Univ. Tex. Publs 5721: 246-259. 
Kent, G. H., 1891. Notes on three noxious insects of Mississippi. Insect Life 3: 466.

Kilpatrick, A. R., 1880a. The screw worm. Am. Entomol. (n. s.) 3(1): 275.

Kilpatrick, A. R., 1880b. The screw worm. Ann. Ent. Bot. (n. s.) 1(11): 275.

Kimball, J. P., 1893. Maggots in the nose successfully treated by injections of chloroform. N. Y. J. Med. 57(10): 273-275.

King, E. F., 1914. Myiasis of the urinary passages. I. Am. med. Ass. 63(26): 2285-2286.

King, E. F., 1915. Idem. Wash. med. Ann. 14: 15-18.

King, W. van O. \& G. H. Bradley, 1935. The screw worm outbreak in Florida. J. econ. Ent. 28(5): 772-777.

Kitto, B. G., R. Neck \& G. L. Bush, 1976. Genetic effects of the mass rearing of screwworm flies. Fed. Proc. 35: 1658.

Knipling, E. F., 1939. A key to blowfly larvae concerned in wound and cutaneous myiasis. Ann. ent. Soc. Am. 33(2): 376-383, pls.

Knipling, E. F., 1950. Status of screw-worm infestation in the southeast. Proc. 5. a. Meet. N. C. Br. States Br. Am. Ass. econ. Ent.: 14.

Knipling, E. F., 1951 Screw-worm status and control. Proc. 6. a. Mt. N. C. States Br. Am. Ass. econ. Ent.: 74-75.

Knipling, E. F., 1953. The possibilities of controlling screwworms by releasing flies sterilized with gamma rays. Proc. ent. Soc. Wash. 55(1): 48.

Knipling, E. F., 1955. Possibilities of insect control or eradication through the use of sexually sterile males. J. econ. Ent. 48: 459-462.

Knipling, E. F., 1957. Control of the screw-worm fly by atomic radiation. Sci. mon. 85(4): 195-202.

Knipling, E. F., 1959a. Sterile-male method of population control. Science, N. Y. 130: 902-904.

Knipling, E. F., 1959b. Screwworm eradication: Concepts and research leading to the sterile-male method. A. Rep. Smithson. Inst. 1957-58: 409418, pls.

Knipling, E. F., 1960a. Control of screwworm fly by atomic radiation (Biological control of plant and animal pests). Publs. Am. Ass. Adv. Sci. 61: $169-182$.

Knipling, E. F., 1960b. The eradication of the screw-worm fly. Scient. Am. 203(4): 54-61, ilus., mapa.

Knipling, E. F., 1960c. Use of insects for their own destruction. J. econ. Ent. 53(3): $415-420$.

Knipling, E. F., 1962. Potentialities and progress in the development of chemosterilants for insect control. Ibid. 55: 782-786.

Knipling, E. F., 1964. Factors to consider in appraising the feasibility of employing sterile insects for population control, in The potential role of the sterility method for insect population control with special reference to combining this method with conventional methods. USDA Res. Serv., ARS 33-98: 12-24.

Knipling, E. F., 1965. Early developments in the sterile-male technique, pp. 1-3, in G. C. LaBrecque \& J. C. Keller, eds., Advances in insect populations control by the sterile-male technique. Int. Atom. Energy Agency Tech. Rep. Ser. 44.

Knipling, E. F., 1967. Sterile technique - porinciples involved, current application, limitations, and future application in Genetics of insect vectors of disease, pp. 587-616. Elsevier Publishing Co., Amsterdam.

Knipling, E. F., 1972. Use of organisms to control insect pests. J. environ. Qual. 1(1): 34-40.

Knipling, E. F. \& H. T. Rainwater, 1937. Species and incidence of dipterous larvae concerned in wound myiasis. J. Parasit. 23(5): 451-455.

Knipling, E. F. \& H. D. Tate, 1935. An outbreak of the screw worm, Cochliomyia americana Cushing and Patton, in northwestern Iowa. J. econ. Ent. 28(2): 472-475, fig. 74.

Knipling, E. F. \& B. V. Travis, 1937. Relative importance and seasonal activity of Cochliomyia americana C. and P. and other wound infesting blowflies. Ibid. 30(5): 727-735. 
Knowles, T. R., 1925. Cutaneous myiasis. Case report. Colo. Med. 22(9): 309-310.

Koutz, F. R., 1947. The screw-worm fly, Cochliomyia americana, in Ohio. J. Am. vet. med. Ass. 110: 385.

Krafsur, E. S., 1978. Aggregations of male screwworm flies, Cochliomyia hominivorax (Coquerel) in south Texas. (Diptera: Calliphoridae). Proc. ent. Soc. Wash. 80(2): 164-170.

Krafsur, E. S. \& L. Garcia, 1978. Responses of the screwworm, Cochliomyia hominivorax, to two sterile male release methods in South Texas, 1975-1976. J. med. Ent. 14(6): 687-697.

Krafsur, E. S. \& B. G. Hightower, 1979. Field tests of sterile screwworm flies, Cochliomyia hominivorax (Diptera: Calliphoridae), against natural populations in three coastal areas of Mexico. J. med. Ent. 16(1): 33-42.

Krafsur, E. S., B. G. Hightower \& L. Leira, 1979. A longitudinal study of screwworm populations, Cochliomyia hominivorax (Diptera: Calliphoridae) in Northern Veracruz, Mexico. Ibid. 16(6): 470-481.

Krueger, F. J., 1930. Secretions of Cochliomyia macellaria Fab. larvae in relation to their development. J. Parasit 12(2): 109.

Kunz, S. E., 1978. Highlights of veterinary entomology - 1952-1977. Bull. ent. Soc. Am. 24(4): 401-406.

Laake, E. W., 1935. The incidence of screw worms in southern Texas and Louisiana in 1934. J. econ. Ent. 28(3): 648-649.

Laake, E. W., 1936. Economic studies of screwworm flies, Cochliomyia species (Diptera, Calliphoridae), with special reference to the prevention of myiasis of domestic animals. Iowa St. Coll. J. Sci. 10(4): 345-359, pl. 1 .

Laake, E. W., 1938. On the hydrogen-ion concentration of myotic wounds and its relation to the oviposition stimulus in Cochliomyia americana C. and P. Am. J. trop. Med. 18(2): 232.

Laake, E. W., 1939a. Myiasis in domestic animals. J. Am. vet. Ass. 95: 47-49.

Laake, E. W., 1939b. On the hydrogen-ion concentration of myotic wounds and its relation to the oviposition stimulus on Cochliomyia americana C. and P. Am. J. trop. Med. 19(2): 193-197.

Laake, E. W., 1944. Screwworm survey in the western area of the United States in 1943. J. econ. Ent. 37(2): 319.

Laake, E. W., 1950a. Recent outbreaks of screw-worms. Proc. 5. a. Mt. N. C. Br. Am. Ass, econ. Ent.: 14-15.

Laake, E. W., 1950b. Screw-worm survey in western United States, 1949. J. econ. Ent. 43(3): 387-389.

Laake, E. W., 1951. Screw-worm survey in western United States 1950. Insect Pest Surv., Spec. Suppl.: 7 pp.

Laake, E. W., H. M. Brundrett \& O. H. Babcock, 1949. Screw-worm survey in western United States, 1948. J. econ. Ent. 42(4): 684-685.

Laake, E. W. \& E. C. Cushing, 1930. Fly trapping on the ranges of the Southwest. Ibid. 23(6): 966-972.

Laake, E. W., E. C. Cushing \& H. E. Parish, 1936. Biology of the primary screw worm fly, Cochliomyia americana, and a comparison of its stages with those of C. macellaria. U. S. Dep. Agric. Bull. 500: 1-24. 14 figs., 1 pl. col.

Laake, E. W., E. Hixson \& H. C. Severin, 1950. Screw-worms. How to recognize and control infestations in livestock. $7 \mathrm{pp}$. Washington, D. C.

Laake, E. W., D. C. Parman, F. C. Bishopp \& R. C. Roark, 1926. Field test with repellents for the screw worm fly, Cochliomyia macellaria Fabr., upon domestic animals. J. econ. Ent. 19(3): 536-539.

Laake, C. W. \& C. L. Smith, 1938. The hydrogen-ion concentration of myotic wounds in sheep and goats. Ibid. 31(3): 441-442.

Laake, C. W. \& C. L. Smith, 1939. The development of immunity in cavies to the larvae of Cochliomyia americana C. \& P. Ibid. 32(2): 339-342.

Laboulbène, J. J. A., 1870. Lucilie. Lucilia hominivorax (Compsomyia macellaria). Dict. encycl. Sci. méd., Paris (2) 3: 166-171. 
Laboulbène, J. J. A., 1968. (Note relative aux larves de la Lucilia hominivorax produisant des accidents chez l'homme au Mexique). Annls Soc. ent. Fr. (Bull.) (4) 8: xxxvi-xxxvii.

Lacey, L. A. \& T. K. George, 1981. Myiasis in an Amazonia porcupine. Ent. . News 92(2): 79-80.

La Chance, L. E., 1961. Radiosensitivity of the various stages of oogenesis in Callitroga hominivorax. Genetics 46(8): 877.

La Chance, L. E., 1962. Effects of radiations on insects. Proc. N. Centr. Br. ent. Soc. Am. 17: 11-14.

La Chance, L. E., 1963. Enhancement of radiation-induced sterility in insects by pretreatment in $\mathrm{CO}_{2}+$ air. Int. J. Radiat. Biol. 7(4): 321-331.

LaChance, L. E., 1973. Radiation induced sterility in insects for the control and or eradication of agricultural pests, pp. 1463-1470, in J. F. Duplan \& A. Chapiro, eds., Advances in radiation research, biology and medicine 3: ix + 1521 pp., ilus. Gordon \& Breach Science Publishers, New York \& London.

LaChance, L. E. \& S. B. Bruns, 1963. Oogenesis and radiosensitivity in Cochliomyia hominivorax (Diptera: Calliphoridae). Biol. Bull. 124(1): 65-83, ilus., pls.

La Chance, L. E. \& M. M. Crystal, 1963. The modification of reproduction in insects treated with alkylating agents. II. Differential sensitivity of of oocyte meiotic stages to the induction of dominant lethals. Ibid. 125: $280-288$.

LaChance, L. E. \& M. M. Crystal, 1965. Induction of dominant lethal mutations in insect oocytes and sperm by gamma rays and an alkylating agent: Dose-response and joint action studies. Genetics, Princeton 51(5): 699-708.

LaChance, L. E., C. Dawkins \& D. E. Hopkins, 1966. Mutants and linkage groups of the screw-worm fly. I. econ. Ent. 59(6): 1493-1499, ilus.

LaChance, L. E. \& D. E. Hopkins, 1962. Mutations in the screwworm fly. Ibid. 55: 733-737.

La Chance, L. E. \& D. E. Hopkins, 1965. Effects of selection on WHAXY: An autosomal dominant mutation in the screw-worm fly with recessive lethal effects. Am. Nat. 99(904): 47-57.

LaChance, L. E. \& A. P. Leverich, 1962. Radiosensitivity of developing re productive cells in female Cochliomyia hominivorax. Genetics, Princeton 47: 721-735.

LaChance, L. E. \& A. R. Leverich, 1968. Cytology of oögenesis in chemosterilized screw-worm flies, Cochliomyia hominivorax, as related to endomitosis in nurse cells. Ann. ent. Soc. Am. 61(5): 1188-1197, ilus.

LaChance, L. E. \& J. G. Riemann, 1964. Cytogenetic investigations on radiation and chemically induced lethal mutations in oocytes and sperm of the screw-worm fly. Mutation Res. 1: 318-333.

LaChance, L. E., J. G. Riemann \& D. E. Hopkins, 1964. A reciprocal translocation in Cochliomyia hominivorax (Diptera: Calliphoridae): Genetic and cytological evidence for preferential segregation in males. Genetics 49(6): 959-972.

LaChance, L. E. \& R. L. Ruud, 1977. Cytological identification of native and irradiated released screwworm flies in trap catches. J. econ. Ent. 70(4): 501-504.

LaChance, L. E., C. H. Schmidt \& R. C. Bushland, 1967. Radiation-induced sterilization (The applications. VII. Screwworm eradication program), in Rest Control - Biological, physical and selected chemical methods, pp. 164-173. Academic Press, N. York.

Lagos, J. S. M., 1937. O emprego do $\mathrm{Hg}$ solúvel no tratamento das myases. Bolm Soc. bras. Med. vet. 7(2): 96-98.

Lahille, F., 1915. Nota sobre la ura y otras larvas dañinas de dipteros. Boln Dir. Gen. Ganad. Min. Agric., B. Aires, 18 pp., 7 figs., 2 pls.

Lamb, K. P., D. P. A. Sands \& J. P. Spradberry, 1978. Assay of Old-World screw-worm fly, Chrysomya bezziana, labelled with $32 \mathrm{P}$. Ent. exp. appl. 23: $55-65$. 
LaPaz, S. de, 1973. Behavior of 2 colonies of sterilized flies of the screw worm of cattle, Cochliomyia hominivorax, in the southeast of Mexico. Folia ent. mex. 25-26: 128-129.

Laurence, S. M., 19c9. Dipterous larvae infection. Br. med. J. 1: 88.

La Paz, S. de, 1973. Behavior of 2 colonies of sterilized flies of the screw worm of cattle, Cochliomyia hominivorax, in the southeast of Mexico. Folia ent. mex. 25-26: 128-129.

Lauzurica, E., 1909. Dos casos de miasis. Revta ib.-am. Cienc. méd. 22: 96-99.

Lawton, A. H., M. W. Dexter \& L. O. Warren, 1957. Double infestation of a varicose ulcer with screw-worm and house fly maggots. Am. J. trop. Med. Hyg. 6(2): 336-338.

Leclerc, J., 1964. Les myases de plaies en Guyane Française. Recl Méd. vét. Éc. Alfort 140(8): 633-638.

Leclercq, M., 1948. Les myiases. Revue méd. Liège 3(6): 133-140, 5 figs.

Lemos, A., 1877. (?). Revta méd.-quir. B. Aires (iv.1877).

Lenko, K. \& N. Papavero, 1979. Insetos no folclore, 518 pp. Conselho Estadual de Artes e Ciências Humanas (Col. Folclore, n. ${ }^{\circ}$ 18). São Paulo.

Leonissa, M. de, 1906. Muscideos e culicideos, as myiasis. Polytechnia 3: 140-167.

Lesbini, C., G. H. Weyenbergh \& P. A. Conil, 1878. Etudes sur la myiasis. Actas Acad. nac. Cienc. Córdoba 3(2): 39-98, pl. 8. (Lesbini, C., Partie médicale, pp. 41-63; Weyẹnbergh, H., Les larves et les nymphes, pp. pp. 64-68, pl. 8, figs. 1-4; Conil, P. A., Description de l'insecte parfait. Calliphora anthropophaga m. Nouvelle espèce de mouche, pp. 69-81, pl. 8, figs. 5-8; Weyenbergh, H., Liste bibliographique sur la myiasis, pp. 83-98).

Levis, W. W., Jr., 1942. History of the screwworm and its indicated control. Fla Poultryman 8(5): 13.

Libermann, J., 1935. Sintesis de insectos que interesan a la zoologia veterinaria argentina. Revta Med. vet., B. Aires 17(1): 16-30.

Lima Filho, O. A. de, 1945. Miíase da vulva. Revta Ginec. Obstet. Rio de J. 1(2): 82-102, pls.

Lindquist, A. W., 1937. Myiasis in wild animals in southwestern Texas. I. econ. Ent. 30(5): 735-740.

Lindquist, A. W., 1938. A study of the incidence and habits of Cochliomyia americana by means of flytraps. J. Kans. ent. Soc. 11(3): 97-104.

Lindquist, A. W., 1940. The introduction of an indigenous blowfly parasite, Alysia ridibunda Say, into Uvalde County, Texas. Ann. ent. Soc. Am. 33(1): 103-112.

Linquist, A. W., 1942a. Ants destroy screwworms. J. Am. vet. Ass. 101: 284.

Lindquist, A. W., 1942b. Ants as predators of Cochliomyia americana C. \& P. J. econ. Ent. 35(6): 850-852.

Lindquist, A. W., 1954. Flies attracted to decomposing liver in Lake County, California. Pan-Pacific Ent. 30(2): 147-152.

Lindquist, A. W., 1955a. Possibilities in the use of gamma radiation for control or eradication of the screw-worm. Proc. Ass. sth. agric. Wkrs: 92.

Lindquist, A. W., 1955b. The use of gamma radiation for control or eradication of the screw-worm. J. econ. Ent. 48: 467-469.

Lindquist, A. W., 1958. Entomological uses of radioisotopes, in Radiation biology and medicine, pp. 688-710. Addison-Wesley Publishing Co., Inc. Reading, Mass.

Lindquist, A. W., 1960. Use of sexually sterile males for eradication of screwworms. Proc. 2. inter-am. Symp. peaceful Appl. nucl. Energy: 229-235.

Lindquist, A. W., 1961a. Chemicals to sterilize insects. J. Wash. Acad. Sci. 51: 109-114.

Lindquist, A. W., 1961b. New ways to control insects. Pest Contr. 29(6): 1-6.

Lindquist, A. W. \& W. L. Barrett, Jr., 1945. Overwintering of Cochliomyia americana at Uvalde, Texas. J. econ. Ent. 38(1): 77-83.

Lindquist, A. W. \& E. F. Knipling, 1957. Recent advances in veterinary entomology. A. Rev. Ent. 2: 181-202.

Lindquist, D. A., 1973. Recent advances in insect control by the sterile male technique. Meded. Fac. Landbouwwet. Rijsksuniv. Geriet. 38(3): 627-635. 
Lindsay, J. W., 1902. Myiasis, the Lucilia macellaria, the screw worm. J. trop. Med. Hyg. 5(14): 220.

Linduska, J. P. \& A. W. Lindquist, 1952. Some insect pests of wildlife. USDA Yb. Agric.: 708-724.

Lins e Silva, M., 1938. Miíase nasal e da loja amigdalina. Hospital, Rio de J. 13(5): 931-933.

Long, G. L., 1979. Flowering vegetation of South Texas as an aggregation site for screwuorm flies, Cochliomyia hominivorax (Coquerel), $75 \mathrm{pp}$. MS Thesis, Pan American University, Edinburgh, Tex.

López Rondón, A., 1936. Un caso clínico de otomiasis. Diario de la Esfera ?.

Lord, W. E., 1954. Controle las gusaneras de las heridas de sus animales. Revia Agric. Comerc. Ind., Panamá 12: 39-40, ilus.

Lucas, E., 1868. Relation d'un cas de parasitisme observé à Acapulco. Thèse, Paris.

Lumbreras Cruz, H. \& F. Polack, 1955. Myiasis cutáneas producidas por larvas de la mosca Cochliomyia hominivorax, Coquerel, 1858. Revta méd. peru. 26: 449-466, ilus.

Lutz, A., 1899. Um caso de myiases da garganta (bicheira). Revta méd. S Paulo 2(8): 215-219.

Luz, A. C. R. da, 1888. Sobre algumas moléstias causadas pelas larvas de insectos dipteros. Brasil-méd. 5: 253-254.

Lyddiat, A. \& D. Boulter, 1977. The amino acid seatuence of cytochrome $c$ from the locust Schistocerca gregaria Forskal. Biochem. J. 163(2): 333338. (Refere-se a Cochliomyia).

Lynch Arribálzaga, E., 1879. Calliphora antropophaga Conil (Nota crítica). An. Soc. cient. argert. 7: 25j-258.

Lynch Arribálzaga, E., 1880a. Compsomyia macellaria (F.). Observaciones críticas sobre los caracteres, sinonimia, etc., de este muscide. Ibid. 10: 70-84.

Lynch Arribálzaga, E., 1880b. Compsomyia macellaria (F.). I. Respuesta al señor Conil. - II. Algunos datos más sobre la sinonimia y la distribución geográfica de este múscide. Ibid. 10(2): 248-253.

McAdory, I. S., 1945. Screwworms and blowflies. Sth. Agric. 75(11): 17.

McCapes, A. M., 1940. Screw worms and their control. Calif. Future Fmr 10(3): 7.

McConal, J., 1976. Do factory screwworm flies lack libido? Cattleman 62(11): $58,154$.

McCrohan, A. M., 1940. Screw worms and their control. Calif. Future Fmr 10(3): 7 .

McCuistion, C. H., E. P. Schoch, Jr., R. McKee, J. S. Wiseman \& R. B. Eads, 1958. Human myiasis. Tex. St. J. Med. 54(11): 796-799.

McCulloch, E. C., 1914. Rhinal myiasis; report of two cases. Milit. Surgeon 35(3): 251-252.

MacDonald, J. C., 1924. Screw worms in nose. J. Okla. St. med. Ass. 17(1): $15-16$.

McElroy, C. H., 1947. Summertime brings screwworm threat. Cattleman 34(2): 36.

McGovran, E. R., 1937. Insecticides to control blowfly larvae in wounds. $J$. econ. Ent. 30(6): 768-878.

McGovran, E. R. \& I. O. Ellison, 1936. Repellency of pine-tar oil to wound-infesting blowflies. Ibid. 29(5): 980-983.

McGregor, W. S. \& R. C. Bushland, 1956. Research on the use of systemic insecticides for the control of livestock pests. Ibid. 49(1): 86-88.

McGregor, W. S. \& R. C. Bushland, 1957. Tests with Dow Et-57 against two species of cattle grubs. Ibid. 50(3): 246-249.

McGregor, W. S., R. D. Radeleff \& R. C. Bushland, 1954. Some phosphorous compounds as systemic insecticides against cattle grubs. Ibid. 47(3): 465-467.

McGregor, W. S., R. D. Radeleff, H. V. Claborn \& R. C. Bushland, 1955. Dieldrin, aldrin and lindane: Systemic insecticides against livestock pests. Agric. Chem. 10(1): 1-4.

Macias, E. G., A. J. Graham, M. Green \& A. W. Pierce, Jr., 1973. Cutaneous 
myiasis in South Texas. New Engl. J. Med. 289(23): 1239-1241.

McInnis, D. O., 1981. Cytogenetics of local populations of the screwworm, Cochliomyia hominivorax, from northeastern Mexico. Ann. ent. Soc. Am. 74: 582-589, 5 figs., 2 tables.

McLean, D. D., 1941a. The screw-worm fly. A report on the infections and outbreaks caused by this seasonal destroyer of game animals and livestock, together with recommendations for control. Calif. Conserv. $6(2): 11,20-21$.

McLean, D. D., 1941b. Screw worm starting. Beginning to show up in cattle. Calif. Wool Grow. 17(27): 5.

Mckley, J. W. \& A. B. Broce, 1981. Evidence of a female sex recognition pheromone in the screwworm fly. Environ. Ent. 10(3): 406-408.

Macquart, J., 1843. Diptères exotiques nouveaux ou peu connus. Mém. Soc. roy. Sci. Agric. Arts Lille (1842): 162-460, ilus. (Também publ. sep., vol. 2(3): 5-304).

Macquart, J., 1851. Diptères exotiques nouveaux ou peu connus. Suite du 4e. supplément. Ibid. 1850: 134-294, ilus. (também publ. como supl.4 (partes): 161-309, 324-336).

Madera, J. M. \& B. Morales, 1937. Miasis en otorrinolaringología. Revta argent. Oto-rino-lar. 6: 377.

Madeira, A. A. et al., 1978. Miiase da cavidade bucal. Revta catar. odontol. 5(1): 12-18, fig.

Magalhães, G. de \& G. de Magalhães, 1934. Injeções hydrargyricas curam mais um caso de myase nasal. Archos Biol., S Paulo 16 (i.c., 18): 80.

Magalhães, P. S. de, 1892. Subsidio ao estudo das myases, 82 pp., figs. Typo. graphia do Brasil, Rio de Janeiro. (res. em Gaz. méd.Bahia (4) 3(2): 86-89, 1892; e Zentbl. Bakt. ParasitKde 14: 370-371, 1893).

Magalhães, P. S. de, 1895. (Diptéres parasites connus au Brésil). Bull. Soc. ent. Fr. 20: 116-118.

Magalhães, P. S. de, 1897. Subsídio ao estudo das myiases. J. Comm., Rio de J., 2 Jan 1897 (Aditamento ao de 1892).

Magalhães, P. S. de, 1902. La myiase dẹs bovidés dans la poésie luso-brésilienne. Archs Parasit. 5(4): 612-614.

Magalhães, P. S. de, 1902. A myiase dos bovideos na poesia pátria. Revta méd. S Paulo 5(3): 49-50.

Maillard, E. O., 1870. De la Lucilia hominivorax. Thèse, Montpellier.

Maillard, E. O., 1872. De la Lucilia hominivorax (Compsomyia macellaria). Archs Méd. navale 18: 222-224.

Mandarino, E. \& M. B. de Paula, 1958. Raras localizações da miíase. Revta bras. Med. 15(1): 63.

Marciano, A. \& D. J. Greenway, 1926. Miasis en otorrinolaringología. Revta argent. Oto-rino-lar. 6: 377. [Ver Madera \& Morales].

Marconi, M. de A., 1976. Folclore do café, 136 pp. Secretaria de Cultura, Ciência e Tecnologia do Estado de São Paulo, Conselho Estadual de Cultura, Série "Folclore", n.* 4. São Paulo.

Marshall, H. L., 1944. The screw-worm fly in Utah. Rocky Mount. med. I. 41(7): $478-480$.

Marshall, H. L. \& D. T. Jones, 1944. The screwworm fly in Utah. Rocky Mt. med. J. 41: $478-480$.

Martin, H. M., 1958. Screwworms in domestic animals in southeastern Pennsylvania in 1957. Bull. Univ. Penn. 59(3): 34-41. (= Vet. Extens. Q. 152).

Martin, W., 1980. Proteus bacteria linked to screwworm life eycle. Agric. Res. 29(5): 15.

Matta, A. A. da, 1911. Miíases no Amazonas (nota clínica). Revta méd. S. Paulo 14(20): 377-379.

Matta, A. A. da, 1921a. Perturbações mentaes produzidas por nasobuco myiase com perfuração do véu do paladar. Brasil-méd. 2(14): 195-197.

Matta, A. A. da, 1921b. Idem. Amazonas méd. (2) 3: 79-83.

Maxwell-Lefroy, H., 1902. Screw worm in cattle at St. Lucia, 13 pp. [Barbados] Imp. Dep. Agric., West Indies, Pamphlet ser. 14. With a preface by D. Morris, 3 pp. 
Mazza, S., 1918. Sobre un caso interesante de miasis palatina. Revta Asoc. méd. argent. 28: 636-637.

Mazza, S. \& R. Basso, 1939. Miasis de úlcera crónica de pierna por Sarcophaga barbata y Cochliomyia hominivorax. (Investigación sobre dipteros argentinos. I. Miasis). Publnes Misión Estud. Patol. reg. argent., Jujuy 41: 47-54, ilus.

Mazza, S. \& A. Cornejo, 1939. Consideraciones sobre miasis observadas en la Provincia de Salta. (Investigaciones sobre dipteros argentinos. I. Miasis). Ibid. 41: 78-86, ilus.

Mazza, S. \& M. E. Jörg, 1939. Cochliomyia hominivorax = americana C. y P., estudio de sus larvas y consideraciones sobre miasis. (Investigaciones sobre dipteros argentinos. I. Miasis). Ibid. 41: 3-46, ilus., pls.

Mazza, S. \& H. Reyes Oribe, 1939. Miasis forunculosa por Cochliomyia hominivorax (Coquerel). (Investigaciones sobre dipteros argentinos. I. Miasis). Ibid. 41: 70-75, 6 figs.

Meaden, C. W., 1895. The cattle fly, Compsomyia macellaria. Trinidad Field Naturalist's Club 2(11): 279-281.

Meadows, M. E., Jr., 1960. Screwworm eradication in Florida. Cattleman 46(11): 23 .

Melton, R. R. \& F. W. King, 1943. Screw worm infestation of the ear. J. Kans. med. Soc. 44(12): 401-402, 407.

Melvin, A. D., 1936. Screw worm, Cochliomyia americana C. and P. in Oklahoma. Insect Pest Surv. Bull. 16(5): 211.

Melvin, A. D., 1937. Cochliomyia americana and C. macellaria, in Galstoff, Lutz, Welch \& Needham, Culture methods for invertebrate animals, pp. 413-414.

Melvin, R. \& R. C. Bushland, 1936. A method of rearing Cochliomyia americana C \& P on artificial media. U. S. Ent. Plant Quarant. St. 88: ?

Melvin, R. \& R. C. Bushland, 1938. Effect of acidity, alkalinity, and moisture content of the soil on emergence of Cochliomyia americana C. and P. J. econ. Ent. 31: 611-613.

Melvin, R. \& R. C. Bushland, 1940. The nutritional requirements of screwworm larvae. Ibid. 33(6): 850-852.

Melvin, R., R. C. Bushland \& C. L. Smith, 1943. The toxicity of certain organic compounds to young screwworm larvae. Mimeo. Circ. USDA Bur. Ent. Plant Ouarant. E-586: 21 pp.

Melvin, R., H. E. Parish, E. F. Knipling \& R. C. Bushland, 1939a. Diphenylamine as a wound protector against the screwworm, Cochliomyia americana C. and P. Ibid. E-481: 4 pp. (Também em SWest. Sheep Goat Rais. 9(17): 24-25, 1939).

Melvin, R., H. E. Parish, E. F. Knipling \& R. C. Bushland, 1939b. Results of studies on diphenylamine as a wound protector against the screwworm, Cochliomyia americana C. and P. Ibid. E-480: 4 pp.

Melvin, R., C. L. Smith, H. E. Parish \&. W. L. Barrett, Jr., 1941a. A new remedy for the prevention and treatment of screwworm infestation of livestock. Ibid. E-540: 4 pp.

Melvin, R., C. L. Smith, H. E. Parish \& W. L. Barrett, Jr., 1941b. A new remedy for the prevention and treatment of screwworm infestations of livestock. Calif. Wool Grow. 17(33): 1, 5.

Melvin, R., C. L. Smith, H. E. Parish \& W. L. Barrett, Jr., 1941c. How to combat screwworm. A new remedy for the prevention and treatment of screwworm infestations of livestock. Angora J. 31(9): 8-9.

Melvin, R., C. L. Smith, H. E. Parish \& W. L. Barrett, Jr., 1941d. A new remedy for the prevention and treatment of screwworm infestations of livestock. Cattleman 28(2): 27-28.

Melvin, R., C. L. Smith, H. E. Parish \& W. L. Barrett, Jr., 1941e. New remedy for the treatment of screwworm. Fm Ranch 60(7): 11.

Mexico. Secretaria de Agricultura y Fomento, 1927. Myiasis (de myia - mosca), $14 \mathrm{pp}$. Tacubaya.

Meyer, A., 1951. Guia do folclore gaúcho. Gráfica Aurora Editora, Ltda. Rio de Janeiro. 
Meyer, S. G. E., 1977. Concentrations of some glycolitic and other intermediates in larvae of Callitroga macellaria (F.) (Diptera, Calliphoridae) during anaerobiosis. Comp. Biochem. Phys. (B) 58(1): 49-55.

Meyer, S. G. E., 1980. Studies on anaerobic glucose and glutamate metabolism in larvae of Callitroga macellaria. Insect Biochem. 10(4): 449-455.

Micks, D. W. \& V. C. Calma, 1952. Nasal myiasis of man due to the screwworm fly (Callitroga americana C. \& P.). Tex. Rep. Biol. Med. 10(4): 854-865, ilus.

Miller, R. F., 1948. Outbreak of screw worm flies in northern California. Calif Wool Grow. 24(33): 5.

Miranda, M. V. P., 1971. Miiase vulvar, relato de um caso e estudo biológico do diptero (Callitroga americana). J. bras. Ginecol. 72(5): 309-318.

Mitchell, R. B. McQ., 1955. Fly-fighting with Cobalt-60. Scientists produce impotent male flies in a campaign against screw-worm scourge of southern livestock. Nat. Hist., N. Y. 64(5): 247-251, ilus.

Monteiro, A., 1938. Fuso espirilose do ouvido e mí́ase do conducto. Acta med., Rio de J. ?: 153-159.

Morales, V. 1923. Presentación de dos casos de miasis cutánea. Revta méd. Chile 51(11): 824-825.

Moreira, E. P., 1933. Sobre um caso gravíssimo de miase naso-retro-pharyngiano, curado com injeções endovenosas de oxy-cyaneto de mercúrio. Publções méd. 50: 14-15.

Moreira, E. P., 1939. Mais algumas observações sobre o método denominado "brasileiro" de tratamento das miases. Ibid. 10(10): 62-65.

Morgan, H. A., 1890. Texas screw-worm (Compsomyia (Lucilia) macellaria). Bull. Louis. agric. Exp. Stn (2) 2: 30-40, 4 figs. (Res. em Insect Life 3(1890-91): 131-132, 1890).

Moura, C. de, 1899. Bicheira da garganta. Revta méd. S Paulo 2(9): 271-272.

Moura, C. de, 1899. Myiase do seio. Ibid. 16(1): 1.

Moya Borja, G. E., 1979. Controle da miíase causada pela Cochliomyia hominivorax, pp. 341-344, 345-347 (Questões e sugestões), in Beck et al., q. v.

Munro, J. A. \& W. G. Bruce, 1936. I. Fly trapping and its application to human welfare. II. Seasonal appearance and relative abundance of flies caught in a baited trap at Fargo. N. Dakota Exp. Stn Circ. 60: 1-12.

Murphy, D. R., 1950. Watch out for screwworms. Wallace's Fmr 75 (16): 34, ilus.

Murray, V. I. E. \& K. Thompson, 1976. Myiasis in man and other animals in Trinidad and Tobago (1972-73). Trop. Agric., Trinidad 53(3): 263266.

Murtfeldt, M. E., 1891. Hominivorus habits of the screw worm in St. Louis. Insect Life 4(5-6): 200-201.

Nason, A. \& G. H. Hoxie, 1908. Screw worm disease - (myiasis). I. Kans. med. Soc. 8(12): 501-505, figs. 1-3.

Naylor, R. E., 1943. The screw worm. Hereford Swine J. 3(10): 24.

Neghme R., A., 1957. Eliminacion de mosca productora de miasis mediante un método biológico de irradiación atómica. Boln chil. Parasit. 12(4): 79-80.

Neghme R., A. \& R. Donoso-Barros, 1944. Miasis humana en Chile. Revta méd. Chile 72: 973-981.

Neiva, A. \& B. Penna, 1916. Viajem scientifica pelo norte da Bahia, sudoeste de Pernambuco, sul do Piauhi e de norte a sul de Goiaz. Mems Inst. Oswaldo Cruz 8(3): 74-224, 28 pls., 1 mapa.

Nellis, D. W., 1977. Screwworm fly transmission by wind. J. Parasit. 63(1): 178-179, 1 fig.

Nelson, D. R., T. S. Adams \& J. G. Pomonis, 1969. Initial studies on the extraction of the active substance inducing monocoitic behavior in Musca domestica, Phormia regina and Cochliomyia hominivorax. I. econ. Ent. 62: 634-639.

Nelson, J. B., 1893. Insects in the human ear. Insect Life 6: 56.

Nettles, W. C., 1941. Screw-worm control. Hoard's Dairyman 86(15): 478. 
Nettles, W. C. \& L. M. Sparks, 1957. Prevention of screwworm losses. Circ. Ext. Serv. Clemson agric. Coll. 341: 1-7, ilus.

Neveu-Lemaire, M., 1921. Myiases exclısivement américaines. Géographie 35(1): 36-43, mapa.

Newton, W. A., 1973. The new screwworm threat. Tex. agric. Ext. Serv. L-1089: $1-2$.

Newton, W. A. \& J. L. Ferguson, 1974. Southwest screwworm eradication program. Texas A \& M Univ. Agric. Ext. Serv. Progr. Rep. 1974: 5 pp.

Newton, W. S., 1882. The screwworm (Letter to editor). Peoria med. Month. 3(8): 325-326.

Niño, F. L., 1941a. Miasis por larvas de Cochliomyia hominivorax (Coquerel, 1858) complicando un cancer de labio. Nota parasitologica. Boln Inst. Clín. quir., B. Aires 17: 510-522, ilus.

Niño, F. L., 1941b. Miasis por larva de Cochliomyia hominivorax (Coquerel, 1858) (Nota parasitologica). Prensa méd. argent. 28(29): 1493-1501, 10 figs.

Niño, F. L., 1950. Consideraciones sobre miasis genital en la mujer. Dos nurvas observaciones de miasis por larvas de Cochliomyia hominivorax (Coquerel) 1858. Ibid. 37(5): 234-237, ilus.

Niño, F. L. \& F. Defazio, 1945. Miasis cutánẹa por larvas de Cochliomyia hominivorax (Coquerel, 1858). Boln Inst. Clín. quir., B. Aires 21: 282-286, ilus.

Niño, F. L. \& J. C. Fernandez, 1944. Miasis cutánea por larvas de Cochliomyia hominivorax (Coquerel, 1858). Prensa méd. argent. 31(52): 26532656, ilus.

Niño, F. L. \& A. J. Triaca, 1934. Miasis forunculosa por larvas posiblemente de Cochliomyia maceliaria. Boln Inst. Clín. quir., B. Aires 10: 201204, 5 figs.

Nores, A., 1897. Miasis de las fosas nasales y del oido. Tesis, Facultad de Medicina de Buenos Aires.

Norris, K. R., 1965. The bionomics of blowflies. A. Rev. Ent. 10: 47-68.

Nory, J. E., 1978. Operation of a screwworm eradication program, pp. 19-36, in R. H. Richardson, ed., The screwworm problem. Evolution of resistance to biological control: $151 \mathrm{pp}$. Univ. Texas Press, Austin.

Núñez Andrade, R., 1960a. Miasis forunculoide. Gac. méd. Méx. 90(9): 741750 , ilus.

Núñez. Andrade, R., 1960b. Miasis cutánea forunculoide humana. Medicina, Méx. 40: 217-222, ilus.

Ocampo Candido, A., D. B. Woodward \& D. B. Martinez y Tapia, 1980. Pruebas de control de calidad en la planta productora de moscas estériles del gusano barrenador del ganado Cochliomyia hominivorax (Coquerel) en Tuxtla Gutiérrez. Chiapas. Folia ent. mex. 43: 48.

Odriozola, M., 1858. Gusanera de las narices. Gac. méd. Lima 2(36): 140142; (38): 159-160; (39): 173-174; (41): 194-196; (46): 276-279.

Oglesby, W. T., 1935. Grub in the head; screw-worm control; undulant fever; mastitis control. Circ. Louis. agric. Exp. Stn 14: 1-5.

Oliveira, C. M. B., 1979. Cochliomyia hominivorax (Coquerel, 1858): Classificação, distribuição e biologia, pp. 337-340, in Beck et al., q. v.

Oliveira, S. A., 1940. Expressões do populário sertanejo. Vocabulário e superstições, 219 pp. Ed. Civilizacão Brasileira, São Paulo.

Oliver, J. E. \& M. M. Crystal, 1972. Chemosterilants against screw-worm flies. 1. J. econ. Ent. 65(1): 303-306.

Ollet, J., 1869. Des accidents produits par les larves de Lucilia hominivorax à la Guyane française, 52 pp. Thèse, Montpellier.

Ortega Gutiérrez. M., 1979. Entomofauna de interés médico en el Estado de Chiapas. Salud públ. Méx. 21(1): 49-58.

Ortega Reyes, M., 1887. Las larvas de las moscas en las fosas nasales ó la enfermedad llamada myiasis. Gac. méd. Méx. 22(1): 3-16, 1 pl.

Osborn, H., 1896. Insects affecting domestic animals: An account of the species of importance in North America, with mention of related forms occurring on other animals. US Bur. Ent., Ent. Bull. (N. S.) 5: 123-133. 
Osorno Mesa, E., 1927. Caso de perforación del vẹlo del paladar por larvas de Chrysomyia macellaria Fabricius. Boln Soc. colomb. Cienc. nat. 16: $157-161$.

Osuna, F. A. V., 1972. Efectividad de algunos insecticidas contra el gusano barrenador del ganado Cochliomyia hominivorax (Coquerel). Folia ent. mex. 23-24: 89.

Parish, H. E., 1937. Fight tests on screwworm flies. J. econ. Ent. 30(5): $740-743$.

Parish, H. E., 1942. Factors predisposing animals to screwworm infestation in Texas. Ibid. 35(6): 899-903.

Parish, H. E., 1943. Factors of screwworm infestation in Texas. Sheep Goat Rais. Mag. 23(10): 18-21.

Parish, H. E., 1945. Overwintering of Cochliomyia americana and C. macellaria at Menard, Texas. J. econ. Ent. 38(1): 83-84.

Parish, H. E. \& E. C. Cushing, 1938. Location for blowfly traps: Abundance and activity of blowflies and other flies in Menard County, Texas. Ibid. 31(6): 750-763.

Parish, H. E. \& E. F. Knipling, 1942. Field studies of certain benzene derivatives as larvicides and wound protectors against the screwworm. Ibid. 35(1): 70-73.

Parish, H. E. \& E. W. Laake, 1935. Species of Calliphoridae concerned in the production of myiasis in domestic animals, Menard County, Texas. J. Parasit. 21(4): 264-266.

Parman, D. C., 1925. Benzene as a larvicide for screw worms. I. agric. Res. 31(5): 885-888.

Parman, D.C., 1940. Screw worm fly treatment urged. SWest. Sheep Goat Rais. 10(5): 749-754.

Parman, D. C., 1945. Effect of weather on Cochliomyia americana and a review of methods and economic application of the study. J. econ. Ent. 38(1): 66-76.

Parman, D. C. \& W. L. Barrett, Jr., 1941. Ranch management for screwworm prevention and eradication in Texas and adjoining states. Cattleman 27(10): 109:113, fig. (Também em Mimeo. Circ. USDA Bur. Ent. Plant Quar. E-520: 8 pp., mapa, 1941).

Parman, D. C., F. C. Bishopp, E. W. Laake, F. C. Cook \& R. C. Roark, 1927. Chemotropic tests with the screwworm fly. Bull. USDA 1472: $1-32$.

Parman, D. C., E. W. Laake, F. C. Bishopp \& R. C. Roark, 1928. Tests of blowfly baits and repellents during 1926. Tech. Bull. USDA 80: 1-14.

Parodi, S. E. \& O. Saccone, 1916. Miasis intestinal producida por larvas de la Compsomyia macellaria y apendicitis concomitante. Prensa méd. argent. 3(31): 329-331, 1 pl. col.

Pastorino, A., 1930. Miasis forunculosa. Actas y Trab. Congr. Med. Centenario, Montev. 3: 236-238.

Patton, W. S., 1921. Notes on the myiasis-producing Diptera of man and animals. Bull. ent. Res. 12: 239-261.

Patton, W. S., 1934. Cochliomyia americana, the true screwworm fly of the New World, and its differentiation from Cochliomyia macellaria with which it has been confused. Trans. r. Soc. trop. Med. Hyg. 28(1): 5-6.

Pazos, J. H., 1904. Compsomyia macellaria (Fabricius, 1794, Rondani, 1875). Revta Med. trop. (?) 3(12): 200-202.

Pearman, R. O. \& L. Haseman, 1943. Cochliomyia americana infestation in man. Am. Surg. 117(3): 468-472.

Pearse, N. H., 1936. The ravages of the blowfly. Some important queries. Pastoral Rev. 46(12): 1338.

Peckolt, W., 1933. Em torno do tratamento mercurial das myiases. Revta Clíns, Rio de J. ?: ?.

Pedro, A., 1923. Novo tratamento das myases. Brasil-méd. 37(14): 190.

Peixoto, L., 1944. Missangas. W. M. Jackson, Inc. Editora, Rio de Janeiro.

Peraza, V. M., 1930. La nigua y la mosca que produce las gusaneras. Boln Secr. Ind. anim. Cuba 11: 1-10, 4 figs. 
Pereira, H., 1928. Oculomyase. Ceará-méd. 6 [i. e., ?7]: 5.

Pereira, J. M. S., 1947. Miase vulvar. Anais bras. Ginec. 24(5): 331-340.

Pereira, M. V., 1876. Molestias parasitarias mais freauentes nos climas intertropicais; diagnostico e tratamento do beriberi; do galvanoplastico e $e$ suas applicações; da especie humana, $13+468 \mathrm{pp}$. These para o Doutoramento em Medicina, Bahia.

Perez, M. L. \& N. Arenas, 1936. Miasis de la vulva. 9. Reun. Soc. argent. Patol. region. Norte 2: 919-923. (Também em Revta méd. lat.am. 21: 1125-1129, 2 figs.; res. em Publções méd. 84: 43, 1936).

Pescetto, F., H. Hevia, H. Reyes \& H. Schenone, 1962. Myiasis tegumentaria. Revta méd. chil. 90: 519-520.

Philippi, R. A., 1861. Beschreibung ciner neue Fliege, deren Larven in der Nase und Hirnhöhle einer Frau gelebt haben. Z. ges. Naturw. 17(6): 513-515.

Phillis, W. A. \& H. R. Agee, 1976. Spectral sensitivity and variation in visual sensitivity of the colonized screwworm fly, Cochliomyia hominivorax (Coquerel) as measured with electroretinogram. J. Ga ent Soc. 11(3): 243-246.

Phinney, D. E. \& M. S. Gibson, 1975. Weather and the screwworm. US Natl Ocean. Atmos. Admin., Wkly Weather Crop Bull., 4 Febr.: 14-15.

Pierre, E., 1888. Quelques considérations sur la présence des larves de la Lucilia hominivorax dans les cavités des fosses nasales. Thèse, Paris.

Pieter, H., 1912. Un cas de myase vulvo-vaginale. Revue Méd. Hyg. trop. 9(3): 176-177.

Pietri Andrez, (-), 1919. Perforación del velo dęl paladar producida por larvas de Lucilia hominivorax. Revta Med. Cirurg., Caracas 11(1): ?

Popov, N. P., 1947. Myiasis of the nose. Arch. Otolaryngol. 45: 112-116.

Pinheiro, F. A., E. de Lello \& O. F. Noce, 1974. O problema das miíases no município de Botucatu, SP. Ciênc. Cultura 26(7): 473-474.

Pinheiro, L., s/d. O Cariri - Seu descobrimento, povoamento, costumes. Ed.?

Pogorelski, B., 1927. Sobre un caso de miasis vulvar. Semana méd., B. Aires 34(17): 1055-1056.

Porto, C., 1934. Myases e seu tratamento. Archos Biol., S Paulo 16 [i. e., 18]: 79-80.

Porto, G., 1929. Myiase nasal e abcesso da loja temporal. Brasil-méd. 43 (31): 899.

Posada-Arango, A., 1883. Un cas de myiase. Suivi de quelques réflexions par le Dr. Viaud-Grand-Marais. J. Méd. Ouest 17: 272-276. (Também, em parte, em J. Méd. Paris 7(7): 260-262, 1884).

Posada Berrio, L., 1910. Myase des fosses nasales. Presse méd. 18(34): 319; (42): 398.

Powell, A. M., 1888. Myiasis narium. St Louis med. surg. J. 55: 206.

Prata, R., 1953. Dentro da vida (Narrativa de um médico de aldeia). Clube do Livro, São Paulo.

Prima, F., 1882. Considerations sur la Lucilia hominivorax; observations recueillies à la Guyane française, 47 pp. Thèse, Paris.

Primio, R. di, 1934. Considerações sobre a Cochliomyia macellaria e sua profilaxia. Archos rio-grand. Med. 1: ?

Prunes, L., 1923. Discusion en la presentacion de casos de miases. Revta méd. Chile 51(11): 826.

Puga-Borne, F., 1895. Otras dos enfermedades nuevas en Chile, la lepra i la miasis. Act. Soc. scient. Chili 5: 1xxxiv-1xxxy.

Pujadas y Ortiz, G., 1923. "Miasis" - Caso clínico. Revta méd. cub. 34(7): 505-507.

Pupo, J. de A., 1928. Sobre dois casos raros de leishmaniose tratados pelo esparseno: a) localização na língua; b) complicação com miíase. Bolm Soc. Med. Cirurg. S Paulo 10(11): 252-254.

Queiroz, A. de, 1945. João. Romance. Editora Livraria do Globo, Porto Alegre.

Queiroz, L. de S., 1935. Miiase ocular. Achos Inst, Penido Burnier 4(1-2): 146. 
Radeleff, R. D., R. C. Bushland \& D. E. Hopkins, 1952. Phosphorus-32 labeling of the screw-worm fly. J. econ. Ent. 45(3): 509-514.

Radice, J. C. \& S. Kaplan, 1950. Miasis humana. Estudio histopatológico. Prensa méd. argent. 37(38): 2259-2263, ilus.

Rahn, J. J. \& G. L. Barger, 1973. Weather conditions and screw-worm activity. Agric. Meteor. 11(2): 197-211.

Ramon, E., 1926. La myiasis cavicola nasal. Revta Soc. méd. mex. 5(27): 1525-1531, figs.

Rawlins, S. C., L. Jurd \& J. W. Snow, 1979. Antifertility effects of ben. zylphenols and benzy1-1,3-benzodioxoles on screwworm flies. J. econ. Ent. 72(5): 674-677.

Reed, C. S., 1930. El parasitismo de Chrysomia (sic) macellaria Fabr. no es facultativo sino que es obligatoria [sic]. Actes Soc. scient. Chili (192225) 32-35: 236-242.

Reed, E. P., 1932. Larvas de dipteros encontradas en las fosas nasales de un enfermo, en el Hospital Van Buren, de Valparaiso. Revta chil. Hist. nat. 36: 143-144.

Reedy, L. M., 1954. Screwworms in a laying flock of chickens. SWest. Vet. $7(3): 267$.

Reis, J. G. F. S., 1817. De cura boum in Brasilia - Da creação dos bois no Brasil [Textos latino e português face a face]. Typographia de Manuel Antonio da Silva Serva, Bahia, (2a. ed., 1830, 311 pp.).

Rezende, C. de, 1939. Berne e myases. Brasil-méd. 53(36): 874-875.

Rezende, E., 1934. Tratamento da milase nasal pelo oxicianeto de mercúrio endovenoso. Hospital, Rio de J. 6(2): 143-145.

Rhodes, W. L., 1930. Two cases of screwworms in the nose. Med. J. Rec. 131(6): 295-296.

Ribeyro, R. E., 1915. Un caso auténtico de miasis vesical. Prensa méd. argent. 2(14): 196-197, 4 figs. (Também em Crón. méd. Lima 32: 25-31, 4 figs., 1915).

Richardson, R. H., Ed., 1978. The screwworm problem. Evolution of resistence to biological control, xiii $+151 \mathrm{pp}$. University of Texas Press, Austin.

Richardson, R. H. \& W. W. Averyhoff, 1978. A cattleman's view of beef with and without screwworm, pp. 3-9, in R. H. Richardson, ed., q. v.

Richardson, R. W., 1935. Srew worm infestation of the nasal mucosa. J. med. Ass. Ga. 24(3): 100-101.

Ricks, D. H., 1941. Screwworm control. Shorthorn Wld 26(7): 12-13.

Riemann, J. G., 1965. The development of eggs of the screwworm fly Cochliomyia hominivorax (Coquerel) (Diptera: Calliphoridae) to the blastoderm stage as seen in whole mount preparations. Biol. Bull. 129(2): 329-339.

Riemann, J. G., 1967. A cytological study of radiation effects in testes of the screw-worm fly, Cochliomyia hominivorax (Diptera: Calliphoridae). Ann. ent. Soc. Am. 60: 308-320, ilus.

Riley, C. V., 1880. Screw worm: Its parentage in doubt. Am. Ent. 3: 203.

Riley, C. V., 1883. Prevalence of screw-worm in Central America. Am. Naturalist 17(4): 423.

Rincón Araujo, N., 1957. Miasis orbitaria. Revta oftal. venez. 2(2): 137-145.

Rivas, J. A., 1914. Un caso de miasis nasal. Revta Varg. 5(3): 51-54. (Também em Gac. méd. Caracas 21(1): 8-9, 1914).

Roark, R. C., D. C. Parman, F. C. Bishopp \& E. W. Laake, 1927. Repellents for blowflies. Ind. Eng. Chem. 19(8): 942-943.

Roberts, R. A., 1931. Myiasis in jack rabbits, Lepus californicus texanus. J. Parasit. 18: 102-104.

Roberts, R. A., 1933. Additional notes on myiasis in rabbits (Dipt.: Calliphoridae, Sarcophagidae). Ent. News 44: 157-159.

Roberts, R. A., 1935. Some North American parasites of blowflies. J. agric. Res. 50(6): 479-494.

Roberts, R. A., 1936. Purpose and organization of screwworm control program. Coastal Cattleman 2(7): 7. 
Roberts, R. A. \& W. E. Dove, 1937. Screwworm (Cochliomyia americana C. and P.). Insect Pest Surv. Bull. 17(8): 424-426.

Robertson, C. M., 1898. The Texas screwworm - Report of a fatal case. Laryngoscope, St Louis 4: 150-155.

Robineau-Desvoidy, J. B., 1830. Essai sur les myodaires. (Paris) Institut de France, (Cl. des) Sci, math. phys., Acad. roy. Sci., Mém. presentées par divers Savans (2) 2: 1-813.

Robinson, J. M., 1935. The screw worm situation in Alabama. J. econ. Ent. 28(5): 777-779, fig. 115.

Robinson, J. M., 1936. The screw worm in Alabama. J. Ala. Acad. Sci. 8: 32-33.

Robledo, E. \& J. F. Henao, 1908. (Présentation d'échantillons: Argas americanus, Compsomyia macelalria, Necator americanus). Bull. Soc. Path. exot. 1(6): 317-318.

Rocha, U. F., 1953. Miiase dos alveolos dentários em animais domésticos adultos. Veterinária, S Paulo 3(1): 39-42, ilus.

Rocha, U. F., 1956. O verdadeiro nome da môsca "bicheira" (Diptera, Calliphoridae). Bolm Ind. anim. 15: 53-58.

Rocha, U. F. \& Z. Vaz, 1950. Miiase e perfuração do rumen de bezerro por larvas de Cochliomyia hominivorax (Coquerel, 1858). Significação econômica. Revta Fac. Med. vet. Univ. S Paulo 4(2): 281-286, pls. (Também em Anais 5. Congr. bras. Vet., S Paulo: 659-664, pls., 1951).

Rohlf, J. A., 1961. New screwworm breaks alerts Southeast. Fm J. 85(11): 44-45.

Rojas R,, L., J. Cantillo G. \& E. Osorno-Mesa, 1974. Miasis uterina. Un caso de miasis uterina por Callitroga americana (Cushing y Patton, 1933). Revta colomb. Obst. Ginec. 25(1): 51-56, fig.

Roquette-Pinto, (-), 1950. Rondônia (5a. ed.). Série "Brasiliana", vol. 39. Companhia Editora Nacional, São Paulo.

Rosa, F., 1950. Miasis forunculosa. Boln Soc. Cirug. Urug. 21(2): 135-137, ilus.

Rosa, W. A. J. \& R. Niec, 1959. Contribución al estudio de las miasis. I. Miasis de las heridas. Revta Investnes ganad., B. Aires 7: 247-286.

Rosa, W. A. J. \& R. Niec, 1961. Tratamiento de las miasis de las heridas con toxafeno. Ibid. 11: 69-84.

Rosenberg, F., 1955. Unusual foreign body of the ear - Case report. Rcky Mt. med. J. 52(12): 1118.

Roura, J., 1883. La Lucilia hóminivora [sic] y la afección nasal que produce. Gac. San. milit. 9: 550-553.

Roveda, R. R. \& R. Ringuelet, 1947. Lista de los parasitos de los animales domesticos en la Argentina. Gac. vet., B Aires 9(46): 73.

Rude, C. S. \& O. H. Graham, 1946. A new treatment for screwworms in livestock. [Mimeo Circ.] USDA Bur Ent. Plant Quarant. E-708: 1-3.

Rude, C. S. \& O. H. Graham, 1947a. Idem. Ibid.: 1-3.

Rude, C. S. \& O. H. Graham, 1947b. Idem. Sheep Goat Rais. 27(6): 10.

Ruffier, F. 1918. A varejeira, in Manual practico de criação de gado no Brazil, pp. 269-272. Chácaras \& Quintais, São Paulo.

Sabrosky, C. W., 1953. The scientific name of the screw-worm, with note on Paralucilia fulvicrura. Proc, ent. Soc. Wash. 55(1): 36-38.

Sabrosky, C. W., 1962. The names for the screw-worms. Co-op. econ. Insect Rep. 12(1): 5.

Sander, P. DeL., 1933. Screw-worm (Cochliomyia macellaria Fab.). Insect Pest Surv. Bull. 13(8): 292.

Sanders, D. A. \& A. N. Tissot, 1933. The screw worm fly. Press Bull Fla agric. Exp. Sta.: 2 leaves.

Sanders, D. A. \& A. N. Tissot, 1934. The screw worm fly in Florida. Ibid.: [2] leaves.

Santiago, M. \& A. A. Beck, 1966. Sobre a infestação de lã de ovinos por Callitroga macellaria. Revta Fac. Farm. Bioq. Santa Maria 12(4): 115-117. 
Saubidet, T., 1943. Vocabulario y refranero criollo con textos y dibujos originales de Tito Saubidet, xv +421 pp., ilus. G. Knaft, Buenos Aires.

Schreider, M. M., N. Schuckmell \& J. Sampseli, 1964. Human myiasis. J. Am. med. Ass. 188: 828-829.

Schurr, K., 1978. Plan for biological control of the fly Cochliomyia macellaria in the Galapagos. Ohio J. Sci. 78: 8.

Scott, H. G., 1963. Myiasis: Epidemiologic data on human cases (North America north of Mexico: 1952-1962 inclusive). US Dep. Hlth Educ. Welfare CDC Inf. Sheet, $14 \mathrm{pp}$.

Scott, H. G., 1964. Human myiasis in North America (1952-1962 inclusive). Fla Ent. 47(4): 255-261.

Scott, H. G. \& K. S. Littig, 1962. Flies of public health importance and their control. Publ. Hlth Serv. Publ. 779: 1-40.

Scruggs, C. G., 1962. Success of screwworm eradication program requires producer cooperation. Cattleman 48(11): 58, 60.

Scruggs, D. G., 1975. The peaceful atom and the deadly fly, $311 \mathrm{pp}$. Jenkins Publ. Co., Austin, Texas.

Scruggs, C. G., 1978. The origin of the screwworm control program, pp. 11-18, in R. H. Richardson, ed., q. v.

Séguy, E., 1948. Introduction à l'étude des myiases. Revta bras. Biol. 8(1): 93-111.

Servicio Cooperativo Interamericano de Productos de Alimentos, 1953. Gusanera o miasis. Divulg. agric. vet. Serv. Extens. Agric. SCIPA, Ser. Vet., 3 pp.

Settepani, J. A., M. M. Crystal \& A. B. Borkovec, 1969. Boron chemosterilants against screw-worm flies: Structure-activity relationships. J. econ. Ent. 62(2): 375-383.

Severin, H. C., 1954. Screw-worms and secondary maggots. 67. a Rep. S. Dak. agric. Exp. Stn 1953-54: 138-139.

Shannon, J., 1909. Screw-worms. Missouri Vall. vet. Bull. 3(12): 456-458.

Shannon, R. C., 1923. Genera of Nearctic Calliphoridae, blowflies, with revision of the Calliphorini. Ins. Insc. Menstr. 11(7-9): 101-118.

Shannon, R. C., 1926. Synopsis of the American Calliphoridae (Diptera). Proc. ent. Soc. Wash. 28(6): 127-128.

Shannon, R. C. \& E. Del Ponte, 1926. Sinopsis parcial de los muscoideos argentinos. Revta Inst. Bacter. B. Aires 4(5): 38.

Sharman, R. S., 1959. Screwworm eradication program in the southeastern United States. Proc. 62. a. Mt. U. S. Livestock San. Ass. (Miami Beach, 1958): 183-186.

Sharman, R. S., 1960. Screwworm eradication in the southeast. Cattleman 46 (11): $25-28$.

Sharman, R. S. \& C. L. Campbell, 1960. Screwworm eradication in the southeastern states. USDA, Agric. Res Serv., Agric. Hb. 167: 103-111, ilus.

Sheely, W. J., 1942. Screwworm is still worst external pest of southern livestock. Fla Cattleman 6(8): 6, 18.

Shillinger, J. E., 1942. Diseases of wildlife and their relationship to domestic livestock. USDA Yb. Agric.: 1222-1223.

Shira, R. B., 1943. Report of a case of oral myiasis. Milit. Surg. 92: 57-58.

Siddal, C., 1941a. A good screw worm remedy. SWest. Sheep Goat Rais. 11(16): 24.

Siddal, C., 1914b. New remedy for screwworm. Coastal Cattleman 7(5): 15.

Siddal, C., 1941c. Period at hand during which screwworm fly population of spring is determined. Angora J. 31(11): 11.

Siddal, C., 1941d. Prevent screwworm flies by eliminating wounds. Coastal Cattleman 7(10): 29.

Siddal, E., 1941e. Remedy for screw-worms is announced by Texas A. and M. entomologist. Angora J. 31(6): 6.

Siddal, C., 1941f. Screwworm outbreak expected. Coastal Cattleman 7(1): 42.

Siddal, C., 1941g. Screwworm outbreak threatening. Sheep Goat Rais. Mag. 21(8): 2 . 
Siddal, C., 1942. Critical time in screwworm fly propagation. Ibid. 22(4): 19.

Silva, A. L. da \& I. de O. Santos, 1965. Miiases ano-retais. Revta bras. Med. 22(5): 273-275, ilus.

Silva, M. P. da, 1911. Note sur l'habitat de Chrysomyia macellaria. Bull. Mus. Hist. nat., Paris 6: 414-415.

Silva, M. P., 1912. Nouveaux cas de myase dus à Chrysomyia macellaria Fabricius, à Bahia. Archs Parasit. 15(3): 425-430, 2 figs., pl. 1, figs. 1-4.

Silveira, J. X. da, 1907. A propósito das míases. Gaz. clín., S Paulo 5(11): 104.

Smith, C. M., G. C. LaBrecque \& A. B. Borkovec, 1964. Insect chemosterilants. A. Rev. Ent. 9: 269-284.

Smith, A. L. \& C. C. Skipper, 1952. Screw-worm surveys in the south-eastern states 1944-1951. Fla Ent. 35(1): 10-13.

Smith, C. L., 1960. Mass production of screw-worms (Calliphora hominivorax) for the eradication program in the southeastern states. J. econ. Ent. 53(6): 1110-1116.

Smith, H. H., 1892. Screw worms and the man-infesting bot in Brazil. Insect Life 5(4): 265-267.

Smith, J. A. P., 1905. Sobre la miasis y su tratamiento. Argent. méd. 3: 260.

Smith, R. H., 1973. Screwworm control. Science, N. Y. 182: 775.

Smith, R. H. \& R. C. von Borstel, 1972. Genetic control of insect populations. Science, N. Y. 178: 1164-1174

Smith, R. S., 1950. Be prepared... Bad screw-worm year. Gulf Cst Cattleman 16(4): 13

Snow, F. H., 1883a. Habitudes anthropophagiques de la Lucilia macellaria Fab. Le "screw-worms". Naturaliste, Paris 5(38): 300-302.

Snow, F. H., 1883b. Hominivorous habits of Lucilia macellaria. "The screw worm". Psyche, Cambr. 4(1883-85): 27-30.

Snow, J. W., 1978. The screwworm situation in Texas and Mexico, 1976. Folia ent. mex. 39-40: 193.

Snow, J. W., J. R. Coppedge, A. H. Baumhover \& R. Gorsira, 1978. The screwworm Cochliomyia hominivorax (Diptera: Calliphoridae) reinfests the island of Curaçao, Netherlands Antilles. J. med. Ent. 14(5): 592-593.

Snow, J. W., H. C. Hofman \& A. W. Baumhover, 1977. The screwworm as a pest on the island of Jamaica and the feasibility of eradication by the sterile insect method. SWest Ent. 2(4): 202-206.

Snow, J. W. \& M. E. Meadows, 1978. Sterile screwworms have libido. Cattleman 64(10): 137-138.

Snow, J. W., J. R. Rauliston \& F. S. Guillot, 1976. Mating tables: A method of studying the mating and the competitive behavior of Lepidoptera and Diptera in the field. Ann. ent. Soc. Am. 69(4): 751-752.

Snow, J. W., A. J. Siebenaler \& F. G. Newell, 1981. Annotated bibliography of the screwworm, Cochliomyia hominivorax (Coquerel). USDA, Sci. Educ. Adm., Agric. Rev. Manuals ARM-S-14: 32 pp.

Snow, J. W. \& C. J. Whitten, 1979. Status of the screwworm (Diptera: Calliphoridae) control program in the southwestern United States during 1977. J. med. Ent. 15(5-6): 518-520.

Souto, G. G., 1943. Miiases nas aves. Bolm Soc. bras. Med. vet. 12(1-2): 25-30, pl.

Spalding, W., 1955. Tradições e superstições do Brasil Sul (Ensaios de folclore). Ed. Organização Simões, Rio de Janeiro.

Spates, G. E., Jr. \& B. G. Hightower, 1967. Sexual aggressiveness of male screw-worm flies affected by laboratory rearing. J. econ. Ent. 60(3): $752-755$.

Spates, G. E., Jr. \& B. G. Hightower, 1970. Variations in the size and reproductive capacity of wild-type and laboratory-adapted populations of the screw-worm fly. J. econ. Ent. 63(5): 1381-1385.

Spencer, J. B., J. R. Coppedge \& H. E. Brown, 1979. Un método para la marcación de moscas del gusano barrenador del ganado. Folia ent. mex. 43: 55-56. 
Spencer, J. P., C. T. Whitten, J. R. Coppedge \& J. W. Snow, 1980. Comparison of screwworm (Cochliomyia hominivorax) captures in liver and swarmlure-baited traps in a tropical area in southern Mexico. SWest Ent. 5(3): 175-178.

Spicer, W. J. \& W. E. Dove, 1938. The screwworm and the Gulf Coast tick in southern Texas. J. econ. Ent. 31(6): 642-646.

Spink, W. T., 1960. Screw-worm eradication program. Insect Condit. Louis. 3: $38-40$

Stabile, A., 1942. Sobre miasis de la vulva. Archos urug. Med. Cirug. 21(2): 187-198, ilus.

Steelman, C. D., 1976. Effects of external and internal arthropod parasites of domestic livestock production. A. Rev. Ent. 21: 155-178.

Stephan, O., 1935. Bicheira [a Cochliomyia macellaria]; sarna [Consultas do I. Biológico]. Biológico, S Paulo 1(1): 14.

Steward, M. A. \& A. N. Boyd, 1934. A new treatment of traumatic dermal myiasis. J. Am. med. Ass. 103: 403.

Stewart, M. A., 1941. Screw-worm fly control. New fly repellent now available. Manufactured by Standard Oil Co. Calif. Wool Grow. 17(30): 5.

Stewart, M. A. \& E. B. Roessler, 1942. The seasonal distribution of myiasis-producing Diptera. J. econ. Ent. 35(3): 408-411.

Stone, W. M., 1964. Rate of survival in Guinea pigs following infestation by screw-worm larvae. J. Parasit. 50(1): 152-154.

Strong, L. A., 1936a. Screw worm control program in the southeast. Natl Wool Grow. 26(10): 28.

Strong, A. L., 1936b. Screw worm control work extended to southwest. Am. Hereford J. 27(6): 11.

Strong, A. L., 1937. Screw worm control. Rep. Chief Bur. Ent. USDA (1936-37): 71-75.

Stroud, R. J. H., 1927. Myiasis in the southwest, with particular reference to the species Chrysomyia macellaria. SWest. Med 11(7): 313-317, ilus.

Swanson, L. E. \& O. F. Goen, 1952. Screwworms and their control. Univ. Fla Agric. Ext. Serv. Circ. 107: 1-4.

Talice, R. V. \& H. Ilaria, 1934. Un nuevo caso de miasis primitiva forunculoide por larvas de Cochliomyia macellaria. Archos urug. Medna Cirug. 5(3): 296-298.

Tannahill, F. H., 1978. Development of an adult suppression system for the screwworm fly, Cochliomyia hominivorax (Coquerel), $44 \mathrm{pp}$. MS Thesis, Pan American University, Edinburgh, Texas.

Tannahill, F. H., J. R. Coppedge \& J. W. Snow, 1980. Screwworm (Diptera: Calliphoridae) myiasis on Curaçao: Reinvasion after 20 years. J. med. Ent. 17(3): 265-267.

Tannahill, F. H., J. W. Snow \& J. R. Coppedge, 1980. Exhaust fume anesthetizer for use with wind-oriented screwworm (Cochliomyia hominivorax) traps. SWest Ent. 5(4): 210-213.

Tao, P. M., 1927. A comparative study of the early stages of some common flies. Am. J. Hyg. 7: 735-761.

Tate, H. D., 1935. The screw worm (Cochliomyia americana C. \& P.) failed to survive the winter of 1934-1935 in Iowa. J. econ. Ent. 28(5): 835837.

Taylor, H. M., 1950. Screwworm (Cochliomyia americana) infestation in man. Ann. Otol. Rhinol. Lar. 59(2): 531-540, ilus. [Também em Bull. Riverside Hosp., Jacksonville 2:33].

Teixeira, F., 1949. Estudos de folclore. Movimento Editorial Panorama, Belo Horizonte.

Teixeira, F. 1954. Medicina popular mineira, 168 pp. Ed. Organização Simões, Rio de Janeiro.

Teixeira, J. A., 1941. Folclore goiano. Companhia Editora Nacional, São Paulo.

Templeton, A. R. \& M. A. Rankin, 1978. Genetic revolution and control of insect populations, pp. 83-111, in R. H. Richardson, q.v.

Tennant, C. E., 1906. Inoculation by screw-worm fly. Clinique, Chicago 27 
(10): $607-612$.

Terranova, A. C. \& M. M. Crystal, 1970. The fate of N, N'tetramethylenebis (7-aziridinecarboxamide) in the black blow fly and the screwworm fly. J. econ. Ent. 63: 455-458.

Terrera, G., 1947. El caballo criollo en la tradición argentina (2a ed.), 430 pp., ilus. Gersosimo, Buenos Aires.

Terry, P. H. \& M. M. Crystal, 1972. Chemosterilants against screwworm flies. II. J. econ. Ent. 65(1): 307-310.

Texas Agr. Exp. Stn \& Texas A \& M Ext. Serv., 1962. Producing sterile screwworm flies. Tex. agric. Prod. 8(5): 3-6.

Texas Agr. Exp. Stn \& Texas A \& M Ext. Serv., 1965. Between atoms and computers - The screwworm's days are numbered. Ibid. 11(4): 4-6.

Thom, P. J. P., 1977. Fluctuacion de poblacion de mosca tornillo [sic] Cochliomyia hominivorax (Coquerel) el el cañon de Rayones, N. L., 84 pp. MS Thesis, Inst. Tecn. Est. Sup. Monterrey.

Thompson, F. C., 1973. De Geer's exotic Musca species (Diptera: Syrphidae and Calliphoridae). Proc. ent. Soc. Wash. 75(3): 354-356. [Musca erythrocephala De Geer = Cochliomyia macellaria].

Thomson, C. G., 1869. 6. Diptera, Species nova descripsit..., pp. 443-614, ilus., in K. Svenska Vetenskaps-Akademien, Kongliga svenska freggaten Eugenies resa omkring jorden 2 (Zool), (Sec.) 1: Insekter: 617 pp. Stockholm, "1868".

Townsend, C. H. T., 1915. A new generic name for the screwworm fly. J. Wash. Acad. Sci. 5(20): 644-646.

Townsend, C. H. T., 1936. On Cochliomyia hominivorax Coquerel (Dipt.). Revta Ent., Rio de J. 6(3-4): 485-487.

Travis, B. V., E. F. Knipling \& A. L. Brody, 1940. Lateral migration and depth of pupation of the larvae of the primary screwworm Cochliomyia americana C. and P. J. econ. Ent. 33(6): 847-850.

Turnbull, F. M. \& L. B. Franklin, 1942. Aural infestation with screw worms. J. Am. med. Ass. 120(2): 117-119.

Turnley, W. H., 1954. Screwworm infestation in humans. J. Fla med. Ass. 40(10): 733-736, ilus.

Umaña, R., 1914. Etude général des myiases, 87 pp., ilus. Thèse, Paris.

Umbarger, C. J. \& J. J. Malanify, 1972. Insect tagging: Natural vs laboratory grown screwworm flies. Int. J. appl. Isot. 23(8): 381-382.

U.S. Department of Agriculture, 1945a. Screwworm outbreaks in Texas. West. Livstk J. 23(26): 6.

U.S. Department of Agriculture, 1945b. Screwworm outbreaks threatens Texas and Florida. Fed. Vet. 2(9): 5-6.

U.S. Department of Agriculture, 1955a. Operation screwworm. USDA entomologists experimenting with atomic energy in attempt to eradicate livestock pest on Island of Curaçao. Cattleman 41(8): 38-39, ilus.

U.S. Department of Agriculture, 1955b. Screwworm fly is eradicated from West Indian Island. Sheep Goat Rais. Mag. 35(5): 35.

U.S. Department of Agriculture, 1955c. Successful eradication of screw-worm based on a new concept of insect control, 1 p. Washington, D. C.

U.S. Department of Agriculture, 1958. Atom versus the screwworm. Cattleman 45(5): 32-34, ilus.

U.S. Department of Agriculture, 1959a. Screwworm infestation found in Mississippi and Louisiana. Santa Gertrudis J. 1(1): 37.

U.S. Department of Agriculture, 1959b. Report. The screwworm problem in the southwestern United States and northeastern Mexico with comments on control and eradication, $38 \mathrm{pp}$. Washington, D. C.

U.S. Department of Agriculture, 1959c. Screwworm eradication program uses fly factory. Mod. vet. Pract. 40(2): 58-59.

U.S. Department of Agriculture, 1960a. Screwworms. Pocket reference to federal requirements governing interstate movement of livestock to prevent the spread and dissemination of screwworms, $6 \mathrm{pp}$. folder. Washington, D. C. 
U.S. Department of Agriculture, 1960b. Questions and answers about screwworm eradication. Cattleman 46(8): 98, 100.

U.S. Department of Agriculture, 1960c. Facts about the screwworm. Circ. USDA, ARS (CA-11-1): $6 \mathrm{pp}$. folder, ilus. Washington, D. C.

U.S. Department of Agriculture, 1962. Status of the screwworm in the United States. ARS spec. Rep. 22-79: 1-13.

U.S. Department of Agriculture, 1963. Facts about screwworm eradication. ARS, USDA 91-39: 1-11, ilus., pl.

U.S. Department of Agriculture, Bureau of Entomology and Plant Quarantine, 1942a. Improved screwworm remedy gets the job done. Sth Stockman 2(10): 74 .

U.S. Department of Agriculture, Bureau of Entomology and Plant Quarantine, 1942b. New screw worm remedy. Shorthorn Wld 27(12): $10-11$.

U.S. Department of Agriculture, Bureau of Entomology and Plant Quarantine, 1951a. EQ 535 and other wound treatments for screw-worm control. USDA, BEPO Mimeo. Circ. E-813: 1-6.

U.S. Department of Agriculture, Bureau of Entomology and Plant Quarantine, 1951b. Screwworms may be killed out in south by use of radiation. N. Mex. Stockman 16(12): 78.

U.S. Department of Agriculture, Bureau of Entomology and Plant Quarantine, 1952. Radiation promises aid in fight on screw-worm fly. Fed. Vet. 9(1): 1, 4.

U.S. Department of Agriculture, Office of Information, Photo Division, 1958. Atoms vs. the screwworm. Pict. Story USDA 108: 1-4, ilus.

U.S. Department of Agriculture, Office of Information, Photo Division, 1959. Atoms vs the screwworm. N. 2 Progress Report. Pict. Story USDA 116: 1-4.

U.S. Department of Agriculture, Office of Information, Photo Division, 1963. Screwworm stronghold attacked. Pict. Story USDA 151: 1-6, ilus.

Urgell, D. G., 1924. Larvas en la nariz. A. M. M. 2(5): 192-196.

Urieta, A., 1951. Se reconocen doce especies de moscas capaces de provocar "engusanamiento". Mundo agrario 3: 34, 36, ilus.

Valdecasas, P. G., 1947. Larviasis ocular. Archos Soc. Oftal. hisp.-am. 7(9): 909-911.

Valette, Frei C., s/d. Riquezas medicinais da flora brasileira. Editora Cupido Ltda., São Paulo.

Vanlaw, E., 1939. Screwworms. J. Am. vet. med. Ass. 95: 219.

Varalla, J. V., 1905. Algunos casos de miasis. An. Círc. méd. argent. 28: 140.

Vargas, J. M., 1928. Monografía sobre casos prácticos de insectos en fosas nasales (?).

Vargas, L., 1951. Chapter 54. Myiasis, pp. 1199-1202, in R. B. H. Gradwohl, L. B. Soto \& O. Felsenfield, eds., Clinical tropical medicine. C. V. Mosby Co., St. Louis.

Vaughn, H., 1941. Screw worm control. Tag all ewes prior to shearing. Calif. Wool Grow. 17(4): 5.

Vaz, H., 1904. A cura da myiasis nasal pela ação da eletricidade. Revta méd. $S$ Paulo 7(10): 215-216.

Vaz, Z., 1935a. Cochliomyia hominivorax, agente causal de miiases em animaes domesticos do Brasil. (Caractéres que permitem distingui-la de C. macellaria). Revta Biol. Hyg. 6(1): 13-18, 8 figs.

Vaz, Z., 1935b. Ectoparasitas de animaes domesticos observados no estado de S. Paulo (exclusive Siphonaptera e Ixodoidea). Archos Inst. biol. $S$ Paulo 6: 29-33.

Vaz, Z., 1938. Sobre a Cochliomyia hominivorax como produtora de myiasis humana. Anais paul. Med. Cirurg. 36(1): 62.

Vaz, Z. \& G. T. de Carvalho, 1938. Sobre um tipo interessante de miíase dos bezerros e seu agente causal. Revta Fac. Med. vet. Univ. S Paulo 1(1): 43-48, ilus.

Verhuell, Q. M. R., 1850. Mededeeling der metamorphose van eene in Guyana voorkomende vliegensoort. Tidschr. wis. en natuurk. Wetensch. 3: 
273-275, fig.

Vidal, A., 1950. Lendas e superstições. Contos populares brasileiros, 626 pp. Editora O Cruzeiro, Rio de Janeiro.

Villaseñor, M. A., S. Luna, K. Goodwich, E. Sánchez, J. Cedillo \& E. Ugalde, 1976. La planta, 20 pp. Comissión Mexico-Americana para la erradicación del guszno barrenador del ganado, México.

Villiers, J. M. de, 1941. Miasis faringea. Revta Sanid. milit., Habana 5(3-4): 101-104, pl.

Villiers, R. de, 1945. Miasis nasal. Kuba 1(4): 59-60.

Vogelsang, E. G., 1951. Miasis lingual del bovino (Bos taurus) por Cochliomyia hominivorax (Coquerel, 1858). Revta Med. vet. Parasit. Caracas 10(1-4): 107-109.

Wallace, W. R., 1936. Screw worm infestation. Il S. Carol. med. Ass. 32(9): 213-215.

Walker, F., 1849. List of the specimens of dipterous insects in the collection of the British Museum 4: 689-1172. London.

Walker, F., 1852. Insecta Saundersiana or characters of undescribed insects in the collection of W. W. Saunders, Esq., Diptera 1: 253-414, ilus. London, "1856".

Ward, (-), 1907. A Nebraska case of the screw worm. West. med. Rev. 12: $483-485$.

Weber, (-), 1867. Recherches sur la mouche anthropophage du Mexique (Lucilia hominivorax). Recl Mém. Obsns Méd. vét. milit. (3) 18: 158-170.

Weed, C. M., 1890. The screw-worm (Compsomyia macellaria). Am. Naturalist 24: 1213 .

Weed, C. M., 1891. Idem. Miss. Exp. Stn Bull. 14: 3-12.

Whitten, M. J., 1974. Introduction to the use of genetics in insect control, pp. 1-16, in R. Pal \& M. J. Whitten, eds., The use of genetics in insect control, xiii + 241 pp., ilus. Elsevier, Amsterdam \& New York.

Whitten, M. J., 1980. Use of the isozyme technique to assess the quality of mass-reared sterile screw-worm flies. Ann. ent. Soc. Am. 73(1): 7-10.

Wiedemann, C. R. W., 1830. Aussereuropäische zweiflügelige Insekten 2: xii +684 pp. ilus.

Williams, D. L., S. C. Gartman \& L. Hourrigan, 1977. Screwworm eradication in Puerto Rico and Virgin Islands. Wrld Anim. Review 21: 31-35.

Williston, S. W., 1884. The screw-worm fly, Compsomyia macellaria. Psyche, Camb. 4: 112-114.

Wilson, D., 1960. Screwworm research. Ground work being laid to eradicate screwworm in southwest. Cattleman 47(5): 118, 120.

Wilson, D., 1963. Screwworm eradication program is working. Ibid. 89(9): $22-24$

Wolffenbüttel, E., 1953a. As várias formas de miíases no homem. Sua profilaxia e seus diferentes tratamentos (comprovados e a serem exper1mentados). Revta bras. Med. 10(2): 135-139.

Wolffenbüttel, E., 1953b. As várias formas de miíases no homem. Sua profilaxia e seus diferentes tratamentos. II. Parte. Miíases (bicheiras) especialmente por larvas necrobiontófagas. Ibid. 10(3): 213-218.

Wolffenbüttel, W., 1953c. Idem. III. Parte. Observações e comentários. Ibid 10(4): 286-289.

Wolffenbüttel, E., 1953d. Idem. IV. Parte. Ibid. 10(5): 365-370.

Wolffenbüttel, E., 1953e. Idem. V. Parte. Miíases em oftalmologia. Ibid. 10 (6): 447-449.

Wolffenbüttel, E., 1953f. Idem. VI. Parte. Ibid. 10(7): 518-521.

Wolffenbüttel, E, 1953g. Idem. VII. Parte. Ibid. 10(8): 594-598.

Woodruff, B., A. Bell, J. Culnane, K. Hindmarsh, B. Lee, R. Lebane \& J. Lumbers, 1979. The screw-worm threat. Rural Res. 102: 4-8.

Wrich, M. J., 1961. A comparison of Co-Ral, Ronnel, and Ruelene dusts for screw-worm control. J. econ. Ent. 54(5): 941-945.

Wrich, M. J. \& R. C. Bushland, 1960. Screw-worm control with insecticide sprays. I. econ. Ent. 53(6): 1058-1061.

Wrich, M. J., W. F. Chamberlain \& C. L. Smith, 1961. Toxicity of General 
Chemical compounds 3582, 3583, and 4072 to screw-worms in laboratory and field tests. Ibid. 54(5): 1049-1050.

Wright, J. E., H. E. Smalley, R. L. Younger \& H. R. Crookshank, 1974. Hormones for the control of livestock arthropods: Effects of 2 juvenile hormone analogues against the screwworm Cochliomyia hominivorax (Coquerel) in vitro and in infested bovine hosts. J. med. Ent. 11(4): 385-389.

Xavier, J. de P., 1944. Miíase palpebral. Revta méd. Paraná 13(7-8): 23-27. Yamaguchi, N., J. Guidugli Neto \& A. H. Gama, 1973. Miíase anal. Revta méd. IAMSPE 4(1-4): 21-23, il.

Yeomans, M. S., 1935. Screw worm menace to livestock industry. Sth. Cultiv. Dixie Fmr 93(1): 8-9, 2 figs.

Young, E. G., 1902. Contribuições para os estudos dipterolojicos. Lucilias, 16 pp. Typographia da Comarca, Iguape (Estado de São Paulo).

Young, J. H., 1962. The screwworm and its control. Okla St. Univ. Ext. Serv. Leaflet L-74: 8 pp., figs.

Yount, C. E. \& M. T. Sudler, 1907. Human myiasis from the screwworm fly (Compsomyia macellaria Fabr.). J. Am. med. Ass. 49(23): 19121916.

Zepeda, P., 1913. Nouvelle note concernant les moustiques qui propagent les larves de Dermatobia cyaniventris et de Chrysomyia macellaria et peut-être celle de Lund, et de la Cordilobia anthrophaga. Revue Méd. Hyg trop. 10(2): 93-95.

Zucoloto, S. \& M. A. Rossi, 1971. Miiase facial com extensão para a caixa craniana. Revta bras. Med. 28(1): 13-16.

\section{FAMILIA GASTEROPHILIDAE}

A posição sistemática deste grupo de dípteros foi muito debatida; alguns trataram-no como parte dos Oestridae ou Tachinidae, outros como Muscidae ou Anthomyidae, e ainda outros como uma família dos Acalyptratae. Hennig (1958) mantém os Gasterophilidae como família distinta, dentro dos Muscoidea e esta posição tem sido seguida até aqui.

A família Gasterophilidae é dividida em quatro subfamílias, sendo que apenas uma - Gasterophilinae - com o gênero Gasterophilus Leach, ocorre no Novo Mundo.

As larvas desta subfamília se desenvolvem no estômago e intestino de equinos; ocasionalmente larvas de $1 .^{\circ}$ estágio de Gasterophilus podem causar oftalmomiíases ou miíases subcutâneas no homem, conhecidas na literatura com o nome de larva migrans, myiasis linearis, creeping disease, creeping eruption, rampant subcutaneous myiasis e Hautmaulwurf. Nem todos os casos de "larva migrans" são contudo causadas por larvas de Gasterophilus: em nosso meio o agente etiológico mais comum de "larva migrans" são as larvas de Ancylostoma caninum e $A$. brasiliense. Para referências ao parasitismo do homem por Gasterophilus consultar James (1948).

7.1. Classificação

\section{Gênero Gasterophilus Leach}

Gasterophilus Leach, 1817: 162. Espécie-tipo, Oestrus equi Clark (Curtis, 1826: pl. 146) = intestinalis De Geer.

Gastrus Meigen, 1824: 174.

Gastrophilus Agassiz, 1846 (emend.).

Características gerais: Cabeça curta, revestida de pêlos bem conspícuos; cerdas fracamente desenvolvidas ou ausentes. Antenas pequenas; arista nua. Aparelho bucal vestigial. Tórax piloso, sem cerdas. Asas com a nervação bem característica. Subcostal e ramos da veia Radial bem próximos da margem costal, veia transversa $\mathrm{M}^{1}+2$ reta, célula apical alargando-se gradualmente em direção à margem da asa. Abdome alongado, oval; em algumas espécies o ovipositor é longo e fortemente curvado debaixo do abdome. $\mathrm{O}$ 
adulto tem a aparência e tamanho de uma abelha comum e esta semelhança é acentuada pelo zumbido que produz durante o vôo.

As espécies de Gasterophilus, assim como seus hospedeiros (Equidae), eram originalmente restritas às regiões Paleártica e Etiópica; porém, muitas espécies foram introduzidas em outras regiões do globo, junto com os equinos. As larvas se desenvolvem somente no trato digestivo de equinos, podendo ocasionalmente infestar cães, coelhos e mesmo o homem.

Chave para as espécies

\section{a. Adultos}

1. Asas manchadas (Fig. 63), com uma larga mancha mediana e duas pequenas manchas isoladas próximas ao ápice; calípteros inferiores maiores que os superiores; 11 a $15 \mathrm{~mm}$.... intestinalis (De Geer)

Asas inteiramente hialinas; calípteros inferiores distintamente maiores que

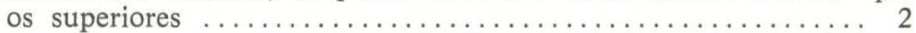

2. Transversal dm-cu situada muito mais distante da base da asa do que

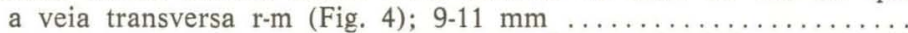
haemorrhoidalis (Linnaeus)

Transversal dm-cu situada oposta à veia transversa r-m (Fig. 3) ....

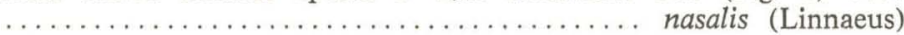

b. Larva III

1. Espinhos arranjados em duas fileiras, sendo a fileira anterior a mais

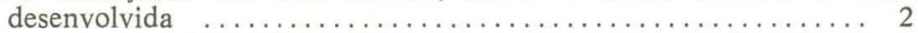

Espinhos em uma única fileira (Fig. 66) . ......... nasalis (Linnaeus)

2. Espinhos longos e proeminentes, apenas dois ou três pares medianos ausentes na nona fileira da face dorsal (Fig. 65) $\ldots \ldots \ldots \ldots \ldots$. $\ldots \ldots \ldots \ldots \ldots \ldots \ldots \ldots$ intestinalis (De Geer)

Espinhos curtos. Nona fileira sem espinhos ou apresentando apenas dois ou três pares medianos de cada lado (Fig. 64) ............... $\ldots \ldots \ldots \ldots \ldots \ldots \ldots \ldots$ haemorrhoidalis (Linnaeus)

7.2. Biologia comparativa das três espécies

\section{Gasterophilus nasalis (Linnaeus)}

Oestrus nasalis Linnaeus, 1758: 584.

Gasterophilus nasalis; Brauer, 1863: 86, figs.; Hawden \& Cameron, 1918: 91, figs.

Oestrus veterinus Clark, 1797: 328.

Gastrophilus veterinus; Séguy, 1928: 68, figs.; Zumpt \& Paterson, 1953: 65, figs.; Grunin, 1955: 56, figs.

Para sinonímia completa, consultar Zumpt \& Paterson (1953).

Adulto. Corpo densamente ṕiloso. Tórax com pêlos amarelados a ferrugíneos, asas sem manchas.

A fêmea voa perto do animal, arremessando-se como uma flexa para fazer oviposição nos pêlos do lábio inferior do animal. Durante cada ataque são depositados de 1 a 4 ovos em cada pêlo. As moscas voam para longe após cada investida, retornando em poucos minutos. Cada fêmea pode depositar cerca de 500 ovos.

Ovos - São amarelados, eclodem dentro de 6 dias, não necessitando para isso umidade ou fricção.

Larva - As larvas recém-eclodidas penetram na boca do animal, alojando-se geralmente entre as cavidades existentes entre os molares. Após 20 ou 30 dias as larvas migram e se localizam de preferência no duodeno e freqüentemente no estômago. E a única espécie conhecida que se fixa na faringe, podendo ocasionar infecções ou asfixia. Quando a infestação é maciça, 
pode ocasionar obstrução do piloro. O período total de desenvolvimento larval pode ser de 10 a 11 meses. A larva madura é eliminada junto com as fezes.

\section{Gasterophilus haemorrhoidalis (Linnaeus)}

Oestrus haemorrhoidalis Linnaeus, 1758: 584.

Gastrophilus haemorrhoidalis; Brauer, 1863: 83, figs.; Hawden \& Cameron, 1918: 91, figs.; Grunin, 1955: 70, figs.; Dove, 1918: 16, figs.

Gasterophilus haemorrhoidalis; Séguy, 1928: 63, figs.; Wells \& Knipling, 1938: 194, figs.: Zumpt \& Paterson, 1953: 64, figs.

Para sinonímia mais completa, vide Zumpt (1965).

Adulto - Corpo predominantemente revestido de pêlos escuros. Base do abdome com pêlos esbranquiçados; na rẹgião mediana os pêlos são escuros, em contraste com os pêlos vermelho-alaranjados do ápice. Tórax com pêlos cinza-oliváceo, com uma faixa preta atrás da sutura. É a menor de todas as espécies, com 9-11 mm. Asas imaculadas. Período de vida: 1-7 dias.

A fêmea arremessa-se em direção ao lábio do animal, depositando aí um ovo na base do pêlo, voando para longe logo a seguir. Após poucos segundos volta a atacar. Os ovos são depositados próximos à pele, geralmente ao longo da porção anterior do lábio inferior. Cada fêmea pode depositar cerca de 160 ovos.

Ovos - Pretos. Eclodem dentro de 5 a 10 dias, havendo necessidade de umidade para eclosão; não necessitam porém de fricção.

Larva - As larvas recém-eclodidas perfuram o lábio para alcançar o interior da boca, chegando aos dentes, e aí permanecem cerca de 6 semanas ou mais. Outras são levadas junto com o alimento ou água e se fixam em várias partes do estômago ou do duodeno. A maior concentração de larvas ocorre próxima ao orifício de saída do estômago. As larvas maduras, ao se desprenderem do estômago, são levadas até o reto, onde se fixam novamente, permanecendo neste local de 2-3 dias, movendo-se então gradualmente em direção à margem do ânus. Quando a infestação é grande, pode ocorrer obstrução da passagem das fezes ou ainda prolapso retal. As larvas maduras são eliminadas juntamente com as fezes, empupando no solo.

\section{Gasterophilus intestinalis (De Geer)}

Oestrus intestinalis De Geer, 1776: 292.

Gastrophilus asininus Brauer, 1863: 71; Lutz, 1917: 105.

Gastrophilus intestinalis; Hawden \& Cameron, 1918; Dove, 1918: 52, figs.: Grunin, 1955: 84, figs.

Gasterophilus intestinalis; Séguy, 1928: 65, figs.; Wells \& Knipling, 1938: 186, figs.; Zumpt \& Paterson, 1953: 64, figs.

Para sinonímia mais completa consultar Zumpt \& Paterson (1953).

Adulto - É a maior das três espécies, aproximadamente do tamanho de uma abelha comum (11-15 mm). Corpo com pêlos castanhos e amarelos. Asas com manchas castanhas, com uma larga faixa mediana e duas pequenas manchas próximas do ápice.

A fêmea sobrevoa o animal e após cada investida deposita seus ovos em qualquer parte do corpo, de preferência nas patas anteriores. Num mesmo pêlo podem ser depositados vários ovos, levando a mosca cerca de um segundo para a deposição de cada ovo. Cada fêmea pode depositar cerca de 500 ovos.

Ovos - Amarelados. Os ovos estão prontos para eclodir dentro de aproximadamente 7 dias após a postura. O calor, umidade e fricção produzidos pelo animal hospedeiro ao se coçar ou lamber o local onde estes estão fixados estimulam sua eclosão.

Larva - As larvas recém-eclodidas são levadas para dentro da boca, perfurando a língua e aí podem permanecer por 3 a 4 semanas. A seguir migram para o estômago ou duodeno do animal, fixando-se aí até o final do terceiro estágio. Raramente são encontradas fixadas em outras regiões. 


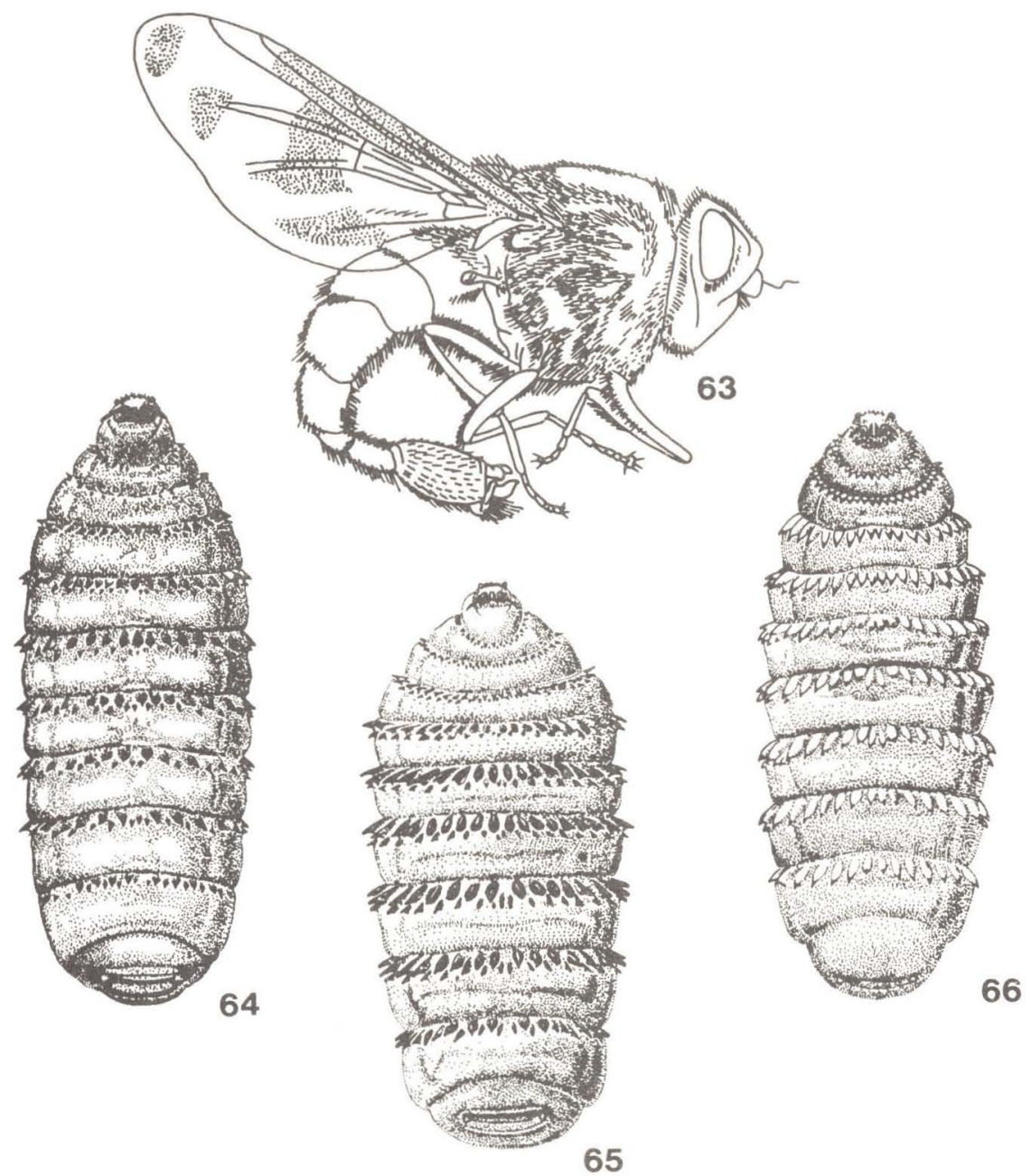

Fig. 63: Gasterophilus intestinalis (De Geer), fêmea (apud Séguy, 1928). Figs. 64-66: Larvas III de Gasterophilus - 64, haemorrhoidalis (Linnaeus); 65 intestinalis (De Geer); 66, nasalis (Linnaeus) (apud Grunin, 1953).

período total de desenvolvimento larval é de 10 a 11 meses. A larva é eliminada junto com as fezes e empupa no solo.

Pupa - A pupa é semelhante para as três espécies. O período pupal começa de 1 a 4 dias após a larva ter penetrado no solo e varia de 15 a 70 dias.

\subsection{Ocorrência e distribuição na América do Sul}

Na região neotropical ocorrem com certa freqüência três espécies: Gasterophilus intestinalis (De Geer), G. haemorrhoidalis (Linnaeus) e G. nasalis (Linnaeus). 
Vol. 1(4), 1983

339

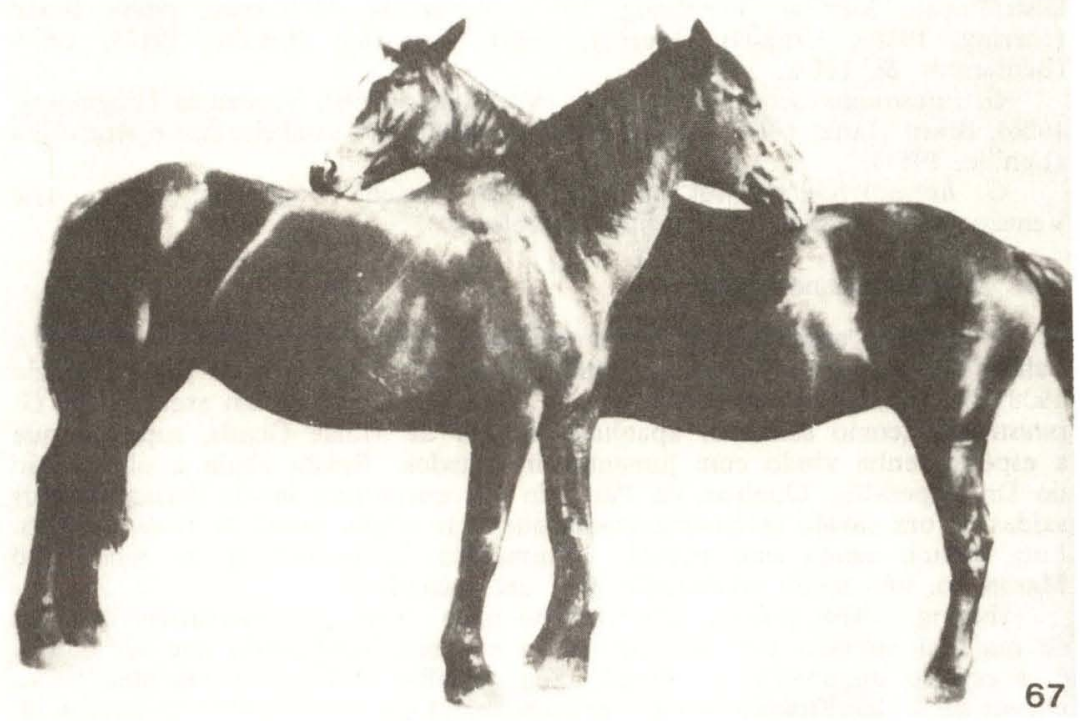

Fig. 67: Cavalos protegendo suas ganachas contra ataque de Gasterophulus (apud U.S. Dep. Agric. Leaflet 450, 1959).

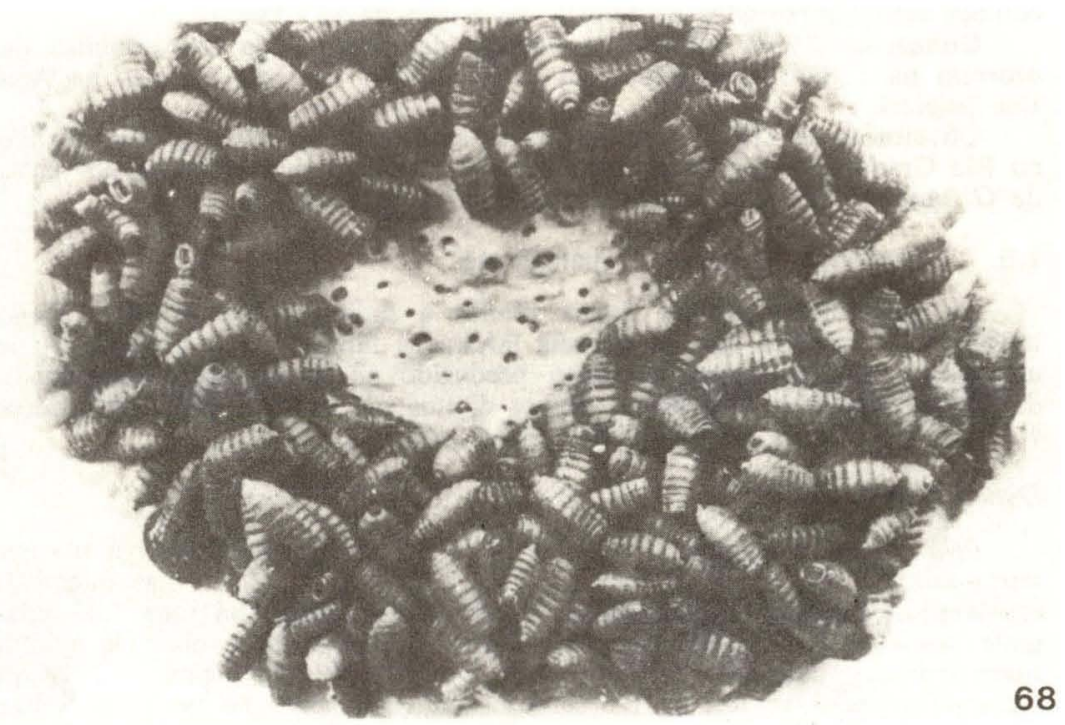

Fig. 68. Porção de estômago de cavalo infestado por larvas de Gasterophilus (apud U.S. Dep. Agric. Leaflet 450, 1959). 
G. nasalis é a mais comum na região neotropical. Segundo Ihering (1930) é a única espécie do gênero cuja adaptação no Brasil está bem documentada. Distribuição: México (Vogelsang, 1956), Venęuela (Vogelsang, 1956), Brasil (Ihering, 1930), Uruguai (Ihering, 1930), Argentina (Lahille, 1911), Chile (Bentjerodt \& Tafra, 1971).

$G$. intestinalis ocorre no México (Vogelsang, 1956), Venezuela (Vogelsang, 1956), Brasil (Lutz, 1917; Guimarães et al., 1954; não estabelecido) e Argentina (Lahille, 1911).

G. haemorrhoidalis foi assinalado no México (Vogelsang, 1956) e na Venezuela (Vogelsang, 1956; não estabelecido).

\subsection{Ocorrência no Brasil}

A primeira notícia sobre Gasterophilus no Brasil foi dada por Lutz (1917). Lahille (1911), para a República Argentina, cita a existência desse parasito desde 1908, sob a forma de epizootias. Lutz (1. c.) refere o caso de um exemplar de $G$. intestinalis (como asininus) apanhado no sul de Minas Gerais, supondo que a espécie tenha vindo com jumentos importados. Relata ainda a observação do Dr. Esperidião Queiroz, do Pará, de que encontrara larvas destes dípteros saídas de um cavalo recém-importado, que Lutz julgou serem de Gasterophilus. Lutz contou ainda que possuía informações de ocorrência da mosca no Maranhão, não tendo conseguido nem um exemplar.

Ihering (1929) publica um trabalho onde relata as observações que fez de material enviado por veterinários do exército, verificando que $G$. nasalis é a espécie dominante no Brasil. Seu trabalho é bastante completo, com chaves para identificação, notas sobre sintomatologia e tratamento da parasitose.

Rolim Filho (1932) publicou um opúsculo ("Gasterophilose"), em que assinala a ocorrência de G. intestinalis (como equi) no Rio Grande do Sul.

Silva Jr. e Proença (1934) publicaram um estudo sobre $G$. nasalis no Brasil, relatando a criação da forma adulta pela primeira vez, a partir de larvas encontradas em animais necropsiados na Escola de Veterinária do Exército.

Guimarães et al. (1954) registraram a ocorrência de G. intestinalis em equinos recém-importados da França, no estado de São Paulo.

Guimarães (1967) publicou o catálogo das espécies de Gasterophilus que ocorrem na região neotropical com a distribuição das três espécies na América tropical.

Oliveira et al. (1971), em necrópsias realizadas em 1000 cavalos abatidos no Rio Grande do Sul, observaram que $86,4 \%$ estavam parasitados por larvas de $G$. nasalis, com uma média de 50,05 larvas por animal.

\subsection{Importância econômica e patogênese}

Os gasterófilos causam danos diretos e indiretos aos animais. Danos indiretos são aqueles que os animais infestados infligem a si próprios ou ao homem - são resultados do susto produzido no animal pela aproximação da mosca durante a oviposição. Danos diretos são os produzidos pelo desenvolvimento da larva no tecido do animal infestado.

\section{Danos indiretos}

Pela mosca. Os equinos temem a mosca e ficam perturbados com sua presença ao voar ao redor do nariz, cabeça, pescoço, etc. Nos dias quentes e ensolarados, quando os gasterófilos são mais freqüentes, há uma luta constante dos cavalos e mulas com as moscas, durante todo o dia. Os animais ficam irritados, correndo e sacudindo a cabeça. Procuram lugares sombreados ou onde sopra o vento. Outros se refugiam em abrigos no pasto ou voltam para as estrebarias. Os potros, quando molestados, procuram proteção debaixo dos animais mais velhos. Enquanto lutam para se livrarem das moscas, os animais não se alimentam e após alguns dias perdem peso. Os cavalos selados, quando atacados, ficam furiosos e correm sem controle, com perigo para o cavaleiro. 
Os equinos, ao perceberem a aproximação da mosca, reunem-se em bandos, procurando proteger suas ganachas (região ventral da mandíbula) apoiando-as na garupa de outros animais (Fig. 67). Os potros e animais jovens, que não são suficientemente altos para se protegerem desta maneira, são os mais atacados.

Outra forma de proteção é a de encostar as ganachas no solo, como se estivessem pastando, impedindo desta forma a oviposição.

Pelas larvas. As larvas recém-eclodidas produzem severa irritação e coceira ao perfurar o lábio e a língua dos animais. Para se aliviarem de tal irritação, estes permanecem próximos aos cochos ou tonéis, com a boca mergulhada na água, ou esfregam violentamente seus lábios e narizes contra o solo, cercas de arame farpado, pedras, etc., causando ferimentos e dilacerações.

\section{Danos diretos}

O ataque direto se dá pela perfuração do epitélio do estômago (Fig. 68) e intestino do animal, pelo aparelho bucal da larva. A fixação da larva provoca úlceras e inflamações locais, que interferem com a digestão. Lesões anatômicas no estômago, causadas pelas larvas de $G$. intestinalis, foram estudadas por Shefstad (1978), usando microscopia eletrônica.

O grau de dano produzido nos animais é proporcional ao grau de infestação, podendo haver desde dificuldade para a passagem de alimento pela obstrução do piloro até ruptura do estômago; os animais freqüentemente sofrem cólicas e outros distúrbios gástricos. Várias centenas de larvas podem ser encontradas em um único animal, tendo sido registrados casos onde se encontraram mais de 1000 larvas no estômago de um potro.

\subsection{Tratamento}

Durante muitos anos o único tratamento conhecido para o combate à gasterofilose equina foi o uso do bisulfeto de carbono, administrado em cápsulas de gelatina (Dove, 1918). Este produto agia como fumigante, envenenando a larva e desprendendo-a do estômago e intestino. Devido à sua alta toxidez, se aplicado por pessoa inexperiente, freqüentemente causava a morte do animal.

Inseticidas clorados, como o BHC (gamexane) demonstraram ser altamente tóxicos para os equinos e de fraca ou nenhuma ação contra as larvas (Corrêa, 1950).

Modernamente, os inseticidas de ação sistêmica são os mais promissores no combate à gasterofilose. O triclorfon e o diclorvos (DDVP) têm sido os produtos mais utilizados no tratamento dessa parasitose. Estes produtos foram testados por Drummond et al. (1959). Uma vẹz que as larvas dos gasterófilos entram em contacto direto com o inseticida, quando administrado por via oral, existia a questão se sua ação era de contacto ou sistêmica. Drummond (1963) registrou controle parcial de $G$. nasalis e $G$. intestinalis através da administração de $30 \mathrm{mg} / \mathrm{kg}$ de triclorfon por via intramuscular, demonstrando a possibilidade da ação sistêmica.

Os produtos mais usados modernamente contra as larvas de Gasterophilus, seu nome comercial e composição química podem ser encontrados na Tabela 7.1.

\section{REFERENCIAS}

Alvarez V. J. M., 1954. Gastrofilosis de los equinos en la Republica Dominicana. Agricultura, Ciudad Trujillo 44: 49-51, figs.

Amaral, N. K., 1946. Serviço de combate à gastrofilose equina. Bolm Dir. Prod. anim. P. Alegre 2(4): 3-10.

Andersen, F. L., P. D. Wright \& G. T. Waiters, 1973. Palatability and efficacy of a powder formulation of Thiabendazole and Trichlorfon for horses. J. am. vet. med. Ass. 163(3): 206-207.

Anon., 1934. Gastrofilosis (gusano del estómago de los equinos). Alm. Min. Agric. Nac. argent. 9: 387-390. 
TABELA 7.1 .

Inseticidas usados contra larvas de Gasterophilus (Diptera)

Base Nome comercial

Diclorvos

Butonato

DDVP

Mebendazole

Triclorfon

Thiabendazole
Neguvon, Bervon, Clorfon, Dipterex, Dyrex

Equizole, Bulvermin, Veperzole, Vermiperan
Composição química

2, 2-diclorovinil dimetil fosfato

metil 5(6)-benzol-2-benzimidazole carbamato

0-0-dimetil (1-hidroxilico-2, 2, 2 tricloroetil) fosfonato

2-(4'-tiazolil) benzi-midazole

\section{Referências}

Voss et al., 1973

Bello et al., 1972; Drudge, et al., 1972a, 1972b; Hass et al. 1973; Hasslinger, 1973, Hasslinger et al., 1975; Violette et al., 1972; Voss et al., 1973

Muylle et al., 1979

Andersen et al., 1973; Bello et al., 1977; Cook, 1973; Delak, 1977; Duarte et al., 1980; Morrow, 1978; Muylle et al., 1979; Hasslinger. 1973

Andersen et al., 1973; Lyons et al., 1977 
Basterrechea, F., 1933. El gusano del estómago de los equinos, Gastrofilosis. Ibid. 8: 328.

Bello, T. R., S. D. Gaunt \& B. J. Torbert, 1977. Critical evaluation of environmental control of bots (Gasterophilus intestinalis) in horses. J. equine Med. Surg. 1(4): 126-130.

Bello, T. R. \& C. L. Seger, 1972. Antiparasitic efficacy of dichlorvos paste formulation against first-instar Gasterophilus intestinalis in the tongues of Shetland pony foals. Am. J. vet. Res. 33(1): 39-44.

Bentjerodt, E. \& E. Tafra, 1971. Parasitismo en equinos. I. Parasitismo gástrico. Tesis, Escuela de Medicina Veterinaria, Universidad Austral de Chile, Valdivia.

Bizzoero, F. A., 1950. Gastrofilosis de los equinos (gusano del cuajo). Alm. Min. Agric. Nac. Argent. 25: 437-439, figs.

Bolle, W. R., 1960. Lucha contra las larvas del gastrofilo intestinal con neguvon. Revta vet. venez. 9: 258-259.

Brauer, F. M., 1863. Monographie der Oestriden, 209 pp., ilus. Wien.

Briones, N., 1897. Presentación de larvas del Gastrphylus (sic) equi. Actes Soc. scient. Chili 6(4-5): 1xxxvii.

Brito, O. da S., 1938. Gastrophilose (divulgação). Bolm vet. P. Alegre 2(12): 322-j25.

Caro, G. A., 1942a. Gastrofilosis equina. Alm. Min. Agric. Nac. Argent. 17: 433-434.

Caro, G. A., 1942b. Idem. Campo y Arados 6: 6.

Caro, G. A., 1945. Idem. Suelo argent. 4: 554, ilus.

Castañedo, J. A., 1949. La gastrofilosis equina. Revta Ganad. Habana 9(12): 11-14, 62, ilus.

Clark, B., 1797. Observations on the genus Oestrus. Trans. Linn. Soc. Lond. 3: 289-329, 1 pl.

Corrêa, O., 1943. A gastrofilóse equina no Rio Grande do Sul. Tese apresentada à Escola de Agronomia e Veterinária da Universidade de Porto Alegre, para concurso de Livre Docência da Cátedra de Doenças Infecciosas e Parasitárias dos Animais Domésticos - Higiene e Polícia Sanitária Animal, 40 pp., 11 figs. Livraria Continente, P. Alegre.

Corrêa, O., 1945. A gastrofilose equina no Rio Grande do Sul. Bolm S. B. Secç. Inform. Propag. agric. Secr. Est. Neg. Agric., Ind. Com. Brasil 115: $1-38$, ilus.

Corrêa, O., 1950. Tratamento da gasterofilose equina no Rio Grande do Sul. An. 3. Congr. bras. Vet., P. Alegre 192-199, ilus.

Corrêa, O., 1950. Tratamento da gasterofilose equina pelo gamexane e sua toxidade para o cavalo. Revta agron. P. Alegre 14: 72.

De Geer, C., 1776. Mémoires pour servir à l'histoire des insectes 6: 523 pp., 30 pls. Stockholm.

Delak, M., 1977. An attempt to control equine gastrophilosis by percutaneous application of trichlorphon. Vet. Arhiv, Zagreb 47(5): 231-238.

Dentone, J. H., 1965. Gastrofilosis. Caballo, B. Aires 3(242): 30.

Dirección de Agricultura, Ganadería y Industria, B. Aires, 1939. Instrucciones para combatir el Gastrophilus o gusano del estómago de los caballos, con el antilarval D.A.G.I. (6a. ed.). Def. sanit. Ganad.: 52-54, ilus.

Dove, W. E., 1918. Some biological and control studies of Gastrophilus haemorrhoidalis and other bots of horses. U.S. Dep. Agric. Bull. 597: 1-51, 4 figs., 11 tabelas, 5 pls.

Drudge, J. H. \& E. T. Lyons, 1972. Critical tests of a resin pellet formulation of dichlorvos against internal parasites of the horse. Am. J. vet. Res. 33(7): 1365-1375.

Drudge, J. H., E. T. Lyons \& T. W. Swerczek, 1972. Acticity of gel and paste formulations of dichlorvos against first instars of Gasterophilus spp. Ibid. 33(11): 2191-2193.

Drummond, R. O., 1963. Test with systemic insecticides for the control of Gasterophilus larvae in horses. J. econ. Ent. 56(1): 50-52.

Drummond, R. O., J. B. Jackson, E. E. Gless \& B. Moore, 1959. Systemic 
insecticides for the control of Gasterophilus bots in horses. Agr. Chem. 14(12): 41-43, 100.

Duarte, M. J. F., P. A. C. Gomes \& M. S. G. Tristão, 1980. Vermífugos de interesse em medicina veterinária. PESAGRO-RIO (Empresa de Pesquisa Apropecuária do Estado do Rio de Janeiro), Circ. técn. 3: 1-51.

Fridkin, A., 1946. "Gastrofilo nasalis" o gusano del cuajo. Alm. Min. Agric. Nac. Argent. 21: 137-140, figs.

Giovannoni, M., 1943. Gastrophilus intestinalis, ou gastrofilo intestinal, in Principais parasitoses dos equinos. Bolm Inst. Biol. Pesq. tecn. Paraná 6: 53-57, fig. 21.

Gomes, O. J., 1943. La lucha contra la gastrofilosis. Esta enfermedad parasitaria que causa muchos perjuicios a los equinos es fácil de combatir. Res, B. Aires 11: 14.322-14.323, figs.

Grunin, K. Ya., 1953. Lichinki ovodov domashnik zhivotnykh SSSR, 124 pp., 139 figs. Izdatel'stvo Akademii Nauk SSSR, Moscou \& Leningrado.

Guimarães, J. H., 1967. Family Gasterophilidae, in Departamento de Zoologia, Secretaria da Agricultura, A Catalogue of the Diptera of the Americas south of the United States 98: 1-4, São Paulo.

Guimarães, L. M., T. L. de Araujo \& C. E. S. Gomes, 1954. Sobre a presença do Gasterophilus intestinalis (de Geer, 1776) em equinos P. S. C. no estado de São Paulo. Revta Fac. Med. vet. S Paulo 5(2): 189-193, pl. (Também em An. 2. Congr. pan-am. Med. vet.: 269-270, 273-274, 1955).

Hass, D. K., J. R. Albert, B. G. Pillow \& L. J. Brown, 1973. Dichlorvos gel formulation as an equine antihelminthic. Am. J. vet. Res. 34(1): 41-43.

Hasslinger, J. D., 1973. Erfolganstichten einer planmässigen Gasterophilus Bekämpfung bei Pferden. Dt. tierärztl. Wschr. 80(16): 369-372.

Hasslinger, M. A. \& D. Jonas, 1975. Control of Gasterophilus intestinalis (De Geer, 1776) with dichlorvos. Br. vet. J. 131: 89-93.

Hawden, S. \& A. E. Cameron, 1918. A contribution to the knowledge of the botflies, Gasterophilus intestinalis, Deg., $H$. haemorrhoidalis, L., and G. nasalis, L. Bull. ent. Res. 9: 91.

Ihering, R. von, 1929. Os oestrideos importados, seu papel como parasitas e em particular os Gasterophilus no Brasil. Bolm Agric., S Paulo 30: 863-883.

Ihering, R. von, 1930. Vários casos de Oestrus e Gasterophilus no Brasil. Revta Soc. paul. Med. vet. 1(2): 30-35.

Joan, T., 1917. Nota sobre un estado larvario de Gastrophilus nasalis (L.) Leach. Boln Min. Agric., B. Aires 21(1): 42-45, figs. 1-3.

Klinge, G., 1951. Gusanos del estómago de los caballos. Vida agríc., Lima 28: $319,321$.

Lahille, F., 1911. Los gastrófilos en la República Argentina. Boln Min. Agric. Rep. Argent. 13(12): 836-856, 8 figs., pl. col.

Leão, R. L., 1961. Gastrofilose equina. Rural, Revta Soc. rural bras. 41: 52-54, ilus.

Linnaeus, C., 1758. Systema naturae per regna tria naturae, Ed. X, 1: 824 pp. Holmiae.

López Vallejo, E., 1907. El gastrófilo del caballo. Circ. Com. Parasit. agríc. Méx. 65: 1-10, figs. 1-12 (figs. 9 e 12 em pl.).

Lutz, A., 1917. Contribuições ao conhecimento dos oestrideos brazileiros. Mems Inst. Oswaldo Cruz 9: 94-112, pls. 27-29.

Lyons, E. T., J. H. Drudge \& S. C. Tolliver, 1977. Critical tests of the antiparasitic activity of thiabendazole and trichlorfon sequentially administered to horses via stomach tube. Am. J. vet. Res. 38(6): 721-723.

Manchiamelo, G. J., 1943. Tres estados del ciclo evolutivo del Gastrophilus nasalis (gastrofilosis equina). Alm. Min. Agric. Nac. Argent. 18: 153154 , figs.

Medina, G., 1968. As gasterophiloses nos equinos. Vida rural e Econ. 1968 (Jan.-Fev.): 26.

Mello, M. J. de, 1951. A incidência do gênero Gastrophilus no Brasil. Biológico, S Paulo 17(1): 16-17. 
Melo, M. J. de, 1946. Gasterofilose dos cavalos. Ibid. 12(6): 166.

Mendy, D., 1915. La gastrofilosis. Sus consecuencias y tratamiento. Bolm Min. Agric. Nac. Argent. 19(3-4): 276-278.

Mendy, D., 1916. La gastrofilosis. Sus consecuencias y tratamiento. Revta Med. vet., Montev. 1(2): 88-91.

Mendy, J. B., 1918. Gastrophilus duodenalis. Parásitos del estómago del caballo. An. Soc. rural argent. 52: 249-250, 16 figs., 1 mapa.

Mendy, R. M., 1945. El gusano del estómago de los yeguarizos o gastrofilosis equina. Alm. Min. Agric. Nac. Argent. 20: 257-262, ilus. (Também em El Campo, B. Aires 29(343): 6, 8-9, 37, 58).

Monte, O., 1944. Notas sobre Gastrophilus. Moscas parasitas de animais. Cha. Qui. 69(1): 68-71, 5 figs.

Morejon Puig, L. F., 1945. Gastrofilos. Bolm Min. Agric. Cuba 6: 1-10.

Morrow, G. L., 1978. Clinical evaluation of febantel and trichlorfon paste formulation in the horse. Vet. Med. small Anim. Clin. 73(11): 1388-1393.

Muylle, E., W. Oyaert \& M. Rogier, 1979. Endoscope examination of the horse stomach in the assessment of the efficacy of a mebendazole (trichlorphon) paste against Gasterophilus intestinalis larvae. Vlaams diergeneesk. Tijdschr. 48(4): 279-282.

Oberg. C., L. Diaz \& G. Valenzuela, 1974. Parásitos identificados en bovinos, ovinos, suinos y equinos en el Laboratorio de Enfermedades Parasitárias de la Escuela de Medicina Veterinaria de la Universidad Austral de Chile, 1963-1977. Boln. chil. Parasit. 29: 99-102.

Oliveira, C. M., D. S. Rassier \& G. B. Lignon, 1971. Gasterofilose equina no Rio Grande do Sul. 1. Congr. est. Med. vet. Rio Grande do Sul. (Também em Revta Medna vet. S Paulo 8(1): 61-66, 1972).

Orfila, R. N., 1938. Los gusanos del cuajo. Pampa Argent. 12(133): 10, fig.

Orfila, R. N., 1945. Los gusanos del cuajo. Campos y Arados, B. Aires 7(81): 12-13.

Pires, A., 1947. El gusano de cuajo del caballo o gastrofilosis equina. Res. B. Aires 15: 21.193-21.194.

Pires, A., 1935. La intradermo-reacción de la esclerostomiasis y gastrofilosis equina. Revta Medna vet., B. Aires 17(3): 137-146.

Pires, A., 1948a. Gastrofilosis de los equinos. Revta Ganad. Habana 8(1): 7.

Pires, A., 1948b. Gastrofilosis equina. Campo y Suelo argent. 32: 16-17.

Prieto, R., 1975. Dinámica estacional del ciclo de oviposición de Gasterophilus intestinalis (De Geer, 1776) y de Gasterophilus nasalis (Linneo, 1761 [sic]). Revta cubana Cienc. vet. 6(1-2): 51-56.

Prieto, R., J. Cueto \& E. Rivera, 1978. Influencia de los factores climáticos sobre las dinámicas de Gasterophilus spp. Ibid. 9(1): 15-23.

Quevedo, J. M., 1912a. Las gastrofilosis. Revta zootécn., B. Aires 3: 485-487.

Quevedo, J. M., 1912b. Las lesiones del gastrófilo de los equinos. Revta Centro Est. Agron. Vet. Univ. B. Aires 5: 117-122, pls.

Quintero G., L. A., 1959. Gasterofilosis equina en Venezuela. Revta Med. vet. Parasit. Caracas 17(1-4): 167-190.

Rocha, U. F., 1954. Gasterophilus nasalis in horses in a region of S. Paulo state. Summ. Comm. 2. pan-am. Congr. vet. Med., S Paulo, Sect. C: 5.

Rocha, U. F., 1954. Observações sobre gasterofilose em equídeos da região de Araçatuba, Estado de São Paulo, Brasil. Revta Fac. Med. vet. S Paulo 5(1): 17-25, pl.

Rocha, U. F., 1955. Idem. An. 2. Congr. pan-am. Medna vet., S Paulo: $250,266$.

Rolim Filho, P. A., 1932. Gasterophilose. P. Alegre.

Sabin Paz, A., 1937. Las gastrofilosis equinas o gusano de cuajo. Caballo, B. Aires 3(12): 35-44, figs.

Santos, E., 1955. A gasterofilose. Granja, P. Alegre 11: 43.

Sanz, B., 1927. Gastrofilosis (in Informe del Director del Instituto Biológico). Mem. Inst. biol. Estac. exp. Soc. nac. Agric. Chile (1926) 6: 34.

Sanz, B., 1929. Gastrophilosis equina. Ibid. (1927) 7: 24-25.

Schmidt Herman, L., 1936. Los gastrófilos del caballo. Boln Curso Medna vet, práct. 1(7): 12-14. 
Schmidt Herman, L., 1939. Los gastrófilos del caballo. Doctor, Santiago de Chile 2(16): 1-2.

Schmidt Herman, L., 1947. Idem. Agric. y Ganad. Méx. 23(8): 8-11.

Séguy, E., 1928. Etudes sur les mouches parasites. I. Conopides, oestrides et calliphorines de l'Europe occidentale. Enc. ent. (A) 9: 1-251, figs.

Serres, J. R., 1916. Gastrofilosis caballar o gusano del estómago. Campo, B. Aires 1(1): 5, fig.

Shelfstad, D. K., 1978. Scanning electron microscopy of Gasterophilus intestinalis lesions of the equine stomach. J. am. vet. med. Ass. 172(3): 310-313, figs.

Silva Jr., J. O. da \& M. C. Proença, 1934. Contribuição ao estudo da gasterofilose e da sp. Gasterophilus nasalis (L., 1758) no Brasil (Com a descrição da larva de 2a. fase e primeira observação no Brasil do inseto adulto). Bolm vet. Exército, Rio de J. 1(7): 159-183, 186-190, pls. 1-4, figs. $1-32$.

Silva Jr., J. O. da \& M. C. Proença, 1938. Idem. Revta milit. Medna vet. 1(7): 563-588, figs.

Silva Jr., J. O. da \& M. C. Proença, 1941. Gasterofilose. Contribuição ao estudo da gasterofilose e da sp. Gaterophilus (sic) nasalis (com a descrição da larva de 2a. fase e primeira observação, no Brasil, do inseto adulto). J. Agric., Rio de J. 6(11):7-8; (12): 8 .

Silva Jr., J. O. da \& M. C. Proença, 1942. Gasterofilose. Ibid. 7(1): 7.

Sobrinho Paz, A., 1925. Gastrofilosis equina y Gasterophilus duodenalis. Gac. rural 18: 933, 935, 937, 939, figs.

Vaitsman, J., 1950. A gasterophilose nos equinos. Agric. e Pecuária 21: 51-52.

Vaitsman, J., 1951. A gasterofilose dos equinos. Seleções agric. 6: 49-50.

Vasconcellos, J. C. de C., 1950. Relatório sobre os trabalhos de desgasterofilização no ano de 1949. Revta milit. Remonta Vet. 10(1-2): 45-57.

Veliz, M. O., 1948. Contribución al estudio de la gastrophilosis en el Valle de Lima. Revta Fac. Medna vet. Lima 3(1): 11-31, figs.; (3-4): 117-126.

Villegas, D. E., 1950. La gastrofilosis equina o "gusano del cuajo". Chacra, B. Aires 20: 16-17, figs.

Violette, C. \& F. Duret, 1972. Etude critique de l'activité d'un anthelmintique équin à base de phosphate de 2-2-dichloro-vinyl-dimethyle (dichlorvos). Revue Méd. vét. 123(11): 1429-1435.

Vogelsang, E. G., 1956. Los Gasterophilus de los equinos en Venezuela. Revta Medna vet. Parasit. Caracas 15: 7-11, pls.

Vogelsang, E. G. \& P. Llamozas Gonzáles, 1943. Contribución al estudio de la parasitología animal en Venezuela, XIV. Gastrofilos de los equinos de Venezuela. Boln Ent. Venez. 2(3): 145-148.

Vogelsang, E. G. \& P. Llamozas González, 1948. Las gastrofilosis de los equinos de Venezuela. Revta Med. vet. Parasit. Caracas 7(1-4): 203. 211, pl.

Voss, J. L. \& C. P. Hibler, 1971. Critical tests of butonate as ascaricide and boticide in horses. Am. J. vet. Res. 32(12): 2085-2086.

Wells, R. W. \& E. F. Knipling, 1938. A report of some recent studies on species of Gasterophilus occurring in horses in the United States. Iowa St. Coll. J. Sci. 12: 181.

Wilned., (-), 1952. Gastrofilo o gusano del cuajo es la larva de una mosca que parasita a los caballos. Mundo agrario 4: 77-78, ilus.

Zumpt, F., 1965. Myiasis in man and animals in the Old World, $\mathrm{xv}+267$ pp., ilus. London.

Zumpt, F. \& H. E. Paterson, 1953. Studies on the family Gasterophilidae, with keys to the adult and maggots. J. ent. Soc. S Afr. 16: 59-72, 17 figs.

\section{FAMILIA HYPODERMATIDAE}

\subsection{Caracterização}

São duas as espécies de maior importância econômica dentro desta família: Hypoderma bovis (Linnaeus) e Hypoderma lineatum (Villiers). 


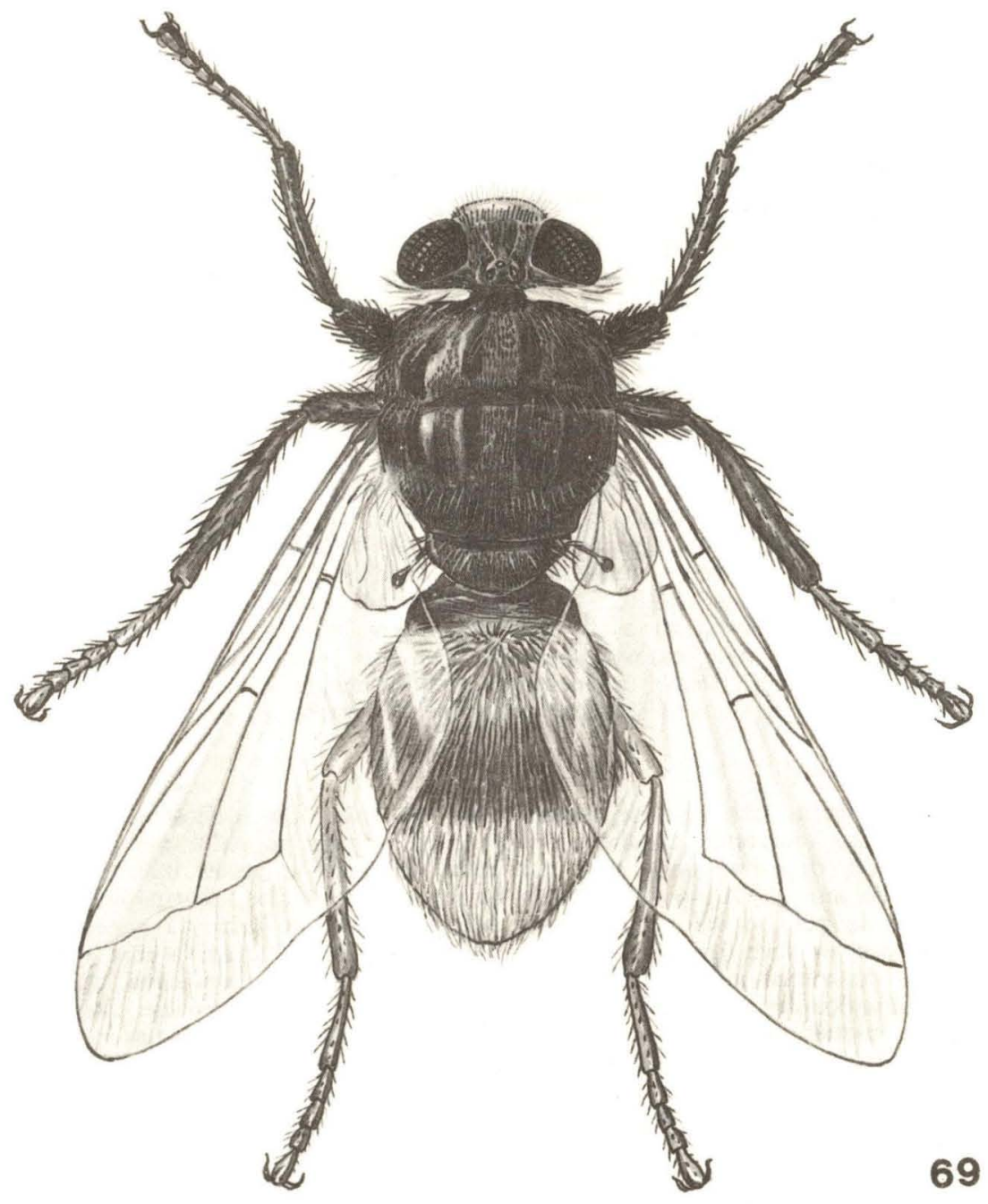

Fig. 69: Hypoderma bovis (Linnaeus). 
Hypoderma bovis é maior, com cerca de $15 \mathrm{~mm}$ de comprimento, com o tórax coberto por densos pêlos amarelados na parte anterior e escuros na posterior; o abdome apresenta pêlos amarelados no ápice.

Hypoderma lineatum tem aproximadamente $13 \mathrm{~mm}$ de comprimento; o tórax é uniformemente coberto por uma mistura de pêlos castanho-escuros e brancos, com quatro áreas polidas formando linhas bem distintas; o ápice do abdome apresenta pêlos vermelho-alaranjados.

Estas duas espécies são de grande distribuição no hemisfério norte, onde causam prejuízos semelhantes aos determinados pela Dermatobia hominis na América tropical. Devido ao ataque das larvas, ocorre perda de peso, com depreciação no valor das carcassas (que se tornam impróprias para o consumo nos pontos onde se localizam as larvas); o ataque reduz ainda o valor dos couros. Nas vacas leiteiras, observa-se redução na produção de leite.

A literatura referente à biologia, importância econômica e medidas de controle neste grupo encontra-se espalhada por centenas e centenas de publicações científicas e populares no hemisfério norte. Para informações gerais de biologia, larva e patogênese destas duas espécies, consultar Zumpt (1965).

\subsection{Ocorrência na América neotropical}

Segundo as informações encontradas na literatura, embora tenha sido freqüentemente introduzida na América neotropical, a Hypoderma ainda não se estabeleceu de modo definitivo. Segundo Vogelsang (1939) e Gallo \& Vogelsang (1951), este inseto só foi observado na Venezuela em bovinos importados; o mesmo foi registrado por Castro \& Trenchi (1955), no Uruguai; Sievers (1928) assinalou a presença de $H$. bovis no Chile, em um touro importado dos Estados Unidos. A única informação contrária é a de Tagle (1959) que comprovou larvas de $H$. lineatum em bovinos nascidos no Chile; entretanto, os poucos casos examinados por este autor não nos permitem saber se o díptero estava estabelecido definitivamente na região, ou se se tratava apenas de uma observação da primeira geração do parasito.

\subsection{Biologia}

As moscas emergem de pupas caídas no solo. Os adultos não picam ou ferroam, entretanto causam enorme pânico ao voar ao redor dos bovinos. As fêmeas depositam seus ovos nos pêlos das patas e partes inferiores do corpo do animal. As larvas eclodem dentro de 3 a 4 dias, dirigindo-se para a base do pêlo, e daí perfurando a pele. Próximo ao lugar de penetração pode ocorrer leve irritação ou inflamação. As larvas levam vários meses dentro do animal infestado. Durante este período, migram para cima, através dos músculos das patas, até atingir a cavidade abdominal ou torácica. Durante a fase migratória, as larvas de $H$. bovis são especialmente numerosas no esô. fago; algumas podem penetrar no canal espinhal, determinado paralisias no hospedeiro. No final da fase migratória, a larva se dirige para as costas do hospedeiro, formando cistos subcutâneos. Após uma ou duas semanas dentro dos cistos, a larva perfura a pele, formando um orifício para respiração e emergência. Depois de um a dois meses nas costas do animal, a larva madura atravessa o estreito orifício de respiração, caindo ao solo, e transformando-se logo a seguir em pupa.

O ciclo completo leva cerca de um ano. Várias centenas de larvas podem ser encontradas nas costas de um único animal parasitado. Bezerros e novilhas são mais atacados que animais adultos.

\section{REFERENCIAS}

Arenas y Martorell, R. \& J. R. Alvarez González, 1934. La hipodermosis bovina en nuestros mataderos. Boln mens. Col. vet. nac. Habana 3: 572.

Bertoni, G. T., 1915. Hypoderma e a berne ou estro americano. Alm. agric. bras. 1915: 239-242.

Castro, E. R. \& H. Trenchi, 1956. Fauna parasitológica comprobada en el 
Uruguay y bibliografía parasitológica nacional. Publ. Lab. Biol. anim. "Dr. Miguel Rubino", Boln 1: 1-46.

Freire, J. J., 1915. Hipodermose bovina ẹm animal importado. Bolm Dir. Prod. anim. R. G. do Sul 5(7): 20-22.

Gallo, P. \& E. G. Vogelsang, 1951. Nosografía veterinaria venezolana. Revta Med. vet. Parasit., Caracas 10: 3-46.

Mayo, N. S., 1920. Parasitas do gado - A mosca estro do gado vaccum. Estrus do carneiro. Brasil agric. 5(8): 222-223, 4 figs.

Oberg, C., L. Díaz \& G. Valenzuela, 1974. Parásitos identificados en bovinos: ovinos, suinos y equinos en el laboratorio de enfermedades parasitarias de la Escuela de Medicina Veterinaria de la Universidad Austral de Chile, 1963-1973. Boln chil. Parasit. 29: 99-102.

Palazzolo, G., 1916. L'Hypodrema bovis e la mosca Dermatobia noxialis o cyaneiventris del Brasile. Nuovo Ercol. 21(26-27): 433-437, 1 fig.

Quin, A. H., 1945. A erradicação dos hipodermas do gado. Campo, Rio de J. 16(186): 39-40, 3 figs.

Sievers, H., 1928. Aparición de la larva de Hypoderma bovis en Chile. Revta chil. Hist. nat. 32: 81-82.

Tagle Villarroel, I., 1959. Grave enfermedad del ganado. Hipodermosis del vacuno. Agric. y Ganad., Santiago de Chile 5(21): 15, 32.

Tagle Villarroel, I., 1959. Primer caso autoctono de hipodermosis en Chile. Boln chil. Parasit. 14(1): 15-17.

Velasquez Q., J., 1962. Ciclo de vida muy prolongado en Hypoderma bovis. Revta Fac. Med. vet. Zootecn. Bogotá 25(123): 803.

Wilned., (-), 1952. Las larvas de una mosca: Hipoderma [sic] bovis perjudican notablemente al ganado bovino. Mundo agrario 4: 58.

\section{FAMILIA OESTRIDAE}

Nesta família, de importância para a nossa região, temos apenas a bem conhecida e quase cosmopolita espécie, Oestrus ovis Linnaeus. As larvas desta espécie são parasitas obrigatórias das cavidades nasais e seios frontais de ovinos e caprinos.

\subsection{Caracterização}

\section{Oestrus ovis Linnaeus}

Oestrus ovis Linnaeus, 1758: 584. Ref. - Papavero, 1977.

Oestridae com a seguinte combinação de caracteres: Cabeça grande, amarelada, apresentando pequenas depressões escuras na parafrontália. Antenas com o terceiro artículo preto; arista nua. Aparelho bucal atrofiado. Frontália no mesmo nível das parafrontálias. Mesonoto castanho-avermelhado, revestido de pelos amarelos, com numerosos tubérculos pretos, pequenos, de tamanho mais ou menos uniforme. Abdome preto, com polinosidade acinzentada, formando um padrão irregular, de acordo com a incidência da luz. Asas com nervuras amarelas; calípteros grandes.

Comprimento total - 10 a $12 \mathrm{~mm}$.

\subsection{Distribuição}

Quase cosmopolita. No Brasil, os primeiros registros são de Lutz (1918), que encontrou casos de larvas em ovelhas no Rio de Janeiro e Minas Gerais. Ihering (1930) menciona a ocorrência desta parasitose na Argentina, Uruguai e Brasil (Rio Grande do Sul). Na Argentina, a distribuição de Oestrus ovis abarca praticamente todo o país (Del Ponte, 1958).

\subsection{Biologia}

Os adultos são mais ativos durante as horas de sol, depositando as larvas nas narinas de ovelhas e cabras. Cada fêmea pode depositar cerca de 60 


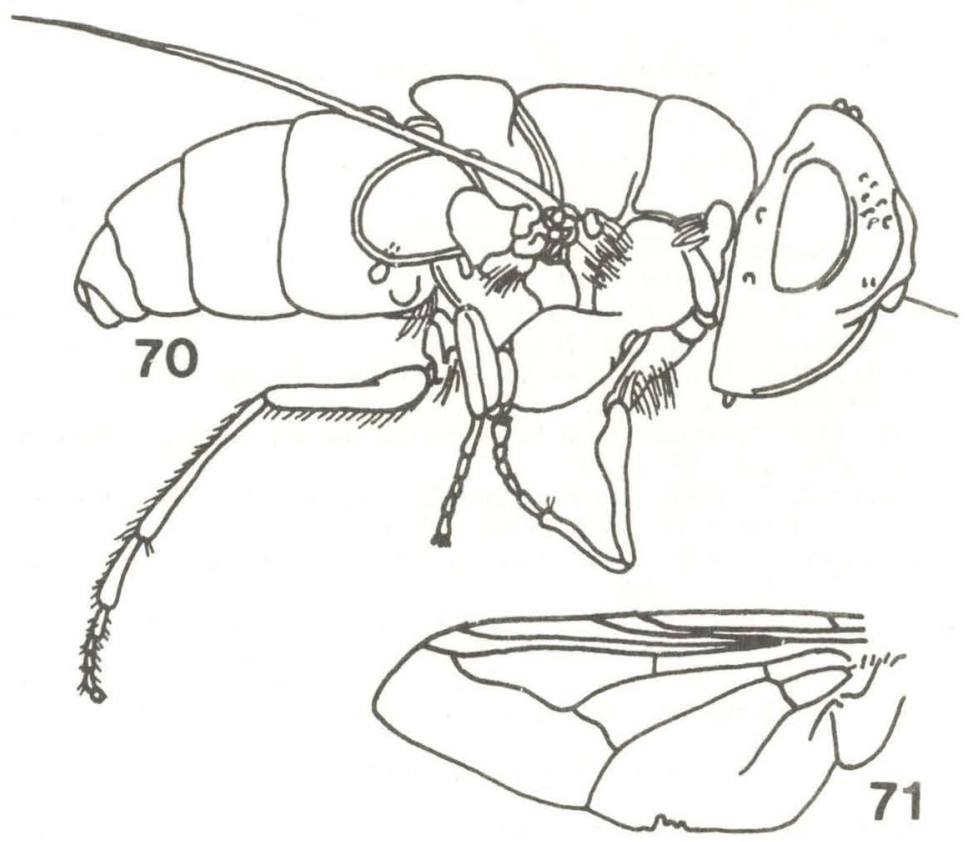

Fig. 70: Oestrus ovis (Linnaeus), fêmea; 71, idem, asa (apud Séguy, 1928).

larvas ou mais, dentro de uma hora. As larvas recém-depositadas caminham para dentro da passagem nasal até alcançar os seios nasais, frontais e maxilares, às vezes até a base dos chifress. A larva, quando crescida, alcança de 25 a $30 \mathrm{~mm}$ de comprimento, apresentando os espiráculos posteriores bem conspícuos. O período larval pode levar desde 25 dias até 2,5-12 meses. No fim deste período, elas caminham para fora das narinas, enterrando-se no solo, empupando em poucas horas. O período pupal leva em média de 3 a 6 semanas. Os adultos não se alimentam.

\subsection{Sintomas}

Na presença da mosca, as ovelhas ou cabras ficam muito excitadas, sacudindo violentamente a cabeça, espirrando e esfregando as narinas no solo. Tais sintomas demonstram que elas estão tentando se livrar de alguma coisa que persiste em penetrar em suas narinas. Nos animais parasitados, observa-se corrimento nasal de uma secreção mucosa a muco-purulenta. Os animais apresentam dificuldade respiratória, esfregando as narinas contra suas patas anteriores ou no solo. Os animais muito infestados perdem apetite, emagrecem, podendo até morrer. De um modo geral, o ataque do parasita é considerado benigno, e responsável por comparativamente poucos casos letais.

Embora não seja seu hospedeiro, o homem pode ser ocasionalmente atacado por esta espécie - os casos registrados são especialmente na zona rural, em indivíduos que vivem em contacto muito íntimo com ovelhas; no homem as moscas depositam as larvas nos olhos, raramente na boca, narinas 

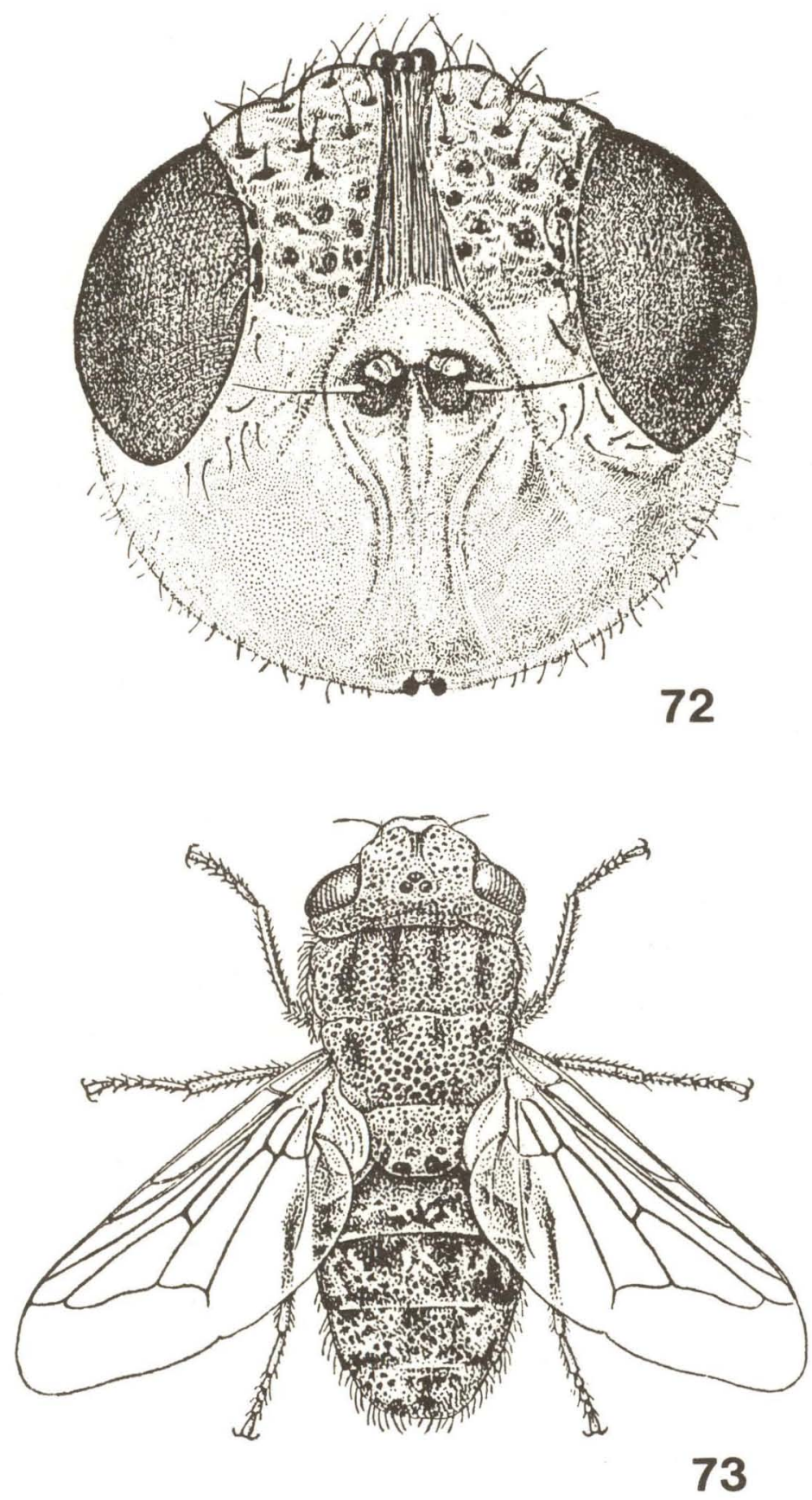

Figs. 72-73: Oestrus ovis (Linnaeus), detalhe da cabeça e adulto (apud Grunin, 1966). 
ou ouvido. Na América do Sul existem registros de oftalmomíases no Uruguai (Gaminara, 1926; Isola \& Osimani, 1944), Chile (Atías et al., 1960), Peru (Lumbreras \& Polack, 1955) e Equador (León \& Andrade, 1958).

\subsection{Tratamento}

Os primeiros tratamentos para esta parasitose incluíam o uso de pimenta, rapé, etc., nas narinas dos animais, com a finalidade de produzir espirros violentos, causando a expulsão de muitas larvas maduras. Outros tratamentos incluem: a) uso de benzeno, sob pressão intranasal, administrado na dose diária de uma colher de chá em cada narina, o que provocaria a eliminação das larvas; b) cresol saponificado a $3 \%$, na dose de $40 \mathrm{ml}$ em cada narina; c) bisulfeto de carbono e parafina líquida, em partes iguais, na dose de $2 \mathrm{ml}$ em cada narina.

Modernamente, vários inseticidas sistêmicos, incluindo o Ronnel, Triclorfon e Ruelene, têm sido muito eficientes no controle de larvas de Oestrus ovis (Duarte et al., 1980). Em experimentos realizados nos Estados Unidos, o Triclorfon, usado na dose oral de 50 a $200 \mathrm{mg} / \mathrm{kg}$ de peso vivo (Drummond, 1962), ou a aplicação nasal de um "spray" com $2,3 \mathrm{mg} / \mathrm{kg}$ de Diclorvos (2, 2-diclorovinil dimetil fosfato) (Pfadt, 1967) eliminaram, respectivamente, $100 \%$ e $95 \%$ das larvas.

Um resumo da ação dos vários inseticidas sistêmicos no controle de Oestrus ovis em ovelhas foi apresentado por Bushland et al. (1963).

\section{REFERENCIAS}

Atencio León, A. \& A. J. Ramírez, 1972. Miasis cavitaria de las ovejas. Revta vet. venez. 32(188): 164-168.

Atías M., A., R. Donckaster Rodriguez, H. Schenone F. \& M. Olivares, 1960. Myiasis ocular producida por larvas de Oestrus ovis. Boln chil. Parasit. 15(2): $37-38$.

Bacigalupo, J. \& C. F. Villamil, 1959. Miasis humana por Oestrus ovis Linneo, 1761 (sic). 1as. Jorn. entomoep. argent.: 833-836, 1 fig.

Bushland, R. C., R. D. Radeleff \& R. O. Drummond, 1963. Development of systemic insecticides for pests of animals in the United States. Ann. Rev. Ent. 8: 215-258.

Chavarría Ch., M. \& R. Ávila Carrillo, 1959. Eine neuartige wirksame Behandlung der durch Oestrus ovis Linn. ausgelösten Myiasis cavitaria. Zbl. vet.-Med. 6(9): 816-824.

Chvarría Ch., M. \& R. Ávila Carrillo, 1960. Nuevo tratamiento efectivo y practico de la miasis cavitaria ocasionada por Oestrus ovis Linn. Cienc. vet., México 5(2): 167-173.

Corrêa, O., 1961. Oestrose (sic) ovina. Granja, Revta agropec. sul-bras. 17: $21-22$.

Cristi, G. A. \& O. A. di Landro, 1950. Oestrosis en Canis familiaris. Primera constatación en el Uruguay. An. Fac. Vet. Montevideo (1948-49) 5(2): 231.

Del Ponte, E., 1939. Revisión de los "Oestridae" argentinos. Physis, B. Aires 17: $525-534$.

Del Ponte, E., 1958. Manual de entomología médica y veterinaria argentinas, 349 pp., ilus. Librería del Colegio, Buenos Aires.

Drummond, R. O., 1962. Control of larvae of Oestrus ovis in sheep with systemic insecticides. J. Parasit. 38: 211-214.

Duarte, M. J. F., P. A. C. Gomes \& M. S. G. Tristão, 1980. Vermífugos de interesse em medicina veterinária. Empresa de Pesquisas Agropecuárias do Rio de Janeiro, PESAGRO, Circ. técn. 3: 1-51.

Gaminara, A., 1925. Un caso de miasis ocular por Oestrus ovis. Boln Cons. nac. Hig., Montevideo 19: 73-78.

González, M. A., 1977. Oestrus ovis. Aspectos epizootiológicos en Mercedes, Corrientes. Gac. vet., B. Aires 39(322): 389-393.

Guerra Grande, J. M., 1952. Consideraciones sobre un caso de oftalmomiasis externa por Oestrus ovis. Archos Soc. oftal. hisp.-am. 12(1): 86-89, ilus. 
Ihering, R. von, 1929. Os oestrideos importados, seu papel como parasitas e em particular os Gasterophilus no Brasil. Bolm Agric., S Paulo 30: 863-883.

Ihering, R. von, 1930. Vários casos de Oestrus e Gasterophilus no Brasil. Revta Soc. paul. Med. vet. 1(2): 30-35.

Isola, W. \& J. J. Osimani, 1944. Un nuevo caso de oftalmomiasis conjunctival produzida por Oestrus ovis en el Uruguay. Archos urug. Med. Cirug. 25(3): 260-264.

Iturbide, A., 1960. El Oestrus ovis y la explotación ovina. Investnes agropec. 1(2): 105-107.

León, L. A. \& M. Andrade, 1955a. Caso de milasis ocular a Oestrus ovis (Diptera, Oestridae), observado en Quito. Boln Inf. cient. nac. Quito 7(63): 171-184, 2 pls. (Também in Boln Lab. clín. Luis Razetti 16: 621-639, figs., 1955).

León, L. A. \& M. Andrade, 1955b. Observaciones sobre la miiasis ocular producida por el Oestrus ovis en el Ecuador (Diptera - Oestridae). Revta ecuat. Ent. Parasit. 2(3-4) (1954-55): 377-388, pls.

Lizcano Herrera, J., 1950. Contribución al estudio del Oestrus ovis Linné, 1761 (sic). Boln Zootecn., Córdoba 6: 92-94.

Lora D., C., M. Vásquez D. \& C. Marchinares A., 1966. Tratamiento de la miasis cavitaria por Oestrus ovis con neguvon. Revta Centro nac. Pat. anim., Lima 5(8-9): 69-74.

Lumbreras Cruz, H. \& F. Polack, 1955. Primer caso peruano de oculomiiasis producida por larvas de Oestrus ovis Linneo, 1758. Revta méd. peru. 26: 95-99, fig.

Lutz, A., 1917. A occurrencia de Oestrus ovis no Rio de Janeiro e nos estados visinhos, p. 111, in seu Contribuições ao conhecimento dos oestrideos brazileiros. Mems Inst. Oswaldo Cruz 9: 94-112, pls. 27-29.

Mayo, N. S., 1920. Parasitas do gado - A mosca estro do gado vaccum Estrus do carneiro. Brasil agric. 5(8): 222-223, 4 figs.

Mello, M. J., 1941. A respeito do Oestrus ovis, parasito das cavidades dos ossos da cabeça dos ovinos. Biológico, S Paulo 71(10): 250.

Neiva, A., 1930. Contribuição à biologia de Oestrus ovis. Revta Ind. anim. 1(6): 628 .

Neiva, C., 1933. A mosca do carneiro Oestrus ovis L., e as myiases humanas. Cha. Qui. 47(1): 94-96, 5 figs.

Oberg, C., L. Díaz \& G. Valenzuela, 1974. Parásitos identificados en bovinos, ovinos, suinos y equinos en el laboratorio de enfermedades parasitarias de la Escuela de Medicina Veterinaria de la Universidad Austral de Chile, 1963-1973. Boln chil. Parasit. 29: 99-102.

Ortecho, C. L. \& D. Marble, 1966. Efectividad del 0,0 dimenthyl 0-P-sulfamoyl phenil phosphorothioate contra la larva del Oestrus ovis. Revta Centro nac. Pat. anim 6(10): 47-54.

Ortega Reyes, M., 1887. Las larvas de las moscas en las fosas nasales, o la enfermedad llamada myiasis. Gac. méd. Méx. 22(1): 3-16, 1 pl.

Osimani, J. J. \& R. Salsamendi, 1945. Oestrus ovis L. Su frecuencia en el Uruguay. Algunas consideraciones sobre su biologia An. Fac. Med. Univ. Montev. 30(1-4): 381-385, figs. (Também em Revta Med. vet., B Aires 27(3-4): 131-134, 1945).

Papavero, N., 1977. The World Oestridae, mammals and continental drift, 240 pp., il. W. Junk, The Hague.

Pfadt, R. W., 1967. Mortality of nasal bots in sheep treated with systemic insecticides. J. econ. Ent. 60: 1420-1422.

Prado, A. \& C. Neiva, 1932. Observações sobre o Oestrus ovis L., com a descripção do hypopygio do adulto e das placas estigmaticas da larva. Brasil méd. 46(26): 575. (Também em Revta Ind. anim. 2(8): 905-908, 2 figs.),

Rabello, E. X. \& D. M. Malheiro, 1954. Presença de larvas de Oestrus ovis L. 1761 [sic] (Diptera, Muscoidea-Oestridae) em Capra hircus L. 1761 [sic] no estado de São Paulo, Brasil. Revta Fac. vet. S Paulo 5: 41-47, 5 pls. 
Rodriguez Novoa, L. J., 1935. "La estridia de los ovinos" o falsa locura de los lanares. Boln Dir. Agric. Ganad. Lima 5: 226, 228-232, 234.

Rodriguez Novoa, L. J., 1942. Gusanos de la cabeza de los carneros, "estridia de los ovinos". Vida agríc., Lima 19: 59-61.

Ronna, E. K. F., 1929. A invasão do "estro" nas ovelhas do Estado. Revta Agric. Rio Gde Sul 17(3): 103-105, 3 figs.

Ronna, E K. F., 1940. A mosca do carneiro e sua distribuição no Brasil. Cha. Qui, 62(2): 188, fig.

Salcés Fermín, (-) \& S. P. Calvo, 1945. Ensayo experimental con D.D.T. sobre Oestrus ovis. Revta Med. vet., B Aires 27(3-4): 137-142, figs.

Salvador Yépez, M. \& F. Gallardo Z., 1971. Presencia de Oestrus ovis L. (Diptera, Oestridae) en ovinos y caprinos del Estado Lara. Revta vet. venez. 31(183): 234-237.

Salvador Yépez, M., F. Gallardo Z. \& R. Torres Artigas, 1968. Contribución al estudio de la parasitología venezolana. Acta cient. venez. 19(1): 46.

Schifini, H. A., 1952. Oestrosis ovina en Guatemala (el gusano de la nariz de las ovejas y cabras). Revta Agric. Guatemala (3) 1(5-7): 27-29.

\section{FAMILIA CUTEREBRIDAE (EXCETO Dermatobia hominis)}

Dípteros robustos. Cabeça e fronte largas. Olhos relativamente pequenos e bem separados entre si, em ambos os sexos. Placa facial oval, fortemente côncava. Carena facial presente ou ausente. Vibrissas ausentes. Antenas com o terceiro artículo curto a alongado. Arista nua, pectinada a plumosa. Cerdas ausentes ou representadas por fracos pêlos. Ocelos presentes, situados em calo ocelar proeminente. Parafaciália pilosa. Parafrontália e genas geralmente com calosidades brilhantes. Probóscida rudimentar, aparentemente funcional. Tórax robusto, piloso, cerdas ausentes. Infraescutelo não desenvolvido. Prosterno e propleura pilosos. Álula grande e reta. Calípteros grandes, nus. Pernas robustas e curtas e mais ou menos alongadas. Tarsos usualmente largos e achatados. Abdome largo, oval, fortemente piloso.

Esta família é restrita ao Novo Mundo, sendo bem representada na região neotropical. Suas espécies foram catalogadas por Guimarães (1967).

\section{Chave para os gêneros}

1. Carena facial ausente ou fracamente indicada (Fig. 74) $\ldots \ldots \ldots \ldots .2$

Carena facial bem desenvolvida (Fig. 76) ................ 4

2. Espécies de tamanho médio $(12-15 \mathrm{~mm})$. Abdome azul-metálico, com reflexos violáceos .......................... Dermatobia

Espécies grandes, de corpo robusto. Abdome de colorido castanho a preto, nunca azul-metálico ......................... 3

3. Arista lateralmente comprimida, fortemente pilosa nos dois lados, até o ápice (Fig. 77) ........................ Pseudogametes

Arista ciliada, com cílios somente na face superior (Fig. 78) .......

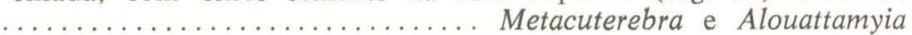

4. Arista nua (Fig. 79); espécies neotropicais ........... Rogenhofera

Arista ciliada, com cílios apenas na face superior; espécies neárticas

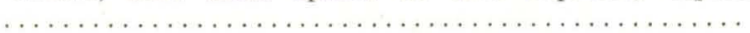

Cuterebra

\subsection{Biologia}

Poucas espécies de Cuterebridae foram estudadas com algum detalhe, especialmente na região neotropical. Para a América do Norte existem boas contribuições de Dalmat (1943), Sillman (1956), Ignoffo (1961), Catts (1965, 1967), Capelle (1970) e Baird (1971, 1972). A grande maioria dos trabalhos restantes trata apenas de alguns tópicos da biologia larval e dos hospedeiros. Os dados existentes sobre as relações parasita-hospedeiro das espécies neotropicais foram resumidos por Guimarães (1971). Uma resenha sobre a biologia dos Cuterebridae do Novo Mundo foi publicada por Catts (1982). 

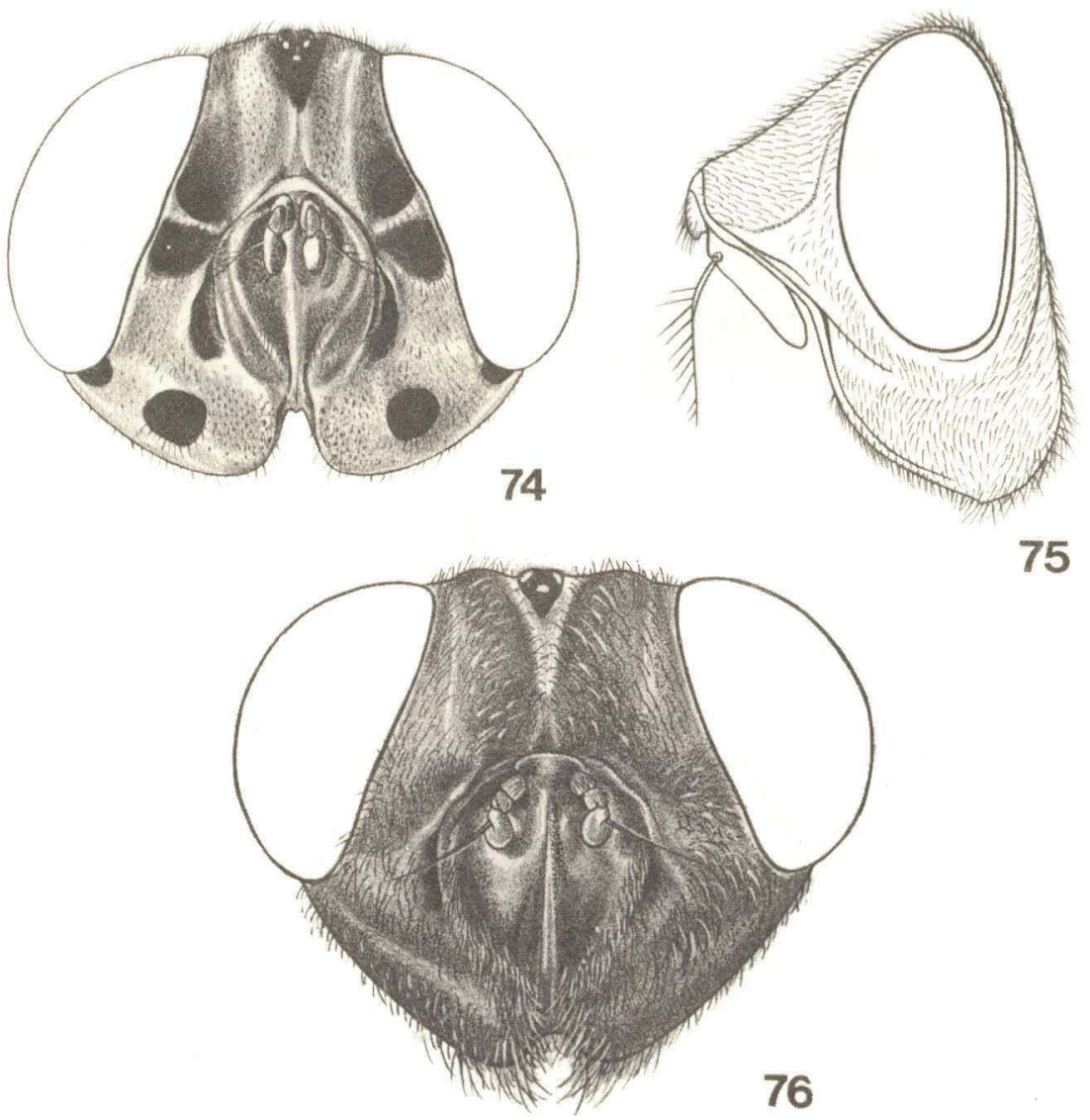

75

Figs. 74-76. Cabeças de Cuterebridae - 74, Metacuterebra; 75, Dermatobia hominis (Linnaeus Jr.); 76, Rogenhofera.

\subsubsection{Cópula}

A cópula de Cuterebra latifrons foi estudada detalhadamente por Catts (1967), na Califórnia. Os adultos foram observados ęm sítios de agregação no topo de colinas durante duas estações de vôo. As moscas, emergidas de pupários espalhados pelos hospedeiros nas ravinas circundantes, voavam na manhã seguinte para os sítios de agregação, preferindo áreas no topo das colinas. Os machos apareciam pela manhã, quando a temperatura do ar estava a $19-22^{\circ} \mathrm{C}$ e terminavam sua atividade antes do meio-dia.

A marcação das moscas macho mostrou que os indivíduos tinham uma distribuição espaçada no topo da colina, devido a sua atividade territorial. Cada macho ocupava uma área específica durante toda a manhã e defendia-a de outros intrusos. A experiência mostrou que os machos permaneciam nesse lugar por toda a sua vida - um período de 10-12 dias. 

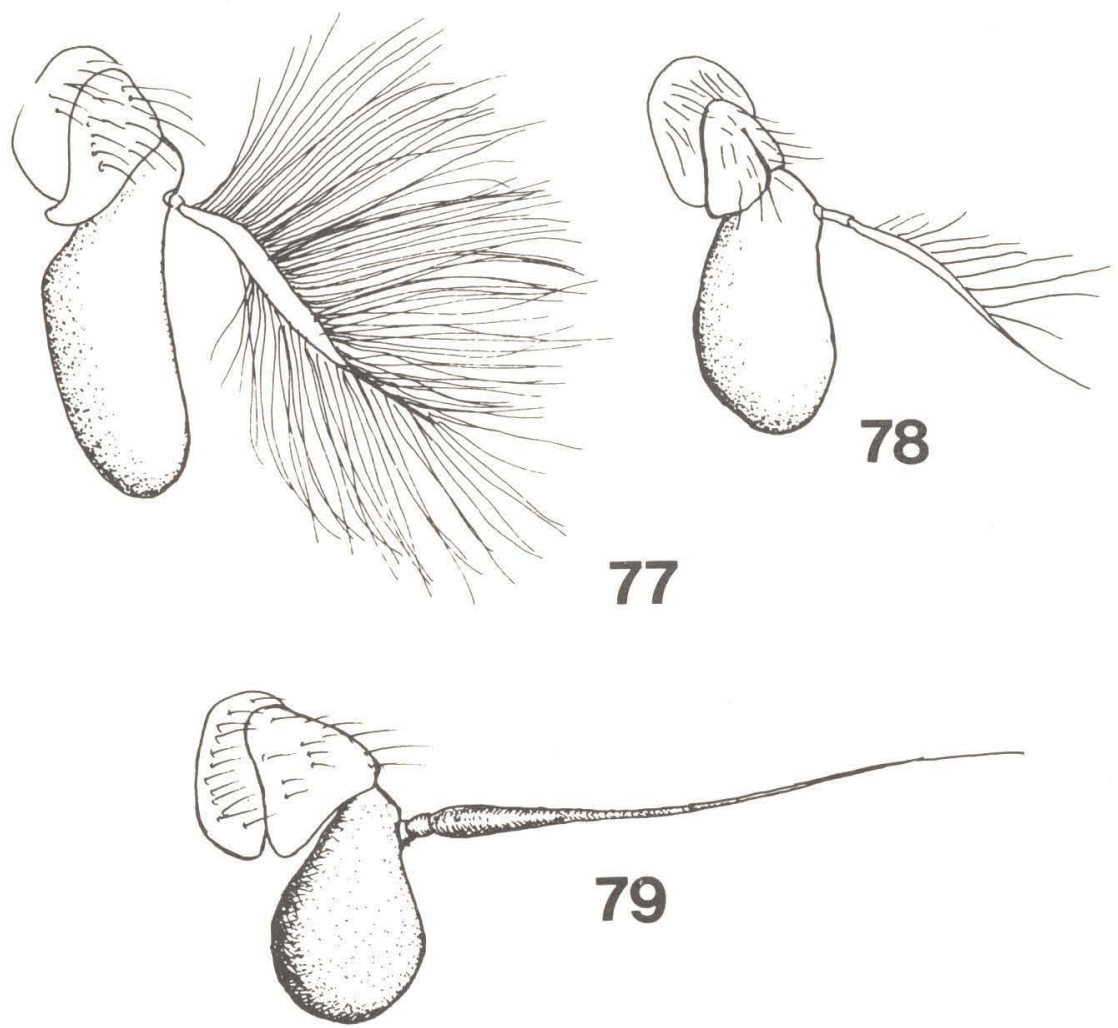

Figs. 77-79: Antenas de Cuterebridae - 77, Pseudogametes; 78, Metacuterebra; 79, Rogenhofera.

As fêmeas apareciam mais tarde, durante o dia, do que os machos, e perfaziam um total de $5 \%$ da população no topo da colina, ali permanecendo apenas o tempo suficientes para copular. As moscas virgens eram bastante visíveis por seu voo rasteiro pelo topo da colina. Os machos que as aguardavam perseguiam-nas e copulavam com as fêmeas em voo; o par unido então caía sobre a vegetação para terminar a cópula. As fêmeas abandonavam as alturas imediatamente após fecundadas, numa série de voos curtos dirigidos às áreas de ravinas. A agregação em C. lepivora foi estudada por Meyer \& Bock 1980).

Lutz (1917) descreveu o sítio de agregação de Pseudogametes hermanni, no Brasil. Os machos desta espécie foram coletados enquanto descansavam em troncos de árvores a cerca de 3-4 $\mathrm{m}$ do chão. As moscas apareciam apenas durante o verão, pelas 9 hs da manhã. Durante um período de poucos anos, Lutz coletou mais de uma centena de espécimes nesse mesmo lugar.

\section{0:1.2. Produção de ovos}

A fecundidade média de C. latifrons é de 1300 ovos, postos em pequenos grupos de 5-10 ovos por sítio (Catts, 1966). 
Baird (1971) determinou a capacidade ovígera de C. jellisoni combinando os totais de ovos depositados e de óvulos contados em dissecções - a capacidade média para 25 fêmeas foi de 1006 (524-1260).

Ryckman \& Lindt (1954) observaram uma fêmea de C. lepivora (criada de Sylvilagus audubonii sanctidiegi) que depositou 242 ovos num período de 72 horas.

d'Andretta \& Jardim (1954) relataram o caso de uma Metacuterebra apicalis que depositou um total de 595 ovos, em 2 dias, no laboratório. Os ovos foram depositados em séries lineares e o período de incubação durou entre 12-14 dias.

O maior número de ovos postos por uma Cuterebra, parasita de roedores, foi assinalado por Penner \& Pocius (1956): 1762 ovos; todos eclodiram entre 5-9 dias.

\subsubsection{Duração do estágio de ovo}

Em todas as espécies de Cuterebra com período de incubação conhecido, a larva infectante (primeiro instar) começou a eclodir no $4 .^{\circ}$ ao $17 .^{\circ}$ dias pós-oviposição, dependendo da temperatura: a larva permanecia dentro do cório até ser estimulada a emergir.

\subsubsection{Estímulos para a emergência da larva}

As larvas não emergem do cório do ovo a não ser que um estímulo específico seja aplicado; este varia de espécie para espécie. Um ligeiro aumento de temperatura faz com que as larvas de $C$. latifrons e $C$. polita emerjam (Catts, 1965, 1967; Capelle, 1970); vibrações fortes e toques com um pincel estimularam as larvas de C. tenebrosa (Molliet, 1950).

Townsend (1915) observou que a estimulação normal para induzir a larva e emergir era o calor resultante do contacto íntimo com o corpo do hospedeiro (sempre um homeotérmico).

Sillman \& Smith (1959) observaram que as larvas também eram estimuladas por um ambiente úmido, pois quando colocadas na boca de Peromyscus leucopus, moviam-se "out of the sight along the side of the tongue towards the back of the throat".

\subsubsection{Oviposição}

Townsend (1915) acreditava que os ovos dos cuterebrídeos não eram depositados sobre os hospedeiros, mas sim que a mosca os punha nos ninhos ou no caminho de coelhos, ratos e outros pequenos mamíferos parasitados. Baseou essa asserção na observação de um número considerável de moscas na região montanhosa do sudoeste da América do Norte, onde elas assentavam em ramos mortos perto de regatos, em rochas próximas de água corrente, ou na terra das margens de riachos.

Estudos recentes demonstraram que há uma gama extremamente variada de hábitos de oviposição entre os cuterebrídeos, e que este comportamento está intimamente ligado a alguma característica específica do hospedeiro.

Assim, C. polita coloca seus ovos ao redor da boca do ninho de seu hospedeiro, Thomomys talpoides, os ovos sendo colocados individualmente sobre as raízes fibrosas que ficam suspensas do teto do ninho (Capelle, 1970). C. latifrons oviposita em gravetos, ramos, etc., que formam o ninho arbóreo de Neotoma fuscipes (Catts, 1967). C. buccata na extremidade do capim que pende sobre os esconderijos de coelhos (Painter, 1930; Beamer: 1950). C. tenebrosa coloca os seus ao acaso, sobre pedras, vegetação, etc.. dentro ou perto da entrada do buraco de seu hospedeiro (Molliet, 1950), o mesmo fazendo $C$. beameri (Beamer et al., 1943).

Leonard (1933) sugeriu que as fêmeas poderiam ovipor diretamente. atraídas pelas tetas úmidas de coelhos fêmeas. Uberlaker \& Keller (1964) propuseram que os ovos de $C$. emasculator eram postos sobre os pêlos de Tamias striatus e que as larvas penetravam no hospedeiro quando este limpava sua pelagem. Segundo Richens (1965), $90 \%$ das larvas de $C$. polita 
infestando roedores foram achadas na porção ventral do corpo e mais do que $75 \%$ na porção posteroventral.

Baird (1971), ao estudar a infestação de C. jellisoni em coelhos, notou uma forte preferência por determinadas porções do corpo do hospedeiro. As larvas, sem exceção, quando introduzidas por várias aberturas, terminavam sempre se instalando na cabeça; localizavam-se preferencialmente ao redor da pele dos olhos e nas bochechas. Catts (1965) demonstrou em infestações experimentais de vários roedores que não havia relação entre o lugar de penetração da larva infectante e o lugar onde esta se desenvolvia. A infestação por C. horripilum, segundo Geis (1957) era principalmente restrita à garganta e pescoço.

\subsubsection{Longevidade da larva infestante}

Catts (1967) demonstrou que algumas larvas de C. latifrons permaneciam viáveis dentro do ovo até 4 meses, a temperaturas de $15 \cdot 25^{\circ} \mathrm{C}$ e umidade relativa de $45-64 \%$.

\subsubsection{A penetração da larva infestante}

Ryckman \& Lindt (1954) sugeriram que a larva de Cuterebra invade o hospedeiro através da parede do trato alimentar, com base na observação da ingestão oral de larvas por coelhos. Beamer \& Penner (1942) observaram larvas de provavelmente $C$. buccata entrando pelas fendas nasais de um coelho. Penner \& Pocius (1956) obtiveram repetidos sucessos em infestar roedores, em laboratório, através das narinas. Radovsky \& Catts (1960) confirmaram a entrada nasal em larvas de C. latifrons. Shannon \& Greene (1926) acreditavam que os ovos de Alouattamyia baeri, parasita de guaribas (Alouatta), poderiam ser deglutidas pelo hospedeiro junto com folhas; as larvas, assim que se encontravam na boca, emergiam e começavam a penetrar pelos tecidos da boca; então, atravessando a carne do animal, atingiam sua pele, através da qual perfuravam um orifício respiratório. Observações de Catts (1967) demonstraram que a penetração pode se efetuar pelas aberturas bucal, nasal e genital. Observou-se também diretamente penetração através da pele (Knab, 1916; Molliet, 1950; Penner, 1958).

\subsubsection{O período larval}

A média de duração do período larval, para larvas maduras de C. jellisoni em coelhos, foi de 36 dias (para 71 larvas) (Baird, 1971). Catts (1967) assinalou um período de 23-38 dias para C. latifrons. O período mais longo foi achado em C. ruficrus por Baird (1972): 74 dias. Segundo Sillman (1955) é possível determinar o estágio da larva in situ pelo exame direto das placas espiraculares expostas.

O comportamento da larva madura ao se enterrar no solo para empupar foi observado por Beamer et al. (1948) e Gregson (1950). Apesar de não se saber que condições de solo são preferidas pelas larvas, Ignoffo (1961) demonstrou em laboratório que a umidade é uma das condições necessárias.

\subsubsection{O período pupal}

O período pupal de C. tenebrosa, em laboratório, foi de 47 dias (Parker \& Wells, 1919). Baird (1972) achou 140 dias para C. ruficrus e 125 para C. jellisoni (Baird, 1971). O estágio pupal de Metacuterebra apicalis, criada de um roedor selvagem do gênero Oryzomys, variou de 29 a 31 dias (Forattini \& Lenko, 1959).

\subsection{Especificidade do hospedeiro}

A especificidade dos hospedeiros de Cuterebra ainda é problemática. Excetuadas algumas espécies e certas áreas geográficas, os dados sobre hospedeiros são poucos e não críticos. As associações de cuterebrídeos e hospe- 
deiros são por vezes dúbias, principalmente por falta de amostragem adequada ou falta de identificação segura.

Grande parte dos trabalhos publicados não apresenta identificação da espécie de Cuterebridae. Neste caso encontram-se os seguintes trabalhos: Allen, 1943, 1952; Anon., 1918, 1960; Atkenson \& Givens, 1951; Baird, 1970, 1971, 1974, 1975; Baker, 1933; Bell \& Chalgren, 1943; Bennett, 1973; Berg, 1881; Boisvenue, 1958; Bruna, 1952; Caldwell, 1966, 1970; Cameron, 1926; Capelle, 1971; Carpenter, 1934; Carson \& Canter, 1963; Carter \& Blackloch, 1913; Catts, 1963, 1967; Chapman, 1938; Cheatum, 1962; Collins \& Hugghins, 1971; Crowe, 1943; Dalmat, 1941; Dimmock, 1890; Dunaway et al., 1964; Dury, 1898; Ecke \& Yeatter, 1956; Egoscue, 1957; Fitch, 1889; Garrigues, 1965; Geis, 1957; Gerstaecker, 1868; Goldman, 1920; Graham, 1962, 1964; Gregson, 1950; Haas \& Martin, 1973; Hadwen, 1915; Hansen et al., 1965; Harkema, 1936; Haugen, 1942; Hawkins, 1942; Hensley, 1976; Hering, 1864; Iversen \& Turner, 1969; Jaeger, 1924; Johnson (C. W.), 1930; Johnson (J. W.), 1892; Knipling \& Bruce, 1937; Layne, 1963; Leidy, 1857, 1888; Leonard, 1933; Linsdale \& Trevis, 1951; Linter, 1890; Longhurst \& Douglas, 1953; Lord, 1866; Lugger, 1897; McGinnes, 1964; McKinney \& Christian, 1970; Marshall, 1960; Milks et al., 1938; Miller \& Getz, 1969; Murphy, 1952; Rainey, 1956; Rathvon, 1869; Riley \& Howard, 1892, 1893; Rosesco, 1957; Rootenbacker et al., 1961; Scholten et al., 1962; Schwantz \& Shook, 1928; Scott (T. G.), 1943, 1947; Seton, 1928; Severinghaus, 1949; Shoemaker \& Joy, 1967; Smith, 1892; Stone, 1970; Stones \& Hayward, 1968; Stringer, 1967; Stringer et al., 1969; Vestal, 1938; Vorhies \& Taylor, 1933; Whitaker, 1963, 1968; Wilson, 1945; Wilson \& Johnson, 1971; Woronecki, 1961; e Worth, 1950.

Como dito por Sillman (1955), muitas espécies foram descritas de larvas e adultos sem dados de biologia; a identificação das espécies foi feita também em parte baseada nos hospedeiros em que foram encontradas, apesar do fato de muitas larvas de diferentes espécies serem muito semelhantes (Dunaway et al., 1967).

10.3. Lista dos hospedeiros

(Classificação seg. Miller \& Kellogg, 1955).

10.3.1. Marsupialia

Caluromys philander (Linnaeus) (Didelphoidea, Didelphidae) - parasitado por Metacuterebra sp. (Cuterebrinae) (Brauer, 1863, Brasil; Guimarães, 1971, Brasil: Amazonas).

Marmosa (Thylamys) microtarsus microtarsus (Wagner) (Didelphoidea, Didelphidae) - parasitado por Metacuterebra townsendi (Cuterebrinae) (Fonseca, 1941, Brasil: São Paulo).

\subsubsection{Primates}

Aotus trivirgatus (Humboldt) (Cebidae, Aotinae) - parasitado por Alouattamyia baeri (Cuterebrinae) (Guimarães, 1971, Brasil: Pará).

Alouatta belzebul (Linnaeus) (Cebidae, Alouattinae) - parasitado por Alouattamyia baeri (Cuterebrinae) (Guimarães, 1971, Brasil: Maranhão).

Alouatta palliata aequatorialis Festa (como palliata inconsonans Goldman) (Cebidae, Alouattinae) - parasitado por Alouattamyia baeri (Cuterebrinae) (Ewing, 1925, Panamá; Zeledón et al., 1959, Costa Rica).

Alouatta palliata palliata (Gray) (Cebidae, Alouattinae) - parasitado por Alouattamyia baeri (Cuterebrinae) (Zeledón et al., 1967, Costa Rica).

Alouatta seniculus (Linnaeus) (Cebidae, Alouattinae) - parasitado por Alouattamyia baeri (Cuterebrinae) (Shannon \& Greene, 1926, Guyana e Panamá; Dunn, 1934, Panamá). O nome correto do macaco, seniculus, foi dado por Hershkovitz (1977: 394).

Alouatta villosa (Gray) (Cebidae, Alouattinae) - parasitado por Alouattamyia baeri (Cuterebrinae) (Hershkovitz, 1977: 394). 
Alouatta sp. (Cebidae, Alouattinae) - parasitado por Alouattamyia baeri (Cuterebrinae) (Zeledón et al., 1959, Costa Rica; Shannon \& Greene, 1956, Guyana; original, Brasil: Pará).

\subsubsection{Lagomorpha}

Lepus (Macrotolagus) californicus Gray (Leporidae) - parasitado por Cuterebra jellisoni (Baird, 1971, 1972, USA: Utah; Ignoffo, 1961). C. ruficrus (Baird, 1972, USA: Utah, Idaho) e Cuterebra sp. (Townsend, 1892, USA: New Mexico; Roberts, 1931, USA: Texas; Lechleitner, 1959, USA: California).

Lepus (Macrotolagus) californicus deserticola Mearns (Leporidae) - parasitado por Cuterebra jellisoni (Philip et al., 1955, USA: Nevada; Ignoffo, 1961, USA: Utah) e C. ruficrus (idem).

Lepus (Macrotolagus) californicus texianus Waterhouse (Leporidae) parasitado por Cuterebra sp. (Roberts, 1931, USA: Texas).

Ochotona princeps (Richardson) (Ochotonidae) - parasitado por Cuterebra sp. (Baird \& Smith, 1979).

Sylvilagus (Paludilagus) palustris paludicola (Miller \& Bangs) (Leporidae)

- parasitado por Cuterebra sp. (Blair, 1936, USA).

Sylvilagus (Paludilagus) palustris palustris (Bachman) (Leporidae) - parasitado por C. cuniculi (Knipling \& Brody, 1940, USA: Georgia; Jellison, 1949, USA: Georgia, Florida).

Sylvilagus (Sylvilagus) aquaticus aquaticus (Bachman) (Leporidae) parasitado por C. buccata (Hunt, 1959, USA: Texas).

Sylvilagus (Sylvilagus) audubonii sanctidiegi (Miller) (Leporidae) - parasitado por C. lepivora (Ryckman \& Lindt, 1954, USA: California; Meyer \& Bock, 1980).

Sylvilagus (Sylvilagus) bachmanni (Waterhouse) (Leporidae) - parasitado por Cuterebra sp. (Connell, 1954, USA: California).

Sylvilagus (Sylvilagus) floridanus (Allen) (Leporidae) - parasitado por C. buccata (Leonard, 1933; Lindquist, 1937, USA: Texas; Beamer \& Penner, 1942, USA), C. lepivora (Coquillett, 1898, USA: Wyoming, California) e Cuterebra sp. (Connell, 1954, USA: California; Manville, 1961, USA: Virginia).

Sylvilagus (Sylvilagus) floridanus alacer (Bangs) (Leporidae) - parasitado por C. buccata (Eddy \& Emerson, 1940, USA: Oklahoma; Morlan, 1952, USA: Georgia; Haas \& Dicke, 1958, USA: Wisconsin), C. horripilum (Haas, 1958, USA: Wisconsin) e Cuterebra sp. (Patton, 1935, USA).

Sylvilagus (Sylvilagus) floridanus floridanus (Allen) - parasitado por C. horripilum (Haas \& Dicke, 1958, USA: Wisconsin).

Sylvilagus (Sylvilagus) floridanus floridanus mallurus (Thomas) - parasitado por C. buccata (Townsend, 1917, USA: Washington, D. C. e Maryland; Knipling \& Brody, 1940, USA: Georgia; Morlan 1952, USA: Georgia; Jacobson, McGinnes \& Catts, 1978).

Sylvilagus (Sylvilagus) floridanus mearnsii (Allen) - parasitado por $C$. buccata (Hansen, 1942, USA: Michigan; Stannard \& Piertsch, 1958, USA: Illinois), C. cuniculi (idem), C. horripilum (Stannard \& Piertsch, 1958, USA: Illinois); Haas \& Dicke, 1958, USA: Wisconsin) e Cuterebra sp. (Jameson, 1943; Stannard \& Piertsch, 1958, USA: Illinois).

Sylvilagus (Sylvilagus) nuttallii (Bachman) (Leporidae) - parasitado por C. lepivora (Hall, 1921, USA: California, Wyoming).

\subsubsection{Rodentia}

a. Sciuromorpha

Citellus (Citellus) tredecimlineatus (Mitchill) (Sciuroidea, Sciuridae) parasitado por Cuterebra sp. (Hall, 1921, USA).

Citellus sp. (Sciuroidea, Sciuridae) - parasitado por C. grisea (Stillman, 1956, USA: oriental e Canadá).

Cynomys (Cynomys) ludovicianus (Ord) (Sciuroidea, Sciuridae) - parasitado por C. tenebrosa (Hall, 1921, USA: Montana).

Eutamias (Neotamias) minimus (Bachman) (Sciuroidea, Sciuridae) 
parasitado por C. polita (Richens, 1965, USA: Utah) e Cuterebra sp. (Lawrence, 1956, USA: n. Michigan).

Sciurus (Guerlinguetus) aestuans Linnaeus (Sciuroidea, Sciuridae) - parasitado por Rogenhofera grandis (Berg, 1876, Argentina).

Sciurus (Guerlinguetus) sp. (Sciuroidẹa, Scirudae) parasitado por Metacu. terebra sp. (Brasil: São Paulo, original).

Sciurus (Neosciurus) aureogaster Cuvier (Sciuroidea, Sciuridae) - parasitado por Cuterebra sp. (Coquerell \& Sallé, 1862, México).

Sciurus (Neosciurus) carolinensis Gmelin (Sciuroidea, Sciuridae) - parasitado por C. emasculator (Atkenson \& Heflin, 1948, USA: Alabama; Bennett, 1955, USA; Jacobson et al., 1979); C. fontinella (Pierre, 1921) e Cuterebra sp. (Allison, 1953, USA: North Carolina).

Sciurus (Neosciurus) carolinensis pennsylvanicus Ord (às vezes citado como carolinensis leucotis) (Sciuroidea, Sciuridae) - parasitado por Cuterebra sp. (Osborn, 1896, USA: New York; Baker, 1968; Parker, 1968, USA: Virginia).

Sciurus (Otosciurus) niger Linnaeus (Sciuroidea, Sciuridae) - parasitado por Cutebra emasculator (Jacobson, Guynn \& Hackett, 1979, USA: Mississippi).

Perognathus (Perognathus) hispidus Baird (Geomyoidea, Heteromyidae) - parasitado por Cuterebra sp. (Goertz, 1966, USA: Oklahoma).

Tamias striatus (Linnaeus) (Sciuroidea, Sciuridae) - parasitado por $C$. emasculator (Bennett, 1955, USA: Massachusetts, Iowa, New York, Arkansas; Dorney, 1965, USA: Wisconsin; Uberlaker \& Keller, 1965, Canadá; Ontario; Bennett, 1972, Canadá: Ontario; Jacobson, Guynn \& Hackett, 1979; USA: Mississippi); e Cuterebra sp. (Lawrence et al., 1965, USA, n. Michigan).

Tamias striatus lysteri (Richardson) (Sciuroidea, Sciuridae) - parasitado por C. emasculator (Fitch, 1856, USA: New York) e Cuterebra sp. (Osborn, 1896, USA: New York; Preble, 1936, USA: New Hampshire e New York; Blair, 1941, USA: Michigan; 1942, USA: Michigan).

Tamiasciurus hudsonicus (Erxleben) (Sciuroidea, Sciuridae) - parasitado por C. emasculator (Dorney, 1965, USA: n. Michigan) e Cuterebra sp. (Osborn, 1896, USA: New York).

Thomomys (Thomomys) talpoides (Richardson) (Geomyioidea, Geomyidae) - parasitado por C. polita (Capelle, 1970, w. USA; Graham \& Capelle, 1970; Richens, 1965), C. thomomuris (Jellison, 1949, USA: Montana) e Cuterebra sp. (Tryon, 1947, USA: Montana).

Thomomys (Thomomys) talpoides wasatchensis Durrant (Geomyioidea, Geomyidae) - parasitado por C. polita (Richens, 1965, USA: Utah; Graham \& Capelle, 1970, w. USA).

\section{b. Myomorpha}

Calomys callosus (Rengger) (Muroidea, Cricetidae) - parasitado por $\mathrm{Me}$ tacuterebra apicalis (Mello, 1978, Brasil: Brasília, D. F.).

Clethrionomys gapperi (Vigors) (Muroidea, Cricetidae) - parasitado por Cuterebra sp. (Manville, 1961, USA: Michigan; Clough, 1965, USA: Wisconsin; Lawrence et al., 1965, USA: n. Michigan).

Holochilus brasiliensis (Desmarest) (Muroidea, Cricetidae) - parasitado por Metacuterebra apicalis (Lutz, 1917, Brasil: São Paulo).

Holochilus brasiliensis leucogaster Brandt (Muroidea, Cricetidae) - parasitado por Metacuterebra apicalis (Brasil: São Paulo, original).

Holochilus brasiliensis venezuelae Allen (como sciureus berbicensis Morrison-Scott) (Muroidea, Cricetidae) - parasitado por Metacuterebra apicalis (Twigg, 1956, Guyana).

Liomys irroratus (Gray) (Geomyoidea, Heteromyidae) - parasitado por C. fontinella Clark (Parker \& Chaney, 1979; USA).

Microtus (Chilotus) oregoni (Bachman) (Muroidea, Cricetidae) - parasitado por Cuterebra sp. (Hunter et al., 1972, Canadá: British Columbia).

Microtus (Microtus) pennsylvanicus (Ord) (Muroidea, Cricetidae) - parasitado por C. angustifrons (Goetz, 1970, USA: Michigan), C. grisea (Buckner, 1958, Canadá: Ontario) e Cuterebra sp. (Manville, 1961, USA: Michigan; 
Clough, 1965, USA: Wisconsin; Lawrence et al., 1965, USA: n. Michigan). Microtus (Microtus) pennsylvanicus drummondii (Audubon \& Bachman) (Muroidea, Cricetidae) - parasitado por Cuterebra sp. (Jacobsen, 1966, Canadá: Manitoba).

Microtus (Microtus) townsendii (Bachman) (Muroidea, Cricetidae) parasitado por C. grisea Coquillett (Boonstra, Krebs \& Beacham, 1980).

Napaeozapus insignis frutectanus Jackson (Dipodoidea, Zapodidae) parasitado por Cuterebra sp. (Blair, 1936, USA: n. Michigan; Manville, 1961)

Nectomys (Nectomys) squamipes (Brants) (Muroidea, Cricetidae) - parasitado por Metacuterebra apicalis (Everard \& Aitken, 1972, Trinidad).

Neotoma (Homodontomys) fuscipes Baird (Muroidea, Cricetidae) - parasitado por C. aldrichi (Austen, 1933), C. ?buccata (Hubbard, 1941, USA: California), C. latifrons (Radowsky, 1960, USA: California; Radowsky \& Catts, 1960, USA: California; Catts, 1966, 1967, USA: California).

Neotoma (Homodontomys) fuscipes macrotis Thomas - parasitado por C. latifrons (Ryckman, 1953, USA: California) e Cuterebra sp. (Gandor, 1929, USA: California).

Neotoma (Neotoma) albigula albigula Hartley (Muroidea, Cricetidae) parasitado por Cuterebra sp. (Calahane, 1939).

Neotoma (Neotoma) floridana (Ord) (Muroidea, Cricetidae) - parasitado por Cuterebra sp. (Goertz, 1966).

Neotoma (Neotoma) floridana attwateri Mearns (Muroidea, Cricetidae)

- parasitado por Cuterebra sp. (Lay \& Baker, 1938).

Neotoma (Neotoma) floridana osagensis Blair (Muroidea, Cricetidae) parasitado por C. beameri (Beamer et al., 1943, USA: Kansas).

Neotoma (Neotoma) lepida Thomas (Muroidea, Cricetidae) - parasitado por C. tenebrosa (Baird \& Graham, 1973, USA: Utah, Idaho).

Neotoma (Neotoma) magister Baird (Muroidea, Cricetidae) - parasitado

por Cuterebra sp. (Poole, 1940).

Neotoma (Teonoma) cinerea (Ord) (Muroidea, Cricetidae) - parasitado por C. tenebrosa (Parker \& Wells, 1919, USA: Montana; Hall, 1921, USA: Montana; Moilliet, 1950; Finley, 1958; Baird, 1979).

Neotoma sp. (Muroidea, Cricetidae) - parasitado por C. cyanella (Keen, 1966, USA: Colorado) e Cuterebra sp. (Vorhies \& Taylor, 1940, USA: Arizona). Ondatra zibethica (Linnaeus) (Muroidea, Cricetidae) - parasitado por Cuterebra sp. (Lawrence et al., 1965, USA: n. Michigan).

Onychomys leucogaster missouriensis (Audubon \& Bachman) (Muroidea, Cricetidae) - parasitado por C. tenebrosa (Parker \& Wells, 1919, USA: Montana).

Oryzomys (Oryzomys) capito velutinus Allen \& Chapman (Muroidea, Cricetidae) - parasitado por Metacuterebra nigricans (Everard \& Aitken, 1972, Trinidad).

Oryzomys (Oryzomys) flavescens (Waterhouse) (Muroidea, Cricetidae) parasitado por Rogenhofera grandis (Lynch Arribálzaga, 1881, Argentina) e Metacuterebra apicalis (Hendriksen, 1942 \& Del Ponte, 1959, Argentinā).

Oryzomys (Oryzomys) nigripes (Desmarest) (Muroidea, Cricetidae) parasitado por Metacuterebra apicalis (Fonseca, 1938, Brasil: São Paulo; d'Andretta \& Jardim, 1954, Brasil: São Paulo; Lenko \& Forattini, 1959, Brasil: São Paulo; Mello, 1978, Brasil: Brasília, D. F.).

Oryzomys phyllotis Merriam (Muroidea, Cricetidae) - parasitado por Metacuterebra chiquibulensis (Disney, 1969, Belize).

Peromyscus (Ochrotomys) nuttalli nuttalli (Harlan) (Muroidea, Cricetidae) - parasitado por Cuterebra sp. (Linzey, 1968, s. USA).

Peromyscus (Peromyscus) leucopus (Rafinesque) (Muroidea, Cricetidae) - parasitado por C. angustifrons (Payne et al., 1964, 1965, USA: Tennessee; Dunaway et al., 1967, USA: Tennessee); Cuterebra fontinella (Sillman, 1955; Hensley, 1976; Tim \& Cook, 1979); e Cuterebra sp. (Burt, 1940, USA: Michigan; Test \& Test, 1943, USA: Indiana; Layne, 1958, USA: Illinois; Hirth, 1959, USA: Connecticut; Abbot \& Parsons, 1961, USA: n. Massachusetts; Selander, 1961, Canadá: Ontario; Manville, 1961, USA: Michigan, 
New York, Virginia; Siegmund, 1964, USA: New Jersey; Brown, 1965, USA, se. Mississippi; Goertz, 1966, USA: Oklahoma; Gingrich, 1979, 1981).

Peromyscus (Peromyscus) leucopus leucopus (Rafinesque) (Muroidea, Cricetidae) - parasitado por C. angustifrons (Payne \& Cosgrove, 1966, USA: Tennessee; Childs \& Cosgrove, 1966, USA: Tennessee).

Peromyscus (Peromyscus) leucopus noveboracensis Fischer (Muroidea, Cricetidae) - parasitado por C. angustifrons (Stillmann, 1956, Canadá: Ontario; Sillman \& Smith, 1959, Canadá: Ontario; Wecker, 1962, USA: Michigan; Dalmat, 1942, USA: Iowa); C. fontinella (Scott \& Snead, 1942, USA: Iowa; Hunter et al., 1972, Canadá: British Columbia); Cuterebra peromysci (Dalmat, 1943, USA: Iowa) e Cuterebra $s p$. (Sealander, 1961).

Peromyscus (Peromyscus) maniculatus (Wagner) (Muroidea, Cricetidae) parasitado por C. approximata (Catts, 1964, 1965; Smith, 1977, USA: Montana), C. grisea (Hunter, 1973) e Cuterebra sp. (Goertz, 1966, USA: Oklahoma; Lawrence et al., 1965, USA: n. Michigan).

Peromyscus (Peromyscus) maniculatus bairdii (Hoy \& Kennicott) (Muroidea, Cricetidae) - parasitado por Cuterebra sp. (Maurer \& Shale, 1968, USA: North Dakota).

Peromyscus (Peromyscus) maniculatus gracilis (Le Conte) (Muroidea, Cricetidae) - parasitado por Cuterebra sp. (Blair, 1942, USA: n. Michigan).

Peromyscus (Peromyscus) trueri (Shufeldt) (Muroidea, Cricetidae) - parasitado por Cuterebra sp. (Manville, 1961, USA: New York).

? Pseudoryzomys wavrini (Thomas) (Muroidea, Cricetidae) - parasitado por Metacuterebra apicalis (Forattini \& Lenko, 1959, Brasil: São Paulo). Cabrera (1961: 482) cita apenas o Paraguai e o norte da Argentina (Chaco) como a distribuição do hospedeiro!

Reithrodon physodes (Olfers) (Muroidea, Cricetidae) - parasitado por Rogenhofera grandis (Del Ponte, 1959, Argentina).

Sigmodon hispidus Say \& Ord (Muroidea, Cricetidae) - parasitado por C. flaviventris (Disney, 1969, Belize) e Cuterebra sp. (Goertz, 1966, USA: Oklahoma).

Zapus hudsonius hudsonius (Zimmermann) (Dipodoidea, Zapodidae) parasitado por Cuterebra sp. (Ericson, 1938, USA: Minnesota; Sheldon, 1938, USA: Vermont).

Zygodontomys brevicauda (Allen \& Chapman) (Muroidea, Cricetidae) parasitado por Metacuterebra apicalis (Everard \& Aitken, 1972, Trinidad).

Zygodontomys lasiurus pixuna Moojen (Muroidea, Cricetidae) - parasitado por Metacuterebra apicalis (Guimarães, 1971, Brasil: Bahia).

c. Caviomorpha

Chinchilla lanigera (Molina) (Chinchilloidea, Chinchillidae) - parasitado por Cuterebra sp. (Led \& Brandelli, 1978).

Echimys armatus armatus (Geoffroy) (Octodontoidea, Echimyidae) parasitado por Metacuterebra funebris (Austen, 1895, Trinidad; Everard \& Aitken, 1972, Trinidad).

Proechimys (Proechimys) guyannensis (Geoffroy) (Octodontoidea, Echimyidae) - parasitado por Cuterebra $s p$. (Everard \& Aitken, 1971, Trinidad).

\subsubsection{Carnivora}

Mephitis mephitis (Schreber) (Mustelidae) - parasitado por Cuterebra sp. (Verts, 1967, USA: n. Illinois).

10.4. Efeitos histológicos e patológicos decorrentes da presença da larva no hospedeiro

Pouquíssimo se sabe sobre as conseqüências fisiológicas de larvas de cuterebrídeo causando miíases dérmicas em pequenos mamíferos. Sabe-se, entretanto, que as larvas provocam vários efeitos clínicos (ex.: um baixo hematócrito, taxa de hemoglobina reduzida, esplenomegalia, hematopoiese extramedular) como resultado de anemia por perda de sangue em pequenos roedores (Clough, 
1965; Child \& Cosgrove, 1966; Payne \& Cosgrove, 1966; Dunaway et al., 1967; McKinney \& Christian, 1970; Weinsbroth et al., 1973).

Os efeitos sobre a atividade e a capacidade reprodutiva de roedores sel. vagens infestados foram estudados por vários autores (Scott \& Snead, 1942; Test \& Test, 1943; Wrecker, 1962). Bennett (1955) estudou em detalhe os danos causados pela presença da larva nos tecidos do hospedeiro. Payne \& Cosgrove (1966) estudaram as lesões histológicas do cisto subcutâneo causado por $C$. angustifrons em Peromyscus leucopus.

Todos esses pesquisadores descobriram que a cicatrização e cura das lesões era extremamente rápida. Ocasionalmente, porém, podem ocorrer formações de abcessos crônicos ou granulomas por corpo estranho. A localização inguinal da larva em diversos roedores levou a conjecturas sobre seu possível perigo para os órgãos genitais adjacentes. Payne \& Cosgrove (1. c.) observaram que a situação da larva é freqüentemente próxima dos órgãos genitais, principalmente do saco escrotal, mas nos espécimes examinados nunca se constatou dano ao escroto ou aos testículos. Todavia, Dalmat (1943) constatou lesões testiculares quando havia 2 ou mais larvas no hospedeiro. Bennet (1955) não observou castração ou outros importantes efeitos sobre os órgãos sexuais em Tamias striatus infestado por Cuterebra.

\subsection{Efeito dos Cuterebridae sobre a população do hospedeiro}

O efeito causado por cuterebrídeos nas subsequentes gerações das populações é bastante desconhecido. Dalmat (1943) dizia que "although in a few of the reported cases of Cuterebra infection the larvae emerged without having inflicted any apparent hardship on the host, most investigators have observed that infected rodents were awkward and therefore easy prey for predators." Apresentou igualmente vários casos de efeitos deletérios causados por estas moscas em animais domésticos e roedores.

Clough (1965) declarou que há evidências de que os cuterebrídeos e os pequenos mamíferos já estabeleceram uma relação estável e que o parasito não reduz grandemente a população do hospedeiro. Test \& Test (1943) e Bucker (1958) disseram que o parasitismo por cuterebrídeos é bastante bem tolerado por pequenos mamíferos sem causar aumento de mortalidade dos hospedeiros.

Possíveis efeitos destes parasitos sobre a dinâmica populacional de $P e$ romyscus leucopus foram sugeridos ou inferidos em discussões sobre a interferência com a reprodução (Sillman, 1955; Sealander, 1961; Wrecker, 1962), sobre mortalidade direta causada pela infestação (Dalmat, 1943) e sobre o aumento da susceptibilidade à predação (Scott \& Snead, 1942; Wrecker, 1962).

Segundo Miller \& Getz (1969) não há indicação alguma de que a incidência de infestação por cuterebrídeos em Peromyscus esteja relacionada à densidade populacional deste rato.

As infestações por cuterebrídeos são altamente localizadas e as moscas não se afastam muito do local de emergência (Dalmat, 1943; Dunaway et al., 1967); as infestações estão geralmente associadas a espécies de roedores que vivem em florestas (Blair, 1942; Goertz, 1966; Dunaway et al., 1967).

\subsection{Miíases no homem e animais domésticos}

Há numerosos casos relatando casos acidentais de miíases no homem e nos animais domésticos (gatos, cães, coelhos, etc.), causados por larvas de Cuterebra: Baker et al., 1943; Beachley \& Bishopp, 1942; Becklund, 1964; Bequaert, 1945, 1947; Bishopp, 1916; Bleyer, 1900; Britton, 1921; Calhoun, 1963; Coleman, 1970; Cooperrider, 1952; Crawley, 1923; Dalmat \& Baker, 1942; French, 1893; Greene, 1956; Hall, 1921, 1925; Hall \& Wigdor, 1918; Harrison, 1894; Harrison \& Mansbridge, 1893; Hatziolos, 1967; Hawkins, 1894; Hodges, 1955; Hooper, 1961; Judd, 1954; Katz \& Taylor, 1971; Kaye \& Higgins, 1964; Lugger, 1897; Miller, 1928; Parker, 1938; Patton, 1921; Penner, 1958; Riley \& Howard, 1895; Salomon et al., 1970; Schöven, 1892; Scott, 1963, 1964; Sharp, 1892; Stockton \& Sundell, 1958; Stunkard \& Landers, 1956; Verrill, 1872; e Weisbroth et al., 1973; Wills \& Jones, 1977. 


\section{BIBLIOGRAFIA}

Abbot, H. G. \& M. A. Parsons, 1961. Cuterebra infestation in Peromyscus. J. Mammal. 42(3): 383-385.

Aldrich, J. M., 1905. Catalogue of North American Diptera. Smithson. misc. Colins 1444: $680 \mathrm{pp}$.

Aldrich, J. M., 1931. Notes on Diptera, no. 5. Proc. ent. Soc. Wash. 33(5): 116-121.

Allen, D. L., 1943. Michigan fox squirrel management. Mich. Game Div. Publs 100.

Allen, J. M., 1952. Gray and fox squirrel management in Indiana. Pittman-Robertson Bull. Div. Fish Game Indiana 1: 102.

Allison, R., 1941. A life history study of Sciurus carolinensis with notes on on the seasonal incidence of infestation with warble-fly larvae. MS Thesis, N. Carol. St. Univ., Raleigh, N.C.

Allison, R., 1953. North Carolina grey squirrel investigations. N. C. Wildl. Res. Commn Game Div., Raleigin, N. C.

d'Andretta, C., Jr. \& J. L. Jardim, 1954. Contribuição ao conhecimento do ciclo biológico de Metacuterebra apicalis (Guérin 1829/38 [sic]) (Diptera, Cuterebridae). Anais Fac. Farm. Odont. Univ. S Paulo 12: 67-73.

Anon., 1918. 43rd a. Rep. Ent. Ontario agric. Coll., Toronto: 19-20.

Anon., 1960. Pocket gophers in Colorado. Cooperative pocket gopher project technical committee. Bull. Colo. St. Univ. exp. Stn 508: 1-26.

Artigas, P. T. \& C. d'Andretta Jr., 1951. Alouattamyia ribeiroi, nova espécie de Cuterebridae (Diptera) do Brasil. Archos Mus. nac., Rio de J. 42: 59-62, 3 pls.

Artmann, J. G., 1975. Cuterebra parasitism of an American woodcock. J. Parasit. 61(1): 65.

Atkenson, T. L. \& L. Givens, 1951. Grey squirrel parasitism by heel fly larvae. J. Wildl. Mgmt 15: 105-106.

Atkenson, T. L. \& J. L. Heflin, 1948. Wheeler squirrel hunt. Ala. Conserv. 19: 8.

Austen, E. E., 1895a. On the specimens of the genus Cutiterebra and its allies (family Oestridae) in the collection of the British Museum, with description of a new genus and three new species. Ann. Mag. nat. Hist. (6) 15: 377-396, pl. 13.

Austen, E. E., 1895b. Further notes on Cutiterebra. Ibid. (6) 16: 147-155. Austen, E. E., 1933. New and little known species of Cuterebra Clark and Bogeria Austen (Diptera: Oestridae). Proc. zool. Soc. Lond. 3: 699713,1 pl.

Bacigalupo, J., C. P. Vuidepot \& E. P. Dideigo, 1931. Ueber das Genus Cuterebra Clark (Diptera, Oestridae). Semana méd., B. Aires 48: 555-556.

Baird, C. R., 1970. Laboratory studies of two species of jackrabbit bot flies, 40 pp. MS Thesis, Utah St. Univ., Logan, Utah.

Baird, C. R., 1971. Development of Cuterebra jellisoni (Diptera. Cuterebridae) in six species of rabbits and rodents. J. med. Ent. 8(6): 615-622, figs,

Baird, C. R., 1972a. Development of Cuterebra ruficrus (Diptera: Cuterebidae) in six species of rabbits and rodents with a morphological comparison of $C$. ruficrus and $C$. jellisoni third instars. Ibid. 9(1): 81-85, 3 figs.

Baird, C. R., 1972b. Termination of pupal diapause in Cuterebra tenebrosa (Diptera: Cuterebridae) with injections of ecdysterone. Ibid. 9(1): 7780,2 figs.

Baird, C. R., 1973. Biology of Cuterebra tenebrosa Coquillett, a bot fly causing cutaneous myiasis in Neotoma woodrats, ix $+108 \mathrm{pp}$. PhD Thesis, Washington State University.

Baird, C. R., 1974. Field behavior and seasonal activity of the rodent bot fly, Cuterebra tenebrosa, in Central Washington (Diptera: Cuterebridae). Gt Basin Nat. 34(4): 247-253.

Baird, C. R., 1975. Larval development of the rodent bot-fly, Cuterebra tenebrosa, in bushy-tailed woodrats and its relationship to pupal diapause. Can. J. Zool. 53(12): 1788-1798, figs. 
Baird, C. R., 1979. Incidence of infection and host specificity of Cuterebra tenebrosa in bushy-tailed wood rats (Neotoma cinerea) from central Washington. J. Parasit. 65: 639-644.

Baird, C. R. \& R. D. Akre, 1977. Morphology of alimentary and reproductive tracts of the rodent bot f'y, Cuterebra tenebrosa (Diptera: Cuterebridae). J. ent. Soc. Br. Col. 74: 27-31, figs.

Baird, C. R. \& K. J. Capelle, 1969. Successful laboratory mating of two species of jackrabbit bot-flies. I. med. Ent. 6(2): 196.

Baird, C. R. \& C. L. Graham, 1973. Cuterebra tenebrosa: Description of immature stages and a redescription of the adult (Diptera: Cuterebridae). Can. Ent. 105: 1281-1293, 8 figs.

Baird, C. R. \& D. H.Smith, 1979. Case reports of bot fly myiasis in pikas (Ochotona princeps). J. Wildl. Dis. 15: 553-555.

Baker, D. W., 1933. 44th Report of the Diagnostic Laboratory. A. Rep. N. Y. St. Coll. 1932-33: 41-49.

Baker, D. W., 1968. Parasites of the gray squirrel in Virginia. J. Parasit. 54(3): 633.

Baker, D. W., et al., 1943. Keys to the larvae of bot flies infesting domestic animals in New York State. Cornell Vet. 32: 424-429, figs.

Bau, A., 1906. Diptera, Fam. Muscaridae, Subfam. Oestrinae. Genera Insect. 43: $1-31$, pls.

Bau, A., 1922. Ueber die technisch-biologische Bedeutung der Oestriden, das verrirte Vorkommen, ihrer Larven, sowie über Oestrus hominis, Hypoderma equi und alcis. Z. tech. Biol. 10(3-4): 177-193.

Bau, A., 1928a. Cuterebra ornata, spec. nov. (Diptera, Cuterebridae). Konowia $7(1)$ : 50-51.

Bau, A., 1928b. Ueber Aulacocephala und Rogenhofera. Ibid. 7: 298-303.

Bau, A., 1929a. Cuterebra semilutea, spec. nov. (Diptera), sowie Schlussel zur Bestimmung der Cuterebra-Arten. Senckenbergiana 11(1-2): 1-7, figs. $1-2$.

Bau, A., 1929b. Versuch einer Teilung der Gattung Cuterebra (Diptera, olim Oestridae) in vier Untergattungen. Zentbl. Bakt. ParasitKde 77(25-26): 542-544, 1 fig.

Bau, A., 1929c. Die Victor v. Roeder'sche Dipterensammlung. Konowia 8: 237-241.

Bau, A., 1929d. Cuterebra conflans und subbuccata, spec. nov., sowie Bemerkung über C. schroederi Enderlein (Diptera, olim Oestridae). Stettin. ent. Ztg 90: 303-307, 1 pl.

Bau, A., 1930. Vier neue Cuterebra-Arten aus Südamerika (Diptera olim Oestridae). Konowia 9(1): 81-89, pl. 1, figs. 1-6.

Bau, A., 1931a. Ueber das Genus Cuterebra Clark (Diptera, Oestridae). Einteilung desselben in sechs Untergattungen. Beschreibung neuer Species und Austellung einer Bestimmungstabelle der mittel- und südamerikanischen Arten. Ibid. 10: 197-240, 2 figs., 2 pls.

Bau, A., 1931b. Cuterebra (Atryposoma) enderleini spec. nov. (Dipt.). Mitt. dt. ent. Ges. 2(2): 20-21, figs. 1-2.

Bau, A., 1932. Rogenhofera gilvopilosa, spec. nov. und $R$, grandis (Guérin) (Dipt. Cuterebr.). Ibid. 3: 11-15.

Beachley, R. G. \& F. C. Bishopp, 1942. Report of a case of nasal myiasis due to a bot fly larva (Cuterebra sp.). Va med. Mon. 69: 41-42.

Beamer, R. H., 1950. An observation on the egg-laying of Cuterebra buccata Fabr. in nature. J. Kans. ent. Soc. 23: 16.

Beamer, R. H. \& L. R. Penner, 1942. Observations on the life history of a rabbit cuterebrid, the larvae of which may penetrate the human skin. J. Parasit. 28: 25 (res.).

Beamer, R. H., L. R. Penner \& C. W. Hibbard, 1943. Some notes on the biology of the pack rat cuterebrid (Cuterebra beameri Hall) in Kansas. J. Kans. ent. Soc. 16: 47-50.

Becklund, W. W., 1964. Revised check list of internal and external parasites of domestic animals in the United States and possessions in Canada. Am. J. vet. Res. 25: 1380-1416. 
Bell, J. F. \& W. S. Chalgren, 1943. Some wildlife diseases in the eastern U. S. J. Wildl. Mgmt 7: 270-278.

Bennett, G. F., 1955. Studies on Cuterebra emasculator Fitch 1856 (Diptera: Cuterebridae) and a discussion of the status of the genus Cephenemyia Ltr. 1818. Can. J. Zool. 33: 75-98.

Bennett, G. F., 1972a. Observations on the pupal and adult stages of Cuterebra emasculator Fitch (Diptera: Cuterebridae). Ibid. 50(11): 13671372.

Bennett, G. F, 1972b. Further studies on the chipmunck warble Cuterebra emasculator (Diptera, Cuterebridae). Ibid. 50(6): 861-864.

Bennett, G. F., 1973. Some effects of Cuterebra emasculator Fitch (Diptera: Cuterebridae) on the blood and activity of its host, the eastern chipmunk. J. Wildl. Dis. 9: 85-93.

Bequaert, J., 1945. Cutaneous myiasis due to Cuterebra in Massachusetts. Psyche, Camb. 52: 175-176.

Bequaert, J., 1947. Cuterebra larvae in a domestic cat in Indiana (Diptera). Bull. Brooklyn ent. Soc. 41: 154.

Berg, C., 1876. Naturgeschichte der Rogenhofera grandis, einer Fliege aus der Familie des Oestriden. Stettin. ent. Ztg 37: 268-272.

Berg, C., 1881. Entomologisches aus dem Indianergebiet der Pampa. Ibid. 42(1): 36-72.

Bird, C. R., 1974. Field behavior and seasonal activity of the rodent bot fly Cuterebra tenebrosa in Central Washington (Diptera, Cuterebridae). Great Basin Naturalist 34(4): 247-253, 1 fig.

Bishopp, F. C., 1942. [Case of nasal myiasis due to Cuterebra larva]. Proc. ent. Soc. Wash. 44(1): 15.

Bishopp, W. A., 1916. Two types of skin myiases. Proc. Am. Ass. isthm. C. Zone 7(2): 87-93.

Blair, W. F., 1941. Some data on the home ranges and general life history of the short-tailed shrew, red-backed vole and woodland jumping mouse in northern Michigan. Am. Midl. Nat. 25: 681-685.

Blair, W. F., 1942. Size of home range and notes on the life history of the woodland deer-mouse and eastern chipmunk in northern Michigan. J. Mammal. 23: 27-36.

Bleyer, J., 1900. Eine Cuterebra-Larve im Augenlide. Arch. Schiffs- $u$. TropHyg. 4: 168-170. [Também em J. trop. Med. Hyg. 2(24): 311$312,1900]$.

Boisvenue, R. J., 1958. Studies on the life history and ecology of Cuterebra spp. occurring in Michigan cottontails with systematic studies on cuterebrine larvae from other mammals. Diss. Abstr. 19: 15-16 (erroneamente catalogado sob Bacteriologia).

Boonstra, R., C. J. Krebs, B. T. Beacham, 1980. Impact of bot fly parasitism on Microtus townsendii populations. Can. J. Zool. 58: 1683-1692.

Boyes, J. W., 1964. Somatic chromosomes of higher Diptera. VIII. Karyotypes of species of Oestridae, Hypodermatidae and Cuterebridae. Can. J. Zool. 42: 599-604, 12 figs., 1 table.

Brauer, F. M., 1861. Ueber die Larven der Gattung Cuterebra Clark. Verh. zool.-bot. Ges. Wien 10 (1860): 777-786.

Brauer, F. M., 1863. Rogenhofera, eine neue Gattung aus der Familie der Oestriden. Ibid. 13: 325-326.

Brauer, F. M., 1863b. Monographie der Oestriden, 292 pp., figs. Wien.

Britton, W. E., 1921. Ox warbles. Bull. Conn. agric. Exp. Stn 226: 213-214. [Cuterebra em gatos].

Brown, L. N., 1965. Bot fly parasitism in the brushmouse and white-footed mouse in the Ozarks. J. Parasit. 51: 302-304.

Bruna, J. F., 1952. Kentucky rabbit investigations. Dep. Fish Wildl. Res. (Fed. Aid Proj.), Frankfort, Ky.

Buckner, C. H., 1958. Cuterebrids (Cuterebra grisea Coq.) attacking small mammals. Bi-mon. Prog. Rep. Div. Forest Biol., Ottawa 14(3): 2-3.

Burt, W. H., 1940. Territorial behavior and populations of small mammals in Southern Michigan. Misc. Publs Mus. Zool. Univ. Mich. 45: 
Cabrera, A., 1957-1961. Catálogo de los mamíferos de América del Sur. Revta Mus. argent. Cienc. nat. 4(1-2): 1-732.

Calahane, V., 1939. Mammals of the Chiricahua Mountains, Cochise County, Arizona. J. Mammal. 20: 418-440.

Caldwell, L. D., 1966. Marsh rabbit development and ectoparasites. Ibid. 47: $527-528$

Caldwell, L. D., 1970. Studies on the life history and development of Cuterebra polita (Diptera: Cuterebridae) in four species of rodents. J. med. Ent. 7: 320-327.

Calhoun, J. B., 1963. The ecology and sociology of the Norway rat. Publ. Hlth Serv. Publs, Wash. 1008: 1-288.

Cameron, A. E., 1926. The occurrence of Cuterebra (Diptera, Oestridae) in western Canada. Parasitology 18(4): 430-435, 1 fig.

Capelle, K. J., 1970. Studies on the life history and development of Cuterebra polita (Diptera: Cuterebridae) in four species of rodents. J. med. Ent. 7: 320-327.

Capelle, K. J., 1971. Chapter 11: Myiasis, pp. 279-305, in J. W. Davis \& R. C. Anderson, Parasitic diseases of wild mammals, $\mathrm{x}+364 \mathrm{pp}$. Iowa St. Univ. Press.

Carpenter, C. R., 1934. A field study of the behavior and social relations of howling monkeys. Comp. Psychol. Monogr. 10: 1-168.

Carson, J. D. \& D. E. Canter, 1963. West Virginia cottontails. W. Va Dep. nat. Res., Div. Game Fish Bull. 5. Charleston, W. Va.

Carter, H. F. \& D. B. Blackloch, 1913. External myiasis in a monkey. Br. med. J. 1: 72 .

Catts, E. P., Jr., 1963. The biology of Cuterebra latifrons Coq. (Diptera, Cuterebridae), 174 pp. Ph.D. Thesis, Univ. Calif., Berkeley.

Catts, E. P., Jr., 1964a. The biology of Cuterebra latifrons Coq. (Diptera, Cuterebridae). Diss. Abstr. 24(9): 3889-3890.

Catts, E. P., Jr., 1964b. Laboratory colonization of rodent bot-flies (Diptera, Cuterebridae). J. med. Ent. 1: 195-196.

Catts, E. P., Jr., 1965. Host-parasite interrelationships in rodent bot-fly infections. Trans, 30th N. Am. Wildl. nat. Res. Conf., Wash.: 184-196.

Catts, E. P., Jr., 1966. Biological studies of the rodent botflies, Cuterebra spp. (Diptera, Cuterebridae). Proc. lst int. Congr. Parasit. 2: 957.

Catts, E. P., Jr., 1967. Biology of a California rodent bot fly, Cuterebra latifrons. J. med. Ent. 4: 87-101.

Catts, E. P., Jr., 1982. Biology of New World bot flies: Cuterebridae. A. Rev. Ent. 27: 313-338, 2 figs., 1 table.

Catts, E. P. \& F. J. Radovsky, 1962 The occurrence and nature of red eye spots in Cuterebra lepivora (Diptera, Cuterebridae). Ann. ent. Soc. Am. 55(3): 353-355.

Chapman, F. B., 1938. Summary of Ohio gray squirrel investigation. N. Am. Wildl. Conf. 3: 677-684.

Cheatum, E. L., 1962. Disease and parasite investigations, 75 pp. Final Rep. Fed. Aid Proj. 1-R, Suppl. E. N. Y. Cons. Dep.

Childs, H. E., Jr. \& G. E. Cosgrove, 1966. A study of pathological conditions in wild rodents in radioactive areas. Am. Midl. Nat. 76: 309-324.

Chillcott, J. G., 1965. Family Cuterebridae, pp. 1109-1110, in A. Stone et al., A Catalog of the Diptera of America north of Mexico. U. S. Dep. Agr., Agric. Handb. 276: 1-1696.

Clark, B., 1815. An essay on the bots of horses and other animals, 72 pp., 2 pls. London.

Clark, B., 1843. An appendix or supplement to a treatise on the oestri and cuterebrae of various animals. Trans. Linn. Soc. Lond. 19(2): 81-94.

Clough, G., 1965. Physiological effect of bot fly parasitism on meadow voles. Ecology 46: 344-346.

Cole, F. R., 1969. The flies of western North America, 693 pp., figs. Univ. Calif. Press, Berkeley.

Cole, F. R. \& A. L. Lovett, 1921. An annotated list of the Diptera (flies) of Oregon. Proc. Calif. Acad. Sci. 4: 197-344. 
Coleman, V. R., 1970. Cuterebra sp. parasitism of man. J. Ga ent. Soc. 5 (2): 106.

Collins, G. D. \& E. J. Huggkhins, 1971. Cuterebrid larva in a shrew from South Dakota. J. Mammal. 52(3): 609-611.

Connell, J. M., 1954. Home range and mobility of brush rabbits in California chaparral. J. Mammal. 35: 392-405.

Cooperrider, D. E., 1952. Check list of parasites of domestic animals reported in Georgia. Vet. Med. 47: 65-70.

Coquillett, D. W., 1898. On Cuterebra emasculator with descriptions of several allied species. Can. Ent. 30: 9-11.

Coquillett, D. W., 1902. New Diptera from North America. Proc. U. S. natn. Mus. 25(1280): 83-126.

Coquillett, D. W., 1904. Several new Diptera from North America. Can. Ent. 36: 10-12

Crampton, G. C., 1944. A comparative morphological study of the terminalia of male calyptrate cyclorrhaphous Diptera and their acalyptrate relatives. Bull. Brooklyn ent. Soc. 39: 1-31, figs.

Crawley, H., 1923. Cuterebra cuniculi in the dog. Ent. News 34: 315.

Crowe, D. E., 1943. Notes on some mammals of the southern Canadian Rocky Mountains. Bull. Am. Mus. nat. Hist. 80: 391-410.

Curran, C. H., 1942. American Diptera. Bull. Am. Mus. nat. Hist. 80: 51-84.

Dalmat, H. T., 1941. Infestation of the northern white-footed mouse with a new species of parasitic fly (Cuterebridae) and notes on other ectoparasites, MS thesis, Iowa St. Coll., Ames.

Dalmat, H. T., 1942a. A new Cuterebra (Diptera: Cuterebridae) from Iowa with notes on certain facial structures. Am. Midl. Nat. 27(2): 418421, 1 fig.

Dalmat, H. T., 1942b. A new parasitic fly (Cuterebridae) from the northern white-footed mouse. I. N. Y. ent. Soc. 50(1): 45.

Dalmat, H. T., 1942c. New genus and species of Cuterebridae (Diptera) from Costa Rica and other taxonomic notes. Trans. Am. ent. Soc. 68 (1-2): 23-29, pl.

Dalmat, H. T., 1942d. Cuterebrid specimens wanted. N. Am. Vet. 23(4): 271.

Dalmat, H. T., 1943a. Synonymic notes on some species of Cuterebra. Ent. News 54(8): 182-183.

Dalmat, H. T., 1943b. A contribution to the knowledge of the rodent warble flies (Cuterebridae). J. Parasit. 29: 311-318.

Dalmat, H. T. \& D. W. Baker, 1942. Key to the larvae of botflies and warbleflies infesting domestic animals in New York State. Cornell Vet. 32: 424.

Davis, W. T., 1937. [Specimen of the rabbit bot fly, Cuterebra buccata]. Bull. Brooklyn ent. Soc. 32(2): 85.

Dimmock, G., 1890. [Larva of species of Oestridae (?Cuterebra emasculator), from a chi-squirrel (Tamias striatus) exhibited to Cambridge Ent. Club, 10 Oct. 1889]. Entomologist's mon. Mag. 104: 189-197, 3 figs.

Disney, R. H. L., 1975. Speculations regarding the mode of evolution of some remarkable associations between Diptera (Cuterebridae, Simuliidae and Sphaeroceridae) and other arthropods. Ibid. 110: 67-74, 1974.

Dixon, J. M., C. H. Walker \& J. H. Nelson, 1969. Ophthalmomyiasis interna caused by Cuterebra larva. Trans. Am. ophthal. Soc. 67: 110-115. (Também em Am. J. Ophthal. 71 (Suppl.): 415-416, 1971).

Dorney, R. S., 1965. Incidence of bot fly larvae (Cuterebra emasculator) in the chipmunck (Tamias striatus) and red squirrel (Tamiasciurus hudsonicus) in northern Wisconsin. J. Parasit. 51: 893-894.

Drumond, R. D. \& R. E. Gingrich, 1972. Detection of systemic activity of insecticides applied dermally to white mice infested with larvae of Cuterebra sp. J. econ. Ent. 65(4): 1211-1212.

Dunaway, P. B., 1966. Problems of evaluating consequences of irradiation on populations of native rodents, pp. 11-18, in G. A., Sacher, ed., Radiation effects on natural populations (A colloquium held in Philadelphia, May 23, 1965). Div. biol. med. Res., Argonne natn. Lab., Ill.

Dunaway, P. B., L. Lawrence, J. A. Payne, B. E. Jacobs, J. D. Story, T. P. 
O'Farrell \& G. D. Martin, 1964. Hematology of native mammals. A. Prog. Rep. Hlth Phys. Div. 1964: 79-82.

Dunaway, P. B., J. A. Payne, L. L. Lewis \& J. D. Story, 1967. Incidence and effects of Cuterebra in Peromyscus. J. Mammal. 48: 38-51.

Dury, C., 1898a. Parasites of the common rabbit (Lepus sylvaticus Bach.). J. Cincinn. Soc. nat. Hist. 19(4): 143.

Dury, C., 1898b. "Squirrel bot fly" (Cuterebra emasculator). Ibid. 19(4): 143.

Ecke, D. H. \& R. E. Yeatter, 1956. Notes on the parasites of cottontail rabbits of Illinois. Trans. Ill. St. Acad. Sci. 48: 208-214.

Eddy, G. W. \& K. S. Emerson, 1940. Notes on Oklahoma botflies. J. Kans. ent. Soc. 13: 44-45.

Egoscue, H. J., 1957. The desert woodrat: A laboratory colony. J. Mammal. 38: $472-481$.

Enderlein, G., 1909. Cutiterebra schroederi, eine neue parasitäre Fliege (Oestridae olim). Stettin. ent. Ztg 70(1): 202-203.

Enzie, F. D. \& A. McIntosh, 1950. Length of the pupal period of Cuterebra buccata (F.). J. Parasit. 36: 46 (res.).

Erickson, A. B., 1938. Parasites of some Minnesota rodents. J. Mammal. 19: $252-253$.

Everard, C. O. R. \& T. H. G. Aitken, 1972. Cuterebrid flies from small mammals in Trinidad. J. Parasit. 58(1): 189-190.

Ewing, N. E., 1925. (Cuterebra larvae in skin of Panama howler monkey (Alouatta palliata inconsonans)). Ibid. 12(2): 107.

Fabricius, J. C., 1775. Systema entomologiae, sistens insectorum classes, ordines, genera, species, adiectis synonymis, locis, descriptionibus, observationibus, $832 \mathrm{pp}$. Flensburgi et Lipsiae.

Fabricius, J. C., 1781. Species insectorum exhibentes eorum differentias specificas, synonyma, auctorum, loca natalia, metamorphosim 2: $517 \mathrm{pp}$. Hamburgii et Kilonii.

Fabricius, J. C., 1794. Entomologia systematica emendata et aucta 4: 472 pp. Hafniae.

Fabricius, J. C., 1805. Systema antliatorum secundum ordines, genera, species, $373+30 \mathrm{pp}$. Brunsvigae.

Ferris, G. F., 1920. The first stage larva of Cuterebra americana (Fabr.) (Diptera: Oestridae). Psyche, Camb. 27: 13-14.

Finley, R. B., Jr., 1958. The wood rats of Colorado: Distribution and ecology. Univ. Kans. Publs Mus. nat. Hist. 10: 213-552.

Fitch, A., 1856. Third report on the noxious and other insects of the State of New York. Trans. N. Y. St. agric. Soc. 16: 315-490, 1 fig., 4 pls.

Fitch, A., 1889. On the emasculating bot-fly. Insect Life 2: 214-216 (com notas de C. H. Merrian, p. 215, e de G. B. Starkweather, p. 216).

Fonseca, F. O. R. da, 1938. Observação de uma fase do ciclo evolutivo de Cuterebra apicalis Guérin (Diptera, Oestridae). Bolm biol. Clube zool. Bras. (n.s.) 3(3-4): 166-167, figs.

Fonseca, F. O. R. da, 1939. Idem. Mems Inst. Butantan 12(1938-39): 195 196, pl.

Fonseca, F. O. R. da, 1940. Nova espécie de Oricuterebra do Brasil (Dipt., Oestridae). Revta Ent., Rio de J. 11: 662-671, 3 figs.

Fonseca, F. O. R. da, 1941. Cuterebrineo novo parasito de didelfideo (Diptera, Oestridae). Ibid. 12: 480-486, 1 fig., 2 pls.

Forattini, O. P. \& K. Lenko, 1959. Nota biológica sobre Metacuterebra apicalis (Guérin, 1823/38 (sic)) (Diptera, Cuterebridae). Arqos Fac. Hig. Saúde públ. Univ. S Paulo 13: 155-158, 2 figs.

French, C., 1893. Cuterebra emasculator in dog. I. comp. Med. vet. Archs 14(6): 379 .

Gandor, F. F., 1929. Experiences with woodrats, Neotoma fuscipes macrotis. J. Mammal. 10: 52-58.

Garrigues, R. M., 1965. A Cuterebra (Diptera: Cuterebridae) infestation in the Grand Canyon rattlesnake, Crotalus viridis abyssus, with a list of those recorded from other hosts. Trans. Kans. Acad. Sci. 67: 689-692.

Gaul, A. T., 1960. Sounds of Insects. Folkways Records Album no. FX6178. (Side I, band 4 - "warble fly", Cuterebra $s p$ ): 
Geis, A. D., 1957. Incidence and effect of warbles on southern Michigan cottontails. J. Wildl. Mgmt 21: 94-95.

Getz, L. L., 1970. Botfly infestations in Microtus pennsylvanicus in southern Wisconsin. Am. Midl. Nat. 84(1): 186-197, 5 figs.

Giard, A., 1874. Notes sur une larve de diptère du genre Cuterebra. Archs Zool. exp. gén. 3(1): iii-vi. (Res. em Bull. scient. Dép. Nord 6(2-3): $68-69,1874)$.

Gingrich, R. E., 1975. Migration behavior of the larval rodent botfly, Cuterebra fontinella in normal and resistant mice. Folia ent. mex. 33: 67-69.

Gingrich, R. E., 1979. Effects of some factors on the susceptibility of Peromyscus leucopus to infestation by larvae of Cuterebra fontinella (Diptera: Cutebridae). J. Parasit. 64: 288-292.

Gingrich, R. E., 1981. Migratory kinetics of Cuterebra fontinella (Diptera: Cuterebridae) in the white-footed mouse, Peromyscus leucopus. Ibid. 67: 398-402.

Gingrich, R. E. \& C. C. Barrett, 1974. Nature of resistance by host animals to larvae of the rodent bot fly Cuterebra fontinella. Folia ent. mex. 29: 76-77.

Gingrich, R. F \& C. C. Barrett, 1976. Natural and acquired resistance in rodent hosts to myiasis by Cuterebra fontinella (Diptera: Cuterebridae). J. med. Ent. 13(1): 61-65.

Gingrich, R. E., R. O. Drummond \& W. J. Gladney, 1972. Use of white mice experimentally infested with larvae of a rodent bot fly for screening systemic insecticides. J. econ. Ent. 65(3): 742-745, figs.

Goertz, J. W., 1966. Incidence of warbles in some Oklahoma rodents. Am. Midl. Nat. 75: 242-245.

Goldman, E. A., 1920. Mammals of Panama. Smithson. misc. Collns 69(5): 229.

Graham, C. L., 1962. Cuterebra (Diptera: Cuterebridae) of Utah and the neighboring States, Master's Thesis, Utah St. Univ., Logan.

Graham, C. L., 1964. Biological studies of three species of Cuterebra (Diptera: Cuterebridae) from northern Utah. Ph. D. Thesis, Thesis, Utah St. Univ., Logan.

Graham, C. L. \& K. J. Capelle, 1970. Redescription of Cuterebra polita (Diptera: Cuterebridae) with notes on its taxonomy, and biology. Ann. ent. Soc. Am. 63(6): 1569-1573, figs.

Greene, C. T., 1925. The tentative arrangement of the muscoid flies based on puparia. Proc. ent. Soc. Wash. 27: 137-163.

Greene, C. T., 1935. Cuterebra fontinella. Ibid. 37: 169.

Greene, C. T., 1956. Dipterous larvae parasitic ou animals and man and some dipterous larvae causing myiasis in man. Trans. Am. ent. Soc. 82(1): 17-34, 21 figs.

Gregson, J. D., 1950. Additional notes on the life-history of Cutenebra tenebrosa Coquillett. Proc. ent. Soc. Br. Columbia 46: 3-4.

Guimarães, J. H., 1967. Family Cuterebridae, in Dep. Zool., Secr. Agric., A Catalogue of the Diptera of the Americas south of the United States 105: 1-28 São Paulo.

Guimarães, J. H., 1971. Notes on the hosts of neotropical Cuterebrini (Diptera, Cuterebridae) with new records from Brasil. Papéis avulsos Zool., S Paulo 25(10): 89-94, figs.

Guimarães, L. R. \& M. Carrera, 1941. Contribuição ao conhecimento dos cuterebrideos do Brasil. Arqos Zool., S Paulo 3(1): 1-12, 3 pls., 9 figs.

Haas, G. E., 1957. Ectoparasites of the Mearns cottontail in Wisconsin. Diss. Abstr. 17: 2094.

Haas, G. E. \& R. J. Dicke, 1958. On Cuterebra horripilum Clark (Diptera: Cuterebridae) parasitizing cottontail rabbits in Wisconsin. J. Parasit. 44: 527-540, pls.

Haas, G. E. \& R. P. Martin, 1973. Bot infestations of pinyon mice in New Mexico. Ent. News 84: 89-90.

Hall, D. G., 1943. A new species of Cuterebra from Kansas (Diptera: Cute- 
rebridae). Proc. ent. Soc. Wash. 45: 25-26.

Hall, M. C., 1921. Cuterebra larvae from cats, with a list of those recorded from other hosts. J. Am. vet. med. Ass. 12: 480-484.

Hall, M. C., 1925. The occurrence of cuterebrid larvae in dogs and cats, and the possible modes of infection. J. econ. Ent. 18: 331-334.

Hall, M. C. \& W. Wigdor, 1918. Notes on the acanthocephalid and arthropod parasites of the dog in North America. I. Am. vet. med. Ass. 53: 493-500.

Hansen, M. F., M. H. Bartel, E. T. Lyon \& B. M. El-Rawi, 1965. The black-tailed jack rabbit in Kansas. II. Helminth and arthropod parasites. Tech. Bull. Kans. agric. Exp. Stn 140: 41-64.

Harkema, R., 1936. The parasites of some North Carolina rodents. Ecol. Monogr. 6: 151-232.

Harrison, W. H., 1894. Two more cases of bots attacking cats. Insect Life 6(4): 708 .

Harrison, W. H. \& W. Mansbridge, 1893. Two more cases of bots attacking cats. Ibid. 6: 327.

Hatziolos, B. C., 1966. Cuterebra larva in the brain of a cat. I. Am. vet. Med. Ass. 148(7): 787-793, ilus.

Hatziolos, B. C., 1967. Cuterebra larva causing paralysis in a dog. Cornell Vet 57(1): 129-146.

Haugen, A. O., 1942. Life history studies on the cottontail rabbit in southwestern Michigan. Am. Midl. Nat. 28: 204-244.

Hawden, S., 1915. A description of the egg and ovipositor of Cuterebra fontinella Clark (cottontail bot). Proc. ent. Soc. Br. Columb. 5: 88-91.

Hawkins, B. C., 1894. A cat warble. Insect Life 6(3): 266.

Hawkins, P. A., 1942. Cutaneous myiasis in small animals. Veterinarian, Indianap. 3: 15, 22.

Hendriksen, K. L., 1942. A note upon two South American species of warble-flies (Cuterebra apicalis Guérin and schmalzi Lutz) parasites of rodents. Ent. Meddr 22: 284-289, 5 figs.

Hensley, M. S., 1976a. Influence of cuterebrid infestation upon select populations parameters in wood mice. $V a$. J. Sci, 27(2): 44.

Hensley, M. S., 1976b. Prevalence of cuterebrid parasitism among rodents in Virginia. J. Wildl. Dis. 12: 172-179.

Hering, E., 1864. Ueber Oestrus-Larven in der Haut einer Feldmaus. Jb. Ver. vaterl. Naturk 20(2-3): 47-48.

Hirth, N. F., 1959. Small mammals in old field succession. Ecology 40: 417-425.

Hodges, F. J., 1955. Cutaneous Cuterebra myiasis. Am. J. Dis. Child. 90: 202-204.

Hooper, B. E., 1961. Subcutaneous myiasis in dogs and cats. Missouri Vet. 10: $19-20$.

Hubbard, D. H., 1941. Some mammalian ectoparasites. J. Mammal. 22: 202:203.

Hunt, T. P., 1959. Breeding habits of the swamp rabbit with notes on its life history. Ibid. 40: 82-91.

Hunter, D. M., 1973. The biology of the botfly, Cuterebra grisea (Diptera: Cuterebridae), infesting deermice (Peromyscus maniculatus), $127 \mathrm{pp}$. M. Sc. Thesis, Simon Fraser Univ., Burnaby, B. C.

Hunter, D. M., R. M. F. S. Sadleir \& J. M. Webster, 1972. Studies on the ecology of cuterebrid parasitism in deermice. Can. J. Zool. 50(1): 25-29.

Hunter, D. M. \& I. M. Webster, 1973a. Determination of the migratory route of botfly larvae, Cuterebra grisea (Diptera, Cuterebridae), in deermice. Int. I. Parasit. 3: 311-316.

Hunter, D. M. \& J. M. Webster, 1973b. Aggregation behavior of adult Cuterebra grisea and $C$. tenebrosa (Diptera: Cuterebridae), Can. Ent. 105: 1301-1307.

Hunter, D. M. $\&$ J. M. Webster, 1974. Effects of cuterebrid larval parasitism on deer-mouse metabolism. Can. J. Zool. 52: 209-217. 
Iannini, P. B., D. Brandt \& L. M. LaForce, 1975. Furuncular myiasis. J. Am. med. Ass. 233(13): 1375-1376.

Ignoffo, C. M., 1961. Biology of Cuterebra jellisoni (Diptera: Cuterebridae) on Lepus californicus deserticola (Lagomorpha: Leporidae). Ann. ent. Soc. Am. 54: 509-512.

Iverson, S. L. \& B. A. Turner, 1969. The effect of Cuterebra spp. on weight, survival and reproduction in Microtus pennsylvanicus. Manitoba Ent. 2(1968): 70-75.

Jacobsen, B., 1966. Unidentified Cuterebra in mice and voles. Proc. ent. Soc. Manitoba 22: 29.

Jacobson, H. A., D. C. Guynn \& E. J. Hackett, 1979. Impact of the botfy (Cuterebra emasculator) on squirrel hunting in Mississippi, USA. J. Wildl. Dis. 7(1): 46-48.

Jacobson, H. A., M. S. Hetrick \& D. C. Guynn, 1981. Prevalence of Cuterebra emasculator in squirrels in Mississippi. J. Wildl. Dis, 17: 79-87.

Jacobson, H. A., B. S. McGinnes \& E. P. Catts, 1978. Bot fly myiasis of the cottontail rabbit, Sylvilagus floridanus mallurus in Virginia, with some biology of the parasite, Cuterebra buccata. J. Wildl. Dis. 14(1): 56-66.

Jaeger, E. C., 1924. "Warbles" on Neotoma. J. Mammal. 5(4): 268.

Jameson, E. W., 1943. Notes on the habits and siphonapterous parasites of the mammals of Welland County, Ontario. J. Mammal. 24: 194-197.

Jellison, W. L., 1949. Cuterebra thomomuris, sp. nov., a warble from the pocket gopher, Thomomys talpoides (Rodentia: Geomyidae). J. Parasit. 35(5): 482-486, figs.

Jimenez, L. M., 1866. Larva de un genero nuevo e probablemente indígeno de los oestrídeos. Gac. méd. Méx. 2: 209-212.

Johnson, C. W., 1930. A bot fly from the white-footed mouse. Psyche, Camb. 37(3): 283-284.

Johnson, J. N., 1892. The rabbit bot. Insect Life 5(2): 137-138.

Jones, P. R., 1906. A new Cuterebra from Nebraska. Ent. News 17: 391-392.

Judd, W. W., 1954. A warble fly, Cuterebra sp., reared from a house mouse, Mus musculus, in the vicinity of London, Ontario. Can. Fld Nat. 68: 140 .

Katz, S. I. \& R. Taylor, 1971. Cutaneous myiasis. Sth. med. J., Nashville 64(6): 759-760, 1 fig.

Kaye, H. D. L. \& R. P. Higgins, 1964. Human botfly infestation in the United States. J. Am. med. Ass. 189(1): 64.

Keen, V. F., 1965. Cuterebra infections in populations of small mammals in Colorado. Diss. Abstr. 26(10): 6248-6249.

Knab, F., 1914. A new Cuterebra from Panama (Diptera). Ins. Insc. menstr. 2: $187-188$.

Knipling, E. F. \& A. L. Brody, 1940. Some taxonomic characters of cuterebrine (Diptera) larvae, with larval descriptions of two species from Georgia. J. Parasit. 26(1): 33-43, pls.

Knipling, E. F. \& W. G. Bruce, 1937. Three unusual host records for cuterebrine larvae (Diptera: Oestridae). Ent. News 48(6): 156-158.

Landi, S., 1960. Bacteriostatic effect of haemolymph of larvae of various botflies. Can. J. Microbiol. 6: 115-119.

Lawrence, W. H., K. L. Hays \& S. A. Graham, 1965. Arthropodous (sic) ectoparasites from some northern Michigan mammals. Occ. Pap. Mus. Zool. Univ. Mich. 639.

Lay, D. W. \& R. H. Baker, 1938. Notes on the home range and ecology of the wood rat. J. Mammal. 19: 418-423.

Layne, J. N., 1958. Notes on mammals of southern Illinois. Am. Midl. Nat. 60: $219-254$.

Layne, J. N., 1963. A study of the parasites of the Florida mouse, Peromyscus floridanus, in relation to host and environmental factors. Tulane Stud. Zool. 11: 3-27.

Lechtleiner, R. R., 1959. Some parasites and infectious diseases in a black-tailded jackrabbit population in the Sacramento Valley, California. Calif. Fish Game 45: 83-91. 
Led, J. E. et al., 1978. Parasitismo por Cuterebra apicalis Guerin, 1829 (Insecta Diptera-Cuterebridae) en rata (Rattus norvegicus). Analecta vet. 6-8(1-3) (19/4-75-76): 35-37, fig.

Led, J. E. \& E. Brandelli, 1978. Miiasis por Cuterebra sp., Clark, 1815 (Diptera; Cuterebridae) en una chinchilla (Chinchilla lanigera). Ibid. 6-8 (1-3) (1974-75-76): 29-33, fig.

Leidy, J., 1857. Remarks on the larva of a species of Oestrus. Proc. Acad. nat. Sci. Philad. 1857: 204.

Leidy, J., 1888. Bot-larvae in the terrapin. Ibid. 1887: 393-394.

Leonard, A. B., 1933. Notes on larvae of Cuterebra sp. (Diptera: Oestridae) infesting the Oklahoma cotton tail rabbit. Trans. Kans. Acad. Sci. 36: 270-274, 5 figs.

Lindquist, A. W., 1937. Myiasis in wild animals in southwestern Texas. J. econ. Ent. 30: 735-740.

Linsdale, J. M. \& L. P. Trevis, Jr,, 1951. The dusky-footed woodrat. A record of observations made on the Hastings Natural History Reservation, 644 pp. Univ. Calif. Press, Berkeley \& Los Angeles.

Linter, J. A., 1890. Bot-fly of the hare. Cultiv. Ctry Gentleman 55: 905-906.

Linzey, D. W., 1968. An ecological study of the golden mouse, Ochrotomys nuttalli, in the Great Smokey Mountains National Park. Am. Midl. Nai. 79: 320-345.

Longhurst, W. M. \& J. R. Douglas, 1953. Parasite interrelationships of domestic sheep and Columbian black-tailed deer. Trans. 18th N. Am. Wildl. Conf.: 168-188.

Lord, J. K., 1866. The naturalist in Vancouver Island and British Columbia, 2: 338-339. R. Bentley, London.

Loughman, W. F. M., 1922. Notes on a case of myiasis. Il R. Army med. Cps 38(6): 458.

Lugger, O., 1897. Parasites of man and domesticated aninmals. Minn. St. Exp. Stn Ent. a. Rep. 2(1896): 44-231, figs. 24-187 (incl. partes das pls. 6-7 e todas das pls. 9-13 e 16).

Lutz, A., 1917. Contribuições ao conhecimento dos oestrideos brazileiros. Mems Inst. Oswaldo Cruz 9: 94-113, pls. 27-29.

Mac Donald, J. M., A. Delahunta \& J. Georgi, 1976. Cuterebra encephalitis in a dog. Cornell Vet. 66(3): 372-380, 4 figs.

McGinnes, B. S., 1964. Parasites of cottontail rabbits in south-western Virginia. Wildl. Dis. 35: ?

McKinney, T. D. \& J. J. Christian, 1970. Incidence and effects of botfly parasitism in the eastern chipmunck. J. Wildl. Dis. 6: 140-143.

McLintock, J. R., 1964. Puparium formation in Diptera (Sarcophaga, Musca, Cuterebra, Hypoderma). Nature, Lond. 201(4925): 1245.

Malloch, J. R., 1919. The Diptera collected by the Canadian expedition, 1913, $18(3, \mathrm{c}): 34 \mathrm{c}-90 \mathrm{c}$.

Manville, R. H., 1961. Cutaneous myiasis in small mammals. J. Parasit. 47: 646.

Marshall, C. M., 1960. Cuterebriasis and game animals. SE. Vet. 11(3): 72-73.

McKenzie, B. E., E. D. Lyles \& J. A. Clinkscales, 1978. Intracerebral migration of Cuterebra larva in a kitten. J. Am. Vet. Med. Ass. 172(2): 173-175, fig.

Maurer, F. W., Jr. \& J. E. Shaley, 1968. Cuterebrid infections of Microtus in eastern North Dakota, Pennsylvania and New York. J. Parasit. 49: 773-774.

Mello, D. A., 1978. Nota sobre a biologia de Cuterebra apicalis (Guérin 1829/ 38 (sic)) (Diptera-Cuterebridae). Revta bras. Pesq. méd. biol. 11(6): 329-331.

Meyer, R. P. \& M. E. Bock, 1980. Aggregation and territoriality of Cuterebra lepivora (Diptera: Cuttrebridae). I. med. Ent. 17: 489-493.

Milks, H. J., J. C. Stephenson \& C. J. Curtin, 1938. Report of the small animals clinic - July 1, 1936 to June 30, 1937. Rep. N. Y. St. vet. Coll. 1936-37: 31-35.

Miller, D. F., 1928. A case of the botfly (Bogeria buccata) as a parasitic upon the common house mouse (Mus musculus) (Dipt. Oestridae). Ent. News 39(1): 13-15. 
Miller, D. N. \& L. L. Getz, 1969. Botfly infections in a population of Peromyscus leucopus. J. Mammal. 50(2): 277-283, figs.

Miller, G. S., Jr. \& R. Kellogg, 1955. List of North American recent mammals. Bull. U. S. natn. Mus. 205: 1-954.

Moilliet, T. K., 1943. Some observations on the life history of Cuterebra tenebrosa Coquillett. Contr. Div. Ent. Can. 2198.

Moilliet, T. K., 1950. Some preliminary observations on the life-history of Cuterebra tenebrosa Coquillett. Proc. ent. Soc. Br. Columb. 46: 1-3.

Morlan, A. B., 1952. Host relationships and seasonal abundance of some southwest Georgia ectoparasites. Am. Midl. Nat. 48: 74-93.

Muma, H. H., 1952. Insect types in the collections of the U. of Nebraska State Museum. Bull. Neb. St. Mus. 3(8): 14.

Murphy, M. F., 1952. Ecology and helminths of the Osage wood rat, Neotoma floridana osagensis, including the description of Longistriata neotoma n. sp. (Trichostrongylidae). Am. Midl. Nat. 48: 204-218.

Newell, G. B., 1979. Dermal myiasis caused by the rabbit bot fly, Cuterebra sp. Archs Dermat. 115(1): 101.

Painter, R. H., 1930. Notes on Kansas bot-flies (Oestridae, Diptera). J. Kans. ent. Soc. 3: 32-35.

Parker, J., 1938. Some common conditions encountered in cat practice. J. Am. vet. med. Ass. 92: 34.

Parker, J. C., 1968. Parasites of the gray squirrel in Virginia. J. Parasit. 54: 633-634.

Parker, O. S. \& A. H. Chaney, 1979. Liomys irroratus (Rodentia: Heteromyidae), a new nost for Cuterebra fontinella (Diptera: Cuterebridae). J. med. Ent. 15: 573.

Parker, R. R. \& R. W. Wells, 1919. Observations on and experiments with Cuterebra tenebrosa Coquillett. Ibid. 5(3): 100-104, pl. 8, figs. 1-12.

Payne, J. A. \& E. Cosgrove, 1966. Tissue changes following Cuterebra in festations in rodents. Am. Midl. Nat. 75: 205-213.

Payne, J. A., P. B. Dunaway, G. D. Martin \& I. D. Story, 1964. Plasma protein alterations in Peromyscus leucopus infested with Cuterebra angustifrons. Am. Zool. 4: 410 (Res.).

Payne, J. A., P. B. Dunaway, G. D. Martin \& J. D. Story, 1965. Effects of Cuterebra angustifrons on plasma proteins of Peromyscus leucopus. J. Parasit. 51: 1004-1008.

Payne, J. A., G. D. Martin, J. D. Story \& G. E. Cosgrove, 1967. Electrophoresis as an aid in detecting pathological conditions in wild mammals. Bull. Wildl. Dis. Ass. 3: 21-22.

Penner, L. R., 1958. Concerning a rabbit cuterebrid, the larvae of which may penetrate the human skin (Diptera, Cuterebridae). J. Kans. ent. Soc. 31: 67-71.

Penner, L. R. \& F. P. Pocius, 1956. Nostril entry as the mode of infection by the first stage larvae of a rodent Cuterebra. J. Parasit. 42: 42.

Philip, C. B., J. F. Bell \& C. L. Larson, 1955. Evidence of infectious diseases and parasites in a peak population of black-tailed jack rabbits in Nevada. J. Wildl. Mgmt 19: 225-253.

Poole, E. L., 1940. A life history sketch of the Allegheny wood rat. J. Mammal. 21: $249-269$.

Preble, N., 1936. Notes on New Hampshire chipmuncks. Ibid. 17: 288-289.

Radovsky, F. J. \& E. P. Catts, 1960. Observations on the biology of Cuterebra latifrons Coquillett (Diptera: Cuterebridae). J. Kans. ent. Soc. 33: 31-36.

Rainey, D. G., 1956. Eastern woodrat, Neotoma floridana: Life history and ecology. Univ. Kans. Publs Mus. nat. Hist. 8: 535-646.

Rathvon, S. S., 1869. The squirrel bot (With comments by B. D. Walsh and C. V. Riley). Am. Ent. 1(6): 116-117.

Rice, P. L. \& G. W. Douglas, 1972. Myiasis in man by Cuterebra (Diptera, Cuterebridae). Ann. ent. Soc. Am. 65(2): 514-516, 3 figs.

Richens, V. B., 1965. Larvae of botfly in the northern pocket gopher. $J$. Mammal. 46: 689-690.

Riley, C. V. \& L. O. Howard, 1889. On the emasculating bot fly. Insect Life 1: 214-216. 
Riley, C. V. \& L. O. Howard, 1892. The rabbit bot. Ibid. 5: 137-138.

Riley, C. V. \& L. O. Howard, 1893. Another emasculating bot. Ibid. 6: 46.

Riley, C. V. \& L. O. Howard, 1895. A cat warble. Ibid. 6: 266.

Roberts, R., 1931. Myiasis in jack rabbits, Lepus californicus texanus. J. Parasi. 18: 102-104.

Roberts, R., 1933. Additional notes on myiasis in jack rabbits (Diptera: Calliphoridae, Sarcophagidae). Ent. News 44: 157-159.

Rodrigues, M. M., C. B. Weiss \& D. W. Muncy, 1976. Ophthalmomyiasis of the eyelid caused by Cuterebra larva. Am. J. Ophthal. 78(6): 1024-1026.

Rosenthal, J. J., 1975. Cuterebra infestation of the conjunctive in a puppy. Vet. Med. small Anim. Clin. 70(4): 462-463.

Rosesco, M. E., 1957. Seasonal abundance of the tick Dermacentor parumapertus on the black-tailed jack rabbit, with notes on other ectoparasites. J. Mammal. 38: 485-490.

Rootenbacker, H. J., G. Meigera \& S. Tuffs, 1964. Stomach worm disease, hypodermal myiasis and intestinal coccidiosis in a rabbit colony. Mich. St. Univ. Vet. 24(3): 134-136.

Ruch, D. M., 1967. Botfly myiasis. Archs Dermat. 96: 677-680.

Ryckman, R. E., 1953. Cuterebra latifrons reared from Neotoma fuscipes macrotis. Pan-Pacif. Ent. 29: 155-156.

Ryckman, R. E. \& C. C. Lindt, 1954. Cuterebra lepivora reared from Sylvilagus audubonii sanctidiegi in San Bernardino County, California. J. econ. Ent. 47(6): 1146-1148, figs.

Sabrosky, C. W., 1957. Two overlooked sources of type designation for genera. Proc, ent. Soc. Wash. 59: 171-172.

Sabrosky, C. W., 1970. Rabbit and rodent bots (Cuterebridae). Bull. ent. Soc. Am. 16(2): 93.

Sabrosky, C. W., 1972. Discovery of the bot fly collection of Bracy Clark, with designation of lectotypes in Cuterebra. J. Ent. (B) 41(2): 89-96.

Salomon, P. F., E. P. Catts \& W. G. Knox, 1970. Human dermal myiasis caused by rabbit bot fly in Connecticut. J. Am. med. Ass. 213: 10351036.

Schaefer, C. W.,1979. Feeding habits and hosts of Calyptrate flies (Diptera: Brachycera: Cyclorrhapha). Ent. Gen. 5: 193-200.

Scholten, T. H., 1964. First record of mating of Cuterebra angustifrons Dalmat (Diptera: Cuterebridae). J. Parasit. 50(3): 444.

Scholten, T. H. \& V. H. Chrom, 1979. Myiasis due to Cuterebra in humans. Can. med. Ass. J. 120(11): 1392-1393.

Scholten, T. H., K. Ronald \& D. M. McLean, 1962. Parasite fauna of Manitzoulin Island Region. 1. Arthropoda parasitica. Can. J. Zool. 40: 605-606.

Schwartz, B. \& W. B. Shook, 1928. Rabbit parasites and diseases. Fmrs' Bull. U. S. Dep. Agric. 1568: 1-30.

Scott, H. G., 1963. Myiasis: Epidemiologic data on human cases (North America north of Mexico: 1952-1962 inclusive), 14 pp. U.S. Dep. Hlth, Educ. Welfare, Publ. Hlth Serv., Atlanta.

Scott, H. G., 1964. Human myiasis in North America (1952-1962 inclusive). Fla Ent. 47(9): 255-261.

Scott, T. G., 1943. Some food coactions of the Northern Plain red fox. Ecol. Monogr. 13: 429-479.

Scott, T. G., 1947. Comparative analysis of red fox feeding trends on two central Iowa areas. Res. Bull. Iowa agric. Exp. Stn 353: 425-487.

Scott, T. G. \& E. Snead, 1942. Warbles in Peromyscus leucopus novaeboracensis. J. Mammal. 23(1): 94-95.

Sealander, J. A., 1961. Haematological values in deer mice in relation to botfly infection. Ibid. 42: 57-60.

Seaman, R. N. \& D. J. Nash, 1976. Variation in the incidence of botfly larvae (Cuterebra) in two sympatric species of Peromyscus in northern Colorado. Great Basin Nat. 36(4): 481-482.

Séguy, E., 1948. Introduction a l'étude des myiases. Revta bras. Biol. 8(1): 93-111.

Seton, E. T., 1920. Does the Cuterebra ever emasculate its host? J. Mammal. 
1: 94.

Seton, E. T., 1928. Lives of game animals, 4 (Rodents): 949 pp. Doubleday, Doran \& Co.

Severinghaus, C. W., 1949. Occurrence of a botfly larva in white-tailed deer. J. Mammal. 30(1): 75.

Shannon, R. C., 1925. (Cuterebra from howling monkey of tropical America; abstr. of rep. before Ent. Soc. Wash.). J. Wash. Acad. Sci. 15(15): 379.

Shannon, R. C. \& C. T. Greene, 1926. A bot-fly parasite in monkeys. Zoopathologica 1(7): 287-290, figs. 152-153, pls. A-B.

Sharp, A. M., 1892. Bots in the necks of kittens, in H. Osborn, Notes on insects. Bull. Ia agric. Exp. Stn 17: 451.

Sheldon, C., 1938. Vermont jumping mice of the genus Zapus. J. Mammal. 19: 324-352.

Shoemaker, J. P. \& S. J. Joy, 1967. Some ectoparasites from West Virginia mammals. II. Proc. W. Va Acad. Sci. 39: 78-80.

Siegmund, O. H., 1964. Further notes on cuterebrid infestations. J. Mammal. 45: 149 .

Sillman, E. I., 1956. Studies on the biology of a cuterebrid (Cuterebridae: Diptera) infesting Peromyscus lecopus novaeboracensis Fischer, the white-footed mouse in southern Ontario. A. Rep. ent. Soc. Ontario 86 (1955): 89-96, figs.

Sillman, E. I., 1957a. Further laboratory and field observations on the ecology of some Ontario Cuterebridae (Diptera), in particular Cuterebra angustifrons Dalmat, 1942. Ibid. 87(1956): 28-40.

Sillman, E. I., 1957b. Some aspects of the biology of Cuterebra angustifrons Dalmat, 1942 (Cuterebridae: Diptera). J. Parasit. 43(5): 33-34.

Sillman, E. I. \& M. V. Smith, 1959. Experimental infestation in Peromyscus leucopus with larvae of Cuterebra angustifrons. Science, N. Y. 130 (3368): 165-166.

Smith, D. H., 1973. A technique for the laboratory mating of rodent bot flies (Diptera: Cuterebridae). J. med. Ent. 10(5): 481.

Smith, D. H., 1977a. The natural history and development of Cuterebra approximata (Diptera: Cuterebridae) in its natural host, Peromyscus maniculatus (Rodentia: Cricetidae), in western Montana. J. med. Ent. 14(2): 137-145.

Smith, D. H., 1977b. Effects of experimental bot-fly parasitism on gonad weights of Peromyscus maniculatus. J. Mammal. 58(4): 679-681.

Smith, D. H., 1978a. Effects of bot fly (Cuterebra) parasitism on activity patterns of Peromyscus maniculatus in the laboratory. J. Wildl. Dis. 14: $28-39$.

Smith, D. H., 1978b. Vulnerability of bot fly (Cuterebra) infected Peromyscus maniculatus to short-tailed weasel predation in the laboratory. Ibid. 14: $40-51$.

Smith, W. C., 1892. The rabbit bot. Insect Life 5(2): 138.

Stannard, L. J., Jr. \& L. R. Petsch, 1958. Ectoparasites of the cottontail rabbit in Lee County, northern Illinois. Biol. Notes nat. Hist. Surv. Div. St. Ill. 38.

Stephens, F., 1893. Another emasculating bot. Insect Life 6(11): 46.

Stockton, J. J. \& J. Sundell, 1958. Nasal myiasis in a dog. Mich. St. Univ. Vet. 19: 8.

Stone, W. B., 1970. Occurrence of botfly larvae in red fox. N. Y. Fish Game J. 17: 64 .

Stones, R. D. \& C. L. Hayward, 1968. Natural history of the desert woodrat, Neotoma lepida. Am. Midl. Nat. 80: 458-476.

Stringer, R., 1967. Parasites of rabbits from North Carolina. Bull. Wildl. Dis. Ass. 3: 93.

Stringer, R. P., R. Warkema \& G. C. Miller, 1969. Parasites of rabbits in North Carolina. I. Parasit. 55: 328.

Stunkard, H. W. \& E. J. Landers, 1956. A Cuterebra larva from the epidural space of a cat. I. Ass. milit. Surg. U. S. 42(4): 432-434, figs.

Swenk, M. H., 1905. Class 1, Hexapoda. Order IV, Diptera. The North 
American species of Cuterebra. J. N. Y. ent. Soc. 13(4): 181-185.

Test, F. H. \& A. R. Test, 1943. Incidence of dipteran parasitosis in populations of small mammals. J. Mammal. 24: 506-507.

Timm, R. M. \& E. F. Cook, 1979. The effect of bot fly larvae on reproduction in white-footed mice, Peromyscus leucopus. Am. Midl. Nat. 101: 211-217.

Timm, R. M. \& R. E. Lee, 1981. Do bot flies, Cuterebra (Diptera: Cuterebridae), emasculake their host? J. med. Ent. 18: 333-336.

Townsend, C. H. T., 1892. Descriptions of oestrid larvae taken from the jack-rabbit and the cottontail. Psyche, Camb. 6: 298-300.

Townsend, C. H. T., 1893. Further notes on the cottontail bot, with the breeding and identification of the fly. Insect Life 5(3): 317-320.

Townsend, C. H. T., 1897. Descriptions of the bot-fly of the cottontail rabbit in New Mexico, Cuterebra lepusculi n. sp. Psyche, Camb. 8: 8-9.

Townsend, C. H. T., 1913. Inquiry into the relationships and taxonomy of the muscoid flies. Can. Ent. 45: 37-57.

Townsend, C. H. T., 1915. On the reproductive and host habits of Cuterebra and Dermatobia. Science, N. Y. 42: 253-255.

Townsend, C. H. T., 1917. A synoptic revision of the Cuterebridae, with synonymic notes and the description of a new species. Ins. Insc. menstr. 5: 23-28.

Townsend, C. H. T., 1919. New genera and species of muscoid flies. Proc. U. S. natn. Mus. 56: 592.

Townsend, C. H. T., 1920. Nota sobre o aparelho genital das fêmeas de Cuterebra e Dermatobia e os seus hábitos parasitários. Folha méd. 1(15): 118-119.

Townsend, C. H. T., 1931. Notes on oestromuscoid types. Revta Ent., Rio de J. 1: 65-104.

Townsend, C. H. T., 1935. Manual of Myiology 2: 280 pp., 9 pls. Itaquaquecetuba.

Townsend, C. H. T., 1938. Idem 6: 234 pp.

Townsend, C. H. T., 1942. Idem 12: 342 pp., 84 pls.

Tryon, C. A., 1947. The biology of the pocket gopher, Thomomys talpoides, in Montana. Tech. Bull. Mont. St. agric. Exp. Stn 448: 1-30.

Twigg, G. I., 1965. Warbles in Holochilus sciureus from the coast of British Guiana. I. Mammal. 46: 98-100.

Verrill, A. E., 1872. Additional observations on the parasitism of man and domestic animals. 5. a. Rep. Conn. Bd Agric. 187-72. (Também em Am. J. Sci. Arts (2) 50: 430).

Verts, B. J., 1967. The biology of the striped skunk, 218 pp., ilus. Urbana, Chicago \& London.

Vestal, E. H., 1938. Biotic relations of the wood rat (Neotoma fuscipes) in the Berkeley Hills. J. Mammal. 19: 1-36.

Vorhies, C. T. \& W. P. Taylor, 1933. The life histories and ecology of jack-rabbits, Lepus alleni and Lepus californicus species, in relation to grazing in Arizona. Tech. Bull. Ariz., agric. Exp. Stn 49: 470-587.

Vorhies, C. T. \& W. P. Taylor, 1940. Life history and ecology of the whitethroated woodrat, Neotoma albigula albigula Hartley, in relation to grazing in Arizona. Ibid. 86: 455-529.

Walker, F., 1866. In J. K. Lord, The naturalist in Vancouver Island and British Columbia 2: 375 pp., 4 figs. London.

Walker, F., 1849. List of the specimens of dipterous insects in the collection of the British Museum 3: 485-687, London.

Washburn, F. L., 1905. The Diptera of Minnesota: Oestridae. Bull. Minn. agric. Exp. Stn 93: 125-140.

Wecker, S. C., 1962. The effects of bot fly parasitism on a local population of the white-footed mouse. Ecology 43: 561-565.

Weisbroth, S. H., R. Wang \& S. Scher, 1973a. Cuterebra buccata. Immune response in myiasis of domestic rabbits. Expl. Parasit. 34(1): 22-31.

Weisbroth, S. H., R. Wang \& S. Scher, 1973b. Immune and pathologic consequences of spontaneous Cuterebra myiasis in domestic rabbits (Oryctolagus cuniculus). Lab. Anim. Sci., Jolliet, Ill. 23(2): 241-247. 
Wheeler, W. M., 1890. The supposed bot-fly parasite of the box-turtle. Psyche, Camb. 5: 403 .

Whitaker, J. O., Jr., 1963. A study of the meadow jumping mouse, Zapus hudsonicus (Zimmermann), in Central New York. Ecol. Monogr. 33: 215-254.

Whitaker, J. O., Jr., 1968. Chapter 7, in J. A. King, Biology of Peromyscus (Rodentia). Spec. Publs Am. Soc. Mammal. 2: 593 pp.

Williston, S. W., 1884. Order VII. Diptera, pp. 403-432, 433, figs. 508-594, in J. S. Kingsley, ed., The standard natural history 2: 555 pp., 666 figs., 20 pls. Boston.

Wills. W. \& G. E. Jones, 1977. Human myiasis in Pennsylvania. Melsheimer eni. Ser. 23: 15-16.

Wilson, L. W., 1945. Parasites collected from wood mouse in West Virginia. J. Mammal. 26: 200.

Wilson, N. \& W. J. Johnson, 1971. Ectoparasites of Isle Royale, Michigan. Mich. Ent. 4(4): 109-115, figs.

Wolf, A. M., 1979. Cuterebra larva in a nasal passage of a kitten. Feline Pract. 9(1): 25-26, 2 figs.

Woronecki, P. P., 1961. Evaluation of some cottontail rabbit management procedures as applied in Piedmont, Virginia, $81 \mathrm{pp}$. (Tese mimeogr.), Va Polytech. Inst.

Worth, C. B., 1950a. Observations on ectoparasites of some small mammals in Everglades National Park and Hillsborough County, Florida. J. Parasiî. 36: 326-335.

Worth, C. B., 1950b. A preliminary host ectoparasite register for some small mammals of Florida. Ibid. 36: 497-498.

Wulp, F. M. van der, 1888. Fam. Muscidae, pp. 2-40, pls. 1-2, in F. D. Godman \& O. Salvin, eds., Biologia Centrali-Americana. Zoologia-Insecta-Diptera 2: 489 pp., 11 figs., 13 pls. London.

Zeledón, R., O. Jiménez Q. \& R. R. Brenes M., 1957. Cuterebra baeri Shannon \& Greene en el mono aullador de Costa Rica. Revta Biol. trop. 5: 129-134, 11 figs.

\section{FAMILIA CUTEREBRIDAE (Dermatobia hominis)}

\subsection{Histórico}

O desenvolvimento da pesquisa sobre Dermatobia pode ser dividido em seis períodos.

1. De 1626 a 1820: Inclui relatos de missionários, médicos e naturalistas que viajaram pela América do Sul (Simón, 1626; Montoya, 1629; Cobó, 1653; Condamine, 1745; Arture, 1753; Juzarte, 1769-70; Gilij, 1780-1784; Humboldt, 1807; Azara, 1809). Linnaeus Jr. (1781) deu à espécie que atacava os homens na América do Sul, causando miíases cutâneas, o nome de Oestrus hominis, numa carta dirigida a Pallas e por este publicada. Estes primeiros relatos foram desacreditados na Europa, pois não se acreditava que existisse um "Oestrus" exclusivo do homem, ou porque tais fatos podiam ser imputados a outras moscas que acidentalmente parasitassem o homem; um bom resumo da história desse período é achado em Keferstein (1856).

2. O segundo período, de 1822 a 1892 , caracterizou-se por uma grande proliferação de trabalhos que descreviam ou citavam quase cada larva achada (Say, 1822; Hill, 1830; Roulin, 1833; Saint Hilaire, 1833; Roulin et al., 1833; Vallot, 1833; Howship, 1833, 1834; Poeppig, 1835; Rengger, 1835; Guyon, 1836; Hope, 1840; Sundevall, 1841, 1843, 1844; Penniston, 1844; Goudot, 1845; Joly, 1846-1847; Rosenschöld, 1849; Londres, 1854; Keferstein, 1856; Coquerel, 1859; Coquerel \& Sallé, 1859; Grube, 1860; Brauer, 1861; Laboulbène, 1860, 1861; Westwood, 1861; Coquerel \& Sallé, 1862; Brauer, 1863; Bates (H. W.), 1864; Gerstaecker, 1868; Smith (F.), 1868; Bonnet, 1870; Posada-Arango, 1871; Verrill, 1872; Weyenbergh, 1874; Costa, 1876; Kirshmann, 1881; Jacobs, 1882, 1883; Laboulbène, 1883; Jousseaume \& Mégnin, 1884; Mégnin, 1884; Matas, 1887, 1888; Osborn, 1889; James (J. F.), 1889; Brauer \& Bergenstamm, 1889; Herzog, 1899; Anon., 1890; Blanchard, 1892; Magalhães, 1892; Barraillier, 1892; Schöyen, 1892). 
Os autores freqüentemente discutiam detalhes da morfologia da larva e especialmente sobre quantas espécies deveriam ser consideradas. Blanchard (1892) compilou todas as descrições e relatos publicados até a época (inclusive das ilustrações) e decidiu, baseado exclusivamente em caracteres larvais, que deveriam existir quatro espécies, que ele designou por seus nomes vulgares: ver macaque, berne, torcel e ver moyocuil.

Macquart (1843) descreveu o adulto pela primeira vez, como Cuterebra cyaniventris, naturalmente sem desconfiar de que se tratava da fase adulta do "Oestrus hominis". A associação entre a larva parasita do homem e o adulto foi estabelecida pela primeira vez por Goudot (1845), que conseguiu criar larvas coletadas na Colômbia; Goudot descreveu a mosca como Cuterebra noxialis. Brauer (1861) erigiu então o gênero Dermatobia para a recepção das duas espécies (cyaniventris e noxialis).

3. No terceiro período, de 1893 a 1910, várias importantes contribuições apareceram - a identidade de cyaniventris com noxialis foi estabelecida (Austen, 1895; Blanchard, 1896) e fizeram-se os primeiros trabalhos de criação de larvas até a fase adulta, com dados sobre a biologia (Neiva, 1908, 1910; Morales, 1911). Apesar de o conhecimento de algumas fases da biologia haver crescido, ainda permanecia um mistério a maneira pela qual as larvas eram depositadas nos hospedeiros. Os leigos e os especialistas incriminavam uma grande variedade de insetos; outros acreditavam que os ovos eram depositados diretamente sobre a pele (Condamine, 1745; Juzarte, 1769-70; Linnaeus Jr., 1781; Humboldt, 1807; Azara, 1809; Wied-Neuwied, 1820; Smith (F.), 1868; Verrill, 1872; Costa, 1876), diretamente sobre as roupas (Barraillier, 1892), sobre folhas e daí para o corpo do hospedeiro (Surcouf, 1913) ou ainda que as larvas passavam para o corpo do hospedeiro a partir do solo (Say, 1822).

4. Solucionou-se o problema e confirmou-se a solução no quarto período, de 1911 a 1918 (Zepeda, 1911; Morales, 1911; Gonzalez-Rincones, 1912, 1913; Morales, 1913; Surcouf, 1913; Zepeda, 1913; Neiva, 1914; Sambon, 1915; Townsend, 1915; Neiva \& Gomes, 1917; Dunn, 1918; Lutz, 1917). O primeiro a demonstrar que os ovos de Dermatobia eram veiculados por mosquitos foi, indubitavelmente, Morales (1911). Neiva (1910) estabeleceu a sinonimia entre hominis e cyaniventris (= noxialis).

5. No quinto período, que podemos colocar entre 1918 a 1943, não se realizaram grandes descobertas, mas adicionaram-se certas informações que faltavam. A genitália masculina (Travassos, 1931; Patton, 1935) e feminina (Townsend, 1920; Patton, 1935) foram descritas; Bates (M.) (1943) analisou as características comuns dos vetores. Realizaram-se as primeiras tentativas de controle da mosca (Oliveira Filho, 1922; Townsend, 1922; Bau, 1922). Ampliou-se a lista de insetos vetores dos ovos (Chanal, 1921; Peryassú, 1922; Shannon, 1925; Castellani, 1925; Pinto, 1930; Pinto \& Fonseca, 1930; Almeida, 1933; Lane, 1936; Fróes, 1936; Pinto \& Lopes, 1938; Lopes, 1938; Siddons \& Roy, 1942). Adicionaram-se detalhes sobre morfologia (Newstead \& Potts, 1925). E continuaram novas descrições e relatos sobre miíases (Matta, 1919, 1920; Pennington, 1919; Silva, 1921; Loughman, 1922; Thiel, 1924; Baldassare, 1924; Castellani, 1925; Andrade, 1927, 1929; Campos, 1927, 1929; Falcão, 1927, 1929; Ramos, 1927; Alencar, 1928; Foster, 1928; Lima, 1929; Martins, 1929; Ferrari, 1929; Dunn, 1930, 1934; Calzada, 1930; Mazza \& Ríos, 1931; Falcão, 1933; Mazza \& Señorans, 1936; Price, 1937; Peña \& Kumm, 1939; Rezende, 1939; Viana Castillo, 1939; Ferrari, 1939; Niño \& Rivas, 1940; Carneiro \& Drumond, 1941; Downing, 1941; Harrell \& Moseley, 1942; Roveda, 1942).

6. Finalmente, de 1943 até o presente, a preocupação é especialmente dirigida ao controle dessa mosca, pelos mais variados meios: Meyer, 1943; Squibb, 1945; Athanassof, 1946; Gomes, 1946; Laake, 1948; Beltran, 1948; Toledo, 1948; Alves Neto, 1949; Castron, 1949; Giovine, 1950; Penha, 1950; Toledo \& Sauer, 1950; Toledo, 1950; Alves Neto, 1951; Cevallos, 1951; Baroni, 1951; Toledo, 1951; Adams, Castillo \& Salmerón, 1952; Morales, 1952; Syàain, 1952; Toledo, 1952; Viale, 1952; Adams, Castillo, Carlos, Salmerón \& Rodrigo, 1952; Creighton \& Neel, 1952 [incluem bibliografia sobre controle de Dermatobia]; Pinheiro \& Baroni, 1953; Moussatché \& Oliveira, 1953; Pinheiro \& Baroni, 1953; Folling, 1953; Laake, 1953; Lowry, 1954; Neel, 


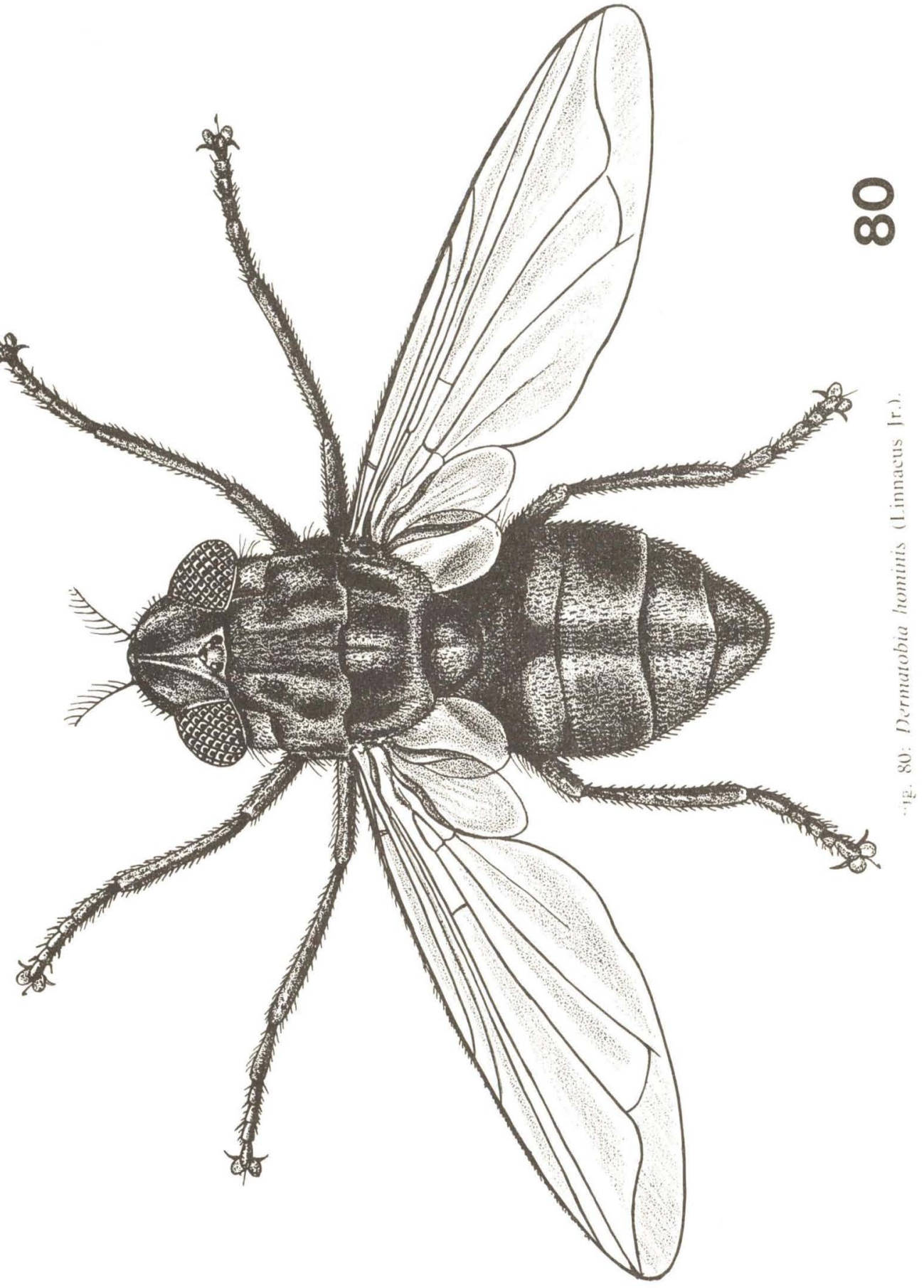


1954; Pinel, 1954; Adams, Castillo, Carlos, Salmerón \& Rodrigo, 1954: Adams, Castillo \& Salmerón, 1954; Neel, Urbina, Havis \& Alba, 1955; Carrera, 1956; Morales, 1956; Ruiz Martinez, 1956; Bolle \& Orinvela, 1957; Hambleton, 1957: Matos, 1957; Padrón Lizardo, 1957; Zeledón, 1957; McGregor \& Wade, 1957; Graham, Wade, Colby \& McGregor, 1957; Anon., 1957; Graham, Kraemer \& Alejandro, 1958; Ruiz Martinez, 1958; Weaver, Posada, Swanson, Newland \& González, 1958; Bolle, 1958; McGregor, Wade \& Colby, 1958; Veiga, 1958; Anon., 1959; Gliesch, 1959; Heiman, 1959; Bergamin, 1959; Graham, 1959; Koone \& Banegas, 1959; Rabello, 1959; Mendez Mena, 1960; Andersen, 1960; Mello, Queiroz \& Madureira, 1960; Johnson, 1960; Graham, Kraemer \& Osorio, 1960; Mullison \& Shaver, 1960; Costa \& Freitas, 1961; Colmenares, 1961; Andersen, 1961; Leão, 1961; Casorso \& Mateus, 1962; Anon., 1962; Müller, 1962; Anon., 1963; Brass, 1964; Graham, 1964; Ludwig, Wade \& Shaver, 1967; D'Alessandro, 1975; Mateus, 1975, 1979; Lello et al., 1976a-b, 1977; Oba et al., 1978; Peraçoli et al., 1980.

Continuam as indefectíveis descrições e relatos sobre miíases e sobre a importância econômica, médica e veterinária da mosca: Santos, 1943; Neghme \& Donoso Barros, 1944; Floch \& Abonnenc, 1944; Delmanto, 1945; Mirabelli \& Lori, 1945; Fiasson, 1945; Anduze, 1945; Goldman, 1946; Donoso Barros, 1947; Calero, 1948; Dao, 1950; Giglio, Actis D. \& Borrone, 1950; Osimani, 1951; Vianna, 1951; Rodriguez Gonzalez, 1952; Mejía, 1952; Wolffenbüttel, 1953; Dao, 1954; Dalmat, 1955; Areba Blanco, 1955; Suárez \& Tagle, 1956; Braaksma, 1956, 1957; Belavsky \& Hrebieck, 1956; Greene, 1956; Ruiz Martinez, 1956; Bacigalupo, 1959; Bruijning, 1959; Núñez Andrade, 1960a-b; Géspedes et al., 1962; Hugh-Jones, 1962; Mañé-Garzón et al., 1962; Sweet, 1962; Scott (H. G.), 1963; Spira \& Spira, 1963; Scott (T. G.), 1964; Brumpt \& Poulet, 1965; Chadah \& Werin, 1966; Dao, 1966; Hodson \& Reed, 1966; Flew \& Gundry, 1967; Pradinaud \& Revierez, 1968; Lombardero \& Fontana, 1968; Negro et al., 1969; Prasad \& Beck, 1969; McIver et al., 1971; Chaia et al., 1974; Keshishian, 1976; Person, 1976; Birnbaum \& Werner, 1977; Everett, DeVillez \& Lewis, 1977; Murray \& Thompson, 1976; Marsden et al,, 1979; Rossi \& Zucoloto, 1973.

Iniciaram-se nos últimos anos alguns estudos sobre criação em massa no laboratório (Banegas, 1968; Banegas, Mourier \& Graham, 1967; Foresti, Lello \& Toledo, 1972), para tentar o controle por esterilização de machos (Jobsen, 1974; Katiyar et al., 1967).

\subsection{Nomes vulgares}

Em inglês, a Dermatobia hominis é comumente designada por "American warble-fly", "American botfly", "human botfly", "tropical warble- ou botfly", "beef-worm".

A lista dos nomes vulgares regionais dados a esta espécie na América Latina são:

1. Bekuru ou bikuru, entre os índios Kaingang do Brasil (Val Floriana, 1920);

2. Berne, Brasil. Nome de origem incerta. Neiva \& Penna (1916) acreditavam tratar-se de uma corruptela do português "berro", aplicado em Portugal às larvas de Hypoderma. Por outro lado, Araripe Jr. escreveu a Blanchard (1896) que "la larve que nous appelions Berne porte aussi le nom de Verme: cette coincidence nous autorise à considerer le premier nom comme une double corruption du second. Dans le nord du Portugal, le peuple prononce Berme au lieu de verme: or, la plupart des Portugais qui arrivent au Brésil viennent du nord du Portugal, et leur prononciation vicieuse à até adopté dans les campagnes, où la maladie est fréquente. Quant à la transformation de Berme en Berne, elle s'explique naturellement par la loi que les philologues appellent 'loi du moindre effort'."

3. Borro, Bolivia (Bolle, 1958).

4. Colmoyote, México e Guatemala (Morales, 1911). Do Náhuatl ocuilin 
$=$ verme, moyotl $=$ mosca $;$ (o)cuil(in)moyotl $=$ colmoyote $=$ verme do mosquito (Santamaria, 1959).

5. Gusano macaco, Venezuela (Gonzalez Rincones, 1913).

6. Gusano de monte, América Central, Equador, Colômbia e Venezuela; "verme da mata": refere-se ao fato de que a infestação por Dermatobia ocorre mais freqüentemente na vizinhança de florestas.

7. Gusano de mosquito ou gusano de zancudo, Venezuela. Refere-se obviamente ao fato de que os ovos da Dermatobia são transportados por mosquitos.

8. Gusano peludo, Bolívia (Gilij, 1780-1784). Com referência à aparência espinhosa da larva.

9. Kturn, kitudn ou ikitugn, entre os índios Kaingang do Brasil (Val Floriana, 1920; Baldus, 1947).

10. Mberuaró, nome dado pelos índios Guarani à mosca. De mberu $=$ mosca

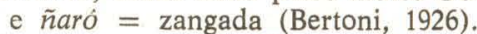

11. Mirunta, Peru (Barraillier, 1892). O nome se refere, ao que parece, à miíase causada por Dermatobia, e não à própria larva.

12. Moyocuil, México (Coquerel \& Sallé, 1859). De acordo com o Prof. Charles E. Dibble, esta palavra é formada de moyotl $=$ mosquito e ocuilin = verme; moy(otl)ocuil(in). Vide Colmoyote e Santamaria (1959).

13. Muskietenworm, Surinam (Londres, 1854).

14. Nuche ou nunche, Colômbia e Venezuela (Say, 1822; Goudot, 1845).

15. Suglacuru ou suylacuru; citado por La Condamine (1745) como usado pelos índios Mayna. Do quéchua sugla ou suyla $=$ ? e curu $=$ verme ou inseto.

16. Torcel ou tórsalo, América Central. Provavelmente uma corruptela do espanhol "torcer" (Grube, 1860; Santamaria, 1942).

17. Tupe, Equador.

18. Ura, Brazil, Argentina, Uruguai e Paraguai. Nome guarani. Já citado por Montoya em 1629.

19. Ver macaque, Guiana Francesa. Segundo Arture (1753): "Cet insecte est du genre de ceux qui se trouvent sous la peau des animaux (...). On en voit assęz fréquemment sur l'espèce de singe qui est la plus commune en France, et c'est probablement de cet animal, qui se nomme en langue du pays, Macaque, que le ver a pris son nom."

\subsection{Insetos confundidos com Dermatobia}

A associação definitiva dos estágios larval e adulto de Dermatobia exigiu um tremendo esforço de observação paciente e experimentação. $O$ povo leigo, todavia, ignorou ou ainda ignora a identidade da mosca adulta e acusa uma variedade de insetos como os responsáveis pelas larvas de Dermatobia.

Blanchard (1894) foi o primeiro a reunir estas crenças populares. Os insetos confundidos com Dermatobia foram-lhe enviados por P. S. de Magalhães, do Brasil. Blanchard citou as seguintes espécies de Diptera: Ornidia obesa (Fabricius), Syrphidae; Phaenicia eximia (Wiedemann) (como Lucilia ruficornis Macquart), Calliphoridae; Paraphryssopoda chrysostoma (Wiedemann) e Hystricocnema plinthopyga (Wiedemann) (ambas como Sarcophaga), Sarcophagidae; Hystricia sp., Tachinidae, e Tipulidae.

Altamirano (1896) citou Atractocerus brasiliensis Lep. \& Serv. (Coleoptera, Atractoceridae), no México.

Rondon (1907) citou um mosquito, "carapanã de ura". Finalmente, Neiva (1910) listou Ornidia obesa (Fabricius), Syrphidae; Mesembrinella sp., Mesembrinellidae; e Tipulidae; estes últimos são conhecidos em algumas partes do Brasil como "mosquito-berne". Em um trabalho posterior (1914) Neiva comentou, sem outros detalhes, que o "carapanã de ura" era um Ichneumonidae, e adicionou à lista de insetos confundidos com Dermatobia - taquinídeo Echinomyia sp. 
Como se pode ver pela lista acima, a associação errônea de certos insetos com Dermatobia pode ser devida a diversas causas: semelhança morfológica entre os adultos (ex., Ornidia, Mesembrinella), incriminação de vetores (mosquitos) ou semelhança de hábitos (califorídeos produtores de miíases).

11.4. Classificação

\section{Gênero Dermatobia Brauer}

Dermatobia Brauer, 1861: 783. Espécie-tipo, Cuterebra cyaniventris Macquart (Guimarães \& Papavero, 1966: 228) = hominis (Linnaeus Jr.).

\section{Dermatobia hominis (Linnaeus Jr.)}

Oestrus hominis Linnaeus Jr., in Pallas, 1781: 158. Localidade-tipo: "Peru" Oestrus humanus Howship, 1833: 81. Localidade-tipo: Colômbia, Mariquita. Oestrus guildingii Hope in Owen, 1833: ? Localidade-tipo: "Trinidad". Cuterebra cyaniventris Macquart, 1843: 23. Localidade-tipo: "Brasil". Cuterebra noxialis Goudot, 1845: 229, pl. 4bis, figs. 1-6. Localidade-tipo: Colômbia, Marmato.

Dermatobia cyaniventris: Brauer, 1961: 783.

Dermatobia noxialis: Brauer, 1861: 783.

Dermatobia hominis: Ward, 1903: 483; Neiva, 1910: 3.

Para maiores detalhes sobre a classificação desta espécie, consultar Guimarães \& Papavero (1966: 229-230).

\subsection{Morfologia}

Dermatobia hominis é uma mosca de tamanho médio, com cerca de $12 \mathrm{~mm}$ de comprimento, apresentando alguma semelhança com califorídeos. Cabeça amarela, escurecida na parte superior. Arista pectinada superiormente. Tórax azul-metálico, revestido de pêlos escuros. Placa facial com uma depressão profunda, com carena incipiente; probóscida muito curta e cilíndrica; palpos ausentes. Asas fracamente testáceas. Pernas amarelas.

$O$ adulto foi descrito detalhadamente por Townsend (1935, 1938). Detalhes adicionais foram acrescentados por Patton (1935).

Detalhes sobre os cromossomos foram publicados por Lello, Toledo \& Foresti $(1971,1974)$. Lello (1972) estudou os elementos figurados da hemolinfa.

Os estágios imaturos foram descritos, apesar de imperfeitamente, por diversos autores (Say, 1822; Roulin, 1833; Howship, 1834; Hope, 1840; Goudot, 1845; Coquerel, 1859; Coquerel \& Sallé, 1859; Grube, 1860; Brauer, 1861; Laboulbène, 1861; Coquerel \& Sallé, 1862; Bonnet, 1870; Matas, 1887; Blanchard, 1893, 1894, 1896).

Os ovos foram descritos por Townsend (1935). A larva I, já descrita por Surcouf (1913) foi melhor caracterizada por Newstead \& Potts (1925). Jobsen \& Mourier (1972) apresentam caracteres morfológicos e dimensões que permitem distinguir os três "instars" das larvas de Dermatobia.

Umaña (1914) e Keilin (1944) estudaram os espiráculos protorácicos das larvas. A pupa foi brevemente caracterizada por Goudot (1845) e bem figurada por James (1948).

\subsection{Anatomia}

Tem-se apenas um medíocre conhecimento da anatomia da larva e do adulto. Da larva, apenas algumas poucas observações do estágio I (transparente), feitas por Surcouf (1913).

Do adulto, umas poucas notas de Townsend $(1920,1935,1938)$.

\subsection{Biologia}

\subsubsection{Habitat}

Esta espécie é primariamente um habitante das florestas; as formações abertas parecem ser uma barreira à sua dispersão (Neiva, 1910). É, portanto, 


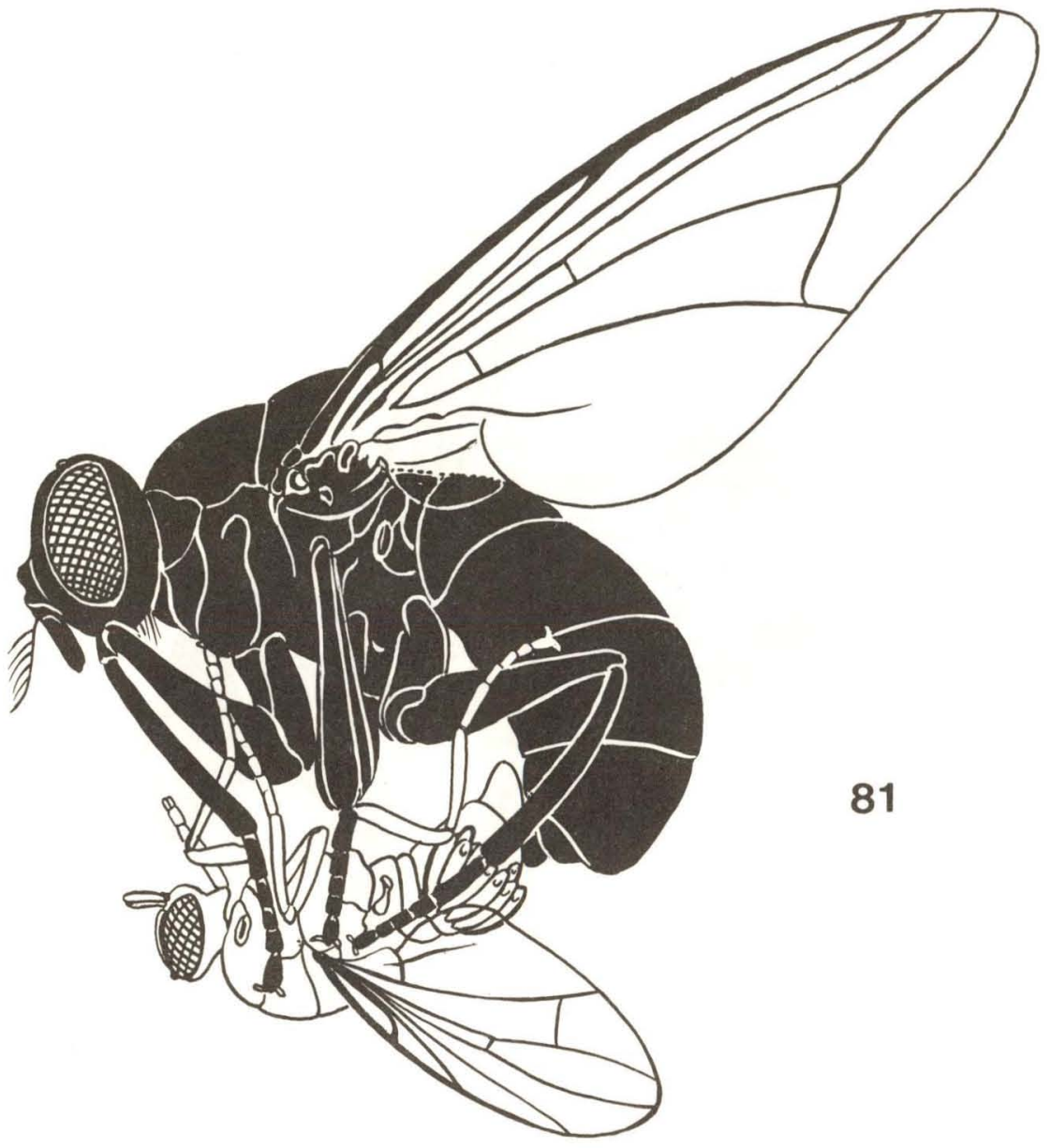

Fig. 81: Dermatobia hominis (Linnaeus Jr.) depositando seus ovos em mosca silvestre (esquemático).

mais abundante na margem das matas primitivas ou secundárias, florestas-galeria, plantações de Eucalyptus (Andrade, 1929), etc.

\subsubsection{Cópula}

A cópula de Dermatobia foi estudada em detalhe por Banegas \& Mourier (1967): o estímulo visual é o mais importante para o encontro sexual. As moscas alcançam a maturidade cerca de 1,5 a 4 horas, após a emergência. A luz intensa e temperatura ao redor de $28^{\circ} \mathrm{C}$ são favoráveis ao acasalamento.

O hábito de agregação de machos, conhecido em vários dípteros caliptrados, foi observado pela primeira vez por Guimarães (1960a). Tal comportamento aumenta a probabilidade do encontro sexual na natureza em populações dispersas ao acaso.

Em condições de laboratório, o macho pode copular duas ou mais vezes (Neiva, 1908). A cópula dura de uns poucos minutos até umas poucas horas. 


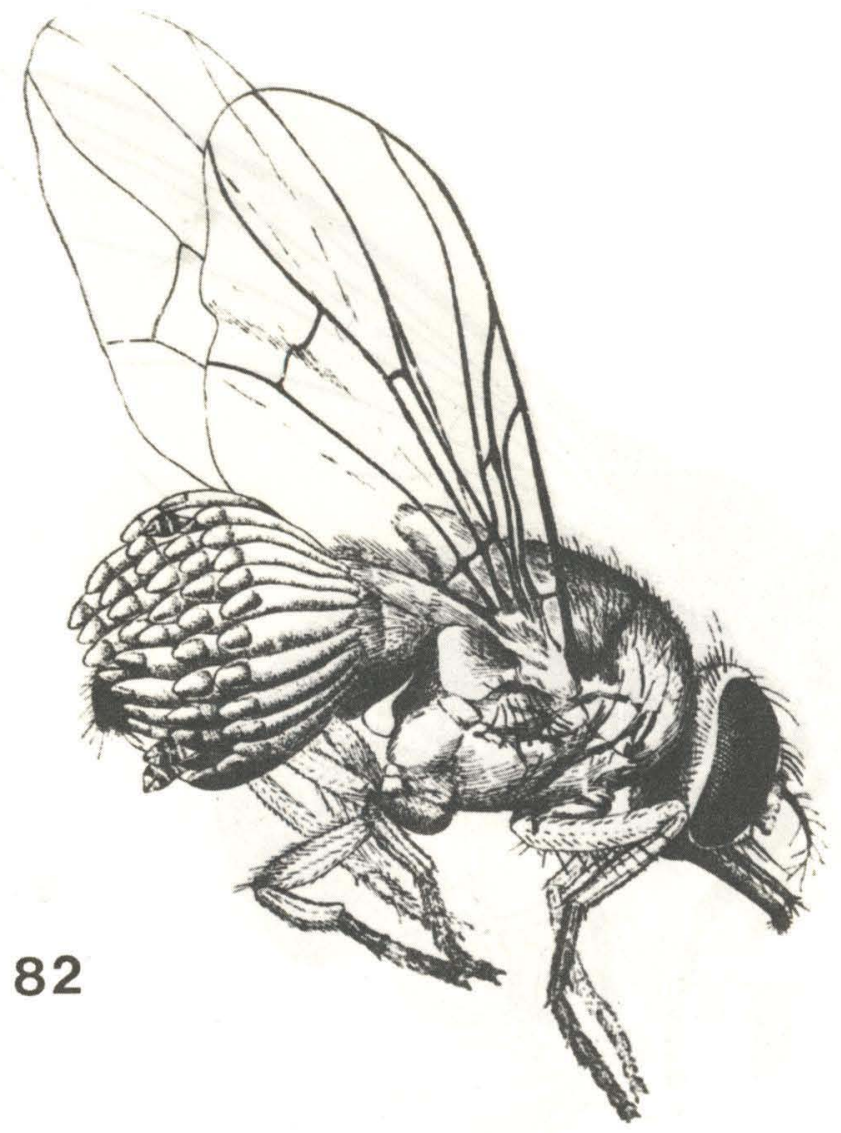

Fig. 82: Muscídeo silvestre vetor de ovos de Dermatobia hominis (Linnaeus Jr.) (apud Neiva \& Gomes, 1917).

A fêmea, cavalgada pelo macho, fica andando, enquanto o macho tenta manter o equilíbrio, ocasionalmente vibrando as asas. Eventualmente a fêmea para e permanece imóvel enquanto dura a cópula (Neiva \& Gomes, 1917).

\subsubsection{Oviposição}

A fêmea, se fertilizada logo após a emergência, começa a oviposição dentro de uma semana; se for fertilizada pela primeira vez após o décimo quinto dia de vida, então a oviposição ocorrerá após 48 horas (Neiva \& Gomes, 1917).

Os ovos são depositados no corpo de outros insetos, especialmente moscas ou mosquitos zoófilos. Para encontrar esses insetos, a Dermatobia freqüenta cavalos e bovinos, que são assiduamente visitados por dípteros muscóideos e culicídeos. A Dermatobia captura durante o vôo os dípteros foré. ticos com as pernas, enquanto deposita seus ovos na extremidade ventral do abdome (Fig. 81). Estes ovos ficam fortemente aderidos e dispostos em cachos em apenas um lado do abdome do vetor (Fig. 82), em número variável (Artigas \& Serra, 1965). O cimento que gruda os ovos é bastante eficiente e resiste aos esforços que faz o vetor para livrar-se deles, esfregando o abdome com suas patas (Neiva \& Gomes, 1917). 
A Dermatobia pode realizar várias posturas. Segundo Neiva \& Gomes (1917) uma fêmea em cativeiro depositou cerca de 182 ovos, distribuídos em posturas parceladas sobre 4 moscas domésticas. Calcula-se que para esvaziar o ovário, esta mosca pode depositar até 800 ovos (Neiva, 1910). Pode haver ainda posturas sobre folhas, diretamente sobre os animais, e sobre a terra, conforme consta de certos trabalhos, mas tais afirmações carecem comprovação.

Conservados em câmara úmida, tais posturas podem dar larvas; fora desta condição, os ovos murcham (Neiva \& Gomes, 1917).

Townsend (1935) e Disney (1975) teceram alguns comentários sobre a possível história evolutiva deste hábito de oviposição. Entretanto, uma hipótese satisfatória sobre a oviposição de Dermatobia hominis em vetores ainda não foi aventada.

\subsubsection{Vetores}

Bates (M., 1943) estudou na Colômbia os hábitos de oviposição de Dermatobia. Das observações de comportamento de oviposição e de incidência relativa de ovos em diferentes espécies de mosquitos, este autor verificou que os vetores apresentavam as seguintes características: a) hábitos zoófilos; b) período diurno de atividade; c) tamanho moderado (a maioria dos Tabanidae apresentam tamanho muito grande para serem capturados e os Hippelates tamanho reduzido); d) hábitos moderadamente ativos (os de hábitos muito vagarosos não estimulam a captura e os muito ativos escapam).

Vários autores, em diferentes épocas, publicaram listas de vetores; a última foi organizada por Artigas \& Serra (1965) e adotada, com modificações, por Guimarães \& Papavero (1966). A mesma tabela, com as modificações que se fizeram necessárias desde aquela época, apresentamos a seguir:

TABELA $\quad 11.1$

Lista dos vetores de ovos de Dermatobia

Família Culicidae

1. Aedes (Finlaya) leucocaelenus Dyar \& Shannon, 1924 - (Lane, 1936: Brasil).

2. Aedes (Ochlerotatus) angustivittatus Dyar \& Knab, 1907 - (Goldman, 1946: Costa Rica).

3. Aedes (Ochlerotatus) serratus (Theobald, 1901) - (Bates, 1943: Colômbia; Goldman, 1946: Costa Rica).

4. Aedes (Ochlerotatus) taeniorrhynchus (Wiedemann, 1821) - Camain \& Abonnenc, 1948: Guiana Francesa; Floch \& Fauran, 1954: Guiana Francesa).

5. Anopheles (Arribalzagia) intermedius (Chagas, 1908) - (Artigas \& Serra, 1965: Brasil).

6. Anopheles (Kerteszia) boliviensis (Theobald, 1905) - (Bates, 1943: Colômbia).

7. Anopheles (Nyssorhynchus) rangeli Gabaldon, Cova-Garcia \& Lopes, 1940 - (Bates, 1943: Colômbia).

8. Culex sp. (?) - (Morales, 1911: Guatemala).

9. Hemagogus (Steatoconops) capricornii Lutz, $1904-$ (Bates, 1943: Colômbia).

10. Mansonia spp. - (Bates, 1943: Colômbia).

11. Mansonia (Mansonia) titillans (Walker, 1848) - (Floch \& Abonnenc, 1944: Guiana Francesa; Floch \& Fauran, 1954: Guiana Francesa).

12. Mansonia (Rhynchotaenia) fasciolata (Lynch Arribálzaga, 1891) - (Floch \& Fauran, 1954a-b: Guiana Francesa).

13. Psorophora sp. - (Knab, 1913: México).

14. Psorophora (Grabhamia) cingulata (Fabricius, 1805) - (Bates, 1943: Colômbia).

15. Psorophora (Janthinosoma) albipes (Theobald, 1907) - (Pinto \& Lopes, 1938: Brasil). 
16. Psorophora (Janthinosoma) cyanescens (Coquillett, 1902) - (Nuñez Tovar, 1924: Venezuela).

17. Psorophora (Janthinosoma) ferox (Humboldt, 1820) - (Neiva \& Gomes, 1917: Brasil; Peryassú, 1922: Brasil; Lane, 1936: Brasil; Floch \& Abonnenc, 1944: Guiana Francesa).

18. Psorophora (Janthinosoma) lutzii (Theobald, 1901) - (Urich, 1913: Trinidad; Lutz, 1917: Brasil; Shannon, 1925: Panamá; Castellani, 1925: América Central; Floch \& Abonnenc, 1944: Guiana Francesa; Floch \& Fauran, 1954: Guiana Francesa).

19. Psorophora (Janthinosoma) sp. - (Gonzalez-Rincones, 1912: Venezuela; Knab, 1913: México; Surcouf, 1913: Venezuela).

20. Trichoprosopon (Rhynchomyia) lampropus (Howard, Dyar \& Knab, 1915) - (Bates, 1943: Colômbia).

21. Trichoprosopon (Rhynchomyia) longipes (Fabricius, 1805) - (Shannon, 1925: Panamá).

22. Wyeomyia sp. - (Bates, 1943: Colômbia).

23. Wyeomyia (Davismyia) petrocchiae (Shannon \& Del Ponte, 1927) (Lane, 1936: Brasil).

24. Wyeomyia (Dendromyia) confusa (Lutz, 1905) - (Artigas \& Serra, 1965: Brasil).

Família Simuliidae

25. Simulium sp. - (Ward, 1903).

26. Simulium pruinosum Lutz, 1910 - (Vulcano, 1959: Brasil).

Família Tabanidae

27. Chrysops sp. - (Pinto \& Lopes, 1938: Brasil).

Família Fanniidae

28. Fannia heydenii (Wiedemann, 1830) - (Neiva, 1914: Brasil; Lutz, 1917: Brasil).

29. Fannia pennicillaris (Stein, 1900) - (Artigas \& Serra, 1965: Brasil).

30. Fannia petrocchiae (Shannon \& Del Ponte, 1926) - (Artigas \& Serra, 1965: Brasil).

31. Fannia scalaris (Fabricius, 1794) - (Artigas \& Serra, 1965: Brasil).

32. Fannia sp. - (Artigas \& Serra, 1965: Brasil).

Família Anthomyiidae

33. Craspedochaeta lindigii (Schiner, 1868) - (Lutz, 1917: Brasil).

34. Limnophora sp. - (Neel, Urbina, Viale \& Alba, 1955: Costa Rica).

Família Muscidae

35. Morellia humeralis (Stein, 1918) - (Artigas \& Serra, 1965: Brasil).

36. Morellia pruna (Shannon \& Del Ponte, 1927; também como Sarcopromusca arcuata (Townsend, 1927)) - (Neel, Urbina, Viale \& Alba, 1955: Costa Rica; Artigas \& Serra, 1965: Brasil).

37. Morellia sp. - (Artigas \& Serra, 1965: Brasil).

38. Musca domestica (Linnaeus, 1758) - (Townsend, 1922: Brasil; Neel, Urbina, Viale \& Alba, 1955: Costa Rica; Zeledón, 1957: Costa Rica).

39. Neivamyia flavicornis (Malloch, 1928; como N. lutzi Pinto \& Fonseca, 1930) - (Pinto \& Fonseca, 1930: Brasil).

40. Pselaphephila sp. (?) - (Pinto \& Fonseca, 1930: Brasil).

41. Stomoxys calcitrans (Linnaeus, 1758) - (Neel, Urbina, Viale \& Alba, 1955: Costa Rica; Zeledón, 1957: Costa Rica).

42. Synthesiomyia nudiseta (Wulp, 1833) - (Neiva \& Gomes, 1917: Brasil; Siddons \& Roy, 1942). 
Família Sarcophagidae

43. Hybopygia terminalis (Wiedemann, 1830) - (Pinto \& Fonseca, 1930: Brasil).

Família Calliphoridae

44. Cochliomyia macellaria (Fabricius, 1794) - (Almeida, 1933: Brasil).

45. Cochliomyia sp. - (Neel, Urbina, Viale \& Alba, 1955: Costa Rica).

Acari, Família Ixodidae

46. Amblyomma cajennense (Fabricius, 1787) - (Dunn, 1918: Panamá).

\subsubsection{Penetração no hospedeiro}

Os ovos de Dermatobia são ligados aos vetores pela extremidade caudal. ficando obliquamente inclinados, de tal modo que sua extremidade cefálica fica imediatamente em contacto com a pele do hospedeiro, quando o vetor pousa sobre este.

Antes da introdução do gado e outros animais domésticos nas Américas, durante o século XVI, Dermatobia parasitava os mamíferos nativos, como onças, suçuaranas, preás, porcos do mato, etc. As citações de aves na literatura, como hospedeiros desta mosca, devem ser atribuídas ao gênero Philornis.

Mesmo antes da emergência da larva, o opérculo do ovo pode ser visto, sob a forma de uma unha; quando aberto, permanece ligado ao córion, pelo que se poderia comparar à raiz da unha.

Quando o ovo entra em contacto com a pele, o opérculo se abre e a larva projeta uma parte de seu corpo de dentro do ovo, movendo-se bastante ativamente. Se não consegue atingir a pele ou um pêlo do hospedeiro, retira-se para dentro do ovo e o opérculo fecha-se novamente. Este efeito pode ser induzido experimentalmente, aproximando-se e afastando-se os ovos da pele (Neiva \& Gomes, 1917).

As larvas levam cerca de uma semana para eclodir e podem permanecer vivas nos ovos por aproximadamente 20-28 dias (Newstead \& Potts, 1925). Podem penetrar na pele logo no primeiro lugar que encontrem ou andar por um certo espaço e então perfurá-la. Townsend (1928) acreditava que as larvas eram incapazes de perfurar a pele do homem e de outros animais se ela fosse lisa e seca; poderiam, entretanto, penetrar, quando a pele estivesse cortada, umedecida, enrugada ou dobrada em pregas. Neiva \& Gomes (1917), ao contrário, afirmavam que esta penetração não depende da resistência ou de solução de continuidade na pele. Não há uma região preferencial para o desenvolvimento das larvas. No homem, as partes descobertas são as mais afetadas; estas podem também se localizar no olho, narinas, etc., causando sérios problemas. Nos animais, principalmente no gado, as regiões dorsal, do pescoço e da cauda, menos acessíveis à língua, são as mais seriamente afetadas (Sambon, 1915).

Koone \& Banegas (1959) dizem que são necessários 1 hora e $15 \mathrm{mi}$ nutos para uma larva entrar na pele do antebraço humano. As larvas penetram até atingir os tecidos subcutâneos, onde ficam em posição quase horizontal, com os estigmas posteriores virados para o lado exterior. Três dias depois desenvolve-se um "furúnculo". Nos primeiros estágios de crescimento larval desenvolve-se no furúnculo um orifício respiratório, muito pequeno, inicialmente, parecendo oferecer pouco acesso ao ar exterior. Posteriormente, esse orifício fica parcialmente oculto por secreções purulentas e outros exsudatos. Ao atingir a maturidade a larva totalmente crescida abandona o hospedeiro, arrastando-se através do orifício respiratório, que ela aparentemente alarga para este objetivo, cai ao solo, onde penetra e empupa.

\subsubsection{Periodo larval}

Não existem dados exatos sobre a duração de cada estágio larval. A partir dos dados de Dunn (1930) as seguintes estimativas podem ser feitas: 

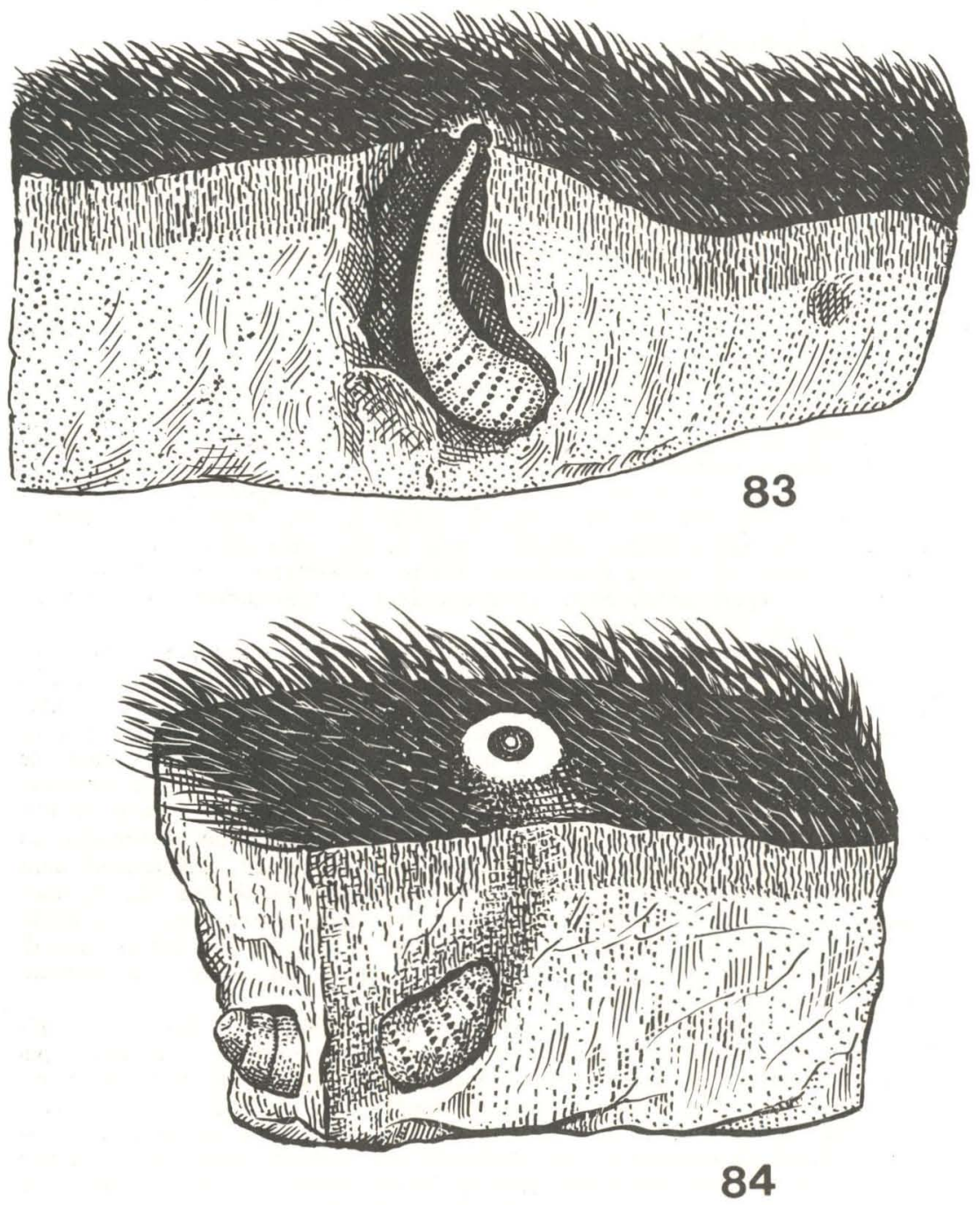

Figs. 83-84: Larvas de Dermatobia hominis (Linnaeus Jr.) em furúnculo na pele do hospedeiro. 


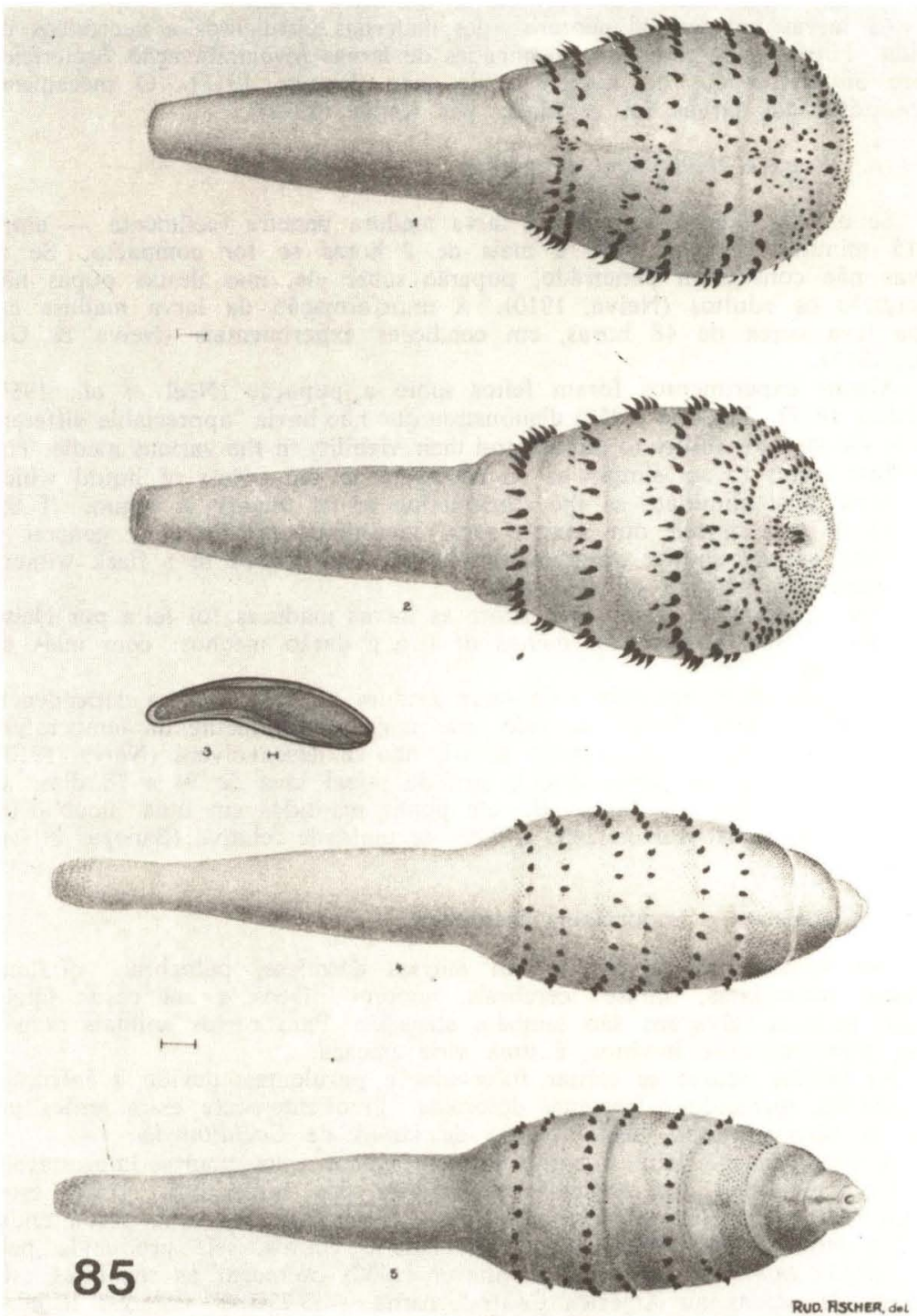

Fig. 85: Ovo e larvas maduras de Dermatobia hominis (Linnaeus Jr.) (apud Neiva, 1914). 
da penetração até a primeira ecdise - 12 dias; da primeira à segunda ecdises - 18 dias; desta até a emergência do hospedeiro - 18 dias, num total de 46-47 dias. No gado a duração do período larval situa-se entre 40-60 dias, dependendo da estação do ano; na estação seca pode durar até 120 dias. A duração média em cobaias é de 35-50 dias; em ratos 30-40 dias; em camundongos 25-35 dias (Jobson \& Mourier, 1972).

As larvas parecem alimentar-se dos materiais purulentos e necróticos da ferida. Filtrados de intestinos esmagados de larvas revelaram ação bactericida sobre Staphylococcus do homem e do gado (Picado, 1935). O mecanismo respiratório das larvas foi estudado por Keilin (1944).

\subsubsection{Pupa e emergência do adulto}

Se o solo é solto e úmido a larva madura penetra facilmente - entre 10-15 minutos (Neiva, 1908) e mais de 2 horas se for compacto. Se as larvas não conseguem penetrá-lo, puparão sobre ele, mas destas pupas não emergirão os adultos (Neiva, 1910). A transformação da larva madura em pupa leva cerca de 48 horas, em condições experimentais (Neiva \& Gomes, 1917).

Alguns experimentos foram feitos sobre a pupação (Neel et al., 1955; Zeledón, 1957). Zeledón (1957) demonstrou que não havia "appreciable differences in the larvae's ability to pupate and their viability in the various media. The substrate seems to act simply as an absorbent of the excess of liquid which the larva must eliminate as the construction of its pupary is begun. If the process is not carried out under such conditions, pupation in general is imperfect, as was shown when mature larvae were placed in a flask without any absorbent material of any kind."

Uma interessante observação sobre as larvas maduras foi feita por Neiva \& Gomes (1917) - as com menos de $0.6 \mathrm{~g}$ darão machos; com mais de $0.6 \mathrm{~g}$ fêmeas.

A profundidade atingida pela larva madura no solo está na dependência direta das condições físicas do solo, mas mais especialmente da temperatura do solo. Se a pupa ficar exposta ao sol, não se desenvolverá (Neiva, 1910)

Em condições de laboratório o período pupal leva de 34 a 78 dias. O período de 34 dias foi observado em pupas mantidas em uma incubadeira a temperatura constante de $24^{\circ} \mathrm{C}$ e $70 \%$ de umidade relativa (Banegas et al., 1967).

\subsection{Patogênese e importância econômica}

No homem, as larvas causam miíases dérmicas, palpebrais, oftalmomiíases, rinomiíases, mí́ases cerebrais, tumores ilíacos e até casos fatais. Vários animais selvagens são também atacados. Para certos animais domésticos, principalmente bovinos, é uma série ameaça.

As feridas podem se tornar infectadas e purulentas, devido a infecções secundárias, tornando-se bastante dolorosas. Freqüentemente essas lesões podem se tornar piores, pela invasão de larvas de Cochliomyia.

A produção de leite e carne torna-se menor e os couros imprestáveis, devido à presença dos orifícios respiratórios dos furúnculos. Todos estes efeitos têm grande importância econômica. Estimou-se que uma perda anual de 200 milhões de dólares em carne, leite e couros, seja produzida pela Dermatobia hominis. Mullison \& Shaver (1960) oferecem as seguintes estimativas de perdas na América Central: carne - 3.250 .000 dólares; leite 450.000 dólares; couros -1.000 .000 de dólares, anualmente.

\subsection{Tratamento e controle}

Durante muitos anos o único método de controle das larvas no gado era a aplicação de rotenona (Laake, 1948), banhos ou pulverização de creolina (Palazzolo, 1916). Para extrair a larva localizada no corpo humano, vários métodos são utilizados, tais como uso de fumo em rolo, toucinho de porco (Smith, 1893), cinza de cigarro (Sauer, 1922), clorofórmio (Folkes, 
1897), cloreto de etila (Price, 1937), ou simplesmente o uso de um esparadrapo no local. Estes métodos atuam obstruindo o orifício respiratório, anestesiando ou matando a larva. Uma vez morta, a larva pode ser retirada com relativa facilidade, pressionando-se o tumor com o polegar e o dedo indicador. Técnicas cirúrgicas foram empregadas nos casos de localizações mais perigosas, como nas of talmomiíases.

Com a descoberta do DDT em 1939 e de novos compostos sintéticos de hidrocarbonetos clorados, foram testados vários produtos no tratamento dos animais domésticos, tais como Lindane (Morales, 1956), Toxafeno (Laake, 1948), DDT (Squibb, 1945), Clordane (Toledo \& Sauer, 1956), Aldrin (Heel, 1954), etc. Estes produtos foram utilizados na forma de banhos, pulverizações, pomadas, etc.

Toledo \& Sauer (1950) registraram que o BHC tem efeito sistêmico contra a larva de Dermatobia no gado. Infelizmente, todos os produtos à base de hidrocarbonetos clorados não podem ser usados indiscriminadamente. Tais inseticidas causam acúmulos de resíduos persistentes no leite ou na gordura dos animais, tornando-os impróprios para o consumo.

Os inseticidas de efeito sistêmico, à base de fósforo orgânico, são atualmente os mais eficientes, pois apresentam resíduos menos persistentes. A Tabela 11.2 mostra os vários produtos utilizados, seus diferentes nomes comerciais e composição química.

A técnica de esterilização de machos, utilizada inicialmente para o controle de Cochliomyia hominivorax, poderia ser de valor no combate ao berne (Knipling, 1964). Banegas et al., (1965) apresentaram uma discussão das possibilidades de erradicação da Dermatobia por este método. Para tal, haveria necessidade de mais pesquisas sobre a biologia desta espécie e a elaboração de um programa de criação em massa.

TABELA 11.2

\section{INSETICIDAS ORGÂNICOS FOSFORADOS SISTEMICOS EMPREGADOS NO CONTROLE DE DERMATOBIA}

1. DDVP (Dichlorvos) - 0-0-dimetil-2-2-diclorovinil-fosfato - Müller, 1962.

2. Ronnel (Trolene, Dow ET-57, Nankor, Korlan, Etrolene, Ectoral, Fenchlorphos) - 0,0-dimetil 0-(2,4,5 - triclorofenil) fosforotioato Graham, Wade, Colby \& McGregor, 1957; Bergamin, 1959; Graham, 1959.

3. Trichlorphon (Dipterex, Dylox, Dyrex, Chlorophos, Bayer L 13/59, Neguvon, Dyvon) - dimetil 2,2,2-tricloro-1-hidroxietil fosfonato - Bolle, 1958; Gliesch, 1959; Mendez Mena, 1960; Mello, Queiroz \& Madureira, 1960; Andersen, 1961; Anon., 1962; Müller, 1962; Anon., 1963.

4. Ruelene (Chloromidate, Montrel, Hypolin) - 0-4-tert-butil-2-clorofenil 0-metil metilfosforamidato - Mullison \& Shaver, 1960; Müller, 1962; Oba et al., 1978.

5. Coumaphos (Co-Ral, Asuntol, Bayer 21/199) - 0,0-dietil 0-3-cloro-4-metil-2-oxo-2 H-1-benzopiran-7-il fosforotioato - Pinheiro \& Baroni, 1953; Laake, 1953; Bolle, 1958; Heirman, 1959; Anon., 1962; Anon., 1963.

6. Dimethoate - 0-0-dimetil-S-(N-metilcarbamoilmetil) fosforotioato - Mello, Queiroz \& Madureira, 1960; Johnson, 1960; Andersen, 1961.

7. Dowco-109 (Narlene) - 0-(4-tert-butil-2-clorofenil) 0-metil metilfosforamidotioato - McGregor \& Wade, 1957; Weaver, Posada, Swanson, Newland \& González, 1958; McGregor, Wade \& Colby, 1958; Anon., 1959; Costa \& Freitas, 1961; Casorso \& Mateus, 1962.

8. Dowco-105 - 0-(4-tert-butil-2-clorofenil) 0-metil etilfosforamidotioato Graham et al., 1958. 


\section{BIBLIOGRAFIA}

Adams, P. C., C. H. Castillo, H. Carlos, A. R. Salmerón \& A. Rodrigo, 1952. Control del tórsalo en Nicaragua. Boln Asoc. gen. Agric. 316: 5-8. (Também em $A$ Fazenda (La Hacienda Co., Inc., N. Y.) 47(4): 46-48, figs., 1952, e La Hacienda 47(1): 54-56, 1952).

Adams, P. C., C. H. Castillo \& R. A. Salmerón, 1952. Application of toxaphene for torsalo fly control. Agric. Chem. 7(12): 33-35, 119, 121, 123, 5 figs.

Adams, P. C., C. H. Castillo \& R. A. Salmerón, 1954. El control del tórsalo en Nicaragua. Revta Consorcio cent. agríc. Manabi 16: 52-54.

Aguilar, F. J., 1958. La Dermatobia hominis (D. cyaniventris) "colmoyote" alcanza grandes proporciones en el país. Revta Col. méd. Guatem. 9(4): 248 , figs.

Alencar, M. de, 1928. Das myiases oculares no homem. Do berne como extrail-o. Ceará méd. 7(4): 5-8. (Resumo em Brasil-med. 43(9): 244, 1929).

Almeida, J. L. de, 1933. Nouveaux agents de transmission de la berne (Dermatobia hominis L. Junior, 1781) au Brésil. C. r. Séanc. Soc. Biol. 113: 1274-1275.

Altamirano, E., 1896. Datos para el estudio de la myiasis cutánea causada por el moyocuil. An. Inst. méd. nac., Méx. 2: 64-69, 82-90, pls. 7-9.

Alves Neto, F., 1949. Toma um novo aspecto a luta contra o berne. De um modo geral está provado que o emprego do canfeno clorado é econômico e eficaz. Revta Criad. 20(6): 37-41, figs.

Alves Neto, F., 1951. Toma novo aspecto o combate ao carrapato e ao berne. Revta Soc. rur. bras. 31: 42-44, figs.

Andersen, E. H., 1960. Biology, distribution and control of Dermatobia hominis. Vet. Med. 55(1): 72-78, figs.

Andersen, E. H., 1961. Systemic insecticides for control of tropical warblefly (Dermatobia hominis) in cattle. J. Am. vet. med. Ass. 139(7): 104-107.

Andersen, E. H., 1962. Control of Dermatobia hominis in Central America. Vet. Rec. 74: 784-787.

Andrade, E. N. de, 1927. Pesquisas sobre o berne, sua freqüência no homem, nos bovinos, suínos e equídeos, e da aplicação de um novo methodo de provavel efficiencia para o seu combate. Bolm biol. Clube zool. Bras. 6:

Andrade, E. N. de, 1929. Pesquisas sobre o berne. Archos Inst. biol. S Paulo 2: 53-60. (Também em Campo, Rio de J. 1(1): 56, 1930).

Andrade, W. J. de, 1958. Caso singular de infestação por môscas do gênero Dermatobia. Publções méd. 30: 85-87, figs.

Anduze, P. J., 1945. Breve nota sobre miasis humana en Venezuela. Boln Ent. venez. 4(1): 37-40.

Anon., 1795. Diccionario portuguez e brasiliano. Officina Patriarchal, Lisboa. (Reimpr. por P. M. da S. Ayrosa, 1934. Revta Mus. paulista 18: 19-319).

Anon., 1890. The man-infesting bot. Insect Life 2: 386.

Anon., 1892. Larve di Dermatobia. Boll. Soc. ent. ital. 24: 96.

Anon., 1910. Os bernes dos animais e sua destruição. Bolm Agric., S Paulo 11(3): 209-217, 4 figs.

Anon., 1916. Vida e costumes do berne. Cha. Qui. 13(6): 422-423, 4 figs.

Anon., 1930. Devemos combater o berne. Fazenda flum. 1(7): 22, 2 figs.

Anon., 1931. Combate ao berne. Bolm Apic. Zootec. Vet. 4(1-3): 90-100.

Anon., 1932. O berne. Agric. Pecuária, Rio de J. 79: 246.

Anon., 1940. A luta contra os bernes e os prejuízos por eles causados às criações. Revta Agric. Piracicaba 15(5-6): 261-263.

Anon., 1941. Berne. Ceres, Minas Gerais 3(15): 167-168.

Anon., 1953. Defesa do gado contra o berne. Sítios Fazendas, S Paulo 19(2): 34-36, 2 fotos, 1 fig.

Anon., 1954. Como combater o berne. Ibid. 20(2): 37-39, 5 figs.

Anon., 1955. Fenotiazina também no combate ao berne. Mundo agríc., S Paulo 4(11): 24-25, 4 figs. 
Anon., 1957. Perspectiva para la extirpación de la Dermatobia en el ganado. Agroquímica (Dow) 2(2): 2.

Anon., 1958. Combate ao berne. Mundo agríc., S Paulo 6(7): 43.

Anon., 1959. New cattle grub systemic. Agric. Res., Wash. 7: 15.

Anon., 1960. Combate à môsca do berne. Sítios Fazendas, S Paulo 26(1): 30, figs.

Anon., 1962. Plano de erradicação do berne. Correio agropec., S Paulo 2(2): 19, 23, 3 figs., 1 gráf.

Anon., 1963. Granjas leiteiras e maior produtividade. Ibid. 2(2): 26-27, 2 figs.

Areba Blanco, J. de, 1955. El gusano de monte, azote de nuestra ganadería. Agric, venez. 19: 34-37, figs.

Arias G., J. M., 1913. El tórsalo. Boln Fom. C. Rica 3(5): 354-357; (7): 503-508; (8): 579-582; (9): 649-655, figs.

Arias G., J. M., 1917. El tórsalo (Dermatobia cyaniventris, Macq.). An. Hosp. San José 2(2): 53-69. (Também em Publ. Dep. Agric. C. Rica 7: 1-19, 6 figs., 1917).

Artigas, P. T. \& R. G. Serra, 1965. Portadores de ovos de Dermatobia hominis (L. Jor., 1781). Atualização da lista de foréticos, com a enumeração de novos agentes transmissores de "berne". Ciênc. Cult., S Paulo 17(1): 21-29.

Arture, (-), 1753. Observations sur l'espèce de ver nommée Macaque. Mém. Acad. r. Sci., Paris 1752: 72-73.

Athanassof, N., 1946. O berne (dermatobiose dos bovinos). Revta Agric., Piracicaba 21(5-6): 227-232.

Azara, F. de, 1809. Voyages dans l'Amérique méridionale, 1: 1x + $389 \mathrm{pp}$. Dentu, Imprimeur-Libraire, Paris.

Bacigalupo, J., 1959. Miasis por Dermatobia hominis Linneo Jr., 1781 diagnosticada por elementos expulsados por presión. Primeras Jorn. ent.epidem. argent. 1: 759-760.

Bacigalupo, J., C. P. Vuidepot \& E. P. Dideigo, 1931. Ueber das Genus Cuterebra Clark (Diptera, Oestridae). Semana méd., B. Aires 48: 555-556.

Baldassare, T., 1924. Contributo all'ophthalmomyiasis. Localizazione palpebrale di larva di Dermatobia cyaneiventris Macq.. 1840. Casistica, osservazione personale, cenni entomologici. Boll. Oculist. 3(7): 663-682.

Baldus, H., 1947. Vocabulário zoológico Kaingang. Arqos Mus. parana. 6: $149-160$.

Balina, P. L., 1917. A proposito de un caso de "ura" (Dermatobia hominis). Prensa méd. argent. 2(22): 293-295, 2 figs.

Ballou, C. H., 1936. El tórsalo. C.N.A. 1(1-2): 24-25.

Banegas, A. D., 1968. Progress report on the rearing of torsalo larvae, Dermatobia hominis (Diptera: Cuterebridae), pp. 7-8 (Resumo), in International Atomic Energy Agency, Panel Proc. Ser., Proc. panel on radiation, radioisotopes and rearing methods of insect pests, organized by the joint FAO/IAEA division of atomic energy in food and agriculture, held in Tel Aviv 12-21 October 1966. Vienna.

Banegas, A. D. \& H. Mourier, 1967. Laboratory observations on the life-history and habits of Dermatobia hominis (Diptera: Cuterebridae). I. Mating behavior. Ann. ent. Soc. Am. 60(5): 878-881.

Banegas, A. D., H. Mourier \& O. H. Graham, 1967. Laboratory colonization of Dermatobia hominis (Diptera: Cuterebridae). Ibid. 60(3): 511-514.

Baroni, P., 1951. Combate prático e eficiente aos carrapatos e bernes do gado bovino. Bolm Campo 7(38): 7-9.

Barraillier, E., 1892. Viaje a Andamarca y Pangoa. Fechado en Jauja a 22 de noviembre de 1892. Boln Soc. geogr. Lima 2(2): 121-144.

Barrett, O. W., 1906. Notes on the man-infesting bot in Mexico. Proc. ent. Soc. Wash. 8: 3-4.

Barros, J. de, 1942. O berne. Bolm Soc. pørt. Ciênc. nat. 13 (Supl. 3): 808816 , figs.

Bates, H. W., 1864. The naturalist on the river Amazons, xii +466 pp., ilus., 1 mapa. I. Murray, London. 
Bates, M., 1943. Mosquitoes as vectors of Dermatobia hominis in eastern Colombia. Ann. ent. Soc. Am. 36(1): 21-24.

Bau, A., 1922. Ueber das technisch-biologische Bedeutung der Oestriden, das verrirte Vorkommen, ihrer Larven, sowie über Oestrus hominis, Hypoderma equi und alcis. Z. tech. Biol. 10(3-4): 177-193.

Beck, A. A. H., H. J. H. de Melo, I. Bianchin \& M. R. J. Soares, eds., 1970. Anais do 1. Seminário Nacional sobre parasitoses dos bovinos, $386 \mathrm{pp}$. Campo Grande.

Belavsky, E. \& I. H. Hrebieck, 1956. How berne and carrapatos damage raw hides. Leath. Trades Rev. 120: 331-332, figs.

Beltram, P. P., 1948. Ha quedado eliminado el problema del nuche; un triunfo de la química en Colombia. Vida rur. 9: 2-3.

Bequaert, J., 1938a. Contribution to the entomology of Yucatan, in the Peninsula of Yucatan. Medical, biological, meteorological and social studies. Publs Carnegie Instn 431: 547-576.

Bequaert, J., 1938b. Notes on the Arthropoda of medical importance in Guatemala. Ibid. 499: 223-228.

Berg, G. H., 1963. El tórsalo. Agricultura El Salv. 4(3): 3-5.

Bergamin, J., 1959. Combate ao berne. "O Estado de São Paulo", (Supl. agríc.), 15. vii. 1959, p. 11.

Bernardez, M., 1910. Quanto perde o Brasil por carrapato e berne? Chacaras Quint. 1(5): 34-35, 1 fig.

Bertoni, G. T., 1915. Hypoderma e a berne ou estro americano. Alm. agric. bras. 1915: $239-242$.

Bertoni, M. S., 1926. La civilización guarani. III. Conocimientos. La higiene guarani y su importancia cientifica y practica. La medicina guarani. Conocimientos cientificos.

Birnbaum, D. \& H. Werner, 1977. Kutane Myiasis durch Dermatobia hominis. Dt. med. Wschr. 102(39): 1385-1386, ilus.

Bishopp, W. A., 1916. Two types of skin myiases. Proc. med. Ass. isthm. Canal Zone 7(2): 87-93.

Blanchard, R., 1892a. Sur les oestrides américains dont la larve vit dans la peau de l'homme. Annls Soc. ent. Fr. (7) 2: 109-154, 12 figs. (Resumo em Insect Life 5(1): 2-3, 1892 e sep. publ., 46 pp., 1892).

Blanchard, R., 1892b. Note additionelle sur les oestrides américains dont la larve vit dans la peau de l'homme. Ibid. (7) 2 (Bull.): ccix-ccxi.

Blanchard, R., 1893. Note sur les larves de Dermatobia provenant du Brésil (Diptère). Ibid. (7) 3 (Bull.): xxiv-xxvii.

Blanchard, R., 1894. Contributions à l'étude des diptères parasites (2e. série). Ibid. (7) 3: 142-160.

Blanchard, R, 1896a. Contributions à l'étude des diptères parasites (3e. série). Ibid. (7) 6: 641-677, pl. 17, figs. 10-13.

Blanchard, R., 1896b. Nouvelles observations sur les larves de Dermatobia noxialis. Bull. Soc. cent. Méd. vét. (n. s.) 14: 527-583, 3 figs.

Blanchard, R., 1904. La Dermatobia cyaniventris existe-t-elle à la Martinique? Revue Méd. Hyg. trip. 1(1-2): 26-29, 2 figs.

Bolle, W. R., 1958. Neue Wege zur Bekämpfung der Dermatobia hominis mit Neguvon und Asuntol. Vet.-med. Nachr. 4: 193-206, figs.

Bolle, W. R., 1960. Nuevos caminos de la lucha contra la Dermatobia hominis con Neguvon y Asuntol. Revta vet. venez. 51(9): 255-257.

Bonnet, G., 1870. Contribution à l'étude du parasitisme. Thèse, Montpellier.

Bordier, G., 1870. La géographie médicale, xxiv + 662 pp., 21 pls. Bibliothèque des Sciences Contemporaines, n. ${ }^{\circ}$ 10. C. Reinwaldt, Libraire-Éditeur, Paris.

Bouvier, G., 1949. Luta contra o berne. Granja, P. Alegre 5(44): 22-23.

Braaksma, H. E., 1956. De muskietenworm, een bijzondere vorm van myiasis. Neds. milit.-geneesk. Tijdschr. 9(3): 65-71.

Braaksma, H. E., 1957. Myiasis caused by Dermatobia hominis in Surinam. Doc. Med. Geogr. Trop. 9(1): 97-99.

Brass, W., 1964. Zur Behandlung der Dermatobialarvenbefalls und der Myiasis 
des Hundes mittels eines Phosphorsäureesters. Dt. tierärztl. Wschr. 71 (13): 356-358, figs.

Brauer, F. M., 1860. Ueber den sogennanten Oestrus hominis und die oftmals berichteten Verrirungen von Oestriden der Säugethieren zum Menschen. Verh. zool.-bot. Ges. Wien 10: 57-72.

Brauer, F. M., 1863a. Beiträge zur Kentniss der Dipteren. II. Dermatobia-Larven aus Felis concolor. Verh. zool.-bot. Ges. Wien 14: 894.

Braver, F. M., 1863b. Monographie der Oestriden, 293 pp., figs. Wien.

Breda, A., 1895. Dermatobia noxialis (Cuterebra noxialis Goudot). Caso clinico. Riv. veneta Sci. nat. 22(10): 467-472, 4 figs.

Briceño-Maaz, T., 1957. El gusano zancudo. Campo, Maracaibo 42: 9-11, figs.

Brooks, H., 1904. A case of Dermatobia hominis with demonstration of larva. Proc. N. Y. path. Soc. (n. s.) 4(6): 128-129.

Bruijning, C. F. A., 1959. Een bijzonder gevaal van myiasis veroorzaakt door Dermatobia hominis (Linnaeus Jr.) in Suriname. Ent. Ber., Amst. 19(1): 7-13.

Brumpt, L. C. \& J. Poulet, 1865. Observations à Paris d'un cas de myiase sous-cutanée à Dermatobia contractée en Guyane. Bull. Soc. Path. exot. 58(1): 88-92.

Busck, A., 1912. On the rearing of a Dermatobia hominis Linnaeus. Proc. ent. Soc. Wash. 14: 9-11.

Calero, M. C., 1948. Cutaneous myiasis in Panama. J. Parasit. 34(4): 343-344.

Calzada, V., 1930. Miasis subcutánea forunculosa por larvas de Dermatobia. Boln Polic. sanit. Anim. 6: 606-616.

Calzada, V., 1940. Sobre existencia de Dermatobia hominis. Boln mens. Dir. Ganad., Montev. 24(4): 430-435, figs.

Camain, R. \& E. Abonnenc, 1948. Sur la myiase à Dermatobia cyaniventris em Guyane Française; rôle vecteur de Aedes taeniorhynchus (Wiedemann, 1821). Publs Inst. Pasteur Guyane 175: 1-3, pl.

Campacci, C. A., 1950. Bernes. Chacaras Quint., S Paulo 81(6): 688-689.

Campos, E., 1927. Berne palpebral, in seu Consultas ophthalmologicas para o medico polyclinico. Rio de Janeiro.

Campos, E., 1929. Ainda a propósito de bernes palpebraes. Bras.-méd. 24.

Campos R, F., 1929. Caso raro de parasitismo de la mosca azul (Dermatobia cyaniventris) en las vecindades rectales de un ratón. Revta Col. nac. Vicente Rocafuerte 11(36-37): 79-80.

Carneiro, G. C. \& G. Drummond, 1941. Estudo preliminar sobre o ataque do gado bovino pelo berne. Bolm Ass. Ex-Alunos Esc. sup. Agric. Est. Minas Gerais 3-4: 45-46.

Carrera, M., 1956. O berne e seu combate. Chacaras Quint. 94(1): 68-70, 1 fig.

Carrera, M., 1964. A môsca do berne. Folha de São Paulo, 23.vi.1964, p. 29.

Carvalho, G. T. de, 1938. Combate aos carrapatos e ao berne. Biológico 4(2): 46.

Casorso, D. R. \& V. Mateus, 1962. Studies on Dermatobia hominis (L. Jr.). I. Comparison of control methods. Am. J. vet. Res. 23(95): 879-883.

Casos, G. A., 1941. Mal de la ura. Campo, B. Aires 25(293): 8-10.

Castellani, A., 1925. Observations on some diseases of Central America. J. trop. Med. Hyg. 27(1): 1-14, 19 figs., 1 pl.

Castro Barona, H., 1954. Tórsalo o gusano de monte. Revta Agric. Comerc. Ind., Panamá 12(15): 26-27.

Castron, I., 1949. Productos contra la-garrapata y el nuche. Revta Agric. Ganad., Cali 11: 27-28.

Céspedes F., R., J. Arguedas S., G. Guillén E. \& G. Hevia U., 1962. Dermatobiosis mortal. Acta med. costarric. 5(3): 175-182, 6 figs.

Cevallos G., M. A., 1951. Investigación sobre el control del "gusano de monte" y "garrapatas" del ganado vacuno, mediante el uso de los insecticidas toxaphene y $\mathrm{BHC}$ en el litoral ecuatoriano. Boln Consorcio cent. agric. Manabí 12: 15-20. 
Chaddah, V. K. \& W. P. Worin, 1966. Cutaneous myiasis. Br. J. clin. Pract. 20: $215-218$.

Chaia, G., G. E. Moya B., L. Chiari, C. N. dos Santos \& R. T. L. Abreu, 1975. Experimental chemotherapy of dermatobiosis in laboratory animals. Revta Inst. Med. trop., S Paulo 17(5): 298-306, 1 fig.

Chaia, G., G. E. Moya B., C. N. Santos \& L. Chiari, 1974. Method of screening of drugs against Dermatobiosis. Proc 3. int. Congr. Parasit., Munich. 1016-1017.

Chanal, L., 1921. Rôle pathogène des moustiques en pathologie humaine et comparée, 91 pp. Lab. Parasit. Fac. Méd. Paris.

Chaves, A., 1936. No plano econômico de sua propagação a berneira transforma outras moscas em "amas secas" de sua prole. Bolm Agric. Zootech. Minas Gerais 9(3): 177-179, 1 fig.

Cheatum, E. L., 1962. Disease and parasite investigations, 75 pp. Final Rep. Fed. Aid Proj. 1-R, Suppl. E. N. Y. Cons. Dep.

Cobó, B., 1593. Historia del Nuevo Mundo. (Editado em 1890 por. M. Jiménez de la Espada - Tomo I da Soc. Bibliófilos Andaluces; 1(1890): viii + 538 pp.; 2(1891): 467 pp.; 3(1892): 350 pp.; 4(1895): 247 pp.; Imp. de E. Rasa, Sevilla).

Cockerell, T. D. A., 1914. Dermatobia in Guatemala. Entomologist 47: 131.

Colmenares, C. R., 1961. Investigaciones geneticas sobre el ganado colombiano "Bon". Revta Vet. Zootec., Manizales 6(5): 40-73.

Condamine, C. M. de la, 1745. Rélation abrégée d'un voyage fait dans l'intérieur de l'Amérique méridionale, depuis de la côte de la Mer du Sud, jusqu'aux côtes du Brésil et de la Guiane, en descendant la rivière des Amazones. Veuve Pissot, Paris.

Coquerel, C., 1859. Note sur une larve d'oestride extraite du bras d'un homme à Cayenne. Revue Mag. Zool. (2)11: 356-361, pl. 12, fig. 2.

Coquerel, C. \& A. Sallé, 1859. Notes sur des larves d'oestrides dévelopées chez l'homme au Mexique et à la Nouvelle Orléans. Ibid. (2) 11: 361-367, pl. 12, figs. $1-4$.

Coquerel, C. \& A. Sallé, 1862. Note sur quelques larves d'oestrides. Annls Soc. ent. Fr. (4)2: 781-794, pl. 19.

Costa, D. A. M., 1876. Estudo zoo-clinico sobre alguns animaes parasitas e venenosos do Brazil. Progresso méd., Rio de J. 1(3): 57-62, 2 figs. (Res. em Gazeta méd. Bahia (2) 1 (12): 554-556; republ. em 1877. Archs Méd. nav. 27: 312).

Costa, H. M. A. \& M. G. Freitas, 1961. Efeito do composto fosforado Dowco-109 (Narlene), administrado pela via oral, sobre a freqüência do berne em bovinos. Arqos Esc. sup. Vet. Minas Gerais 13: 145-156.

Creighton, J. T. \& W. W. Neel, 1952. Biología y combate del tórsalo o nuche, Dermatobia hominis (L. Jr.): Reseña bibliografica. Turrialba 2(2): 59-65, figs.

Curran, C. H., 1939. The human bot-fly. Nat. Hist., N. Y. 44: 45-48, 2 figs. (Res. em Sci. Digest, June 1940).

D'Alessandro, A., 1975. Comparative experiments with Dermatobia in Latin America, pp. 125-126, in K. C. Thompson, ed., Proc. workshop on the ecology and control of the external parasites of economic importance on bovines in Latin America, August 25-30, 1975; C. I. A.T., Cali.

Dalmat, H. T., 1955. Cutaneous myiasis of the scalp due to Dermatobia hominis (L. Jr.) (Diptera, Cuterebridae). Am. J. trop. Med. Hyg. 4(2): 335.

Dao L., L., 1950. Miasis humana en Venezuela: Contribución al estudio de las miasis cutáneas a Dermatobia hominis. Revta Policlín., Caracas 13: 290-310, figs.

Dao L., L., 1963. Miasis cutánea a Dermatobia hominis. Dermatol. trop. 2(3): 158-163.

Dao L., L., 1966. Miasis por "gusano de monte" (Dermatobia hominis). Tribuna méd. 3.

Dawe, M. T., 1922. Efwatakala grass (Melinis minutiflora) as a means for the control of the tsetse fly. Trop. Life 18(5): 69-71, 1 fig. 
Delmanto, A., 1945. Sobre a miíase oftálmica. Tratamento de sua localização intra-orbitária. Publções méd. 155: 17, 19-21, 23-24, 2 figs.

Dikmans, G., 1931. Larvae of Dermatobia collected from sheep in New Mexico. J. Parasit. 18(1): 56.

Disney, R. H. L., 1975. Speculations regarding the mode of evolution of some remarkable associations between Diptera (Cuterebridae, Simuliidae and Sphaeroceridae) and other arthropods. Ent. monthly Mag. 110 (13191321) (1974): 67-74.

Donoso B., R., 1947. Miasis humana en Chile. Consideraciones clinicas y epidemiologicas. Revta chil. Hig. Med. prev. 9(1): 3-60, 10 pls.

Downing, J. D., 1941. Myiasis from the third stage larva of Dermatobia hominis. Archs Derm. Syph. 43(1): 180.

Dugès, A., 1894. (Título desconhecido). "El Universal", Méx., 15.vii.1894.

Dunn, L. H., 1918. The tick as a possible agent in the collocation of the eggs of Dermatobia hominis. J. Parasit. 4(4): 154-158. (Também em Proc. med. Ass. Isthm. Canal Zone 11(1) (1918): 21-25, 1921).

Dunn, L. H., 1924. Prevalence and importance of the tropical warble fly, Dermatobia hominis in Panama. J. Parasit. 20: 219-226.

Dunn, L. H., 1929. Notes on some insects and other arthropods affecting man and animals in Colombia. Am. J. trop. Med. 9(6): 493-508.

Dunn, L. H., 1930. Rearing the larva of Dermatobia hominis Linn. (sic) in man. Psyche, Camb. 37: 327-342, 1 fig., pl. 13.

Dunn, L. H., 1934a. Prevalence and importance of the tropical warble fly, Dermatobia hominis Linn. (sic) in Panama. J. Parasit. 20(4): 219-226.

Dunn, L. H., 1934b. Entomological investigations in the Chiriqui region of Panama. Psyche, Camb. 41(3): 166-183.

Duprey, A. J. B., 1906. The mosquito woms of Trinidad and their real nature. J. trop. Med. Hyg. 9: 22-23.

Dussel, F. F., 1917. Summary and discussion of the work performed at the Board of Health Laboratory during the calendar year 1916. Proc. med. Ass. Isthm. Canal Zone 19(1): 7-25.

Elliott, B., Jr., 1907. A case of Dermatobia noxialis. N. Orl. Med. Surg. J. 60(9): 656.

d'Empaire, A., 1905. Gusano de monte extraido del saco lacrimal. Rev. Benef., Maracaibo ?: ?

Everett, E. D., R. L. DeVillez \& C. W. Lewis, 1977. Cutaneous myiasis due to Dermatobia hominis. Archs Dermat., Chicago 113(8): 1122-1123, ilus.

Fairchild, G. B., 1943. An annotated list of the bloodsucking insects, ticks and mites from Panama. Am. J. trop. Med. 23: 577.

Falcão, E. de C., 1927. Myiase palpebral determinada pela Dermatobia cyaniventris Macq., 1840. Bras.-méd. 41(40): 1038-1042; (47): 1237-1238.

Falcão, E. de C., 1929. Considerações acerca das ophthalmomyiases determinadas pela Dermatobia cyaniventris Macquart, 1840. Ibid. 43(38): 1134-1138.

Falcão, E. de C., 1933. Rino-miíase por Dermatobia cyaniventris (Macquart). Revta oto-lar. S Paulo 1(6): 461-463.

Ferrari, A., 1929. Considerações sobre a ophthalmomyiasis determinada pela Dermatobia cyaniventris Macquart, 1840. Bras.-méd. 43(47): 1428.

Ferrari, A., 1939. Berne e myiases. Ibid. 53(22): 793-794.

Ferraris, J. B., 1915. La ura. Revta Fed. rur. Urug. 44(6): 363-365.

Ferraris, J. B., 1917. Dermatobia noxialis. Revta min. ind., Linares 5(32): 489-493, figs.

Fiasson, R., 1945. Notes sur les parasites animaux du Haut-Apure (Venezuela). Revue Sci. méd. pharm. vét. Afr. fr. libre 2(2): 125-151, 5 pls., mapa.

Finch, F. H., 1937. Some notes on the South American warble fly. Pastoral Rev. Grazier's Rec. 47(7): 773-774, ilus.

Fischer, H. C., 1922. Entomological report. Rep. Hlth Dep. Panama Canal Zone 1921: 59-60.

Fischer, J. B., 1866. Answer to correspondents. Pract. Entomologist 1(10): 102.

Flew, G. P. \& J. H. Grundy, 1967. Infection with Dermatobia hominis 
occurring in British Guiana. Il R. Army med. Cps 113(3): 148-155, 3 figs.

Floch, H. \& E. Abonnenc, 1944. Sur la myiase à Dermatobia cyaniventris en Guyane Française. Rôle vecteur de Mansonia titillans. Publs Inst. Pasteur Guyane 85: 1-3, figs.

Floch, H. \& P. Fauran, 1954a. Mansonia fasciolata (Lynch Arribálzaga, 1891) vecteur des oeufs de Dermatobia cyaniventris (Macquart, 1840) en Guyane Française. Archs Inst. Pasteur Guyane 15: 114, fig.

Floch, H. \& P. Fauran, 1954b. Les vecteurs de la myiase furunculeuse en Guyane Française. Bull. Soc. Path. exot. 47(5): 652-656, 13 figs.

Folkes, M. M., 1897. The gusano worm and its treatment. Med. Rec., N. Y. $51(2): 50$.

Folling, B. N., 1953. Tórsalo puede y debe controlarse. Revta Agric., Comerc. Ind., Panamá 9: 24-26.

Fonseca, F. O. R. da, 1929. Diário de uma viagem ao oriente da Bolívia, de Porto Esperança a San José de Iquitos. Mems Inst. Oswaldo Cruz 22: $175-222$, pls. $52-108$.

Forel, A. H., 1896. Ueber Dermatobia noxialis. Verh. schweiz. naturf. Ges. 1896: $150-152$.

Forero, G. L., 1956. El género Cryptolucilia sp., nuevo huésped vector de la Dermatobia cyaniventris en Colombia. Revta Fac. Med. vet. zootéc. Univ. nac. Colomb. 21: 445-448, 1 fig.

Foresti, F., E. de Lello \& L. A. Toledo, 1972. Cultura de Dermatobia hominis (Lin. Jr.) em laboratório. Ciência Cult. 23 (Supl.): 266.

Foster, R. T., 1928. Myiasis dermatosa (Dermatobia hominis). Vet. Bull. (mimeo. supl. to Army med. Bull.) 222(2): 67-68.

Fróes, H. P., 1936. Sobre a multiplicidade dos veiculadores da Dermatobia hominis, "mosca do berne". Revta méd. Bahia 4(3): 52-58, figs. (Também em Trabalhos 1. ${ }^{\circ}$ Congr. reg. Med. Bahia: 184-186, 1937).

Gallo, P., 1938. Importantes datos sobre el tórsalo. "La Prensa", Managua, 19.ii.1938, p. 2, fig. 2.

Gann, T. W. T., 1902. Beef-worm in the orbital cavity. Lancet, Lond. 1: 19-20, 3 figs. (Também em J. trop. Med., Lond. 5(7): 114-115, 3 figs., 1902; res. em N. Y. med. J. 79(3): 125, 1902 e Phila. Med. J. 9(9): 161).

Garcia Suárez, J. \& I. Tagle Villarroel, 1956. Myiasis por Dermatobia cyaniventris (Macquart 1840) en caballos chilenos llevados al extranjero. Boln chil. Parasit. 19(4): 77-78, (1955).

Gemignani, E. V., 1945. "La ura" Drematobia cyaniventris. Chacra 16: 84, fig.

Gerstaecker, C. E. A., 1868. Ueber von Dr. Hensel beobachtete OestridenLarven bei Säugethiere und Menschen in Süd-America. Sber. Ges. naturf. Freunde Berl. 1867: 31-32.

Giglio, H. E., A. Actis Dato \& H. J. Borrone, 1950. Tumoración ilíaca por miasis cutánea por larva de Dermatobia hominis (Linn.) (sic). Revta Asoc. bioquim. argent. 15: 245-250, figs.

Gilij, P. S., 1780-1784. Saggio di storia americana, o sia storia naturale, civile e sacra de' regni e delle provincie spagnuole di Terra-Ferma, nell'America meridionale, descritta dall'Abate Filipo Salvatore Gilij e consacrata alla Santità del N. S. Papa Pio Sesto felicemente regnante, 1 (1780: storia geografica e naturale della provincia dell'Orinoco); 2 (1781; Costumi degli Orinochesi); 3 (1782; Religione e delle lingue degli Orinochesi e di altri americani); 4 (1784; Stato presente di Terraferma). Luigi Perego Erede Salvioni. Roma.

Giovine, N., 1950. Mais um grande passo na solução do problema do berne no Brasil. Agric. e Pecuária 21: 58-59.

Gliesch, R., 1959. Versuche mit Neguvon zur Bekämpfung der Dermatobienlarven. Vet.-med. Nachr. 3: 162-164.

Gmelin, J. F., 1788. Caroli à Linné Systema Naturae, per regna tria naturae, secundum classes, ordines, genera, species, cum characteribus et differentiis (ed. 13), 1(5): 2225-3220. Laur. Salvii, Holmiae. 
Gnaegi, H., 1951. Metamorfosis completa del tórsalo y su control en los trópicos. Revta Agric. Comerc. Ind. Panamá 9: 24-25.

Goldman, L., 1946. Pyodermic myiasis in children. Observations with special reference to torsalo. Am. J. Dis. Child. 69(5): 280-283, 3 figs.

Gomes, C. E. S., 1946. Como se dá a infestação dos animais pelo berne e como combatê-lo. "Folha da Manhã", S Paulo 23.ii.1946.

Gonçalves, N. B., 1943. O emprego do "timbó" na prophylaxia do berne. Chacaras Qui. 49(4): 417-418, fig.

Gonzales, J. E., 1865. La mosca hominivora. These, Monterey.

Gonzales, J. E., 1867. La mosca hominivora. Gac. méd. Méx. 3(9): 149-155.

Gonzales Rincones, R., 1912-1913. El aeroplano guatemalteco del gusano macaco. El Universal, Caracas, xi.1912, 12.xii.1913 (Também em Gonzales Rincones \& Guyon, 1953, q. v.).

Gonzales Rincones, R., 1936. Acerca de los progresos en el estudio de la Dermatobia cyaniventris. Revta chil. Hist. nat. 40: 54-56.

Gonzales Rincones, R., 1939. Esquema evolutivo de la Dermatobia cyaniventris. Boln Acad. Cienc. exact., Madr. 4(18): 103-107, 1 pl.

Gonzales Rincones, R. \& L. Guyon, 1953. Clasificación general de los dipteros, 234 pp., 62 figs. Univ. Centr. Venez., Caracas.

Goudot, J., 1844. Observations sur un diptère exotique dont la larve nuit aux boeufs (le cuterèbre nuisible). Bull. Soc. ent. Fr. 1844: xli.

Goudot, J., 1845. Observations sur un diptère exotique dont la larve nuit aux boeufs (le cuterèbre nuisible). Annls Sci. nat. (3) 3: 221-230, pl. 4bis, figs. 1-6.

Gradenigo, P., 1894. Caso di Dermatobia noxialis osservato in un bambino lattante. Atti Ist. veneto $52[=7(5)]$ : 965-968, pl. 3 (1893-94). (Também em Atii XI Congr. Med. int., Roma 6 (Oftalm.): 40-42, 1895).

Graff, S., 1925. Larve der Bremse Dermatobia cyanoventris (sic). Münch. med. Wschr. 72(50): 2171.

Graham, O. H., 1959. Cattle grub control with systemic insecticides. SWest. Vet. 12: $267-270$.

Graham, O. H., 1964. Problems in livestock control of mutual interest to Mexico and the United States. Folia ent. mex. 7-8: 71.

Graham, O. H., P. Kraemer \& O. Alejandro, 1958. Control del tórsalo (Dermatobia hominis, L. Jr.) con insecticidas orgánicos fosforados de acción sistémica. Turrialba 8(4): 153-157.

Graham, O. H., P. Kraemer \& A. Osorio, 1960. Contrarresto del tórsalo con insecticidas orgánicos fosforados sintéticos. La Hacienda (La Hacienda Co., Inc., N. Y.) 55(10): 43-45.

Graham, O. H., L. L. Wade, R. W. Colby \& W. S. McGregor, 1957. Use of Dow ET-57 for systemic control of Dermatobia hominis in cattle. Agric. Chem. 12(10): 51, 109.

Greene, C. T., 1956. Dipterous larvae parasitic on animals and man and some dipterous larvae causing myiasis in man. Trans. Am. ent. Soc. 82(1): 17-34, 21 figs.

Grube, E., 1860. Beschreibung einer Oestridenlarve aus der Haut des Menschen. Arch. Naturgesch. 26: 9-16, pl. 1, figs. 4-5. (Também em Arb. schles. Ges. Vaterl. Kultur 1859: 25).

Günther, K., 1931. A naturalist in Brazil. The flora and fauna and the people of Brazil, 400 pp., ilus. G. Allen \& Unwin Ltd., London.

Guérin, (-), 1833. Larves d'oestres chez l'homme. Institut, Paris 1: 50.

Guevara Rojas, F., 1903. (?). Curios. pat. 10: ?

Guimarães, J. H., 1966. Nota sobre os hábitos dos machos da Dermatobia hominis (Linnaeus Jr.) (Diptera, Cuterebridae). Papéis Avulsos Zool., $S$ Paulo 18: 277-279.

Guimarães, J. H., 1967. Family Cuterebridae, in Departamento de Zoologia, Secretaria da Agricultura, A Catalogue of the Diptera of the Americas south of the United States 105: 1-28. São Paulo.

Guimarães, J. H. \& N. Papavero, 1966. A tentative annotated bibliography 
of Dermatobia hominis (Linnaeus Jr., 1781) (Diptera, Cuterebridae). Arqos Zool., S Paulo 14(4): 223-294, 2 pls.

Guyon, M., 1835. Mémoire pour servir à l'histoire naturelle et médicale du ver macaque, écrit à la Martinique en 1823. Bull. Soc. Sci. Arts Let. Dep. Var 3(2-4): 142-156.

Guyon, G. 1839. Nouvelles observations sur le ver macaque. Gaz. méd. Paris $7(20): 315$.

Hambleton, E. J., 1957. Resumé of the life-history and control of the torsalo, Dermatobia hominis. 12 pp. Plant Pest Control Branch, Agric. Res. Serv., Washington, D. C.

Harrel, W. B. \& V. Moseley, 1942. Surgical treatment of subdermal myiasis due to Dermatobia hominis. Sth. med. J., Nashville 35: 720-723.

Hecht, O., 1944. Algunas experiencias en la cría de la Dermatobia hominis y la de su larva. Mems 2. Congr. mex. Med. (Méx., 1947): 571-578.

Hecht, O., 1951. Beiträge zur Biologie der neotropischen Dasselfliege Dermatobia hominis L. (sic). Z. ParasitKde 15(2): 109-118.

Heirman, A. L., 1959. Enkele gegeven over de bestrijding van dierlijke ectoparasieten in Panama (Ervaringen met Asuntol, een nieuw tekensbestrijdingsmiddel). Tijdschr. Diergeneesk. 84: 1026-1028.

Herrera, M., 1923. Guia para visitar la colección de los aracnideos, miriapodos $e$ insectos, con especial indicación de los artropodos nocivos al hombre y a la agricultura, 200 pp., 59 pls. Secr. Agric. Fomento Méx. [P1. 27: Dermatobia (moyocuil)].

Herzog, M., 1899. A case of Oestrus hominis. Med. News, N. Y. 74(9): 268. (Também publ. sep. 3 pp., N. Y., 1899).

Hill, N. T., 1830. Account of the larva of a supposed Oestrus hominis, or gad-fly, which deposits its eggs on the bodies of the human species, with the particulars of a case. Edinb. new philos. J. 22: 284-288, 1 fig. (Também em London's Mag. nat. Hist. 5: 483).

Hodson, H. S. \& D. E. Reed, 1966. La industria lechera en la America tropical. Capítulo XIV. Enfermedades y parásitos del ganado. Importancia de las enfermedades y parásitos de los animales. Méx. avíc. agropec. 40(4): 190-192, figs.

Hope, F. W., 1840. On insects and their larvae occasionally found in the human body. Trans. ent. Soc. Lond. 2: 256-271, pl. 22, figs. 1-5.

Howship, J., 1833. An account of two cases of inflammatory tumour produced by a deposit of the larva of a large fly (Oestrus humanus) beneath the cutis in the human subject; accompanied with drawings of the larva. Proc. ent. Soc. Lond. 12: 181.

Howship, J., 1835. Some account of two cases of inflammatory tumour produced by a deposit of the larva of a large fly (Oestrus humanus) beneath the cutis in the human subject; accompanied with drawings of the larva. Med. Q. Rev. (5) 3: 174-179, 1 pl., 3 figs.

Huber, I. C., 1899. Bibliographie der klinischen Entomologie (Hexapoden, Acarinen) 3 (Diptera. Muscidea und Oestriden; Sarcophila, Sarcophaga, Calliphora, Anthomyia, Musca, Lucilia, Trichomyza, Compsomyia, Hypoderma, Dermatobia, Ochromyia), (1) +29 pp. Jena.

Hubler, W. R., J., A. H. Rudolph \& E. F. Douglas, 1974. Dermal myiasis [D. hominis]. Arch. Dermat. 110(1): 109-110.

Hugh-Jones, M. E., 1962. Dermatobioses in cattle in South America. Vet. Rec. 74(35): 961.

Humboldt, A. von, 1807. Voyage de Humboldt et Bompland. lre. partie: Physique générale et rélation historique du voyage. Paris.

Jacobs, J. C., 1882. De la présence des larves d'oestrides et de muscides dans le corps de l'homme. C. r. Soc. ent. Belg. 27: cl-clxiii. (Também em Bull. Soc. ent. Belg. (3) 25: cl-clvi, 1893).

Jacobs, J. C., 1883. On the presence of oestridean and muscidean larvae in the human body. Translated, with foot-notes, references and remarks, by T. S. Cobbold. Veterinarian, Lond. 29(4) [= vol. 56]: $10-12,81-83,156-159,234-236$, pls. 1-2; pp. 307-310. 
James, J. F., 1889. A human parasite. Am. Nat. 23: 65.

Janzen, D. H., 1976. The occurrence of the human warble fly (Dermatobia hominis), in the dry deciduous forest lowlands of Costa Rica. Biotropica 8(3): 210.

Jobsen, J. A., 1974. Onderzoek over de toepassing van de steriele mannet jes techniek bij Dermatobia hominis (L. Jr.). Ent. Ber., Amst. 34(1): 1-3.

Jobsen, J. A. \& H. Mourier, 1972. The morphology of the larval instars and pupa of Dermatobia hominis L. Jr. (Diptera: Cuterebridae). Ibid. 32(11): 218-224, 6 figs.

Johnson, W. P., 1960. The effect of dimethoate on Dermatobia hominis in cattle. Am. J. vet. Res. 21: 1046-1048.

Joly, N., 1846a. Recherches zoologiques, anatomiques, physiologiques et médicales sur les oestrides qui attaquent l'homme, le cheval, le boeuf et le mouton. Annls Soc. Phys. Nat. Soc. Agric. Lyon 9: 157-305, 8 pls. (Res. em C. r. hebd. Séanc. Acad. Sci., Paris 23(10): 510-513).

Joly, N., 1846b. Note sur l'existence des larves d'oestrides chez l'espèce humaine. Mém. Acad. Sci. Inscript. Toulouse 1846: 20. (extrato de 1846a).

Joly, N., 1846-48. Recherches zoologiques, anatomiques, physiologiques et médicales sur les oestrides en général et particulièrement sur les oestres qui attaquent l' homme, le cheval, le boeuf et le mouton. J. vét. Midi 9: 508-518, 560-568, 1846; 10: 22-39, 124-136, 267-279, 316-332, 502-509, 1847; 11 (= Ser. 2, vol. 1): 188-203, 1848 .

Joly, N., 1879. Les oestrides, notamment ceux qui attaquent l'homme, le cheval, le boeuf et le mouton. Nature, Paris 7: 74-76, 90-94, 287-290, 343-344, 358-359, figs.

Jousseaume, F. \& J. P. Mégnin, 1884. Note sur la présence d'une larve d'oestride (Dermatobia noxialis J. Goudot) chez l'homme, à Paris. Bull. Soc. zool. Fr. (6) 9: 114-116.

Juzarte, T. J., 1769-70. Diario da navegação do Rio Tieté, Rio Grande Paraná, e Rio e Gatemy em que se dá Rellação de todas as cousas mais no. taveis destes Rios, seu curso, sua distancia, e de todos os mais Rios que se encontrão, Ilhas perigos, e de todo o acontecido neste Diario, pelo tempo de dous annos e dous mezes. Que principia em 10 de Março de 1769. MS na Biblioteca do Museu Paulista, Univ. S. Paulo. (Editado por A. d'E. Taunay, 1922, Anais Mus. paul. 1(2): 31-118).

Katiyar, K. P., F. Ferrer \& C. Moya, 1967. Studies on the biology, morphology and sterilization of the tropical warble fly, Dermatobia hominis L. Jr., in the application of nuclear energy to agriculture. Trien. Rep. (1963-1966) Inter-Am. Inst. agric. Sci. OAS Training and Res. Cent.: 84-103. Turrialba.

Kaye, H. D. L. \& R. P. Higgins, 1964. Human botfly infestation in the United States. J. Am. med. Ass. 189(1): 64.

Keferstein, G. A., 1837. Naturgeschichte der schädlichen Insecten nach eigenen fremden Beobachtungen 1 (Die den Menschen und den Thieren schädlichen Insecten): $8+346$ pp. Keyser, Erfurt.

Keferstein, G. A., 1856. Ueber Oestrus hominis. Verh. zool.-bot. Ges. Wien 6: 637-652.

Keilin, D., 1944. Respiratory systems and respiratory adaptations in larvae and pupae of Diptera. Parasitology 36(1-2): 1-66, 54 figs.

Keshishian, J. M., 1976. Infestation by Dermatobia hominis. J. Am. med. Ass. 235(10): 1003.

Keyt, F. T., 1900. A case of "beef worm" (Dermatobia noxialis) in the orbit. Br. med. I. 1: 316, 2 figs.

Kirschmann, S., 1881. Oestrus-Larven beim Menschen. Wien. med. Wschr. 31(49): 1370-1371.

Knab, F., 1913. The life history of Dermatobia hominis. Am. I. trop. Dis. prev. Med. 1(6): 464-468.

Knab, F., 1916. Egg-disposal in Dermatobia hominis. Proc. ent. Soc. Wash. 18: $179-184$

Koone, H. D. \& A. D. Banegas, 1959. Biology and control of Dermatobia 
hominis in Honduras (Diptera: Cuterebridae). J. Kans. ent. Soc. 32(3): 100-108.

Kremer, M., C. Rebholtz \& J. P. Rieb, 1978. Iconographie des plaques stigmatiques de Dermatobia hominis Linné Jr. $(=D$. cyaniventris Macquart 1843). Ann. Parasit., Paris 53(4): 439-440, 4 figs.

Laake, E. W., 1948. Livestock parasite control investigations and demonstrations in Brazil. J. econ. Ent. 42(2): 276-280.

Laake, E. W., 1954. Torsalo and tick control with toxaphene in Central America. Ibid. 46: 454-458.

Laat, (-) van der, 1913. Algunas notas sobre otra plaga del ganado. El tórsalo. Boln Fom., C. Rica 3: 264-266.

Laboulbène, A., 1861a. Description et figure d'une larve d'oestride de Cayenne, extraite de la peau d'un homme. Annls Soc. ent. Fr. (4) 1: 249-253, pl. 7, figs. 19-21. (Também em Gaz. méd. Paris (3) 16(31): 66-68).

Laboulbène, A., 1861b. Rapport sur une larve d'oestride extraite de la peau d'un homme à Cayenne. C. r. Séanc. Soc. Biol. 3 (1860): 161-166.

Laboulbène, A., 1883a. (Larve d' un diptère parasite, la Dermatobia noxialis) Bull. Soc. ent. Fr. 1883: xcii.

Laboulbène, A., 1883b. Examen de la larve vivante d'un insecte diptère du Brèsil (Dermatobia noxialis) observée à Paris. Bull. Acad. Méd. (2) 12 (= vol. 47): 729-731.

Laboulbène, A., 1889. Larve de Dermatobia sortie d'une plaie humaine. Bull. Soc. ent. Fr. 1889: lxiv.

Lagleyze, P., 1914. (D. hominis). Boln Soc. Oftalm., B. Aires 1(1): 15.

Lahille, F., 1915. Nota sobre la "ura" y otras larvas dañinas de dipteros, 18 pp., 7 figs., 2 pls. Minist. Agric., B. Aires.

Lane, J., 1936. Notas sobre mosquitos de São Paulo. Bolm Inst. Hyg. Fac. Med. vet. Univ. S Paulo 60: 3-15, 14 figs.

Leão, R. L., 1961. Dermatobiose, o "berne" e meios de combate. Revta Soc. rur. bras. 41: 22-24.

Lello, E. de, 1972. Observações dos elementos figurados da hemolinfa do berne, Dermatobia hominis (Lin. Jr.) (Diptera, Cuterebridae), pp. 187 197, in C. C. M. Landim, N. J. Hebling, E. de Lello \& C. S. Takahashi, eds., Livro de homenagem a Warwick E. Kerr. Fac. Ciênc. méd. biol. Botucatu.

Lello, E. de, 1978. Reação inflamatória causada pelo berne em coelhos imunizados ou não com extrato antigênico de Dermatobia hominis. Ciência Cult. 30(7) (Supl.): 582.

Lello, E. de, N. G. S. Mota \& M. T. S. Serrão, 1976a. Imunização de coelhos por extrato antigênico de berne, D. hominis (Diptera, Cuterebidae). I. Ciência Cult. 28(7) (Supl.): 249.

Lello, E. de, N. G. S. Mota \& M. T. S. Serrão, 1976b. Comportamento de coelhos imunizados com extratos de berne (D. hominis), frente às larvas desse parasita. II. Ibid. 28(7) (Supl.): 249.

Lello, E. de, N. G. S. Mota \& M. T. S. Serrão, 1977. Circulating antibodies and inflamatory reaction to larvae in rabbits immunized with homogenized larvae of Dermatobia hominis. Proc. informal Conf. "Vertebr. Resist. Arthrop. Parasit.”, 26-29. XV Int. Congr. Ent., Washington, D.C.

Lello, E. de, L. A. Toledo \& F. Foresti, 1971. Cromossomos somáticos do berne Dermatobia hominis (Lin. Jr.) (Diptera: Cuterebridae). Ciência Cult. 23 (Supl.): 427.

Lello, E. de, L. A. Toledo \& F. Foresti, 1974. Chromosomes of Dermatobia hominis (Linnaeus Jr., 1781) (Diptera, Cuterebridae). Caryology 27(2): $161-167,11$ figs.

Lima, J. P., 1942. Como combater o berne. Serv. Inf. agríc. Min. Agric., Rio de J.

Lima, S.S.S., 1979. Considerações em torno de um caso de berne palpebral. Bras.-méd. 21: ?

Linnaeus, C., Jr., 1780. (Carta a Dru Drury, 10 de março de 1780), p. xi, in D. Drury, 1837. Illustrations of exotic entomology, containing upwards 
of six hundred and fifty figures and descriptions of foreign insects 1: 126 pp. London.

Linnaeus, C., Jr., 1781. (Mittheilungen über Oestrus hominis). Pallas' Neue nord. Beytr. Phys. Geogr. Erd. u. Völk. 1: 157-158.

Logan, D., 1892. The bot-fly of human beings. Insect Life 5: 58-59.

Lombardero, O. J. \& B. A. J. Fontana, 1968. La "ura" (Dermatobia hominis) en la Provincia de Formosa. Gac. vet. 30(215): 297-306, figs., 1 mapa.

Londres, (-), 1854. On insect larvae under the human skin. Mon. med. J. 13: 371.

Lopes, H. S., 1938. Sur quelques diptères porteurs d'oeufs de la Dermatobia hominis L. Jr. au Brésil (Dipt. Oestridae). C. r. Séanc. Soc. Biol. 129: 427.

Lowry, W. L., 1954. Combata al torsalo, las garrapatas y piojos que atacan a sus animales. Circ. Min. Agric. y Ganad. Stan. 18: 1-6.

Ludwig, P. D., L. L. Wade \& R. J. Shaver, 1967. Biological activity of Ruelene against Dermatobia hominis (torsalo) and Boophilus. Folia ent. mex. 15-16: 58.

Lugger, O., 1897. Parasites of man and domesticated animals. Minn. St. Exp. Stn Ent. A. Rep. 2(1896): 44-231, figs. 24-187 (incl. partes das pls. 6-7 e todas as pls 9-13 e 16).

Lutz, A., 1917. Contribuições ao conhecimento dos oestrideos brazileiros. Mems Inst. Oswaldo Cruz 9: 94-113, pls. 27-29.

McGregor, W. S. \& L. L. Wade, 1957. El Narlene para el control de la Dermatobia en el ganado. Agroquímica (Dow) 2(2): 4-5.

McGregor, W. S., L. L. Wade \& R. W. Colby, 1958. Systemic control of Dermatobia hominis (L. Jr.) in Central and South American cattle with Narlene insecticides. J. econ. Ent. 51: 724-725.

McIver, S. B., et al., 1971. Cutaneous myiasis by Dermatobia hominis. J. Can. med. Ass. 104: 771.

Macquart, J. S., 1843. Diptères exotiques nouveaux ou peu connus 2(2): 309 pp., 36 pls. Roret, Paris.

Magalhães, P. S., 1892. Subsidio ao estudo das myiases, 82 pp. Typographia do Brazil, Rio de J. (Res. em Gazeta méd. Bahia (4) 3(2): 86-89, e em Zentbl. Bakt. ParasitKde 14: 370-371, 1893).

Magalhães, P. S., 1895. (Dermatobia). Bull. Soc. zool. Fr. 20(5): 116-118.

Magalhães, P. S., 1896. Observations sur les dermatobies (Extrait d'une lettre addressée à R. Blanchard). Ibid. 21(8): 178-179.

Magalhães, P. S., 1897. O berne. Uma nova phase no estudo do berne. "Jornal do Commercio", Rio de J., 2.ii.1897 (também publ. sep., 77 pp., Rio de J., 1897).

Magalhães, P. S., 1897b. Subsidio ao estudo das myiases, o berne. Uma nova phase no estudo do berne. Gazeta méd. Bahia 1(11): 508-520.

Magath, T. B., 1920a. Dermatobia hominis. Program Abstr. Pap. Am. Soc. Zool. (18th A. Meet.): 38.

Magath, T. B., 1920b. Dermatobia hominis. Archs Derm. Syph. 2(6): 716721, 4 figs. (Res. em Trop. Dis. Bull. 18(1): 28 e em Anat. Rec. 20(2): 206).

Manchiamelo, G. J., 1942. La ura en el territorio nacional de Misiones, N. y E. de la Provincia de Corrientes. Boln téc. N. A. N. 5: 275-297.

Mañé-Garzón, F., J. M. Tiscornia \& F. C. Gonzalez, 1962. Miasis forunculosa por larvas de Dermatobia en el niño. Archos Pediat. Urug. 32(1): 22-29, 2 figs.

Manget, J. D., 1909. Dermatobia noxialis infection; report of a case contracted in southern Mexico. Med. Rec., N. Y. 75(26): 1100-1101, 2 figs.

Marsden, P. D., A. J. Shelley \& P. Armitage, 1977. O número de larvas de Dermatobia hominis nos couros do gado tipo zebu de diferentes cores. An. XIII Congr. Soc. bras. Med. trop.: 350.

Marsden, P. D., A. J. Shelley \& P. Armitage, 1979. The number of Dermatobia hominis lesions in zebu cow hides of different colors. Trans. R. Soc. trop. Med. Hyg. 73(4): 458-459.

Martins, A., 1929. Berne ocular - myiase nasal. Bras.-méd. 26: ? 
Martius, C. F. P. von, 1863. Beiträge zur Ethnographie und Sprachenkunde 2 (Zur Sprachenkunde. Glossaria linguarum brasiliensium. Glossarios de diversas lingoas e dialectos, que fallão os indios no Imperio do Brazil), 548 pp. Junge \& Sohn, Erlangen.

Matas, R., 1887. Report of a case of a patient from whose subcutaneous tissues three larvae of a species of Dermatobia were removed, with remarks. New Orl. med. surg. J. (n. s.) 15(3): 161-179, 4 figs.

Matas, R., 1888. A man-infesting bot. Insect Life 1: 76-80, 3 figs. (Res. de 1887). Mateus V., G., 1975. Ecology and control of Dermatobia hominis in Colombia, pp. 117-123, in K. C. Thompson, ed., Proc. Workshop on the ecology and control of the external parasites of economic importance on bovines in Latin America, August 25-30, 1975. C. I. A. T., Cali.

Mateus V., G., 1979. Dermatobiosis, pp. 315-329, 331-333 (questões e sugestões, in Beck, et al., q. v.

Matos, A. C. da C., 1957. Combate ao berne. Biológico 23: 246.

Matta, A. A. da, 1919. Considerações sobre a dermatobiose. Notas de um estudo apresentado à Sociedade Brasileira de Sciencias. Revta Acad. bras. Sci. 4(3): 84-92, 16 figs. (Res. em Rev. appl. Ent. (B) 10(8): 156, 1922).

Matta, A. A. da, 1920. Considerações sôbre a dermatobiose (ura ou berne) no Brasil. Amazonas méd. (2) 3(9): 2-15, 1 pl.

Mazza, S. \& M. de los Ríos, 1931. Primera comprobación de miasis cutánea por Dermatobia hominis en Jujuy. 7. Reun. Soc. argent. Pat. reg. 2: 787-796, 8 figs.

Mazza, S. \& A. J. Señorans, 1936. Miasis forunculosa por Dermatobia hominis en el Chaco. Reun. Soc. Pat. reg. Norte 2: 479-481, 2 figs.

Meaden, C. W., 1892. The so-called mosquito worm. J. Trin. Fld Nat. Club 1 (4): 91-93.

Mégnin, J. P., 1884. Un deuxième cas de tumeur causée par une larve d'oestride observée en France chez l'homme. C. r. Séanc. Soc. Biol. (8) 1(11): 143-145.

Mejía, J. M., 1952. La garrapata y el nuche sangran la economía. Boln Agric. Medellin 383: 3339-3340.

Mello, D., J. C. Queiroz \& F. Madureira, 1960. Efeito de 0,0-dimetil-S-alfa-mercapto-N-metilacetamido-ditio-fosfato em larvas de Dermatobia hominis e no carrapato Boophilus microplus, em bovinos. Arqos Inst. Biol., S Paulo 27: 43-49.

Mendez Mena, M. M., 1960. El neguvón en el tratamiento de la Dermatobia hominis. Revta Med. vet. Parasit., Maracay 18(1-8): 111-124.

Meyer, J. R., 1943. Ação direta do alho sobre o berne (Dermatobia hominis). Biológico 9(11): 379-382.

Meyer, J. R., 1943. O alho no tratamento do berne. Ibid. 9(7): 163-168.

Miles Stuart, P., 1919. Nota sobre un caso de una enfermedad llamada ura. Physis, B. Aires 4: 577.

Mirabelli, H. J. \& R. D. Lori, 1945. La ura: Su presencia en el hombre y los animales domesticos. Campo, B. Aires 29: 87-81, figs. (Também em Suelo argent. 4: 602-604 e em Boln Vet. Ganad. 2(7): 43-45, 1945).

Miranda, M. de, 1919. Observação de três casos de berne. Bras.-méd. 33(38): 299.

Modeer, A., 1786. Styng-Flug Slägtet (Oestrus trompe, tarandi, haemorrhoidalis, nasalis, bovis, elaphi, antilopum, fasciculosus, hominis). K. svenska VetenskAkad. nya Handl. (2) 7: 125-158, 180-185.

Mollica, J., 1939. Berne e myiases. Bras.-méd. 53: 713-716.

Monge S., J. R., 1949. Mosca tórsalo (o gusano de monte). Revta Agric. Comer. Ind., Panamá 8(92): 13.

Montoya, A. R. de, 1629. Tesoro de la lengva gvarani, $14+408$ pp. Iuan Sanchez, Madrid.

Morales, M. E., 1952. Inicio de la campaña contra el tórsalo (Dermatobia hominis L. (sic)) y las garrapatas en Costa Rica. Suelo rico 6(28): 182194, pls. 
Morales, M. E., 1955. El "gusano de monte" o "tórsalo" (Dermatobia hc. minis Lin. Jr.), una terrible plaga en el ganado de Costa Rica. Anais 2. Congr. pan-am. Med. vet., S Paulo: 257.

Morales, M. E., 1956. Algunas observaciones sobre el control del tórsalo en Costa Rica. Proc. 10th int. Congr. Ent., Montreal 3: 17-25, 3 figs.

Morales, R., 1911. Una observación de la manera como se transmite al hombre el colmoyote, Dermatobia noxialis, Cuterebra noxialis, por Rafael Morales. Transmisión de las larvas del colmoyote (Dermatobia noxiails) por intermedio del Culex. "El Nacional", Guatemala, xii.1911. (Republ. in Gonzales-Rincones \& Guyon, 1945, q. v.).

Morales, R., 1913. Comprobaciones a nuestro trabajo sobre la Dermatobia cyaniventris publicado em 1911. Juventud méd., Guatemala 13(12): 4-8.

Morales, R., 1958. Comprobación a nuestro trabajo sobre la Dermatobia cyaniventris publicado en 1911. Revta Col. méd. Guatem. 9(4): 249253, figs. (Reprodução do de 1913).

Mouchet, A. \& L. Dyé, 1908. Contributions à l'étude des larves cuticoles d'oestrides américains. Revue Méd. Hyg. trop. 5(4): 262-276, 2 figs.

Mourier, H. \& A. D. Banegas, 1970. Observations on the oviposition and the ecology of the eggs of Dermatobia hominis (Diptera: Cuterebridae). Vidensk. Meddr dansk naturh. Foren. 33: 59-68, figs.

Moussatché, I. \& S. J. de Oliveira, 1953. O problema do berne espera uma solução. Mundo agríc. 4(2): 17-19.

Moya Borja, G. E., 1973. Efecto de la radiación gama sobre la fertilidad de Dermatobia hominis Linnaeus Jr. Arquos Univ. rur. Rio de J. 3(1): 7-9.

Moya Borja, G. E., 1970. Retrospectiva da dermatobiose. Biologia e epidemiologia da Dermatobia hominis, pp. 303-314, in Beck et al., q. v.

Moya Borja, G. E., 1981. Sexual sterility of Stomoxys calcitrans (L.) induced by females of Dermatobia hominis (Linnaeus Jr.) treated with thiotepa. Revta bras. Biol. 41(1): 117-120, 2 figs., 4 tabs.

Moya Borja, G. E. \& A. B. Borkovec, 1981. Sexual sterility of Dermatobia hominis (Linnaeus Jr.) induced by chemosterilants. Ibid. 41(1): 51-56, 4 tabs.

Müller, O., 1962. Informe a los gobiernos de Costa Rica, El Salvador, Guatemala, Honduras, México, Nicaragua, y Venezuela sobre lucha contra el tórsalo (Dermatobia hominis) y las garrapatas (Boophilus sp. y Amblyomma sp.) en Centroamerica. Inf. Progr. Ampl. Asist. téc. Org. Nac. unid. Aliment. 1434: 1-16, pl.

Mullison, W. R. \& R. J. Shaver, 1960. Informe de los experimentos conducidos en Venezuela con Ruelene. Agroquímica, Midland 4(1): 1-5, 9 figs.

Muñoz-Rivas, G., 1956. Notas sobre Dermatobia hominis. Revta Fac. Med. vet. Zootéc. Univ. nac. Colomb. 21: 528-535, figs.

Murray, U. I. E. \& K. Thompson, 1976. Myiasis in man and other animals in Trinidad and Tobago (1972-73). Trop. Agric. 53(3): 263-266.

Neel, W. W., 1954. Control of human bot fly in cattle. J. econ. Ent. 47(3): 540-541.

Neel, W. W., O. Urbina, J. R. Havis \& J. de Alba, 1955a. Combate del tórsalo (Dermatobia hominis L. Jr.) por medio de insecticidas, en Turrialba, Costa Rica. Turrialba 5(4): 139-146, 6 figs. (Também publ. sep.).

Neel, W. W., O. Urbina, E. Viale \& I. de Alba, 1955b. Ciclo biológico del tórsalo (Dermatobia hominis L. Jr.) en Turrialba, Costa Rica. Ibid. 5(3): 91-104, 3 figs.

Neghme R., A. \& R. Donoso B., 1944. Miasis humana en Chile. Revta méd. Chile 72(11): 973-981.

Negro, R. C., J. Ferrer, J. J. Osimani \& M. A. Galli, 1969. Oftalmomiasis por Dermatobia hominis. Archos Pediat. Urug. 40(11): 60-66, figs.

Neiva, A., 1908. Contribuição ao estudo de Dermatobia cyaniventris Macq. 
Bras.-méd. 22: 311-312. (Também em Trab. Inst. Manguinhos, 8 pp., Rio de J.).

Neiva, A., 1910. Algumas informações sobre o berne. Chacaras Quint 2(1): 3-8, 10 figs. (Res. em Revta Ent., Rio de J. 11: 25, 1940).

Neiva, A., 1914. Informações sobre o berne. Mems Inst. Oswaldo Cruz 6: 206-211, pls. 27-28. (Res. em Revta Ent., Rio de J. 11: 42, 1940).

Neiva, A. \& J. F. Gomes, 1917. Biologia da môsca do berne (Dermatobia hominis) observada em todas as suas fases. Anais paul. Med. Cirurg. 8(9): 197-209. (Republ. em Collect. Trab. Inst. Butantan 2: 3-20, 1927; res. em Revta Ent., Rio de J. 11: 65, 1940).

Neiva, A. \& J. F. Gomes, 1930. El gusano de monte. Revta Agric. P. Rico 24(9): 99-106, 123, 1 fig.

Neiva, A. \& B. Pena, 1916. Viajem scientífica pelo norte da Bahia, sudeste de Pernambuco, sul do Piauhí, e de norte a sul de Goyaz. Mems Inst. Oswaldo Cruz 8: 72-224, 1 mapa, pls 1-28. (Também publ. sep., mesma paginação, Rio de J.).

Newstead, R. \& W. H. Potts, 1925. Some characteristics of the first larval stage of Dermatobia hominis Gmelin (sic). Ann. trop. Med. Parasit. 19(2): 247-260, pls. 4-5.

Niño, F. L. \& C. I. Rivas, 1940. Nota parasitológica a propósito de una observación de miasis forunculosa por larva de Dermatobia hominis. Boln Inst. Clin. quir., B. Aires 16: 214-219, figs. (Também em Prensa méd. argent. 27(31): 1594-1598, figs., 1940).

Núñez Andrade, R., 1960a. Miasis cutánea forunculoide humana. Revta mex. 40(844): 217-222, 6 figs.

Núñez Andrade, R., 1960b. Miiasis forunculoide. Gac. méd. Méx. 90: 741-750.

Nuñez-Tovar, M., 1924. Notas de historia natural médica. Experiencias para determinar que zancudo transmite el gusano de monte. Boln Cám. Cormerc., Caracas 13: 2540.

Oba, M. S. P., K. Hojo, A. Lopes F. \& H. H. Benedetto, 1978. Estudo da ação do Ruelene $25 \mathrm{E}$ em confronto com as três modificações dessa formulação sobre larvas de Dermatobia hominis em bovinos pela técnica do "pour-on". Biologico, S Paulo 44(10): 231-236.

Oliveira, M. de, 1922. La mouche "berne" du Brésil. Rev. Zootech., Paris 9: $913-915,3$ figs.

Oliveira, S. J. de, 1947. Informações sobre o berne. Bolm Campo 3(15): 11-12, 2 figs.

Oliveira, S. J. de, 1949. Informações sobre o berne. Granja, P. Alegre 5: $12-13$, figs.

Oliveira, S. J. de, 1949. O berne. Ciência para Todos (supl. divulg. cient. de "A Manhã", Rio de J.) 1(11): 10, 2 figs.

Oliveira Filho, L. de, 1922. Combate ao berne, 26 pp., 14 figs. Serv. Publções Secr. Agric. Est. S Paulo. (Republ. de artigos separados em "O Estado de São Paulo", Set. 1921).

Olivier, A. G., 1811. Encyclopédie méthodique. Dictionnaire des insectes 8: 722 pp. Pankouke, Paris.

Ortiz, M. I., 1929. La miasis cutánea por el Dermatobia cyaniventris en el Paraguay. Revta Sanid. milit. Paraguay 3(26): 2533-2549, figs.

Osborn, H., 1889. Another human bot-fly. Insect Life 1: 226.

Osimani, J. J., 1951. Brote epidermico de miasis humana forunculosa por Dermatobia hominis Linn. (sic). Archos urug. Med. Cirurg. 38(3): 119-125.

Padrón Lizardo, O., 1957. Miasis de anexos oculares por Dermatobia hominis. Revta Oftal. Venez. 2(2): 123-126.

Palazzolo, G., 1916. L'Hypoderma bovis e la mosca Dermatobia noxialis o cyaneiventris del Brasile. Nuovo Ercol. 21(26-27): 433-437, 1 fig.

Parma, B., C. Romaña \& J. A. Codazzi Aguirre, 1932. Comprobación de la ura en el norte santafecino. 7. Reun. Soc. argent. Pat. reg. Norte 2: 797-800, 4 figs. 
Parona, C., 1892. Larva de Dermatobia (torcel) nell'uomo. Boll. Soc. ent. ital. 24: 313-315.

Parona, C., 1893. Idem. Boll. Mus. zool. Genova 9: 3 pp.

Patton, W. S., 1921. Notes on the myiasis-produncing Diptera of man and animals. Bull. ent. Res. 12: 239-261.

Patton, W. S., 1935a. Studies of higher Diptera of medical and veterinary importance. A revision of the genus Glossina Wiedemann based on a comparative study of the male and female terminalia. Ann. trop. Med. Parasit. 29(4): 483-496, 11 figs.

Patton, W. S., 1935b. Classification of the myiasis producing Diptera of man and animals, in Parasites, transmetteurs, animaux vénimeux. Recl Trav. 25e. Anniv. scient. Paylovsky (1909-1934), Moscou: 269-271.

Peña Chavarria, A. \& H. W. Kumm, 1939. Algunas consideraciones generales sobre la miasis cutánea (tórsalo) en Costa Rica. Revta méd. C. Rica 3(64): 635-641, 4 figs.

Penha, A. M., 1950. Inseticidas para combater carrapato e berne do gado. Biológico, S Paulo 16(6): 134.

Pennington, M. S., 1919. Notas sobre un caso de la enfermedad llamada "ura" causada por larva de la Dermatobia cyaneiventris Macq. Physis, B. Aires 4(18): 557-578, 2 figs.

Penniston, T., 1844. A case of malis oestri or gadfly bite, occurring in the human subjetc. New Orl. med. surg. J. 1(2): 24-27, 1 pl.

Peraçoli, M. T. S., E. de Lello \& N. G. S. Mota, 1980. Comportamento da resposta imune-humoral (sic) em coelhos imunizados com antígenos de Dermatobia hominis Linnaeus (sic), frente às larvas desse parasita (Diptera: Cuterebridae). Cienc. Cultura 32(11): 1537-1541, fig. 3.

Person, D. A., 1976. (Infestation by Dermatobia hominis). J. Am. med. Ass. 235(10): 1003.

Peryassú, A. G., 1922. Os mosquitos portadores de ovos da mosca do berne (nota prévia). Folha méd. 3(14): 105.

Piazza, A., 1914. Dermatobia cyaniventris o noxialis. Ura de Misiones. Bicho berne de Brasil. Revta Fac. Agron. Univ. nac. La Plata 10(3): 179-181.

Picado, C., 1913. Historia de los tórsalos bovinos. Bln Fom., B. Aires 1913: 720.

Piccolo, L., 1910. O berne do boi. Chacaras Qui. 1(1): 17-18, 3 figs.

Pinel, H., 1954. La garrapata, el tórsalo y su control. Agricultura, Tegucigalpa 8: 16-21, figs.

Pinheiro, J. V. \& O. Baroni, 1953. O combate ao berne nas pastagens sombreadas. Bolm Campo 9(61): 37, 1 pl., 2 gráficos, figs.

Pinheiro, J. V. \& O. Baroni, 1953. O combate ao berne e a utilização das pastagens nos eucaliptais. Bolm Comp. paul. Estr. Ferro, Serv. flor. 4: $1-12$.

Pinto, C., 1930. Tratado de parasitologia, arthropodes parasitos e transmissores de doenças 2: 397-845, figs. 191-356, pls. 8-36. Bibl. Scient. Bras., Coll. med.-cirurg. n. ${ }^{\circ} 177$ A. Typ. Pimenta de Mello \& Cia., Rio de Janeiro.

Pinto, C., 1938. Zoo-parasitos de interesse medico e veterinario, 376 pp., 106 pls., 162 figs., 1 mapa. Pimenta de Mello \& Cia., Rio de Janeiro.

Pinto, C. \& F. D. R. da Fonseca, 1930a. Novo genero e nova especie de mosca hematophaga da sub-familia Stomoxydinae, hospedadora intermediaria da Dermatobia hominis. Revta méd.-cirúrg. Braz. 38(7): 241247, 1 fig., 3 pls.

Pinto, C. \& F. D. R. da Fonseca, 1930b. Novos hospedeiros intermediarios da Dermatobia hominis (L. Junior, 1781) (Diptera, Oestridae). Ibid. 38 (7): 247-250, 1 pl.

Pittier, H., A. Peña, E. Gonzalez F., J. Gomes A. \& A. Guzman, 1941. Origen del tórsalo en Costa Rica. Revta Agric., S José 13(10): 512; (11): 560; (12): 601-602.

Poeppig, E., 1835. Reise in Chile, Perú und auf dem Amazonenstrom, 2 vols. \& Atlas, Leipzig. 
Pontes, H. de A., 1935. O berne, sua destruição, história, desenvolvimento, meios de combate, etc., $24 \mathrm{pp}$. Prata, Minas Gerais.

Posada Arango, A., 1871. La Cuterebra noxialis. Abeille méd. 28(24): 209-212.

Posada Berrio, L., 1909. Larves cuticoles d'oestrides américains. Revue Méd. Hyg. trop. 6(3): 194-197.

Pradinaud, R. \& R. Revierez, 1968. Myiase furonculeuse de la paupière supérieure en Guyane Française. Bull. Soc. fr. Derm. Syph. 75(6): 808-810.

Prasad, S. \& A. R. Beck, 1969. Myiasis of the scalp from Dermatobia hominis. J. Am. med. Ass. 210(1): 133, 1 fig.

Price, A. S., 1937. The warble-fly Dermatobia hominis Linn. (sic). Report of two cases imported from Costa Rica. N. Y. St. J. Med. 37(13): 1503-1505, fig.

Primio, R. di, 1932. Algumas considerações sobre a Dermatobia hominis (Lineu Jr., 1781) no Rio Grande do Sul. Archos rio-grand. Med. 11(7): ?

Rabello, E. X., 1959. Demonstrações de combate ao berne. Revta Soc. rur. bras. 39: 47 , fig.

Ramos, J. D., 1927. Reparos à terapeutica de myiase palpebral e orbitaria pelo berne. Bolm Soc. méd.-cirúrg. Rio Preto 2: ? (Também em Semana ophthal. 1928: ?).

Rangel, R., 1905. Larvas cutícolas de América. Boln Hosps, Caracas 4(10): 243-249.

Rehaag, H., 1931. Os bernes. Bolm Agric. Zootechn. Vet. Minas Gerais 4: 49-56, 4 figs.

Rengger, A., 1835. Reise nach Paraguay in den Jahren 1818 bis 1826 von Dr. J. R. Rengger, xxxxvi + $495+$ (1) pp., 3 pls., 1 mapa, retrato. H. R. Sauerlaender, Aarau.

Rezende, C. de., 1939. Berne e myiases. Bras.-méd. 53(56): 874-875.

Ribeiro, R., 1926. O berne. Correio agríc. 4(9): 257-260.

Rodríguez, E., 1903. Parásitos tropicales. Gac. méd. (?) 20: ?

Rodriguez-Gonzales, M., 1952. Forunculosis cutánea por larvas de Dermatobia cyaneiventris (Macquart, 1840). Incidencia en perros (Canis familiaris). Boln mens. Dir. Ganad., Montev. 33(2): 91-97, figs. (Também em An. Fac. Vet. Urug. 6(1): 113-115, 2 figs., 1954).

Rondon, C. M. S., 1907. Relatório da Comissão Rondon. 1. Estudos e reconhecimentos. Com. Linhas telegr. estrat. Mato Grosso ao Amazonas 1: 363 pp., figs., mapa.

Roosevelt, T., 1914. Through the Brazilian wildernes, 374 pp., ilus., mapa. J. Murray, London.

Rosenschöld, E. M., af, 1849. Entomologiska underrättelser fran Paraguay. Öfvers. K. svenska VetenskAkad. Forhandl. 6: 59-62. (Também em Frorieps Tagesber. 1: 65-67, 1850).

Rossi, M. A. \& S. Zucoloto, 1973. Fatal cerebral myiasis caused by tropical warble fly, Dermatobia hominis. Am. J. Vet. Hyg. 22(2): 267-269.

Roulin, F. D., 1833. (Larves d'oestres chez l'homme). Institut, Paris 1(4): 25. (Também em Isis (Oken's) 4: 309, 1837).

Roulin, F. D., (-) Guérin \& J. M. Vallot, 1833. Extrait d'un rapport sur la découverte de larves d'oestres chez l'homme par MM. ...; fait par M. Isidore Geoffroy Saint Hilaire à l'Académie des Sciences de Paris, le 15 de juillet 1833. Ibid. (10) 1: 85.

Roveda, J. M., 1943. Miasis oculares provocadas por la "ura" observadas en Misiones. Archos Oftal. B. Aires 18(2): 80-96, figs.

Ruiz Martinez, C., 1956. El gusano de monte y su combate. Revta pecuaria Caracas 24(249): 17.

Ruiz Martinez, C., 1956a. Perjuicios que causa el "nuche" en el ganado vacuno. Revta Wimco, Caracas 3(26): ?

Ruiz Martinez, C., 1956b. Experimentos para el combate por medio de insecticidas del gusano de monte o tórsalo. Revta pecuaria Caracas 24 (255): 17.

Ruiz Martinez, C., 1956c. Las gusaneras del ganado y su control. Ibid. 24 (247): 24. 
Ruiz. Martinez, C., 1958. Combata el gusano de monte con Shell Toxafeno 50\%. Mejores Cosechas con Shell, Caracas 4: ?

Saint Hilaire, I. G., 1833a. Rapport fait à l'Académie des Sciences, le 15 juillet 1833, sur trois notices relatives à l'éxistence de l'oestre de l'homme, communiquées à l'Académie par MM. Roulin, Guérin et Vallot. Annls Soc. ent. Fr. 2: 518-527.

Saint Hilaire, J. G., 1833b. Extrait d'un rapport sur la découverte de larves d'oestre chez l'homme, par MM. Roulin, Guérin et Vallot fait par M. Isidore Geoffroy Saint Hilaire à l'Académie des Sciences de Paris, le 15 juillet 1833. Institut, Paris 1: 85.

Sallé, A. \& C. Coquerell, 1862. Notes sur quelques larves d'oestrides. Ibid. (4) 2: 781-794, pl. 19, 7 figs.

Sambon, L. W., 1915. Observations on the life-history of Dermatobia hominis (Linnaeus Jr., 1781). Trop. Dis. Res. Fund, Advis. Comm. Rep. 1914: 119-150, 4 figs. London.

Sangagli, G., 1892. Ecninococcus ed Oestrus nell'uomo. Rc. Ist. lomb. Sci. Lett. (2) 25: 1167-1178. (Também em Gazz. med. lomb. 53(35): 423$424,1893)$.

Santamaria, F. J., 1942. Diccionario de americanismos, vol. 3. Ed. Pedro Robredo, México.

Santamaria, F. J., 1959. Dicionario de mejicanismos. Ed. Porrua, México.

Santos, E., 1936. Incrível, mas veridico, o mecanismo de reprodução da mosca do berne. Campo, Rio de J. 7(83): 22-23, fig.

Santos, E., 1943. O berne (Dermatobia hominis). A sua influência na desvalorização de nossos couros. Sítios Fazendas, S Paulo 8(4): 13-15.

Sarmento Filho, D., 1928. O berne. Bolm Agric. Zootech. Vet. Minas Gerais 1 (12): 73-89.

Say, T., 1822. On a South American species of Oestrus which inhabits the human body. J. Acad. Sci. Philad. 2(2): 353-360. (Também em Bull. univ. Sci 3: 264, 1822 e em Froriep's Notizen 6(122): 177-180, 1824).

Scheiber, S. H., 1860-1862. Vergleichende Anatomie und Physiologie des Oestriden-Larven. Sber. Akad. Wiss. Wien (math.-naturw. Cl.) 41 (15): 409-496, pls. 1-2, figs. 1-33, 1860; 45(1): 7-68, pls. 1-3, figs. 34-62, 1862.

Scheiber, S. H., 1863. Bericht über die sogennanten Oestrus hominis nach den bisherigen Standpunkt der Wissenschaft. Virchows Arch. path. Anat. Phys. (2) 6(26): 209-217.

Schiner, I. R., 1868. Reise der österreichischen Fregatte Novara um die Erde, Zool. Theil, Diptera: 388 pp., 4 pls. Wien.

Schmalz, J. B., 1901. Zur Lebensweise der brasilianischen Dasselfliege (Dermatobia cyaneiventris). Insekten-Boerse 18(28): 220-221.

Schöyen, W. M., 1892. Bot-fly larvae burrowing under the skin of man. Insect Life 4(7-8): 275.

Scott, H. G., 1963. Myiasis: Epidemiologic data on human cases (North America north of Mexico: 1952-1962 inclusive), 14 pp. U.S. Dep. Hlth, Educ. Welfare, Publ. Hlth Serv., Atlanta.

Scott, T. G., 1964. Human myiasis in North America (1952-1962 inclusive). Fla Ent. 47(9): 255-261.

Serra, O. P., 1954. Observações sobre a postura de Dermatobia hominis. Anais Fac. Farm. Odont. Univ. S. Paulo 12: 75-78.

Serra, R. G., 1963. Contribuição à biologia da Dermatobia hominis (L. Jun., 1781): Capacidade ovígera e oviposição. Revta Fac. Farm. Bioqu. Univ. $S$ Paulo 1(2): 119-124.

Shannon, R. C., 1925. Brief history of the egg-laying habits of Dermatobia. J. Wash. Acad. Sci. 15(6): 137-138.

Siddons, L. B. \& D. W. Roy, 1942. On the life-history of Sinthesiomyia nudiseta van der Wulp (Diptera, Muscidae), a myiasis producing fly. Parasitology 34: 239-245, 19 figs.

Silva, L., 1921. Berne palpebral. Bras.-méd. 2(35): 383.

Silva, M. O. da, 1939. Os damnos que causam os bernes. Agric. Pecuaria, Rio de J. 191: 14. 
Silva, O. da, 1937. O berne, Bolm Campo, Rio de J. 1(3): 21-22, 3 figs.

Simón, P., 1626. Primera parte de las noticias historiales de la conquista de la Tierra Firme en las Indias Ocidentales. Cuenca.

Smith, F., 1868. Observations on the economy of Brazilian insects, chiefly Hymenoptera, from the notes of Mr. Peckolt. Trans. ent. Soc. Lond. 1868: 133-136.

Smith, H. H., 1893. Screw worms and man-infesting bot in Brazil. Insect Life 5: 265-266.

Spira, E. \& A. Spira, 1963. Dermatobia hominis in a squirrel monkey. Small Anim. clin. 3(12: 667-671, figs.

Squibb, R. L., 1945. Studies on the control of the nuche fly and cattle tick. J. Anim. Sci. 4(3): 291-296.

Squibb, R. L., 1945. Estudios sobre el control de la mosca nuche y la garrapata del ganado. Honduras agríc., 1(12-13) (i.e., 13-14): 14-15.

Stuart, A., 1905. Note on Dermatobia noxialis. J. Ass. milit. Surg. U. S. 17: 548-549, 3 figs.

Sundevall, C. J., 1841. Om en Fluglarv i menskliga luden. Dorh. skand. Naturf. Möte 1841: 295-296.

Sundevall, C. J., 1843. Ueber eine Fliegenlarve in der menschlichen Haut. Isis (Oken's) 1843: 297-298.

Sundevall, C. J., 1844. Om Oestrus hominis. Öfvers. K. svenska VetenskAkad. Forhandl. 1(7): 162-163.

Surcouf, J., 1913. La transmission du ver macadue par un moustique. C. $r$. hebd. Séanc. Acad. Sci. Paris 156: 1406-1408, 2 figs. (Res. em Rev. appl. Ent. (B) 1(7): 106-107, 1913).

Swain, J. C., 1950. Tropical warble fly. SWest. Vet. 3(3): 33.

Swain, R. B., 1952. Smear EO-335 to kill torsalo larvae. J. econ. Ent. 45(6): 1101

Sweet, R. D., 1962. A clinical occasion provided by a larva of Dermatobia hominis. Br. J. Derm. 74(4): 141-143, 1 fig.

Takasugi, S., 1919. Ueber Dermatobia hominis. Jap. Z. Derm. Urol. 19(2): 146-147.

Tamayo, M. O., 1904. La Dermatobia cyaneiventris. Fstudio zoológico de un díptero americano. Crón. méd., Jima 21: 276-283, 295-299.

Tastevin, C., 1922. Grammatica da lingua Tupy. Revta Mus. paul. 13: 537-763.

Theil, P. H. van, 1924. Over het vorkommen van der larve van Dermatobia hominis bij den jaguar. Herinnerigsb. Inst. trop. Geneesk. 1924: 138152, 1 pl., 2 figs.

Toledo, A. A. de, 1948. Notas sobre a biologia e controle do berne. Biológico, $S$ Paulo 14(11): 264-267.

Toledo, A. A. de, 1949. O melhor preparado de combate ao berne. Colheitas e Mercados 5(1-2): 24-25.

Toledo, A. A. de, 1950. Controle do berne e das bicheiras com BHC (hexacloreto de benzeno). Ibid. 16(7): 133-136.

Toledo, A. A. de, 1951. Experiências sobre o combate ao berne por inseticidas. Ibid. 17(7): 123-129.

Toledo, A. A. de, 1952. Nocividade das chuvas no efeito dos inseticidas sobre o berne. Ibid. 18(4): 57-61.

Toledo, A. A. de \& H. F. G. Sauer, 1950. Efeito de alguns inseticidas clorados sobre o berne. Ibid. 16(2): 25-34, 2 figs.

Toledo, L. A., F. Foresti \& E. de Lello, 1971. Cromossomos politênicos do berne, Dermatobia hominis (Lin. Jr.). Ciênc. Cult., S Paulo 23 (Supl.): 428.

Townsend, C. H. T., 1915. On the reproductive and host habits of Cuterebra and Dermatobia. Science, N. Y. 42: 253-255.

Townsend, C. H. T., 1920. Nota sobre o anarelho genital das fêmeas de Cuterebra e Dermatobia e os secs habitos parasitarios. Folha méd. 1 (15): 118-119.

Townsend, C. H. T., 1923. O berne e sua eliminação. Alm. agríc. bras. 1922: 
147-158, 4 figs. (Também em Bibl. agríc. pop. bras. 1922; ed. Chácaras e Quintais, S Paulo).

Townsend, C. H. T., 1923. Analyse do ambiente do berne e resposta. Ibid. 1923: 225-231.

Townsend, C. H. T., 1931. Notes on oestromuscoid types. Revta Ent., Rio de J. 1: 65-104.

Townsend, C. H. T., 1935. Manual of Myiology 2: 280 pp., 9 pls. Itaquaquecetuba.

Townsend, C. H. T., 1936. Berne vivípara? in Estudando os insetos daninhos - Contribuições entomológicas originais para Chácaras e Quintais. Chacaras. Qui. 54(5): 604-605, 1 fig.

Townsend, C. H. T., 1938. Manual of Myiology 6: 234 pp. Itaquaquecetuba.

Townsend, C. H. T., 1942. Idem 12: 342 pp., 84 pls. São Paulo.

Travassos, L., 1931. Algumas observações sobre a Dermatobia hominis (L. Jr., 1781) (Diptera: Oestridae). Bolm biol. Clube zool. Bras. 18: 35-38, 4 figs.

Umaña, R., 1914. Etude général des myiases, 87 pp., il. Thèse, Paris.

Urich, F. W., 1913. Mosquitos of Trinidad. Proc. agric. Soc. Trin. 13(103): 525-530.

d'Utra, G., 1917. Destruição do berne do gado. Chacaras Qui. 16(6): 504-505.

Vaitsman, J., 1951. Outra praga causada pelas môscas. Cometa (Bolm mens. Pearson, S.A.), 9.ix.1951.

Vaitsman, J., 1960. Berne - Praga causada pelas môscas. Sítios Fazendas, S Paulo 26(9): 40-42, 5 figs.

Val Floriana, M. M. de, 1920. Diccionarios Kaingang-Portuguez e PortuguezKaingang. Revta Mus. paulista 12: 7-381.

Vallot, J. N., 1833. Larves d'oestres chez l'homme. Institut, Paris 1: 50.

Veiga, J. S., 1958. Novo bernicida. "O Estado de São Paulo" (Supl. agríc.), 17. xii.1958, p. 14, 3 figs.

Verrill, A. E., 1872. Additional observations on the parasitism of man and animals. 5. a. Rep. Conn. Bd Agric. 1871-72. (Também em Am. J. Sci. Arts (2) 50: 430).

Viale, E., 1952. Los insecticidas orgánicos en la lucha contra el nuche y la garrapata. Agric. trop. 8(12): 11-12.

Viana Castillo, B., 1939. Gusano de zancudo. Un caso de localización rara en el hombre. Revta Policlín., Caracas 9: 3183-3185.

Vianna, E. V., 1951. Oftalmomíase por Dermatobia cyaneiventris (berne). Arqos bras. Oftal. 14(2): 47-54.

Vieira, M. I., 1961. Evite prejuízos combatendo o berne. Agric. Pecuária, Rio de J. 453: 10.

Vivas-Berthier, G., 1941. El gusano de monte, de zancudo o de mosquito. Revta Med. vet. Parasit., Caracas 3: 129-152, figs.

Vogelsang, E. G., 1935. El gusano de monte (Dermatobia hominis Linn, Jr., 1781). Revta ganad., Caracas 8: 16-17.

Vulcano, M. A., 1959. Descrição do alótipo de Simulium pruinosum Lutz, 1910 e caracteres adicionais da fêmea. Mems Inst. Oswaldo Cruz 57 (1): $33-43,10 \mathrm{pls}$.

Ward, H. B., 1903a. On the development of Dermatobia hominis. Mark Anniv. Vol.: 483-513, pls. 35-36.

Ward, H. B., 1903b. Some points in the development of Dermatobia hominis. Stud, Lab. Nebraska 58: 1-10. (Também em New Orl. med. surg. J. 56(4): 243-252, 2 figs.).

Weaver, F., S. S. Posada, L. E. Swanson, H. W. Newland \& M. A. González, 1958. Use of Narlene for control of nuche in cattle. Bull. Mich. St. Univ. agric. Exp. Stn 41: 2-18. (Também em Revta Fac. nac. Agron., Medellín 19: 25-50, figs., 1959).

West, DeP., 1950. O combate à mosca berne. Bahia rural 18(1): 16.

Westwood, J. O., 1861. On larvae of Oestrus hominis. Proc. ent. Soc. Lond. 1861: 18-19.

Weyenbergh, H., 1874. La ura. Periódico zool. argent. 1: 67-71, 129-132. 
Wied-Neuwied, M., Prinz zu, 1820. Reise nach Brasilien in den Jahren 1815-1817, 1: 380 pp., figs. H. L. Brömer, Frankfurt a.M.

Wille, J., 1925. Uebersicht der landwirtschaftlich wichtig Insecten von Rio Grande do Sul (Brasilien). Z. angew. Ent. 11(3): 415-426.

Wolffenbüttel, E., 1953. As várias formas de míases no homem. Sua profilaxia e seus diferentes tratamentos (comprovados e a serem experimentados). Revta bras. Med. 10(2): 135-139.

Wolffhügel, G., 1917. La ura, Dermatobia hominis [Say (sic)] pertenece a la fauna uruguaya. Revta Med. vet., Montev. 1917: 451-452.

Woods, T., 1913. Algumas palavras sobre o bicho berne. Estancia 1(3): 87.

Zeledón, R., 1956. Anotaciones sobre una curiosa oviposición de la mosca del tórsalo en condiciones experimentales (Dintera: Cuterebridae). Revta Biol. trop. 4(2): 179-185, 1 pl.

Zeledón, R., 1957. Algunas observaciones sobre la biología del la Dermatobia hominis (L. Jr.) y el problema del tórsalo en Costa Rica. Ibid. 5(1): 63-75.

Zepeda, P., 1911. [Título desconhecido]. Presse méd. 1911: ?

Zepeda, P., 1913. Nouvelle note concernant les moustiques qui propagent les larves de Dermatohia cyaneiventris et de Chrysomyia macellaria et peut être celle de Lund et de la Cordylobia anthropophaga. Revue Méd. Hyg. trop. 10(2): 93-95.

Zuern, F. A., 1872. Die Schmarotzer auf und in den Körper unserer Haussaugethiere sowie durch erstere veranlassten Krankheiten, deren Behandlung und Verhütung, 1 (Thierische Parasiten): 236 pp., 4 pls. Weimar.

Zumpt, F., 1973. Diptera parasitic on vertebrates in Africa south of the Sahara and in South America and their medical significance, in B. J. Meggers, E. S. Ayensy \& W. D. Duckworth, eds., Tropical forest ecosystems in Africa and South America: A comparative review, viii + 350 pp. Smithsonian Institution Press, Washington, D. C.

\section{APENDICE: \\ OS PUPÁRIOS DE CALLIPHORIDAE ENCONTRADOS NUM MEGATHERIUM NO CHILE}

No catálogo das espécies neotropicais de Calliphoridae, James (1970) mencionou a existência de pupários de Calliphoridae num crânio de Megatherium medinae Philippi, achado na localidade de Pica, Antofagasta, Chile.

Graças à gentileza do Prof. Dr. Raúl Cortés P., das Universidades do Chile (Santiago) e del Norte (Arica), conseguimos as fotos desses pupários, reproduzidas nas figuras 86-88. Não se pode saber, naturalmente, se estes califorídeos estavam ou não causando miíases nesse Megatherium.

No Chile, ainda segundo informações do Prof. Cortés, coelhos e outros pequenos mamíferos são atacados por Sarconesia chlorogaster (Wiedemann) (Calliphoridae, Toxotarsinae). Não há trabalho algum publicado sobre esta espécie causando miíases. Seria interessante que os pesquisadores chilenos conseguissem criar esta espécie e publicar ilustrações das larvas, a fim de que se possa saber se é esta espécie que se encontrava no crânio do Megatherium.

\section{REFERENCIA}

James, M. T., 1970. Family Calliphoridae, in Museu de Zoologia, Universidade de São Paulo, A Catalogue of the Diptera of the Americas south of the United States 102: 1-28. São Paulo.

\section{ADENDO}

Gagné (1981) registrou a ocorrência de Chrysomya albiceps (Wiedemann) (Calliphoridae) em um ferimento de uma cabra, em Porto Rico, o que pode representar o primeiro registro de míiase por espécie de Chrysomya no Novo Mundo.

Gagné, R. J., 1981. Chrysomya sp., Old World blow flies (Diptera, Calliphoridae) recently established in the Americas. Bull. ent. Soc. Am. 27(1): 2-22. 


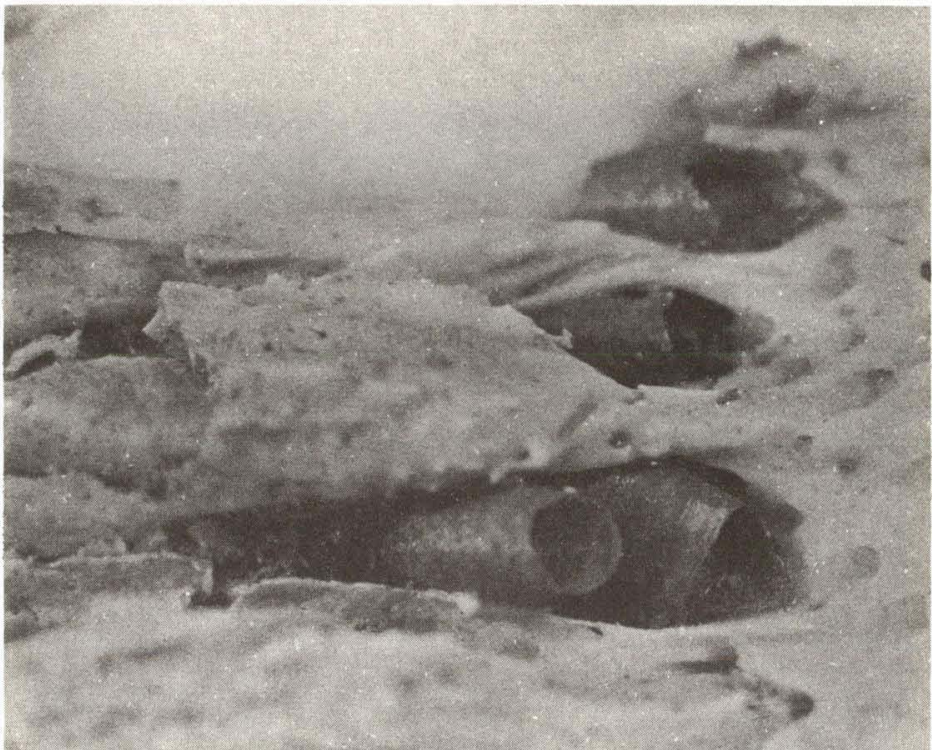

86

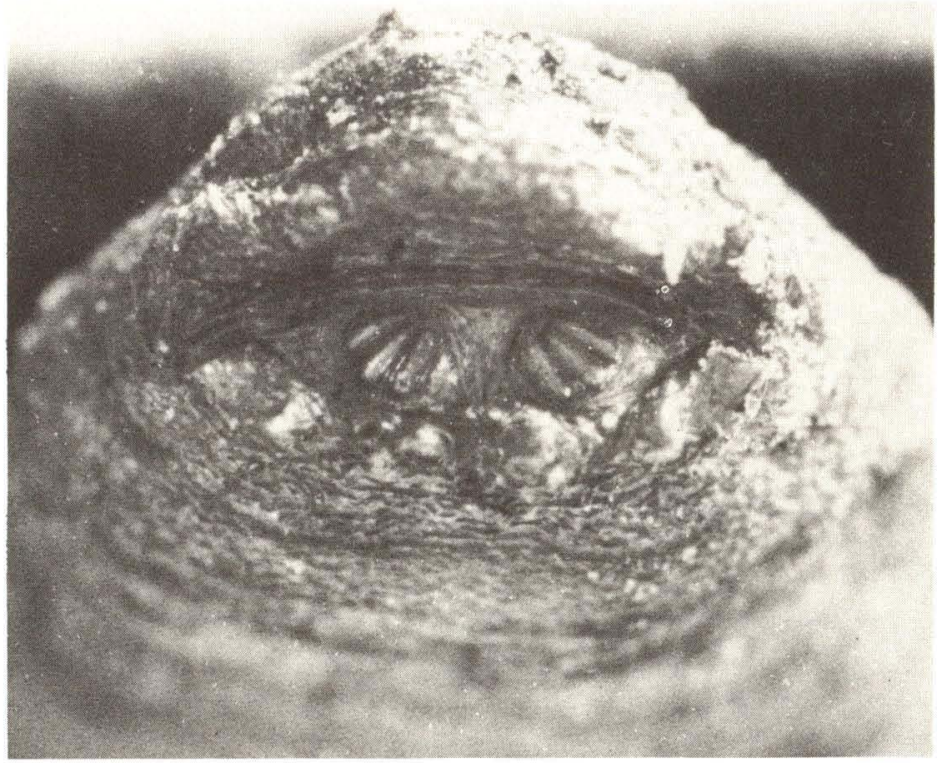

Figs. 86-87: Pupários de Calliphoridae em crânio de Megatherium medinae Philippi - 86, vista geral; 87, detalhe da extremidade caudal do pupário (Cortesia do Prof. Dr. Raúl Cortés). 


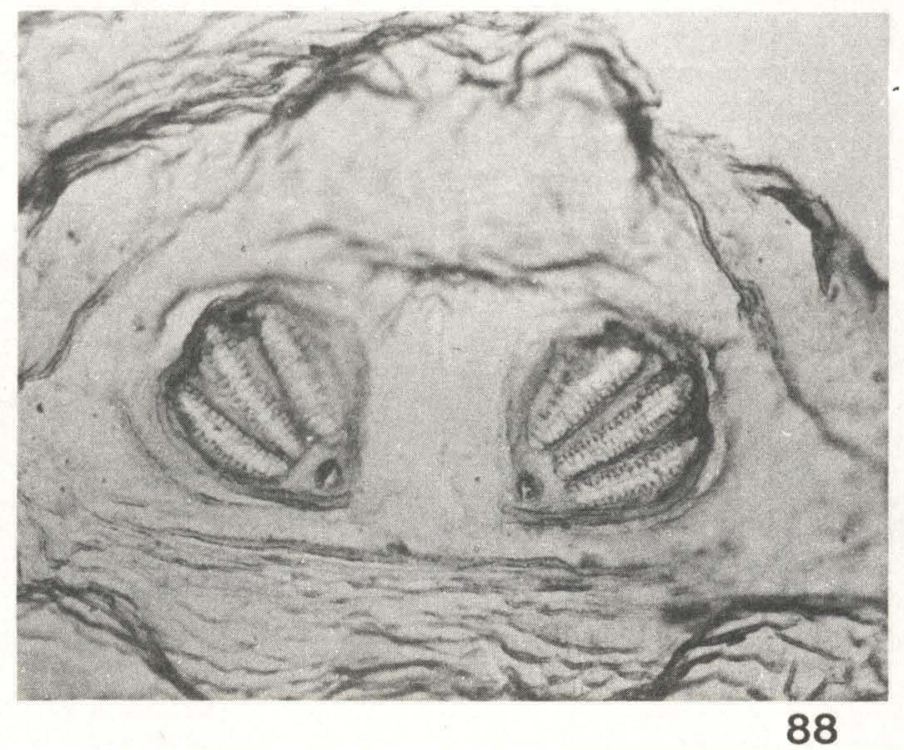

Fig. 88: Espiráculo posterior do pupário de Calliphoridae encontrado em crânio de Megaherium medinae Philippi (Cortesia do Prof. Dr. Raúl Cortés). 